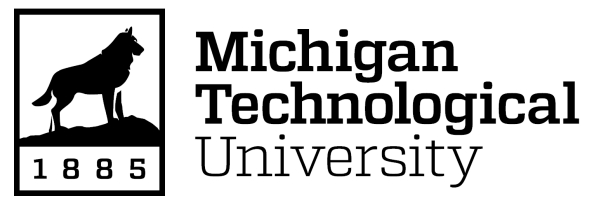

Michigan Technological University Digital Commons @ Michigan Tech

Dissertations, Master's Theses and Master's Reports

2017

\title{
ASSESSMENT OF ARCTIC GRAYLING RE-INTRODUCTION POTENTIAL IN THE BIG MANISTEE RIVER, MICHIGAN.
}

Cameron Goble

Michigan Technological University, cwgoble@mtu.edu

Copyright 2017 Cameron Goble

\section{Recommended Citation}

Goble, Cameron, "ASSESSMENT OF ARCTIC GRAYLING RE-INTRODUCTION POTENTIAL IN THE BIG MANISTEE RIVER, MICHIGAN.", Open Access Dissertation, Michigan Technological University, 2017. https://doi.org/10.37099/mtu.dc.etdr/336

Follow this and additional works at: https://digitalcommons.mtu.edu/etdr

Part of the Terrestrial and Aquatic Ecology Commons 


\section{ASSESSMENT OF ARCTIC GRAYLING RE-INTRODUCTION POTENTIAL IN THE BIG MANISTEE RIVER, MICHIGAN.}

By

Cameron W. Goble

\section{A DISSERTATION}

Submitted in partial fulfillment of the requirements for the degree of DOCTOR OF PHILOSOPHY

In Biological Sciences

MICHIGAN TECHNOLOGICAL UNIVERSITY

2017

(C) Cameron W. Goble 2017 
This dissertation has been approved in partial fulfillment of the requirements for the Degree of DOCTOR OF PHILOSOPHY in Biological Sciences.

\section{Department of Biological Sciences}

Dissertation Advisor: Nancy A. Auer, PhD

Committee Member: $\quad$ Casey J. Huckins, PhD

Committee Member: John A. Vucetich, PhD

Committee Member: James P. Magee, MS

Department Chair: Chandrashekhar P. Joshi, PhD 


\section{Table of Contents}

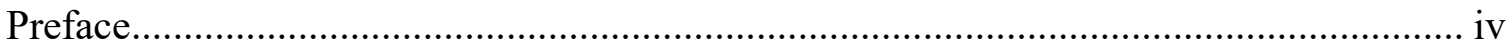

Acknowledgements ............................................................................................... vi

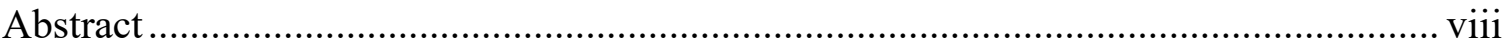

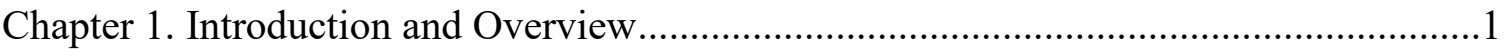

Chapter 2. Fish distributions and habitat associations in Big Manistee River, MI

tributaries: implications for Arctic Grayling restoration ................................................10

Chapter 3. Bioenergetic assessment of potential Arctic Grayling restoration sites in Big

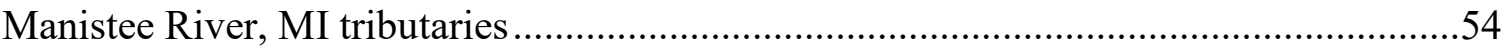

Chapter 4. Simulated population viability for re-introduced Arctic Grayling populations

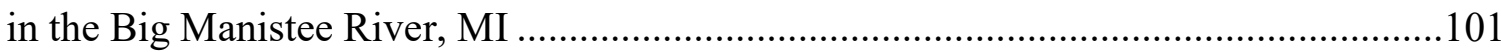
Appendix A. Summary fisheries survey data from 2011 - 2013 Big Manistee River

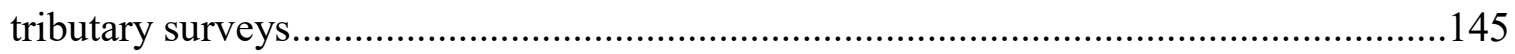

Appendix B. Arctic Grayling North American range map with relative extinction sensitivities by latitude, age-at-maturity and maximum age by latitude, and extinction probability sensitivity plots across a hypothesized latitudinal gradient of life-history characteristics

Appendix C. Invertebrate drift densities from 22 sampling reaches in Big Manistee River, MI tributaries 168 


\section{Preface.}

\section{Goals and Objectives}

The goal of this research was to assess conditions in a portion of the Big Manistee River watershed to determine the feasibility of re-establishing native Arctic Grayling into the State of Michigan. As part of a research group comprised of Michigan Technological University faculty and graduate students, and natural resources staff from the Little River Band of Ottawa Indians we assessed abiotic habitat and biotic communities in eight tributaries of the Big Manistee River and developed criteria based on literature review of extant North American populations to determine the suitability of the tributaries as potential restoration sites.

Objectives included:

1. Assess the distributions and model the habitat associations of fish species currently living in the Big Manistee River watershed (Chapter 2).

2. Assess the food availability (i.e. invertebrate drift) for drift-feeding salmonids and model the energetic potential of 22 Big Manistee River tributary reaches (Chapter 3)

3. Perform population viability assessment and sensitivity analyses to determine the probability of extinction for a potential re-introduced Arctic Grayling population in the Big Manistee River (Chapter 4). 


\section{$\underline{\text { Format of dissertation chapters }}$}

Except for the introduction and overview (Chapter 1) all chapters have been developed and formatted for publication in fisheries oriented scientific journals. Each chapter has been reviewed by members of the graduate committee and in the case of chapters 2 and 4 have received additional review and input from co-authors external of the graduate committee. Chapter 2 has been submitted for publication in Transactions of the American Fisheries Society and was co-authored with Drs. Nancy Auer, Casey Huckins, J. Marty Holtgren, and Stephanie Ogren, and fellow graduate student Brian Danhoff who each assisted with data collection and review of the manuscript. Primary data collection, data analyses, and manuscript writing was conducted by Cameron Goble. Chapter 3 will be submitted for publication in Transactions of the American Fisheries Society or North American Journal of Fisheries Management and was co-authored with Dr. Nancy Auer who performed reviews of data analyses and manuscript writing. Primary data collection, data analyses, and manuscript writing was conducted by Cameron Goble. Chapter 4 will be submitted for publication in Transactions of the American Fisheries Society and was co-authored with Dr. Nancy Auer who performed reviews of data analyses and manuscript writing. Primary data collection, data analyses, and manuscript writing was conducted by Cameron Goble.. 


\section{Acknowledgements}

My sincerest thanks go to my graduate advisor Dr. Nancy A. Auer for her incredible mentoring and guidance throughout my time here at Michigan Tech. Without her support and expertise this project would not have been possible, and I would not be nearly as prepared to enter the ranks of science as I am today. I would also like to thank each of the members of my graduate committee for lending their expertise to this work and to my professional development in general. Drs. Casey Huckins and John Vucetich each provided unique perspectives on ecology, fisheries science, and environmental ethics that I hope to carry forward beyond my graduate career. Jim Magee of the United States Fish and Wildlife Service in Dillon Montana brought his expertise on Arctic Grayling protection and restoration to my committee which benefitted the entire project. Special thanks go to J. Marty Holtgren and Stephanie Ogren who were instrumental in the development of this project and who serve as unofficial committee members but provided incredibly helpful support and guidance throughout this project.

I would be remiss if I didn't thank all the full-time and seasonal staff at the Little River Band of Ottawa Indians natural resources department for the incredible field work they put in to gather the data for this project. The list of people is long, and unfortunately, I am bad at remembering names but please know that I am grateful to each and every one of you. My friend and fellow graduate student on this project, Brian Danhoff spent countless hours in the field with me over the course of three years and without him I would have been doomed (and likely lost somewhere along Peterson Creek). I would also like to thank the Department of Biological Sciences at Michigan Technological 
University, particularly Dr. Chandrashekhar Joshi, Emily Betterly, and Patty Asselin for their support over the last six years.

Last but certainly not least I must thank my family for their tremendous support in putting up with my field work travels, stress, and everything that goes along with being a graduate student for so many years. My wife Faith has been so understanding and supportive and kept me focused on the end-goal while shouldering the load of keeping our family functioning. My daughters Alyssa and Harper have provided so much inspiration and support for me that I can't thank them enough. And my parents Ron and Beth Goble who instilled in me a love of learning and who have been so supportive of me, Faith, and the girls over the years.

Partial funding for this research was provided by the Little River Band of Ottawa Indians through a U.S. Fish and Wildlife Service Tribal Wildlife Grant (U-17-NA-1) awarded to Nancy Auer. Additional funding was provided by the Department of Biological Sciences at Michigan Technological University through Graduate Teaching Assistantships and through a National Science Foundation GK-12 fellowship awarded to Cameron Goble. 


\section{Abstract}

Arctic Grayling Thymallus arcticus were once the dominant fluvial salmonid species in Michigan's Lower Peninsula. By the late $19^{\text {th }}$ century most populations in the State had experienced drastic declines and by 1936 the species was declared extinct in Michigan. Beginning in 2011 the Little River Band of Ottawa Indians and Michigan Technological University partnered on research to determine the feasibility of reestablishing the species in the Big Manistee River watershed which was home to one of the last Arctic Grayling populations in the Lower Peninsula. The objectives of this research were to: A) assess abiotic habitat suitability for Arctic Grayling, B) identify potential biotic interactions that could impact Arctic Grayling re-introduction success, C) assess food availability and bioenergetic capacity of eight Big Manistee River tributaries, and D) model population viability and extinction sensitivities of a potential re-introduced Arctic Grayling population. Results from this study indicate that suitable biotic conditions for Arctic Grayling are available in all of the eight tributaries included in this study. Brook and Brown Trout currently occupy all of the potential re-introduction tributaries and densities of Brown Trout $>0.10 / \mathrm{m}^{2}$ should be considered a potentially limiting factor in determining overall site suitability (Chapter 2). A bioenergetic assessment indicates that $59 \%$ of the study reaches exhibit positive Net Energy Intake (NEI) for drift-feeding salmonids indicating that they are likely suitable re-introduction areas. No statistically significant relationship was found between invertebrate densities or NEI and the densities of salmonid species currently occupying these habitats indicating that food availability is not a limiting factor for salmonids in the Big Manistee River 
system (Chapter 3). Population viability analysis indicates that it is possible to establish a viable Arctic Grayling population in the middle portion of the Big Manistee River watershed studied. Sensitivity analyses suggest that Arctic Grayling populations in the southern portion of their range (i.e. Michigan and Montana) are most sensitive to factors influencing reproductive output while northern populations (Canada and Alaska) are most sensitive to factors affecting adult survival (Chapter 4) Overall, the combined findings from this research suggest that conditions are favorable for Arctic Grayling re-established in the Big Manistee River watershed. 
Chapter 1. Introduction and overview.

As their name suggests, Arctic Grayling Thymallus arcticus are native to Arctic Ocean drainages in North America, Asia, and Europe (Figure 1), as well as the upper Missouri River system in Montana and much of Michigan's Lower Peninsula (Northcote 1995). However, the current distribution of native fluvial Arctic Grayling in the contiguous United States has been reduced to $<5 \%$ of their historic range with the only known populations occurring in the headwaters of the Missouri River system in Montana (Steed et al. 2010). Historically, Arctic Grayling are believed to have been the dominant native salmonid species in most major river systems in the Lower Peninsula north of the White and Riffle River drainages (Nuhfer 1992). The first European accounts of Arctic Grayling in the State came during the 1840's (Bissell 1890) with the species being scientifically described as Thymallus ontariensis by Cuvier and Valenciennes in 1848 (as translated in Jordan and Evermann 1896) based on specimens said to have originated from the vicinity of Lake Ontario. The first definitive "Michigan Grayling" specimens were described and named Thymallus tricolor by Cope in 1865 based on fish collections from various locations in the State of Michigan (Milner 1874). While there is some uncertainty surrounding when and by whom the first scientific description of Arctic Grayling in Michigan occurred, there can be little doubt of its importance as a subsistence species to early European settlers and Native American tribes living in the northern Lower Peninsula (Hinsdale 1932; Kuhnlein and Humphries 2017). Early accounts indicate that many populations were experiencing dramatic declines in numbers by the 1870's (Metcalf 1880; Bebe 1887; Bissell 1890) prompting calls for the supplementation 
and protection of the species (Hallock 1873; Bissel 1890). Despite those early warnings, within 60 years of its European "discovery" the species had been extirpated from the State of Michigan (Vincent 1962).

Several factors are believed to have contributed to the Arctic Grayling population declines including overharvest, competition and/or predation from non-native fish species, and habitat destruction (Leonard 1949; Taylor 1954; Vincent 1962). Records indicate that large numbers of Arctic Grayling were being harvested from many Lower Peninsula rivers in the mid to late 1800 's with recreational catches often measured in the hundreds of fish per day and commercial harvest supplying markets in larger cities (Norris 1879). When discussing the decline of Arctic Grayling populations in Michigan, Hubbard (1900) described a noticeable lack of small fish even as larger individuals were still being caught somewhat regularly indicating that reproduction and/or recruitment had been negatively impacted. Hubbard (1900) attributed the observed lack of small fish to predation by non-native trout. The first documented introductions of non-native salmonids in Michigan also occurred during this time with plantings of Rainbow Trout Oncorhynchus mykiss in the Au Sable River in 1876 (Bower 1910) and Brown Trout Salmo trutta in the Pere Marquette River in 1884 (Luton 1985) both of which contained Arctic Grayling until the late 1890's to early 1900's (Vincent 1962; Michigan Department of Natural Resources 1978). In addition to introductions of Brown and Rainbow Trout, Brook Trout Salvelinus fontinalis (which are native to the State's Upper Peninsula; Hubbard 1887; Smedley 1938) began to appear in increasing numbers in rivers that had historically held only Arctic Grayling (Vincent 1962). 
Metcalf (1880), and Lowe (in Taylor 1954) suggested that habitat destruction and siltation of spawning grounds were likely to blame. Riverine habitats were being drastically altered by large scale timber harvesting practices and increasing agricultural development (Vincent 1962). Logs were often transported to lumber mills by floating them down rivers increasing bank erosion, sediment deposition, and scouring of the riverbeds during the Arctic Grayling spawning season in early spring (Harris 1905; Mershon 1916; Leonard 1939). Taylor (1954) summarizing the field notes of biologist John Lowe suggests that bank erosion and increased sediment loads attributed to deforestation were primarily responsible for the demise of Arctic Grayling in the Otter River (Houghton County) which was the last know population in the State of Michigan. Given new insight into the sensitivity of southern Arctic Grayling populations to reductions in fecundity (Chapter 3) it seems likely that habitat degradation affecting egg or larval survival played a significant role in the loss of the species in Michigan and may have hindered more recent efforts to re-establish the species.

Attempts to supplement Arctic Grayling stocks in Michigan began as early as the as the 1870's (Metcalf 1880) through egg and brood stock collections from Lower Peninsula rivers such as the Big Manistee and Au Sable (Norris 1878 and Mather 1880 In Mershon 1923; Jerome 1879). As Arctic Grayling stocks in the Lower Peninsula became depleted to the point where in-state collection of gametes was no longer a viable option, eggs and fry were transported from Montana in an attempt to re-establish the species in Michigan (Creaser and Creaser 1935). The early efforts to stock Arctic Grayling from Montana occurred in 1900 and attempts continued regularly until 1936 (Leonard 1949) 
after which most Arctic Grayling restoration activities ceased in the Lower Peninsula for the next 50 years (Nuhfer 1992). It has been surmised that most early Arctic Grayling restoration attempts in Michigan failed in part due to recent (relative to the time of restoration) and ongoing habitat degradation occurring in the rivers where eggs and fry were being planted (Metcalf 1880).

Michigan is not alone in its historical lack of success at restoring Arctic Grayling populations. Kaya (1990) summarized restoration attempts in Montana between the 1920's and 1980's and suggested that in spite of planting tens-of-millions of Arctic Grayling eggs, fry, and fingerlings throughout the state virtually none of the efforts had yielded self-sustaining populations. One of the primary criteria used in evaluating streams for Arctic Grayling restoration potential in Montana is whether habitat conditions have sufficiently improved (presumably as a function of time or targeted restoration) from the time of extirpation (Kaya 1992). An attempt to re-establish Arctic Grayling in the State of Michigan occurred between 1987 and 1991 during which time the Michigan Department of Natural Resources (MI-DNR) stocked approximately 250,000 Arctic Grayling fry, fingerlings, or yearlings in rivers and lakes throughout the state (Nuhfer 1992). These efforts were unsuccessful due to a variety of factors (Nuhfer 1992) and no further restoration investigations were undertaken until 2011 when the Little River Band of Ottawa Indians (LRBOI) and Michigan Technological University (MTU) partnered on research to explore the feasibility of re-establishing Arctic Grayling in the Big Manistee River watershed. 
The LRBOI have shown great interest in protecting and restoring native and culturally significant species such as Arctic Grayling, Lake Sturgeon Acipenser fulvescens, and Elk Cervus canadensis within the 1836 treaty area (Auer et al. 2013). As part of the Tribe's native species restoration goals LRBOI and MTU developed habitat assessment criteria in order to determine whether current conditions in the Big Manistee River, Michigan and its tributaries would be suitable for potential Arctic Grayling reintroductions (Auer et al. 2013). Between 2011 and 2013 LRBOI and MTU performed > 100 surveys of the abiotic and biotic characteristics of 23 Big Manistee River tributary reaches. Danhoff et al. (2017) assessed abiotic conditions and found suitable habitat for all life-stages of Arctic Grayling in all but one of the tributaries studied. Additionally, Goble et al. (Chapter 2.) described fish-habitat relationships and documented successful natural recruitment of Brook and Brown Trout in each tributary indicating that each tributary is able to support naturally reproducing populations of salmonids with similar habitat requirements as Arctic Grayling. Together these findings indicate that there is potential for successfully re-establishing Arctic Grayling in the Big Manistee River watershed and provide necessary assessment criteria, background information, and the impetus for this study as a next step towards future re-introduction efforts. In 2016 the LRBOI partnered with the Michigan Department of Natural Resources (MDNR), MTU and other universities, federal agencies, and non-governmental organizations in developing a statewide Arctic Grayling restoration initiative based in part on the findings of the 2011 - 2013 LRBOI/MTU research (J. M. Holtgren, Michigan DNR, personal communication). 


\section{References}

Auer, N. A., C. J. Huckins, B. M. Danhoff, and C. W. Goble. 2013. Development of a Native Species Restoration Plan for the 1836 Treaty Area: Suitability of the Big Big Manistee River for Arctic Grayling Re-establishment. Michigan Technological University Project Completion Report U-17-NA-1, Houghton, Michigan.

Bebe, J. 1887. Trout vs. Grayling. The American Angler 5:72-73.

Bissell, J. H. 1890. Grayling in Michigan. Transactions of the American Fisheries Society 19:27-29.

Bower, S. 1910. The Rainbow Trout in Michigan. Transactions of the American Fisheries Society 39:130-142.

Creaser, C. W., and E. P. Creaser. 1935. The Grayling In Michigan. Michigan Academy of Science, Arts, and Letters 20:599-608.

Cuvier, G., and M. A. Valenciennes. 1848. Histoire Naturelle Des Poissons. Tome vingt et unième. Suite du livre vingt et unième et des Clupéoïdes. Livre vingtdeuxième. De la famille des Salmonoïdes. Bertrand, Paris, France.

Danhoff, B. M., C. J. Huckins, N. A. Auer, C. W. Goble, S. A. Ogren, and J. M. Holtgren. 2017. Abiotic Habitat Assessment for Arctic Grayling in a Portion of the Big Manistee River, MI. Transactions of the American Fisheries Society XX:ppp-ppp.

Hallock, C. 1873. The Michigan Grayling. Forest and Stream December 11, 1873.

Harris, W. C. 1905. The decatence of the Grayling. Outing 45:762-764.

Hinsdale, W. B. 1932. Distribution of the Aboriginal Population of Michigan. University of Michigan Press, Ann Arbor, Michigan. 
Hubbard, B. 1887. Memorials of a half-Century. Page 581. G. P. Putnam's Sons, New York.

Hubbard, L. Jr. 1900. The doom of Michigan’s Grayling. Outing 37:85-86.

Jerome, G. H. 1879. Third Report of the Superintendent of the Michigan State Fisheries for 1877-8. Michigan State Board of Fish Commissioners, Lansing, Michigan.

Jordan, D.S. and B.W. Evermann, 1896. The fishes of North and Middle America: a descriptive catalogue of the species of fish-like vertebrates found in the waters of North America, north of the isthmus of Panama. Part I. Bulletin of the U.S. National Museum. 47:1-1240.

Kaya, C. M. 1990. Status report on fluvial Arctic Grayling (Thymallus arcticus) in Montana. Unpublished Report to Montana Department of Fish Wildlife and Parks, Helena, Montana.

Kaya, C. M. 1992. Restoration of fluvial Arctic Grayling to Montana streams: Assessment of reintroduction potential of streams in the native range, the upper Missouri River drainage above Great Falls. Montana State University. Bozeman, MT.

Kuhnlein, H. V., and M. M. Humphreys. 2017. Traditional animal foods of indigenous peoples of northern North America: http://traditionalanimalfoods.org/. Centre for Indigenous Peoples' Nutrition and Environment, McGill University, Montreal, Canada.

Leonard, J. W. 1939. Montana Grayling in Michigan. Michigan Conservation, Lansing, MI.

Leonard, J. W. 1949. The Michigan Grayling. Michigan Conservation, Lansing, Michigan. 
Luton, J. R. 1985. The first introductions of Brown Trout, Salmo trutta, in the United States. Fisheries 10: 10-13.

Mather, F. 1880. A few words on fish propagation and protection. Pages 182-188 in W. B. Mershon. 1923. Recollections of my Fifty Years Hunting and Fishing. Stratford Company, Boston, Massachusetts.

Mershon, W. B. 1916. The Grayling in Michigan, why and how "the flower of fishes" was exterminated - doubtful whether any are left in the state. Forest and Stream $86: 799$.

Mershon, W. B. 1923. Recollections of My Fifty Years Hunting and Fishing. The Stratford Company, Boston, Massachusetts.

Metcalf, M. 1880. The Michigan Grayling: 1880 Essay and Letters by Martin Metcalf. Pages 135-163 in R. A. Drews editor 1961. Michigan History Volume 45. Michigan Historical Commission, Lansing, Michigan.

Michigan Department of Natural Resources, Fisheries Division. 1978. Pere Marquette River natural river plan. Lansing, MI.

Milner, J. W. 1874. Notes on the grayling of North America. Report of the Commissioner of Fish and Fisheries. Washington, DC.

Norris, L. D. 1878. The Michigan Grayling. What must be done to prevent the annihilation of this excellent food and game fish. Transactions of the Michigan Sportsman's Association. Pages 173-181 in W. B. Mershon. 1923. Recollections of my Fifty Years Hunting and Fishing. Stratford Company, Boston, Massachusetts.

Norris, T. 1879. The Michigan Grayling. Scribner's Monthly, November 1879:17-23 
Northcote, T. G. 1995. Comparative biology and management of Arctic and European Grayling (Salmonidae, Thymallus). Reviews in Fish Biology and Fisheries 5:141194.

Nuhfer, A. J. 1992. Evaluation of the reintroduction of the Arctic Grayling into Michigan lakes and streams. Michigan Department of Natural Resources Fisheries Research Report, Ann Arbor, Michigan.

Smedley, H. H. 1938. Trout of Michigan. Muskegon, Michigan. Privately published. 49 pp.

Steed, A. C., A. V. Zale, T. M. Koel, and S. T. Kalinowski. 2010. Population viability of Arctic Grayling in the Gibbon River, Yellowstone National Park. North American Journal of Fisheries Management 30:1582-1590.

Taylor, W. R. 1954. Records of Fishes in the John N. Lowe Collection from the Upper Peninsula of Michigan. Museum of Zoology, University of Michigan, Ann Arbor, MI.

Vincent, R. E. 1962. Biogeographical and Ecological Factors Contributing to the Decline of Grayling, Thymallus arcticus Pallas, in Michigan and Montana. Doctoral Dissertation, The University of Michigan, Ann Arbor, Michigan. 
Chapter 2. Fish distributions and habitat associations in Big Manistee River, MI tributaries: implications for Arctic Grayling restoration.

Cameron W. Goble ${ }^{\mathrm{a}}$, Nancy A. Auer ${ }^{\mathrm{a}}$, Casey J. Huckins ${ }^{\mathrm{a}}$, Brian M. Danhoff ${ }^{\mathrm{a}}$, J. Marty Holtgren $^{\mathrm{b}}$, and Stephanie A. Ogren ${ }^{\mathrm{c}}$.

${ }^{a}$ Department of Biological Sciences, Michigan Technological University, 1400

Townsend Drive, Houghton, Michigan 49931, USA

${ }^{\mathrm{b}}$ Michigan Department of Natural Resources, Fisheries Division Tribal Coordination Unit Charlevoix Fisheries Research Station, 96 Grant Street, Charlevoix, Michigan, 49720, USA

' Grand Rapids Public Museum, 272 Pearl Street NW, Grand Rapids, Michigan 49504, USA 


\section{Abstract}

The Big Manistee River, Michigan flows through the historic Reservation of the Little River Band of Ottawa Indians and once supported the last known native Arctic Grayling population in the State's Lower Peninsula. Arctic Grayling have been extirpated from the State of Michigan since 1936 and interest by the Tribe, Michigan Department of Natural Resources, universities, and public interest groups exists for reintroduction. Several factors are believed to have contributed to the loss of this species from Michigan including overharvest, habitat destruction, and competition and/or predation from other fish species. The objective of this study is to identify potential biotic limitations (competition, predation, etc.) for Arctic Grayling re-introduction in the Big Manistee River watershed and describe how instream habitat features currently relate to populations of potentially interacting species. Field surveys conducted summer 2012 in eight Big Manistee River tributaries identified abiotically suitable habitat for Arctic Grayling in 20 of 22 sampling reaches. However, high densities of a non-native salmonid (Brown Trout) appear to be influencing some of the habitat associations observed for two species that historically co-occurred with Arctic Grayling and currently occupy these habitats. Brook Trout, and Slimy Sculpin were most abundant in river reaches with Brown Trout densities $<0.10$ fish $/ \mathrm{m}^{2}$. Based on habitat conditions and Brown Trout densities there appear to be four distinct tributary regions for which specific management strategies could be developed to enhance the success of Arctic Grayling reintroduction efforts. Reintroduction of Arctic Grayling in the Big Manistee River watershed would support LRBOI and MDNR goals for native species restoration, and provide a unique and 
historic angling opportunity in the State of Michigan that has been absent for nearly 100 years.

\section{Introduction}

Arctic Grayling Thymallus arcticus and Brook Trout Salvelinus fontinalis were the only native salmonids known to live in rivers and streams of Michigan although it remains unknown to what extent they co-existed. Arctic Grayling were primarily found throughout the northern half of the Lower Peninsula with abundant populations occurring in most major rivers including the Big Manistee, Au Sable, Jordan, and Boardman (Vincent 1962). Brook Trout were and are widely distributed throughout the Upper Peninsula and were believed to have been dispersing south through the Lower Peninsula since the mid 1800's (Strang 1855; Hubbard 1887; Vincent 1962). The Otter River, Houghton Co., harbored the last known population of Arctic Grayling in Michigan (Leonard 1949) and is notable as the only location where Arctic Grayling were reported present in the Upper Peninsula and naturally co-occurred with Brook Trout in Michigan (Taylor 1954). Arctic Grayling were extirpated from the Otter River (Upper Peninsula of MI) by 1936 (McAllister and Harington 1969) however the last recorded captures from their primary range in the Lower Peninsula occurred at least 30 years earlier (Mershon 1916).

Several factors are believed to have contributed to the Arctic Grayling population declines including overharvest, habitat destruction, and competition and/or predation from non-native fish species (Leonard 1949; Taylor 1954; Vincent 1962). Records 
indicate that large numbers of Arctic Grayling were being harvested from many Lower Peninsula rivers in the mid to late 1800 's with recreational catches often measured in the hundreds of fish per day and commercial harvest supplying markets in larger cities (Norris 1879 ). By the 1870 's many riverine habitats were being drastically altered by large scale timber harvesting practices and increasing agricultural development (Vincent 1962). Harvested logs were often transported to mills by floating them down rivers which increased bank erosion, sediment deposition, and scouring of the riverbeds during the Arctic Grayling spawning season in early spring (Harris, 1905; Mershon 1916; Leonard 1939). Taylor (1954) summarizing the field notes of biologist John Lowe suggests that bank erosion and increased sediment loads attributed to deforestation were primarily responsible for the decline of the Arctic Grayling population in the Otter River. The introduction of non-native salmonids in Michigan began in the 1870's with plantings of Rainbow Trout Oncorhynchus mykiss in the Au Sable River in 1876 (Bower 1910) and Brown Trout Salmo trutta in the Pere Marquette River in 1884 (Luton 1985) both of these Lower Peninsula rivers contained Arctic Grayling until the late 1890's to early 1900's (Vincent 1962; Michigan Department of Natural Resources 1978).

Whereas most of Michigan's Lower Peninsula rivers were devoid of Arctic Grayling by the 1890's the Big Manistee River (Figure 1) was home to one of the last known populations with captures documented into the early 1900's (Vincent 1962). This river flows through the historic reservation of the Little River Band of Ottawa Indians (LRBOI) and restoration and protection of native fishes such as Arctic Grayling are the focus of many of the Tribe's ongoing management efforts (Holtgren and Auer 2016). 
Fluvial Arctic Grayling have specific habitat requirements during various life stages including optimal water temperature ranges, substrates, and channel characteristics (Hubert et al. 1985). Danhoff et al. (2017) compared abiotic conditions in tributaries of the Big Manistee River to locations in Montana, Alaska, and northern Canada with extant populations and identified suitable Arctic Grayling habitat in all but the smallest Big Manistee River tributary surveyed. Interactions with other fish species, which may outcompete or prey upon Arctic Grayling could impact reintroduction efforts. Arctic Grayling was historically the most abundant and likely only (Harris 1905) salmonid species found in the Big Manistee River and its tributaries (Babbitt 1900; Creaser and Creaser 1935), yet Brown Trout, Brook Trout, and Rainbow Trout are now widely distributed throughout much of the watershed (Rozich 1998; Burroughs et al. 2010).

The objective of this study is to model which abiotic habitat features and/or interspecific relationships were associated with populations of co-occurring fish species in tributaries of the Big Manistee River, and to predict how these relationships might influence potential Arctic Grayling reintroduction strategies. While many fluvial salmonids are thought to be primarily insectivorous drift feeders throughout much of their life-cycle (Harvey and Railsback) Brook, Brown, and Rainbow Trout are also known to transition to a more piscivorous diet as they grow and mature (East and Magnon 1991; L'Abée-Lund et al. 1992; Turek et al. 2014) indicating the possibility of competition for resources with, and predation on, Arctic Grayling should re-introduction occur. Previous research into the effects of competition and predation between fluvial salmonids has indicated that competition for food and space, and high predator densities can influence 
the abundance and habitat associations of native salmonids (Fausch and White 1981; Quist and Hubert 2005). Better understanding of the relationships between abiotic habitat features and the abundance, density, and biomass of species currently occupying potential Arctic Grayling habitats in Michigan will help guide future restoration efforts and sitespecific fish-habitat models, developed for the Big Manistee River watershed, will be necessary for informing management and potential Arctic Grayling restoration decisions. It was hypothesized that, in Big Manistee River tributaries, reach-scale abundance of potential Arctic Grayling competitors or predators would not be significantly related to abiotic habitat conditions, or heterospecific fish densities.

\section{Study area}

The Big Manistee River watershed is one of the largest in the State of Michigan with an area of $4,610 \mathrm{~km}^{2}$ and a mainstem river length of 373 kilometers (Chiotti et al. 2008). Data for this study were collected from eight tributaries of the Big Manistee River located between Tippy and Hodenpyl Dams in Michigan (Appendix 2.1; Figure 2.1). Tippy Dam is located approximately 47 river kilometers (rkm) upriver of Lake Michigan and blocks all upstream fish movement. Hodenpyl Dam, located approximately $68 \mathrm{rkm}$ upriver of Lake Michigan, forms a second barrier marking the upper boundary of the 21 rkm study area. The Big Manistee River in this $21 \mathrm{rkm}$ stretch is characterized by a deeply incised valley, moderately high gradient $(1.3 \mathrm{~m} / \mathrm{km})$, and predominately gravel and cobble substrates (Rozich 1998). Also in this stretch eight $1^{\text {st }}$ through $3^{\text {rd }}$ order groundwater-fed tributaries discharge into the mainstem providing an additional $50.8 \mathrm{rkm}$ of connected fluvial habitat. 


\section{Methods}

Instream habitat and fish population surveys were conducted monthly June through August 2012 in 22 sampling reaches of the eight tributaries (see Figure 2.1 for tributary names and reach locations). Reaches were selected that represent a range of abiotic conditions found in the watershed. Each reach was classified as Lower (closest to

mainstem), Middle, and Upper (most upstream) based on their distance from the tributary confluence relative to the overall length of the stream. Following the U.S. Environmental Protection Agency Environmental Monitoring and Assessment Program (U.S. EPA EMAP) protocols for wadeable streams (Lazorchak et al. 2000), reach lengths were set at 40x mean wetted stream width or a minimum length of $120 \mathrm{~m}$ for reaches averaging $<3$ $\mathrm{m}$ wide. For detailed descriptions and methods for abiotic features of tributaries in this study such as substrate size structure, temperature, etc., see Danhoff et al. (2017).

Instream habitat and water parameters.

A channel morphology profile was developed for each reach using field measurements of linear lengths and widths for each unique habitat type or channel geomorphic unit (CGU) following the classifications of Hawkins et al. (1993). Transitions between unique CGUs were marked with a handheld GPS unit and referenced with hip-chain measurements collected in summer 2011. Each reach was divided into between 56 and 146 transects (depending on reach length) spaced approximately two meters apart where the wetted stream width was measured to the nearest $0.5 \mathrm{~m}$. Using ArcMap 10.1 (ESRI®) the field length and width measurements were combined to create 
habitat maps of each reach and calculate the overall surface area of the reach and CGU types (Danhoff et al. 2017). Since reaches differed in size all CGU area values were standardized as proportions of the overall reach area (i.e. 0 - $100 \%$ of the total reach area). Each transect was divided into six evenly spaced points across the width of the stream (i.e. $0,20,40,60,80$, and $100 \%$ ) and water depth (to nearest $0.01 \mathrm{~m}$ ), bottom velocity, and $60 \%$ column velocity (to nearest $0.01 \mathrm{~m} / \mathrm{sec}$ ) was measured and these values used to calculate the mean and maximum depths and velocities for each reach. All measures of water depth and velocity were conducted under summer baseflow conditions to ensure comparability between sites.

The gradient (percent slope) of each reach was calculated using ArcMap 10.1 and referenced to field measurements. Elevation (m) data for each tributary channel were derived from $10 \mathrm{~m}$ resolution U.S. Geological Survey digital elevation models (DEMs) by extracting the DEM pixels masked by the stream layer of the National Hydrography Dataset (USDA/NRCS - National Geospatial Management Center). Each 10-m pixel was converted from elevation to a percent gradient using the slope function of the Spatial Analyst toolbox (ESRI®) and the mean of all pixels was calculated for each reach. Field reference data were collected by marking a 33-m section of each reach and measuring the percent incline between two $1.5 \mathrm{~m}$ posts with a SUUNTO M-5/360 PC Clinometer.

Large woody debris (LWD; defined as wood pieces $>50 \mathrm{~cm}$ in length, $10 \mathrm{~cm}$ diameter, and in contact with the water) was identified as the primary source of instream overhead cover in most reaches. The amount of available LWD cover was quantified by counting, measuring, and calculating the surface area of LWD structures within each 
reach. When multiple pieces of LWD were clustered (i.e. logjams) it was decided to measure the cluster as a single structure and the overall surface area, rather than individual pieces, was calculated. As with the areal CGU measurements, LWD surface area was standardized as a proportion of the overall reach area.

A modification of the Wolman pebble count (Wolman 1954) where the intermediate axis of a randomly selected substrate particle was measured at 100 points throughout each reach was used to estimate substrate compositions. Substrate particles were categorized for analyses as: course $(>2.0 \mathrm{~mm})$, sand $(0.06-2.0 \mathrm{~mm})$, and silt/clay $(<0.06 \mathrm{~mm})$ in order to calculate the relative frequencies of different substrate types within each reach. Discharge, water temperature, dissolved oxygen (DO) concentration, $\mathrm{pH}$, and turbidity were measured monthly on the same day as fish population surveys were conducted (see Danhoff et al. 2017 for detailed summaries of pebble count and water parameter methods).

Fish population surveys.

In June 2012, one multi-pass depletion electrofishing survey (following methods of Hayes et al. 2007) and two single-pass electrofishing surveys (MDEQ 1997), one in July and one in August 2012, were conducted in each of the 22 reaches using a SmithRoot LR-14 backpack electrofishing unit initially set to output pulsed DC current at 30 $\mathrm{Hz}$ and peak voltage of $275 \mathrm{~V}$, and adjusted as needed to maintain $\leq 12 \%$ duty cycle depending on conductivity and water temperature. During the multi-pass survey, a 6.35 $\mathrm{mm}$ mesh block net was placed at both the downstream and upstream reach boundaries to 
prevent fish from escaping or entering the reach in order to meet the closed population assumption required for estimating abundance (Hayes et al. 2007). Three passes were conducted back to back in all but two reaches, Eddington Creek Middle, and Peterson Creek Upper, where two passes yielded depletions $>80 \%$ and a third pass was deemed unnecessary (Lockwood and Schneider 2000). All fish captured were identified to species, counted, measured to the nearest $1.0 \mathrm{~mm}$ total length (TL), weighed to the nearest $0.1 \mathrm{~g}$, and placed into an instream holding tank to prevent recaptures for the duration of the survey. To account for differences in electrofishing effort between reaches of different sizes all species counts from the first electrofishing pass were standardized as the number of fish captured per minute of electrofishing (CPUE) and mean CPUE for each species across the three sampling occasions was calculated. A $\log _{e}(x+1)$ transformation (Hubert and Fabrizio 2007) was performed on all CPUE values due to non-normality (Kolmogorov-Smirnov test; $P>0.05$ ) which significantly improved normality of the data $(P<0.05)$.

Based on previous age-and-growth information from this part of the Big Manistee River watershed (LRBOI unpublished data) salmonids smaller than $100 \mathrm{~mm}$ TL were classified as young-of-year (YOY) or juveniles, and those $100 \mathrm{~mm}$ TL or larger were classified as sub-adults or adults for analyses. Population estimates from the multi-pass surveys were computed for each species, and age group of salmonid (i.e. juvenile Brook Trout, adult Brook Trout, juvenile Brown Trout, and adult Brown Trout) and both age groups combined (i.e. all Brook Trout, all Brown Trout) using the Carle Strub k-pass maximum likelihood estimator (Carle and Strub 1978) under the "removal" function in 
the Fisheries Stock Assessment (FSA; Ogle 2015) package for program R (R Development Core Team 2015). All sizes of Slimy Sculpin were pooled for population estimates. Density estimates ( $\left(\mathrm{ish} / \mathrm{m}^{2}\right.$ ) were calculated by dividing the numerical population estimates by the total area of each reach. Similarly, biomass $\left(\mathrm{g} / \mathrm{m}^{2}\right)$ was calculated as the product of the numerical population estimate and the mean weight of the species in each reach divided by the reach area. Correlations were tested among 19 habitat variables, mean salmonid and sculpin $C P U E$, density, and biomass. Where significant correlations $(P \leq 0.05)$ among habitat variables were identified the variables with the largest correlation coefficients with the fish population indices were retained for further regression analyses and those with lower correlation coefficients were removed (Hubert and Rahel 1989). Species richness (N) and Shannon diversity (H') were also calculated for each reach. Both species richness and diversity were calculated excluding Brown Trout in order to compare the fish community between reaches with high densities of Brown Trout and low (or zero) Brown Trout densities. An exponential transformation was used to convert Shannon entropy values $\left(\mathrm{H}^{\prime}\right)$ to their effective numbers $\left(\mathrm{expH}^{\prime}\right.$; Jost 2006). Univariate and stepwise multiple regression models were developed using SAS version 9.2 for Windows (SAS Institute, Cary, North Carolina) to describe the variation in population indices for each species.

\section{Results}

In total, 10,090 fish representing 22 species were captured throughout the fish population surveys in 2012 (Table 2.1). Species richness across all reaches ranged from two species captured in the middle and upper reaches of Cedar Creek to 12 species 
captured in the lower reach of Hinton Creek (Appendix 2.1). The most widely distributed and abundant species were Brook Trout, Brown Trout, and Slimy Sculpin which were captured in all tributaries and accounted for $>96 \%$ of the overall number of fish caught (Table 2.1). Each of the other 19 species accounted for $<1 \%$ of the overall catch and six of those species were captured only from single streams (Table 2.1). Brook Trout were captured in 21 of 22 reaches with mean CPUE ranging from 0.03 to 4.04 fish/minute, density ranging from $<0.01$ to $1.31 \mathrm{fish} / \mathrm{m}^{2}$, and biomass ranging from 0.05 to 20.83 $\mathrm{g} / \mathrm{m}^{2}$ (Table 2.2; includes CPUE standard deviations). Brown Trout were captured in 19 of 22 reaches with mean $C P U E$ ranging from 0.04 to 2.84 fish/minute, density ranging from $<0.01$ to $0.39 \mathrm{fish} / \mathrm{m}^{2}$, and biomass ranging from $<0.01$ to $12.48 \mathrm{~g} / \mathrm{m}^{2}$ (Table 2.2). Slimy Sculpin were captured in 21 of 22 reaches with mean $C P U E$ ranging from 0.01 to $3.25 \mathrm{fish} /$ minute, density ranging from $<0.01$ to $1.22 \mathrm{fish} / \mathrm{m}^{2}$, and biomass ranging from $<0.01$ to $4.82 \mathrm{~g} / \mathrm{m}^{2}$ (Table 2.2). Rainbow Trout were infrequently captured during 2012 surveys (62 fish accounting for $<1 \%$ of the overall catch) and were not included in further analyses.

Of the 19 habitat variables measured nine were found to be significantly $(P<$ 0.05) correlated with Brook Trout CPUE (Table 2.3). After removing inter-correlated habitat variables (retaining the variables with the highest correlation coefficients, see methods), we retained three variables: mean wetted width, water temperature, and proportion of run habitat for regression modeling (Table 2.4). Brown Trout CPUE was found to have significant negative correlation with Brook Trout CPUE (Table 2.3) and was added to create a second multiple regression model incorporating the interspecific 
relationship. When Brown Trout $C P U E$ was excluded from the model, multiple regression yielded a two-variable model (Equation 1) with wetted width (partial $r^{2}=0.42$; $P<0.01$ ) and water temperature (partial $r^{2}=0.14 ; P=0.02$ ) accounting for $56 \%$ of the observed variation in Brook Trout CPUE (Figure 2.2).

Brook Trout $C P U E^{a}=2.41-0.13$ (wetted width)

-0.12 (water temperature)

$$
\left(r^{2}=0.56, P<0.01\right)
$$

${ }^{a} \log _{e}(x+1)$ transformed

The addition of Brown Trout CPUE resulted in the removal of all habitat variables during the stepwise model development and yielded a simple regression of Brook Trout CPUE and Brown Trout CPUE that accounted for $47 \%$ of the observed variation (Table 2.4). In general Brook Trout were most abundant in the narrow and relatively cold reaches and this was reflected in the strongest correlations occurring with measures of stream size (i.e. reach area, wetted width, width:depth ratio) and water temperature.

Nine habitat variables were found to be significantly $(P<0.05)$ correlated with Brown Trout CPUE (Table 2.3). After removing inter-correlated habitat variables, we retained two variables: reach area, and the proportion of course substrate for regression modeling (Table 2.4). Brook Trout CPUE, and Slimy Sculpin CPUE were found to have significant negative correlations with Brown Trout CPUE (Table 2.3). Although simple regression identified two habitat variables and two species interaction variables as significantly related to Brown Trout $C P U E$ the stepwise multiple regression procedure excluded reach area and Slimy Sculpin CPUE yielding a two-variable model (Equation 2) 
with Brook Trout CPUE (partial $r^{2}=0.47, P<0.01$ ), and proportion of course substrate (partial $r^{2}=0.21, P<0.01$ ) that accounted for $68 \%$ of the observed variation in Brown Trout CPUE (Figure 2.2).

$$
\begin{gathered}
\text { Brown Trout } C P U E^{a}=0.38-0.60\left(\text { Brook Trout } C P U E^{a}\right) \\
+0.01(\text { proportion of course substrate) } \\
\left(r^{2}=0.60, P<0.01\right) \\
{ }^{a} \log _{e}(x+1) \text { transformed }
\end{gathered}
$$

Brown Trout $C P U E$ was the only variable significantly $(P<0.05)$ correlated with Slimy Sculpin CPUE with a negative association that accounted for $24 \%$ of the observed variation (Tables 2.3 and 2.4). Brown Trout were generally most abundant in the large, deep, and relatively warm reaches and were also positively associated with the proportion of course substrate.

There were no differences between Brook Trout size classes in which variables were significantly $(P<0.05)$ correlated with density or biomass, and regression analyses were performed using pooled density and biomass estimates for all sizes of Brook Trout. Two habitat variables: wetted width, and the ratio of wetted width to depth were found to have significant $(P<0.05)$ negative correlations with Brook Trout density and biomass and Brook Trout density (but not biomass) was positively correlated with density of Slimy Sculpin (Table 2.3). Simple regression models of Brook Trout density with Slimy Sculpin density, and Brook Trout biomass with width:depth ratio accounted for $21 \%$ and $27 \%$ of the observed variation in density and biomass, respectively (Table 2.4). As with 
Brook Trout, no differences between size classes were observed for Brown Trout density or biomass so regression analyses were performed for all sizes combined. Proportion of course substrate was positively correlated and accounted for $32 \%$ of the observed variation in Brown Trout density while Slimy Sculpin density was negatively correlated and accounted for $26 \%$ of the observed variation (Tables 2.3 and 2.4). A two-variable regression model (Equation 3) was developed with mean depth (partial $r^{2}=0.38, P<$ 0.01 ) and the proportion of course substrate (partial $r^{2}=0.21, P<0.01$ ) that accounted for $59 \%$ of the observed variation in Brown Trout biomass (Figure 2.3).

Brown Trout biomass $=-5.73+31.76($ mean depth $)+0.08($ course substrate $)$

$$
\left(r^{2}=0.59, P<0.01\right)
$$

Three variables were retained for assessing Slimy Sculpin density: Brook Trout Density, Brown Trout Density, and mean bottom velocity (Table 2.4). A two-variable multiple regression model (Equation 4) was developed with Brown Trout density (partial $\left.r^{2}=0.26, P=0.02\right)$ and mean bottom velocity (partial $\left.r^{2}=0.18, P=0.02\right)$ that accounted for $44 \%$ of the observed variance in Slimy Sculpin density (Figure 2.3).

$$
\begin{gathered}
\text { Slimy Sculpin density }=0.69-1.17 \text { (Brown Trout density) } \\
-1.45 \text { (mean bottom velocity) } \\
\left(r^{2}=0.44, P<0.01\right)
\end{gathered}
$$

The proportion of course substrate in a reach was the only variable found to be significantly correlated with Slimy Sculpin biomass with a negative association that 
accounted for $31 \%$ of the observed variation (Tables 2.3 and 2.4). Slimy Sculpin abundance was not significantly related with stream size and was largely negatively associated with both bottom velocity, and the proportion of course substrate.

Of the 21 tributary reaches surveyed, gradients ranged from $0.3 \%$ to $8.6 \%$ (Table 2.5; Appendix 2.1) and was generally greatest in the downstream, low-elevation reaches on the east side of the Big Manistee River (Table 2.5b). The steepest gradient (8.6\%) across all reaches was found near the mouth of Cedar Creek due to a large cascade that marked the upstream reach boundary (see Danhoff et al. 2017). The mid-elevation and upper-elevation reaches on the east side were lower gradient (average of 1.1 and $0.6 \%$ respectively; Table $2.5 \mathrm{c} \& \mathrm{~d}$ ) as were most reaches on the west side of the river (average of $1.5 \%$; Table $2.5 \mathrm{a}$ ). Mean values of discharge, $\mathrm{DO}$ concentration, $\mathrm{pH}$, and turbidity were calculated across all three sampling events (June, July, and August) because no significant differences between sampling events were detected (ANOVA, $P>0.05$ for all). Mean July water temperatures near each tributary confluence in 2012 ranged from $10.7 \pm 1.2$ to $15.0 \pm 1.5^{\circ} \mathrm{C}$ and maximum summer (June through August) water temperatures observed in each tributary mouth occurred on July 25 and ranged from $16.1^{\circ} \mathrm{C}$ in Cedar Creek to $19.2^{\circ} \mathrm{C}$ in Sand Creek (Figure 2.4). While water temperatures did differ between sampling events (temperatures were highest during July sampling) the "average summer value" of this variable is reported to provide similar comparisons to other water quality and physical habitat variables (Appendix 1).

\section{Discussion}


Modeling of biotic and abiotic interactions with the three most abundant species captured has implications for potential Arctic Grayling restoration in this watershed since Brown Trout, Brook Trout, and Slimy Sculpin together accounted for approximately 96\% of the overall catch (Table 2.1). While all three-species occurred in all of the Big Manistee River tributaries surveyed, there was variation in their abundance at the reach scale (120 - $325 \mathrm{~m}$ ) indicating that localized habitat conditions (see Danhoff et al. 2017) and/or biotic interactions could be influencing fish community and population characteristics in these tributaries. In general Brook Trout were most abundant in the smaller and relatively colder upper elevation reaches while Brown Trout were most abundant in the larger, deeper, and relatively warmer mid-elevation reaches. Brown Trout abundance appears to be driving some of the observed habitat associations and fish community compositions in the study reaches. For example, Brown Trout CPUE was the best predictor variable for both Brook Trout and Slimy Sculpin CPUE, and Brown Trout density was the best predictor variable for Slimy Sculpin density (Table 2.4). In general, Brook Trout abundance was greatest and most variable in the narrowest reaches, which had the lowest abundance of Brown Trout (Figure 2.5). In general species diversity (excluding Brown Trout) was greater in the tributary regions where Brown Trout densities were $<0.10 \mathrm{fish} / \mathrm{m}^{2}$.

Researchers and the public have become increasingly aware that introductions of salmonid species outside of their native ranges can have deleterious effects on native salmonids (Rahel 1997; Fausch 2008). Examples can be seen in the western United States where introductions of Brook Trout have negatively impacted native salmonids such as 
Cutthroat Trout Oncorhynchus clarkii (Krueger and May 1991; Dunham et al. 2002;

Peterson et al. 2004), and Bull Trout Salvelinus confluentus, (Gunckel et al. 2002;

Reiman et al. 2006). Similarly, introduced Brown Trout are known to outcompete native

Brook Trout for energetically profitable microhabitats (Fausch and White 1981)

spawning locations (Essington el al. 1998), and food (Dewald and Wilzbach 1992).

Brown Trout and Brook Trout are known to consume small fish (East and Magnon 1991;

L'Abée-Lund et al. 1992) and Slimy Sculpin are known egg predators with the potential to negatively impact salmonid recruitment (Bunnell et al. 2014). The 'Biotic - Abiotic Constraining Hypothesis' (BACH), first proposed by Quist et al. (2003) may explain the apparent influence of biotic interactions in Big Manistee River tributaries. The premise of the $\mathrm{BACH}$ is that a species' abundance is determined by habitat conditions unless predator and/or competitor abundance is high in which case negative biotic interactions override suitable habitat conditions and are the primary limiting factor (Quist et al. 2003). Quist and Hubert (2005) tested the BACH on three co-occurring salmonid species, Cutthroat Trout, Brook Trout, and Brown Trout and found that regardless of habitat conditions Cutthroat Trout density was always low $\left(<0.05 \mathrm{fish} / \mathrm{m}^{2}\right)$ when Brook Trout and Brown Trout densities were high $\left(>0.10 \mathrm{fish} / \mathrm{m}^{2}\right)$.

The four tributaries: Arquilla, Hinton, Slagle, and Woodpecker Creeks, identified as most abiotically suitable for Arctic Grayling with regard to abiotic conditions (Danhoff et al. 2017) had Brown Trout densities $>0.10 \mathrm{fish} / \mathrm{m}^{2}$, which are high enough to have an 'overriding effect' as proposed by Quist et al. (2003) and defined by Quist and Hubert (2005) on Brook Trout and Slimy Sculpin abundance (Figure 2.6). However, within each 
tributary there were reaches with low densities of Brown Trout (i.e. $<0.10 \mathrm{fish} / \mathrm{m}^{2}$; Figure 2.7) where Brook Trout and Slimy Sculpin were the most abundant fish species and the likelihood of negative interactions with Brown Trout would be lower, suggesting these reaches could be targeted for Arctic Grayling restoration efforts. In a 2012 survey of the Big Hole River, Montana and its tributaries, Cayer and McCullough (2013) found the greatest densities (measured as fish/mile) of Arctic Grayling occurred in tributaries where Brook Trout (and/or Rainbow Trout) densities were generally $>$ Brown Trout densities. While there is potential for competitive and predatory interactions between Arctic Grayling, Brook Trout, and Slimy Sculpin these species are known to co-occur elsewhere in North America. For example, in the Big Hole River watershed in Montana, Byorth and Magee (1998) found evidence of habitat partitioning between Arctic Grayling and Brook Trout and intraspecific competition appeared to be a more significant factor affecting Arctic Grayling habitat use and growth than interspecific competition. In Michigan, Arctic Grayling naturally co-occurred with Brook Trout in the Otter River, MI (Taylor 1954) and with Slimy Sculpin in the Big Manistee River watershed suggesting that there is potential for each species to find suitable habitat and potentially partition resources within the fish community.

Water temperature has been suggested as a limiting factor for Salmonid species such as Arctic Grayling, Brook Trout, and Brown Trout (Kaya 1992; Lyons et al. 2010). In each tributary mean July water temperatures recorded near the confluence were within the optimal temperature range for Brook Trout, Brown Trout, and Arctic Grayling growth (11-16 ${ }^{\circ} \mathrm{C}, 12-19^{\circ} \mathrm{C}$, and $9.5-16^{\circ} \mathrm{C}$, respectively; Raleigh 1982, Raleigh et al. 1986, 
Hubert et al. 1985, Danhoff et al. 2017). While maximum summer water temperatures were above the upper optimal bounds for growth of Brook Trout and Arctic Grayling, they were below suggested lethal levels for each species $\left(25.3{ }^{\circ} \mathrm{C}\right.$ and $29.3{ }^{\circ} \mathrm{C}$ respectively; Raleigh 1982, Lohr et al. 1996) and in this study represent short duration events rather than long term exposures and thermal refuges appear to be present (Figure 2.4; see Danhoff et al. 2017).

Based on current abiotic conditions (see Danhoff et al. 2017) and Brown Trout densities there appear to be four distinct tributary regions that could provide potentially different management strategies and opportunities for Arctic Grayling reintroduction efforts: 1) all west tributaries (Figure 2.7A), 2) low elevation east tributary reaches (Figure 2.7B), 3) mid elevation east tributary reaches (Figure 2.7C), and 4) high elevation east tributary reaches (Figure 2.7D). The tributaries on the west side of the Big Manistee River are relatively short (1 to $1.6 \mathrm{rkm}$ ), high gradient (average of $1.5 \%$ slope), and less thermally stable than tributaries on the east side of the river (Figure 2.4). With the exception of Woodpecker Creek (which was stocked with 20,000 Brown Trout in March 2012 by the Michigan Department of Natural Resources; MDNR), the west side tributaries have low densities $\left(<0.10 \mathrm{fish} / \mathrm{m}^{2}\right)$ of Brown Trout in all reaches (Figures $1 \&$ 7A). On the east side of the Big Manistee River there are three elevation regions and the highest densities (all $>0.10 \mathrm{fish} / \mathrm{m}^{2}$ ) of Brown Trout are typically found in the midelevation reaches with average gradient $1.1 \%$ (Figure 7C). Low Brown Trout densities, $<$ $0.10 \mathrm{fish} / \mathrm{m}^{2}$ were observed in 7 out of 9 lower and upper elevation reaches (Figures 2.1 $\& 2.7 \mathrm{~B} \& \mathrm{D})$. Although none of the tributaries identified as containing low densities ( $<$ 
$0.10 \mathrm{fish} / \mathrm{m}^{2}$ ) of Brown Trout overlapped with those identified as "most" suitable at the tributary-scale by Danhoff et al. (2017) at the reach-scale four of the 13 reaches meeting $>80 \%$ of the abiotic criteria also had Brown Trout densities $<0.10 \mathrm{fish} / \mathrm{m}^{2}$. Based on these results the most suitable sites for Arctic Grayling reintroduction in this portion of the Big Manistee watershed are as follows: a) Peterson - Lower, b) Hinton - Lower, c) Eddington - Lower, and d) Eddington - Middle. Additionally, Slagle and Woodpecker Creeks would provide interesting experimental reintroduction sites as they rank as the $1^{\text {st }}$ and $2^{\text {nd }}$ most abiotically suitable tributaries respectively (and Slagle Creek is the largest of the tributaries surveyed; see Danhoff et al. 2017) but five-of-six reaches exceed the proposed $0.10 \mathrm{fish} / \mathrm{m}^{2}$ Brown Trout density threshold.

Reintroduction of Arctic Grayling in the Big Manistee River watershed would provide an opportunity for fishery management agencies in the watershed to examine current goals and adopt strategies focusing on native species. Arctic Grayling restoration planning for the Big Manistee River watershed should target abiotically suitable locations while also considering sites where predation and/or competition (e.g., by Brown Trout) is potentially more limiting than habitat, and thereby develop reintroduction and management strategies that account for this possibility. For example, remote site incubators (RSI's) have been successfully used for Arctic Grayling in Montana (Kaeding and Boltz 2004) and are being considered for possible reintroduction efforts in Big Manistee River tributaries. Remote site incubators should enhance survival of early life stages of Arctic Grayling by protecting developing eggs and embryos from sedimentation and predation by other species prior to hatch and swim-up. Management of non-native 
salmonids should also be considered as a potential Arctic Grayling restoration technique. Successful examples of this strategy can be seen in restoration and conservation of other native salmonid species such as the Colorado River Cutthroat Trout and Greenback Cutthroat Trout in western states where moratoriums on stocking of non-native species have been adopted (CRCTCT 2006; GCTRT 1998). Between 2011 and 2012 nearly 125,000 Brown Trout and Rainbow Trout were stocked in the Big Manistee River study area by the MDNR (MDNR 2016). If Arctic Grayling restoration proceeds for this watershed it may be beneficial to reduce or eliminate additional stocking of non-native species.

\section{Acknowledgements}

The authors would like to thank all of the full-time and seasonal staff at the Little River Band of Ottawa Indians Natural Resources Department who provided assistance conducting field surveys and lab work. We would also like to thank the Department of Biological Sciences at Michigan Technological University for providing support for this research. Partial funding was provided by the Little River Band of Ottawa Indians through a U.S. Fish and Wildlife Service Tribal Wildlife Grant (U-17-NA-1) awarded to Nancy Auer, Casey Huckins, J. Marty Holtgren, and Stephanie Ogren. Additional funding was provided by the Department of Biological Sciences at Michigan Technological University through Graduate Teaching Assistantships and through National Science Foundation GK-12 fellowships awarded to Cameron Goble and Brian Danhoff. This work was submitted by Cameron Goble in partial fulfillment of a Doctor of Philosophy degree at Michigan Technological University and special thanks go to the 
members of the graduate committee: Casey Huckins, James Magee, John Vucetich, as well as J. Marty Holtgren and Stephanie Ogren for their insightful comments and reviews of this manuscript. This is contribution \# xxx of the Great Lakes Research Center, MTU. 


\section{References}

Babbitt, A. 1900. Michigan Grayling: (Thymallus Tricolor.). Transactions of the American Fisheries Society 29:106-108.

Baker, E. A, and T. G. Coon. 1997. Development and evaluation of alternative habitat suitability criteria for Brook Trout. Transactions of the American Fisheries Society 126:65-76.

Bower, S. 1910. The Rainbow Trout in Michigan. Transactions of the American Fisheries Society 39:130-142.

Bowlby, J. N., and J. C. Roff. 1986. Trout biomass and habitat relationships in southern Ontario streams. Transactions of the American Fisheries Society 115:503-514.

Bunnell, D. B., J. G. Mychek-Londer, and C. P. Madenjian. 2014. Population-level effects of egg predation on a native planktivore in a large freshwater lake. Ecology of Freshwater Fish 23:604-614.

Burroughs, B. A., D. B. Hayes, K. D. Klomp, J. F. Hansen, and J. Mistak. 2010 The effects of the Stronach Dam removal on fish in the Pine River, Big Manistee County, Michigan. Transactions of the American Fisheries Society 139:15951613 .

Byorth, P., and J. Magee. 1998. Competitive Interactions between Grayling and Brook Trout in the Big Hole River Drainage, Montana. Transactions of the American Fisheries Society 127:921-931.

Carle, F. L., and M. R. Strub. 1978. A new method for estimating population size from removal data. Biometrics 34:621-630.

Cayer, E., and A. McCollough. 2013. Arctic Grayling monitoring report 2012. Montana Fish Wildlife and Parks. Dillon, MT. 
Chiotti, J. A., J. M. Holtgren, N. A. Auer, and S. A. Ogren. 2008. Lake Sturgeon spawning habitat in the Big Big Manistee River, Michigan. North American Journal of Fisheries Management 28:1009-1019.

CRCTCT, 2006. Conservation agreement for Colorado River cutthroat trout (Oncorhynchus clarkii pleuriticus) in the States of Colorado, Utah, and Wyoming. Colorado Division of Wildlife, Fort Collins. 10p.

Creaser, C. W., and E. P. Creaser. 1935. The Grayling In Michigan. Michigan Academy of Science, Arts, and Letters 20:599-608.

Danhoff, B. M., C. J. Huckins, N. A. Auer, C. W. Goble, S. A. Ogren, and J. M. Holtgren. 2017. Abiotic Habitat Assessment for Arctic Grayling in a Portion of the Big Manistee River, MI. Transactions of the American Fisheries Society XX:ppp-ppp.

Dewald, L., and M. A. Wilzbach. 1992. Interactions between native Brook Trout and hatchery Brown Trout: Effects on habitat use, feeding, and growth. Transactions of the American Fisheries Society 121: 287-296.

Dunham, J. B., S. B. Adams, R. E. Schroeter, and D. C. Novinger. 2002. Alien invasions in aquatic ecosystems: Toward an understanding of brook trout invasions and potential impacts on inland cutthroat trout in western North America. Reviews in Fish Biology and Fisheries 12: 373-391.

East, P., and P. Magnon. 1991. Some factors regulating piscivory of brook trout, Salvelinus fontinalis, in lakes of the Laurentian Shield. Canadian Journal of Fisheries and Aquatic Sciences 48: 1735-1743.

Essington, T. E., P. W. Sorensen, and D. G. Paron. 1998. High rate of redd superimposition by brook trout (Salvelinus fontinalis) and brown trout (Salmo trutta) in a Minnesota stream cannot be explained by habitat availability alone. Canadian Journal of Fisheries and Aquatic Sciences 55: 2310-2316. 
Fausch, K. D. 2008. A paradox of trout invasions in North America. Biological Invasions 10: $685-701$.

Fausch, K D., C. L. Hawkes, and M. G. Parsons. 1988. Models that predict standing crop of stream fish from habitat variables: 1950-85. U.S. Department of Agriculture, Forest Service, Pacific Northwest Research Station General Technical Report PNW-GTR-213.

Fausch, K. D., and R. J. White. 1981. Competition between Brook Trout (Salvelinus fontinalis) and Brown Trout (Salmo trutta) for positions in a Michigan stream. Canadian Journal of Fisheries and Aquatic Sciences 38: 1220-1227.

GCTRT, 1998. Greenback Cutthroat Trout Recovery Plan. United States Fish and Wildlife Service, Denver.

Gunckel, S. L., A. R. Hemmingsen, and J. L. Li. 2002. Effect of bull trout and brook trout interactions on foraging habitat, feeding behavior, and growth. Transactions of the American Fisheries Society 131: 1119-1130.

Harris, W. C. 1905. The decatence of the Grayling. Outing 45:762-764.

Hawkins, C. P., J. L. Kershner, P. A. Bisson, M. D. Bryant, L. M. Decker, S. V. Gregory, D. A. McCullough, C. K. Overton, G. H. Reeves, R. J. Steedman, and M. K. Young. 1993. A Hierarchical Approach to Classifying Stream Habitat Features. Fisheries 18:3-12.

Hayes, D. B., J. R. Bence, T. J. Kwak, and B. E. Thompson. 2007. Abundance, Biomass, and Production. Pages 327 - 374 in C. S. Guy, and M. L. Brown, editors. Analysis and interpretation of freshwater fisheries data. American Fisheries Society, Bethesda, Maryland.

Holtgren, J. M., and N. A. Auer. 2016. Re-envisioning State and Tribal collaboration in fishery assessment and restoration. Fisheries 41:244-257. 
Hubbard, B. 1887. Memorials of a half-Century. Page 581. G. P. Putnam's Sons, New York.

Hubert, W. A. and M. C. Fabrizio. 2007. Relative abundance and catch per unit effort. Pages 279-325 in C. S. Guy, and M. L. Brown, editors. Analysis and interpretation of freshwater fisheries data. American Fisheries Society, Bethesda, Maryland.

Hubert, W. A., R. S. Helzner, L. A. Lee, and P. C. Nelson. 1985. Habitat suitability index models and instream flow suitability curves: Arctic Grayling in riverine populations. U.S. Fish and Wildlife Service Biological Report 82(10.110). Washington D.C.

Hubert, W. A., and F. J. Rahel. 1989. Relations of physical habitat to abundance of four nongame fishes in high-plains streams: A test of habitat suitability index models. North American Journal of Fisheries Management 9: 332-340.

Jost. L. 2006. Entropy and diversity. OIKOS 113: 363-375.

Kaeding, L. R., and G. D. Boltz. 2004. Use of remote-site incubators to produce Arctic grayling fry of wild parentage. North American Journal of Fisheries Management 24: $1031-1037$.

Kaya, C. M. 1992. Restoration of fluvial Arctic Grayling to Montana streams: Assessment of reintroduction potential of streams in the native range, the upper Missouri River drainage above Great Falls. Montana State University. Bozeman, MT.

Krueger, C. C., and B. May. 1991. Ecological and genetic effects of salmonid introductions in North America. Canadian Journal of Fisheries and Aquatic Sciences 48: 66-77. 
L’Abée-Lund, J. H., A. Langeland, and H. Saegrov. 1992. Piscivory by Brown Trout Salmo trutta L. and Arctic Char Salvelinus alpinus L. in Norwegian lakes. Journal of Fish Biology 41: 91-101.

Lazorchak, J. M., B.H Hill., D. K. Averill, D.V. Peck, and D.J. Klemm (editors). 2000. U.S. Environmental Protection Agency. Environmental Monitoring and Assessment Program Surface Waters: Field Operations and Methods for Measuring the Ecological Condition of Non-Wadeable Rivers and Streams

Leonard, J. W. 1939. Montana Grayling in Michigan. Michigan Conservation, Lansing, MI.

Leonard, J. W. 1949. The Michigan Grayling. Michigan Conservation, Lansing, MI.

Lockwood, R. N., and J. C. Schneider. 2000. Stream fish population estimates by markand-recapture and depletion methods. Chapter 7 in Schneider, J. C. (ed.) 2000. Manual of fisheries survey methods II: with periodic updates. Michigan Department of Natural Resources, Fisheries Special Report 256, Ann Arbor.

Lohr, S. C., P. A. Byorth, C. M. Kaya, and W. P. Dwyer. 1996. High-temperature tolerance of fluvial grayling and comparisons with summer river temperatures of the Big Hole River, Montana. Transactions of the American Fisheries Society 125: 933-939.

Luton, J. R. 1985. The first introductions of Brown Trout, Salmo trutta, in the United States. Fisheries 10: 10-13.

Lyons, J., J. S. Stewart, and M. Mitro. 2010. Predicted effects of climate warming on the distribution of 50 stream fishes in Wisconsin, U.S.A. Journal of Fish Biology 77: 1867-1898.

McAllister, D. E., and C. R. Harington. 1969. Pleistocene Grayling, Thymallus, from Yukon, Canada. Canadian Journal of Earth Sciences 6:1185-1190. 
Mershon, W. B. 1916. The Grayling in Michigan, why and how "the flower of fishes" was exterminated - doubtful whether any are left in the state. Forest and Stream 86:799.

Michigan Department of Environmental Quality (MDEQ), Surface Water Quality Division. 1997. GLEAS Procedure \# 51 survey protocols for wadeable rivers. Chapter 25 in Schneider, James C. (ed.) 2000. Manual of fisheries survey methods II: with periodic updates. Michigan Department of Natural Resources, Fisheries Special Report 25, Ann Arbor.

Michigan Department of Natural Resources, Fisheries Division. 1978. Pere Marquette River natural river plan. Lansing, MI.

Michigan Department of Natural Resources (MDNR). 2016. Fish Stocking Database [online database]. Michigan Department of Natural Resources, Lansing, Michigan. Available: www.michigandnr.com/fishstock/.

Norris, T. 1879. The Michigan Grayling. Scribners Monthly Magazine 19:17-23.

Ogle, D.H. 2015. FSA: Fisheries Stock Analysis. R package version 0.8.4.

Peterson, D. P., K. D. Fausch, and G. C. White. 2004. Population ecology of an invasion: Effects of brook trout on native cutthroat trout. Ecological Applications 14: 754772.

Quist, M. C., C. S. Guy, and J. L. Stephen. 2003. Recruitment dynamics of Walleyes (Stizostedion vitreum) in Kansas reservoirs: generalities with natural systems and effects of a centrarchid predator. Canadian Journal of Fisheries and Aquatic Sciences 60:830-839.

Quist, M. C., and W. A. Hubert. 2005. Relative effects of biotic and abiotic processes: a test of the biotic-abiotic constraining hypothesis as applied to Cutthroat Trout. Transactions of the American Fisheries Society 134: 676-686. 
Rahel, F. J. 1997. From Johnny Appleseed to Dr. Frankenstein: changing values and the legacy of fisheries management. Fisheries 22: 8-9.

Raleigh, R. F. 1982. Habitat suitability index models: Brook Trout. U.S. Fish and Wildlife Service FWS-OBS-82/10.24.

Raleigh, R. F., L. D. Zuckerman, and P. C. Nelson. 1986. Habitat suitability index models and instream flow curves: Brown Trout, revised. U.S. Fish and Wildlife Service Biological Report 82(10.124).

R Development Core Team. 2015. R: a language and environment for statistical computing. R Foundation for Statistical Computing, Vienna. Available: www.Rproject.org. (December 2015)

Reiman, B. E., J. T. Peterson, and D. L. Myers. 2006. Have brook trout (Salvelinus fontinalis) displaced bull trout (Salvelinus confluentus) along longitudinal gradients in central Idaho streams? Canadian Journal of Fisheries and Aquatic Sciences 63: 63-78.

Rozich, T. J. 1998. Big Manistee River Assessment. Michigan Department of Natural Resources, Fisheries Division, Special Report No. 21. Ann Arbor, Michigan.

SAS Institute Inc. 2008. SAS/STAT ${ }^{\circledR} 9.2$ user's guide. SAS Institute Inc., Cary, North Carolina.

Stoneman, C. L., and M. L. Jones. The influence of habitat features on the biomass and distribution of three species of southern Ontario stream salmonines. Transactions of the American Fisheries Society 129:639-657.

Strang, J. J. 1855. Some Remarks on the Natural History of Beaver Islands, Michigan. Annual Report of the Smithsonian Institute. Pages 282-288. 
Taylor, W. R. 1954. Records of Fishes in the John N. Lowe Collection from the Upper Peninsula of Michigan. Museum of Zoology, University of Michigan, Ann Arbor, MI.

Vincent, R. E. 1962. Biogeographical and Ecological Factors Contributing to the Decline of Grayling, Thymallus Arcticus Pallas, in Michigan and Montana. The Univeristy of Michigan, Ann Arbor, Michigan.

Wolman, M. G. 1954. A Method of Sampling Coarse River-Bed Material. Transactions of the American Geophysical Union 35:951-95. 
Table 2.1. Total number of fish captured, tributaries where species was captured, and proportion of the total catch represented by each species, and throughout 2012 fish population surveys (species are listed in order of their proportional contribution to the overall catch).

\begin{tabular}{|c|c|c|c|}
\hline Species & Streams & Count & Proportion of total catch $(\%)$ \\
\hline Slimy Sculpin & All & 3915 & 38.80 \\
\hline Brown Trout & All & 3836 & 38.02 \\
\hline Brook Trout & All & 1982 & 19.64 \\
\hline Blacknose Dace & Peterson & 95 & 0.94 \\
\hline Rainbow Trout & Arquilla, Cedar, Eddington, Hinton, Slagle, \& Woodpecker & 62 & 0.61 \\
\hline Chestnut Lamprey & Arquilla, Cedar, Peterson, Slagle, \& Woodpecker & 51 & 0.51 \\
\hline Blackside Darter & Arquilla \& Hinton & 31 & 0.31 \\
\hline Johnny Darter & Arquilla, Hinton, \& Sand & 21 & 0.21 \\
\hline Lamprey Species & Arquilla, Hinton, Peterson, \& Slagle & 21 & 0.21 \\
\hline Black Bullhead & Arquilla, Hinton, \& Sand & 14 & 0.14 \\
\hline Creek Chub & Peterson & 13 & 0.13 \\
\hline Brook Stickleback & Sand \& Woodpecker & 11 & 0.11 \\
\hline Silver Lamprey & Arquilla, Hinton, \& Slagle & 8 & 0.08 \\
\hline American Brook Lamprey & Hinton, Peterson, \& Slagle & 7 & 0.07 \\
\hline Longnose Dace & Woodpecker & 5 & 0.05 \\
\hline Northern Redbelly Dace & Eddington \& Peterson & 5 & 0.05 \\
\hline White Sucker & Sand \& Slagle & 4 & 0.04 \\
\hline Northern Brook Lamprey & Hinton, Sand, \& Slagle & 3 & 0.03 \\
\hline Bluegill & Hinton \& Slagle & 2 & 0.02 \\
\hline Fathead Minnow & Sand & 2 & 0.02 \\
\hline Pumpkinseed Sunfish & Hinton & 1 & 0.01 \\
\hline Smallmouth Bass & Hinton & 1 & 0.01 \\
\hline Total & & 10090 & \\
\hline
\end{tabular}


Table 2.2. Mean catch per unit effort (CPUE; number of fish captured per minute of electrofishing time), density (number of fish per square meter), and biomass (grams of fish per square meter) of Brook Trout, Brown Trout, and Slimy Sculpin in 22 Big Manistee River tributary sampling reaches. CPUE Standard deviations are presented in parentheses.

\begin{tabular}{|c|c|c|c|c|c|c|c|c|c|c|}
\hline \multirow[b]{2}{*}{ Tributary } & \multirow[b]{2}{*}{ Reach } & \multicolumn{3}{|c|}{ Brook Trout } & \multicolumn{3}{|c|}{ Brown Trout } & \multicolumn{3}{|c|}{ Slimy Sculpin } \\
\hline & & $\begin{array}{c}C P U E \\
\text { (fish/minute) }\end{array}$ & $\begin{array}{l}\text { Density } \\
\left(\text { fish } / \mathrm{m}^{2}\right)\end{array}$ & $\begin{array}{l}\text { Biomass } \\
\left(\mathrm{g} / \mathrm{m}^{2}\right)\end{array}$ & $\begin{array}{c}C P U E \\
\text { (fish/minute) }\end{array}$ & $\begin{array}{l}\text { Density } \\
\text { (fish/m²) }\end{array}$ & $\begin{array}{c}\text { Biomass } \\
\left(\mathrm{g} / \mathrm{m}^{2}\right)\end{array}$ & $\begin{array}{c}C P U E \\
\text { (fish/minute) }\end{array}$ & $\begin{array}{l}\text { Density } \\
\left(\text { fish } / \mathrm{m}^{2}\right)\end{array}$ & $\begin{array}{c}\text { Biomass } \\
\left(\mathrm{g} / \mathrm{m}^{2}\right)\end{array}$ \\
\hline Arquilla & Lower & $0.15( \pm 0.12)$ & 0.01 & 0.11 & $1.28( \pm 0.17)$ & 0.11 & 4.94 & $0.50( \pm 0.08)$ & 0.09 & 0.43 \\
\hline Arquilla & Upper & $1.63( \pm 0.36)$ & 0.21 & 2.59 & $1.42( \pm 0.31)$ & 0.16 & 4.82 & $1.38( \pm 0.34)$ & 0.23 & 1.52 \\
\hline Cedar & Lower & $1.21( \pm 0.11)$ & 0.27 & 4.17 & $0.33( \pm 0.25)$ & 0.06 & 2.22 & $0.68( \pm 0.21)$ & 0.14 & 0.50 \\
\hline Cedar & Middle & $4.04( \pm 0.48)$ & 1.31 & 20.83 & 0.00 & 0.00 & 0.00 & $1.05( \pm 0.69)$ & 0.78 & 3.03 \\
\hline Cedar & Upper & $2.58( \pm 0.57)$ & 0.43 & 5.41 & 0.00 & 0.00 & 0.00 & $0.65( \pm 0.33)$ & 0.32 & 1.20 \\
\hline Eddington & Lower & $1.55( \pm 0.51)$ & 0.15 & 1.97 & $0.18( \pm 0.08)$ & 0.06 & 1.06 & $2.17( \pm 0.04)$ & 0.49 & 3.00 \\
\hline Eddington & Middle & $1.18( \pm 0.16)$ & 0.11 & 2.63 & $0.11( \pm 0.15)$ & 0.00 & 0.00 & $0.51( \pm 0.37)$ & 0.25 & 1.27 \\
\hline Eddington & Upper & $2.07( \pm 0.27)$ & 0.26 & 3.51 & $0.00^{b}$ & 0.00 & 0.00 & $0.55( \pm 0.16)$ & 0.08 & 0.49 \\
\hline Hinton & Lower & $0.44( \pm 0.06)$ & 0.03 & 0.27 & $1.18( \pm 0.19)$ & 0.08 & 2.74 & $1.00( \pm 0.23)$ & 0.12 & 0.57 \\
\hline Hinton & Middle & $0.33( \pm 0.13)$ & 0.09 & 2.67 & $1.74( \pm 0.46)$ & 0.28 & 10.72 & $0.21( \pm 0.06)$ & 0.07 & 0.50 \\
\hline Hinton & Upper & $0.62( \pm 0.20)$ & 0.07 & 1.49 & $1.92( \pm 0.01)$ & 0.39 & 9.26 & 0.00 & 0.00 & 0.00 \\
\hline Peterson & Lower & $0.06( \pm 0.05)$ & $<0.01$ & 0.15 & $0.47( \pm 0.18)$ & 0.04 & 2.25 & $0.62( \pm 0.15)$ & 0.05 & 0.20 \\
\hline Peterson & Middle & $0.03( \pm 0.03)$ & $<0.01$ & 0.12 & $1.55( \pm 0.65)$ & 0.13 & 6.61 & $1.06( \pm 0.53)$ & 0.09 & 0.58 \\
\hline Peterson & Upper & $0.30( \pm 0.10)$ & 0.07 & 2.64 & 0.00 & 0.00 & 0.00 & $1.71( \pm 0.43)$ & 0.49 & 4.62 \\
\hline Sand & Middle & $0.98( \pm 0.53)$ & 0.20 & 3.42 & $0.13( \pm 0.07)$ & 0.01 & 0.18 & $1.26( \pm 0.93)$ & 0.51 & 1.69 \\
\hline Sand & Upper & $0.77( \pm 0.27)$ & 0.14 & 2.25 & $0.04( \pm 0.01)$ & $<0.01$ & 0.15 & $1.85( \pm 0.33)$ & 1.22 & 4.48 \\
\hline Slagle & Lower & $0.00^{a}$ & $<0.01$ & 0.05 & $1.47( \pm 0.22)$ & 0.11 & 6.94 & $1.33( \pm 0.35)$ & 0.14 & 2.11 \\
\hline Slagle & Middle & 0.00 & 0 & 0.00 & $2.84( \pm 0.06)$ & 0.21 & 12.48 & $1.05( \pm 0.31)$ & 0.10 & 1.12 \\
\hline Slagle & Upper & $0.14( \pm 0.10)$ & 0.01 & 0.52 & $0.79( \pm 0.07)$ & 0.06 & 7.11 & $3.25( \pm 0.81)$ & 0.38 & 4.82 \\
\hline Woodpecker & Lower & $0.14( \pm 0.05)$ & 0.01 & 0.08 & $1.74( \pm 0.30)$ & 0.16 & 6.05 & $1.02( \pm 0.25)$ & 0.16 & 0.82 \\
\hline Woodpecker & Middle & $0.10( \pm 0.05)$ & 0.01 & 0.37 & $2.11( \pm 0.03)$ & 0.34 & 10.75 & $0.52( \pm 0.03)$ & 0.10 & 0.58 \\
\hline Woodpecker & Upper & $0.10( \pm 0.06)$ & 0.02 & 0.78 & $1.86( \pm 0.61)$ & 0.12 & 1.81 & $0.01( \pm 0.02)$ & $<0.01$ & $<0.01$ \\
\hline
\end{tabular}

${ }^{a}$ No Brook Trout were collected on the first electrofishing pass from which $C P U E$ was calculated, two were collected on subsequent passes.

${ }^{b}$ No Brown Trout were collected on the first electrofishing pass from which CPUE was calculated, one was collected on subsequent passes. 


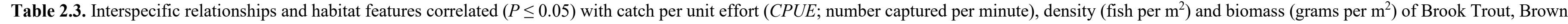
Trout, and Slimy Sculpin in 22 Big Manistee River tributary sampling reaches. + indicates a positive correlation; - indicates a negative correlation.

\begin{tabular}{|c|c|c|c|c|c|c|c|c|c|}
\hline Variable & $\begin{array}{l}\text { Brook } \\
\text { Trout } \\
C P U E\end{array}$ & $\begin{array}{c}\text { Brown } \\
\text { Trout } \\
\text { CPUE }\end{array}$ & $\begin{array}{c}\text { Slimy } \\
\text { Sculpin } \\
\text { CPUE }\end{array}$ & $\begin{array}{c}\text { Brook } \\
\text { Trout } \\
\text { density }\end{array}$ & $\begin{array}{c}\text { Brown } \\
\text { Trout } \\
\text { density }\end{array}$ & $\begin{array}{l}\text { Slimy } \\
\text { Sculpin } \\
\text { density }\end{array}$ & $\begin{array}{c}\text { Brook } \\
\text { Trout } \\
\text { biomass }\end{array}$ & $\begin{array}{c}\text { Brown } \\
\text { Trout } \\
\text { biomass }\end{array}$ & $\begin{array}{c}\text { Slimy } \\
\text { Sculpin } \\
\text { biomass }\end{array}$ \\
\hline \multicolumn{10}{|c|}{ Biota } \\
\hline Brook Trout & & - & & & & + & & & \\
\hline Brown Trout & - & & - & & & - & & & \\
\hline Sculpin Sp. & & - & & $\begin{array}{r}+ \\
\text { Habitat }\end{array}$ & - & & & & \\
\hline Mean wetted width & - & + & & - & & - & - & + & \\
\hline $\begin{array}{l}\text { Site area } \\
\text { Pool \% }\end{array}$ & - & + & & & & & & + & \\
\hline Riffle \% & - & + & & & & - & & + & \\
\hline Run $\%$ & + & & & & & & & & \\
\hline Discharge & - & + & & & & & & + & \\
\hline Mean depth & - & + & & & & & & + & \\
\hline Maximum depth & - & + & & & & & & + & \\
\hline Width:depth ratio & & & & - & & & - & & \\
\hline Mean bottom velocity & & & & & & - & & & \\
\hline Maximum bottom velocity & & & & & & & & + & \\
\hline Mean column velocity & - & & & & & - & & + & \\
\hline $\begin{array}{l}\text { Maximum column velocity } \\
\text { LWD \% }\end{array}$ & & + & & & & - & & + & \\
\hline Course substrate $\%$ & & + & & & + & - & & + & - \\
\hline $\begin{array}{l}\text { Water temperature } \\
\mathrm{pH} \\
\text { Turbidity } \\
\text { Dissolved oxygen }\end{array}$ & - & + & & & & & & & \\
\hline
\end{tabular}


Table 2.4. Simple Regression equations describing interspecific relationships and abiotic habitat factors associated with catch per unit effort (CPUE; fish per minute), density (fish per $\mathrm{m}^{2}$ ) and biomass (grams per $\mathrm{m}^{2}$ ) of Brook Trout, Brown Trout, and Slimy Sculpin in 22 Big Manistee River tributary sampling reaches.

\begin{tabular}{|c|c|c|}
\hline Regression equation & $r^{2}$ & $P$ \\
\hline \multicolumn{3}{|c|}{ Brook Trout $C P U E^{a}$} \\
\hline $0.89-0.69\left(\right.$ Brown Trout $\left.C P U E^{a}\right)$ & 0.47 & $<0.01$ \\
\hline $1.08-0.16($ wetted width) & 0.42 & $<0.01$ \\
\hline $1.57-0.09$ (water temperature) & 0.29 & 0.01 \\
\hline$-0.0002+0.88(\%$ Run $)$ & 0.20 & 0.04 \\
\hline \multicolumn{3}{|c|}{ Brook Trout density } \\
\hline $0.04+0.44($ Slimy Sculpin density) & 0.21 & 0.03 \\
\hline $0.60-0.02$ (width:depth ratio) & 0.18 & 0.04 \\
\hline \multicolumn{3}{|c|}{ Brook Trout biomass } \\
\hline $6.45-1.07$ (width:depth ratio) & 0.27 & 0.01 \\
\hline \multicolumn{3}{|c|}{ Brown Trout $C P U E^{a}$} \\
\hline $0.91-0.68\left(\right.$ Brook Trout $\left.C P U E^{a}\right)$ & 0.47 & $<0.01$ \\
\hline$-0.02+0.01(\%$ course substrate $)$ & 0.32 & $<0.01$ \\
\hline $0.33+0.0004($ Site area $)$ & 0.29 & 0.01 \\
\hline $0.97-0.58\left(\right.$ Slimy Sculpin $\left.C P U E^{a}\right)$ & 0.24 & 0.02 \\
\hline \multicolumn{3}{|c|}{ Brown Trout density } \\
\hline$-0.04+0.003(\%$ course substrate $)$ & 0.32 & $<0.01$ \\
\hline $0.16-0.20$ (Slimy Sculpin density) & 0.26 & 0.02 \\
\hline \multicolumn{3}{|c|}{ Brown Trout biomass } \\
\hline$-2.50+38.69($ mean depth $)$ & 0.38 & $<0.01$ \\
\hline$-1.42+0.11(\%$ course substrate $)$ & 0.35 & $<0.01$ \\
\hline \multicolumn{3}{|c|}{ Slimy Sculpin $C P U E^{a}$} \\
\hline $0.75-0.20\left(\right.$ Brown Trout $\left.C P U E^{a}\right)$ & 0.06 & 0.04 \\
\hline \multicolumn{3}{|c|}{ Slimy Sculpin density } \\
\hline $0.40-1.31$ (Brown Trout density) & 0.26 & 0.02 \\
\hline $0.61-1.66$ (mean bottom velocity) & 0.24 & 0.02 \\
\hline $0.19+0.47$ (Brook Trout density) & 0.21 & 0.03 \\
\hline \multicolumn{3}{|c|}{ Slimy Sculpin biomass } \\
\hline $3.44-0.04(\%$ course substrate $)$ & 0.31 & $<0.01$ \\
\hline
\end{tabular}

${ }^{a} \log _{e}(x+1)$ transformed 
Table 2.5. Gradients (\% slope) of Big Manistee River tributary sampling reaches in four elevation regions: A) west side (all reaches), B) low-elevation reaches on east side, C) mid-elevation reaches on east side, D) high-elevation reaches on east side. Arquilla Creek Middle and Sand Creek Lower are not included due to sampling constraints preventing full surveys.

\begin{tabular}{lcc}
\hline A) $\begin{array}{l}\text { West tributaries } \\
\text { all reaches }\end{array}$ & Reach & $\begin{array}{c}\text { Mean gradient } \\
(\%)\end{array}$ \\
\hline Eddington & Lower & 0.8 \\
& Middle & 1.8 \\
& Upper & 2.7 \\
Sand & Middle & 0.3 \\
& Upper & 1.6 \\
Woodpecker & Lower & 0.9 \\
& Middle & 3.4 \\
& Upper & 0.5 \\
& Overall & 1.5 \\
& average & \\
\hline & & \\
\hline East tributaries & Reach & Mean gradient \\
mid-elevation reaches & & $(\%)$ \\
\hline Arquilla & Upper & 1.6 \\
Hinton & Middle & 1.4 \\
Hinton & Upper & 0.9 \\
Peterson & Middle & 1.0 \\
Slagle & Middle & 0.7 \\
& & \\
& Overall & 1.1 \\
\hline
\end{tabular}

\begin{tabular}{lcc}
\hline $\begin{array}{l}\text { East tributaries } \\
\text { low-elevation reaches }\end{array}$ & Reach & $\begin{array}{c}\text { Mean gradient } \\
(\%)\end{array}$ \\
\hline Arquilla & Lower & 2.4 \\
Cedar & Lower & 8.6 \\
Hinton & Lower & 2.6 \\
Peterson & Lower & 1.2 \\
Slagle & Lower & 2.2 \\
& Overall & 3.4 \\
\hline
\end{tabular}

D) \begin{tabular}{lcc}
\hline $\begin{array}{l}\text { East tributaries } \\
\text { upper-elevation reaches }\end{array}$ & Reach & $\begin{array}{c}\text { Mean gradient } \\
(\%)\end{array}$ \\
\hline Cedar & Middle & 0.3 \\
Cedar & Upper & 0.5 \\
Peterson & Upper & 0.5 \\
Slagle & Upper & 1.2 \\
& Overall & 0.6 \\
& average & \\
\hline
\end{tabular}




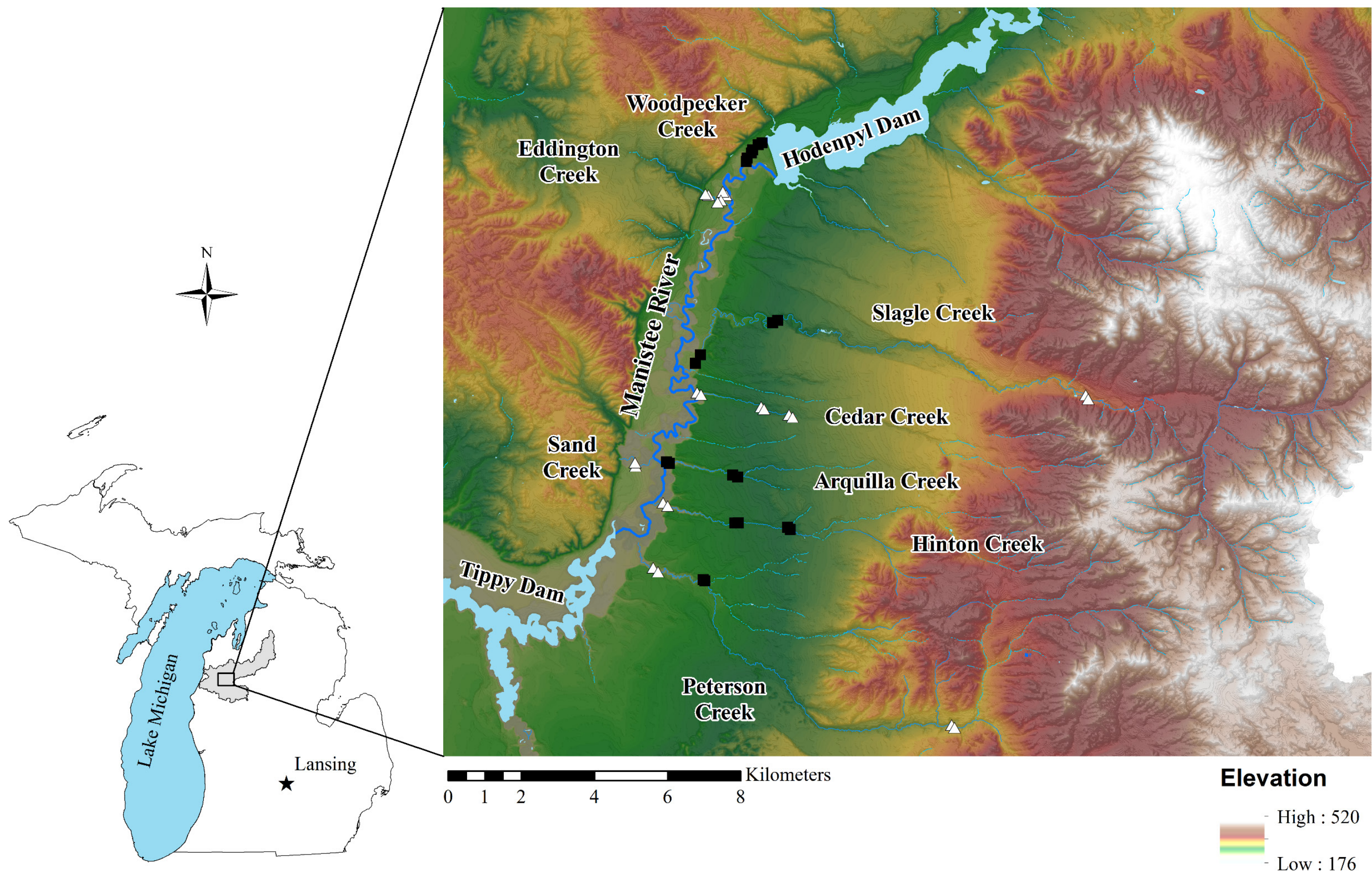

Figure 2.1. Location of the Big Manistee River watershed in the State of Michigan and 22 tributary reaches sampled during May - August 2012. White triangles indicate reaches with Brown Trout densities $<0.10$ fish $/ \mathrm{m}^{2}$ and black squares indicate reaches with Brown Trout densities $>0.10 \mathrm{fish} / \mathrm{m}^{2}$. 

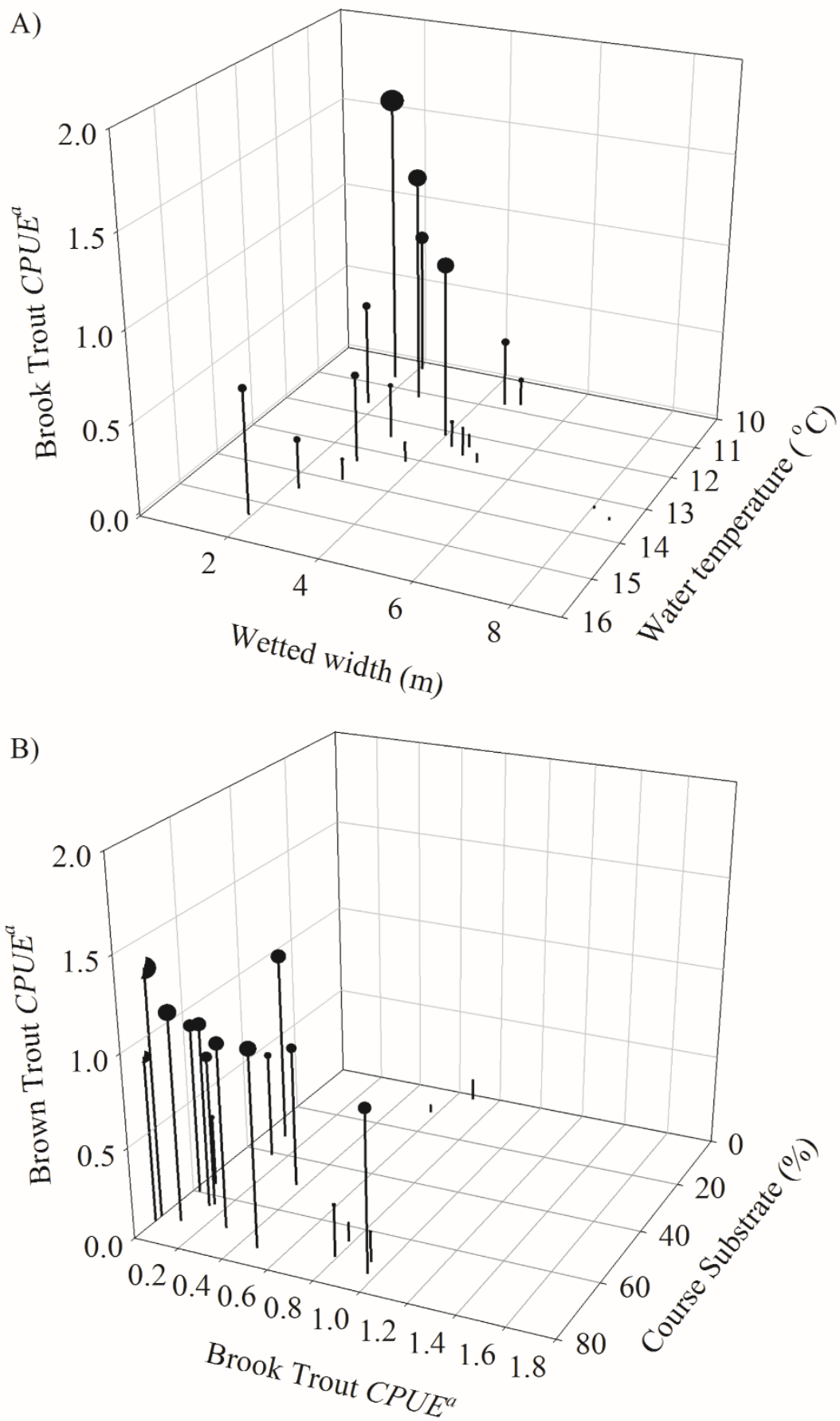

Figure 2.2. Relationships between (A) Brook Trout catch per unit effort (CPUE; fish per minute), stream wetted width (m), and average water temperature; and (B) Brown Trout $C P U E$, Brook Trout $C P U E$, and the proportion of substrate particles larger than $2 \mathrm{~mm}$ during three sampling occasions in 22 Big Manistee River tributary reaches. ${ }^{a}$ indicates $\log (\mathrm{X}+1)$ transformation. 

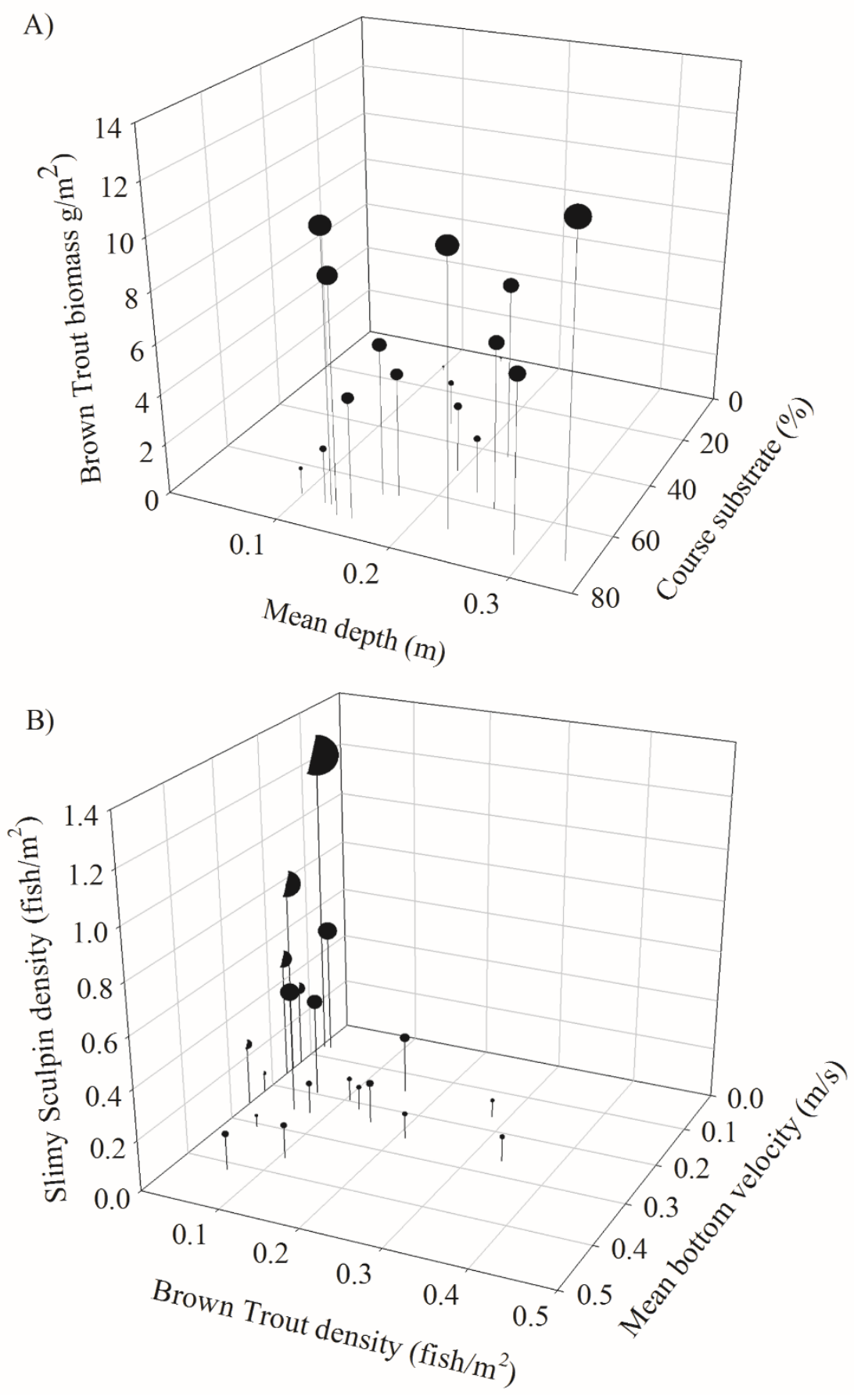

Figure 2.3. Relationships between (A) Brown Trout biomass (grams of fish per $\mathrm{m}^{2}$ ), mean water depth, and the proportion of substrate particles larger than $2 \mathrm{~mm}$; and (B) Slimy Sculpin density (number of fish per $\mathrm{m}^{2}$ ), Brown Trout density, and mean bottom velocity in 22 Big Manistee River tributary reaches. 


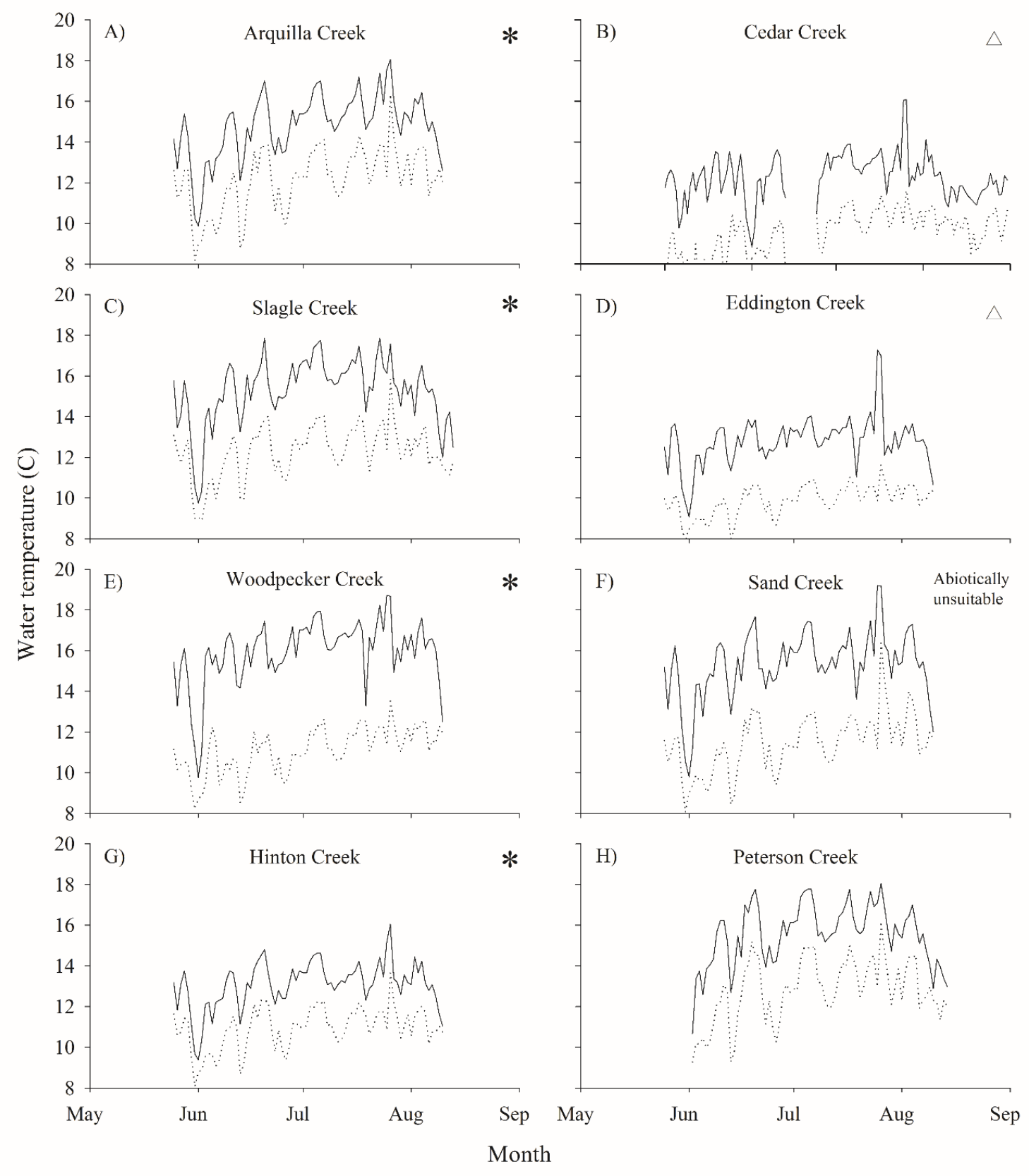

Figure 2.4. Maximum (solid line) and minimum (dashed line) daily water temperatures (C) recorded in lower reaches of Big Manistee River tributaries during summer 2012. * identifies most abiotically suitable tributaries according to Danhoff et al. (in prep), $\triangle$ identifies tributaries with lowest abundances of Brown Trout (excluding Sand Creek which is classified as abiotically unsuitable for Arctic Grayling reintroduction). 


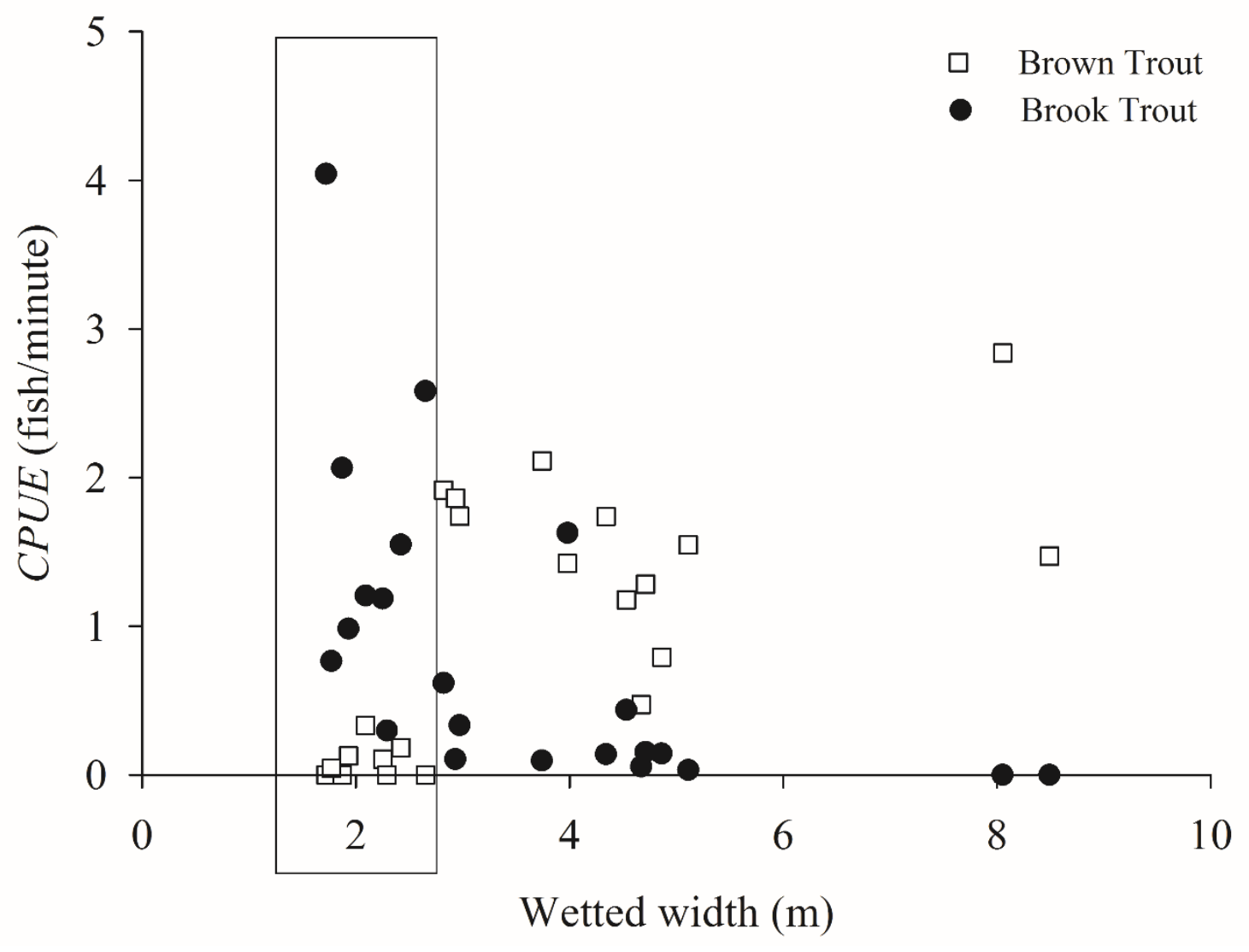

Figure 2.5. Relationship of Brown Trout and Brook Trout catch per unit effort (CPUE; fish per minute) with wetted width (m) in 22 Big Manistee River tributary reaches. Box indicates reaches where Brown Trout CPUE is lowest, Brook Trout CPUE is highest and most variable, and potential predation on Arctic Grayling is expected be lowest. 


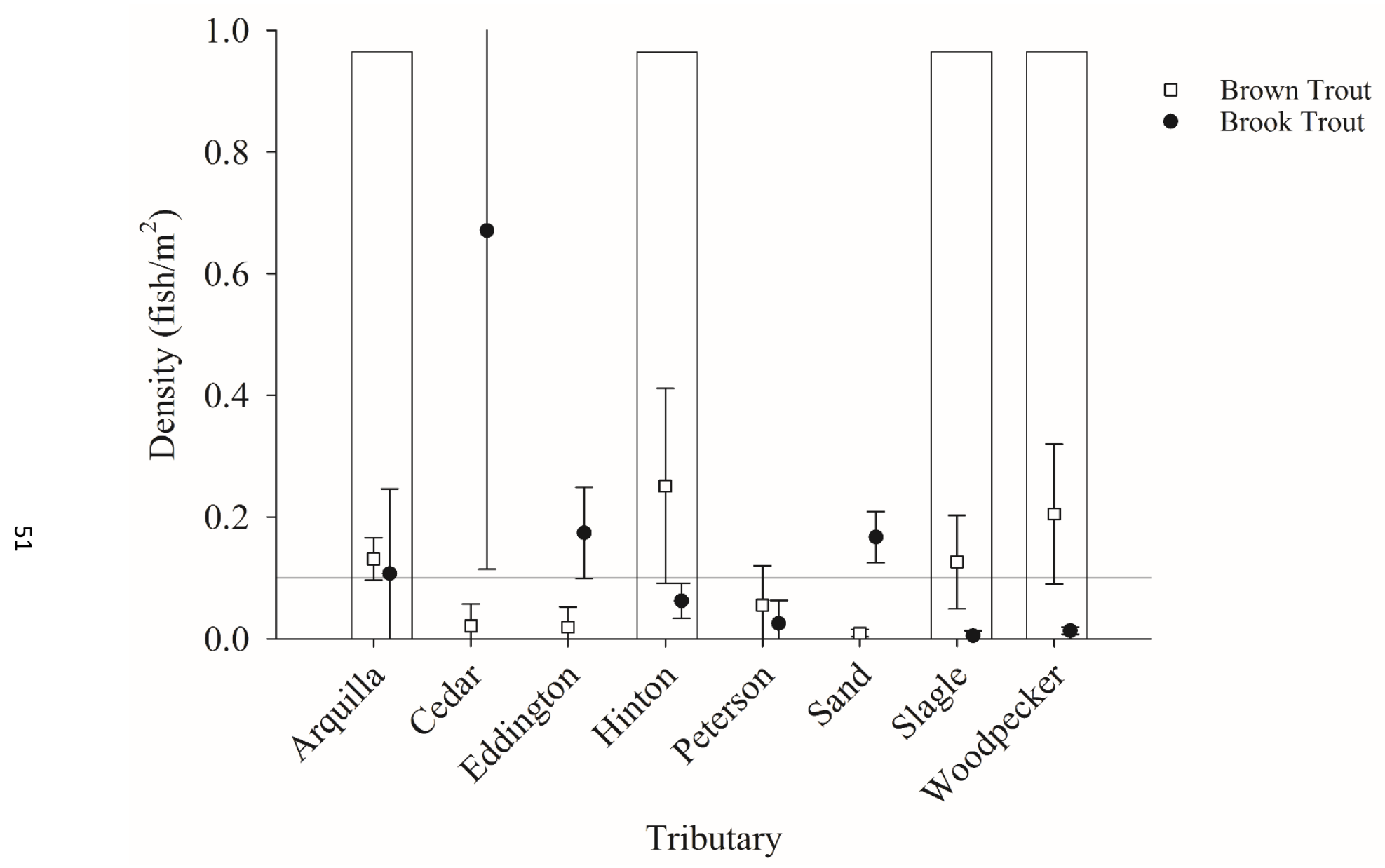

Figure 2.6. Brown Trout and Brook Trout Density (mean \pm standard deviation fish per $\mathrm{m}^{2}$ ) in eight Big Manistee River tributaries. Boxes indicate tributaries identified as most abiotically suitable for Arctic Grayling by Danhoff et al. $($ in prep), horizontal line $=$ the $0.10 \mathrm{fish} / \mathrm{m}^{2}$ threshold for a 'high density' Brown Trout population in Wyoming proposed by Quist and Hubert (2005). 


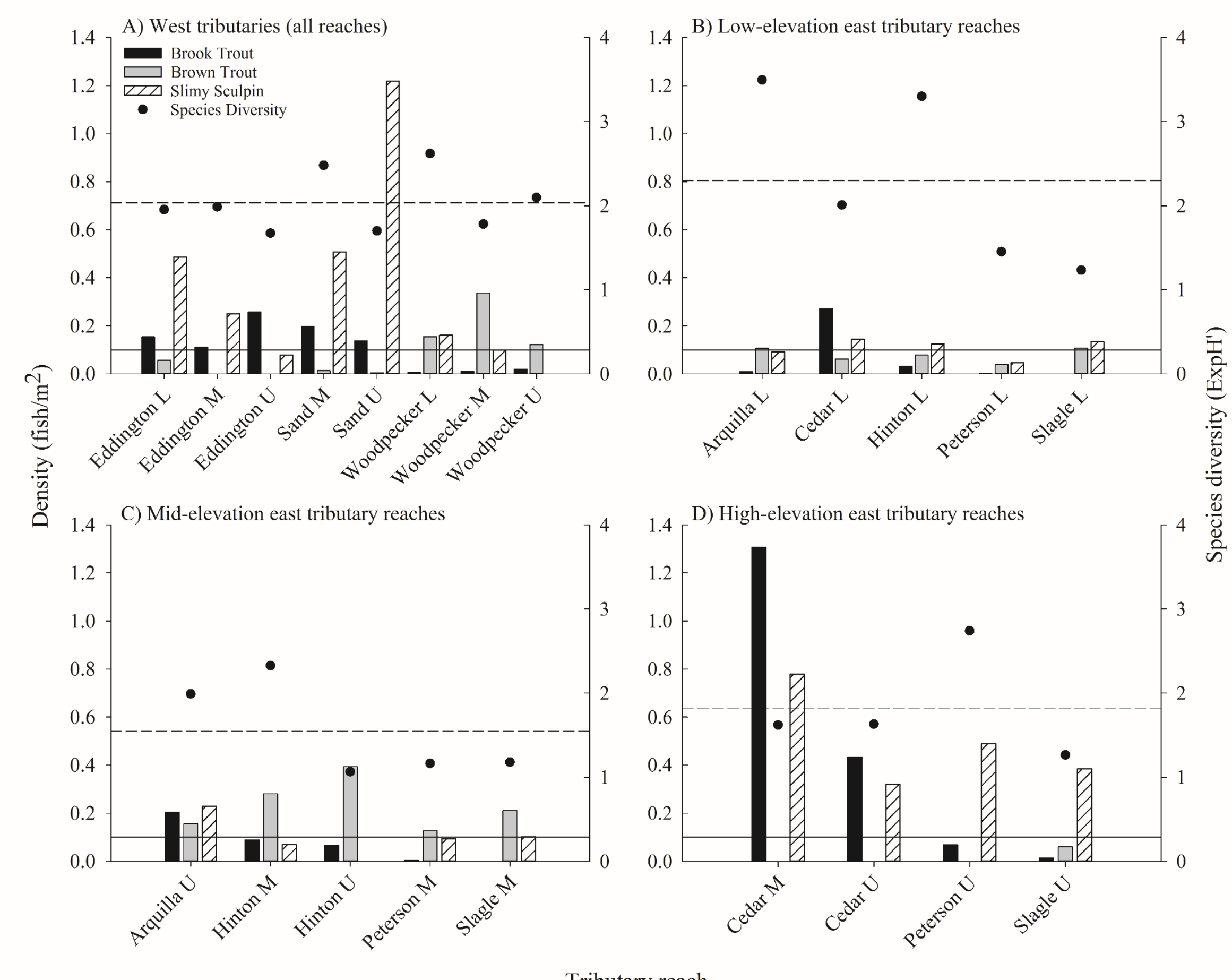

Figure 2.7. Densities (fish $/ \mathrm{m}^{2}$ ) of Brook Trout, Brown Trout and Slimy Sculpin and Shannon diversity values in Big Manistee River tributary reaches: "L" = "lower", "M" = "Middle", and "U" = "Upper". Solid horizontal line $=0.10 \mathrm{fish} / \mathrm{m}^{2}$ threshold for a high-density Wyoming Brown Trout population described by Quist and Hubert (2005). Dashed horizontal line $=$ mean Shannon diversity value for each region 
Appendix 2.1. Physical habitat characteristics and number of fish species captured in 22 Big Manistee River, MI tributary sampling reaches.

\begin{tabular}{|c|c|c|c|c|c|c|c|c|c|c|c|c|}
\hline Tributary & Reach & $\begin{array}{l}\text { Reach } \\
\text { length } \\
(\mathrm{m})\end{array}$ & $\begin{array}{l}\text { Reach } \\
\text { area } \\
\left(\mathrm{m}^{2}\right)\end{array}$ & $\begin{array}{l}\text { Mean } \\
\text { gradient } \\
(\%)\end{array}$ & $\begin{array}{l}\text { Mean } \\
\text { width } \\
(\mathrm{m})\end{array}$ & $\begin{array}{l}\text { Mean } \\
\text { depth } \\
\text { (m) }\end{array}$ & $\begin{array}{c}\text { Mean } \\
\text { discharge } \\
\left(\mathrm{m}^{3} / \mathrm{sec}\right)\end{array}$ & $\begin{array}{c}\text { Mean } \\
\text { velocity } \\
(\mathrm{m} / \mathrm{s})\end{array}$ & $\begin{array}{c}\text { Average } \\
\text { temperature } \\
\left({ }^{\circ} \mathrm{C}\right)\end{array}$ & $\begin{array}{c}\text { Course } \\
\text { substrate } \\
(\%)\end{array}$ & $\begin{array}{c}\text { Woody } \\
\text { debris } \\
(\%)\end{array}$ & $\begin{array}{l}\text { Fish } \\
\text { species } \\
(\#)\end{array}$ \\
\hline \multirow[t]{2}{*}{ Arquilla } & Lower & 160 & 809.6 & 2.4 & 4.7 & 0.17 & 0.14 & 0.27 & 12.6 & 63 & 20 & 10 \\
\hline & Upper & 198 & 838.9 & 1.6 & 4.0 & 0.15 & 0.09 & 0.22 & 12.1 & 74 & 15 & 3 \\
\hline \multirow[t]{3}{*}{ Cedar } & Lower & 133 & 276.4 & 8.6 & 2.1 & 0.12 & 0.09 & 0.51 & 10.2 & 71 & 26 & 5 \\
\hline & Middle & 120 & 213.3 & 0.3 & 1.7 & 0.18 & 0.04 & 0.23 & 10.7 & 22 & 22 & 2 \\
\hline & Upper & 120 & 343.3 & 0.5 & 2.6 & 0.09 & 0.03 & 0.16 & 11.2 & 39 & 13 & 2 \\
\hline \multirow[t]{3}{*}{ Eddington } & Lower & 120 & 299.9 & 0.8 & 2.4 & 0.10 & 0.05 & 0.30 & 9.9 & 70 & 21 & 4 \\
\hline & Middle & 120 & 271.5 & 1.8 & 2.3 & 0.11 & 0.06 & 0.32 & 9.7 & 65 & 21 & 4 \\
\hline & Upper & 120 & 217.8 & 2.7 & 1.9 & 0.10 & 0.05 & 0.28 & 9.9 & 58 & 20 & 3 \\
\hline \multirow[t]{3}{*}{ Hinton } & Lower & 199 & 944.9 & 2.6 & 4.5 & 0.20 & 0.20 & 0.37 & 10.9 & 50 & 15 & 12 \\
\hline & Middle & 120 & 359.4 & 1.4 & 3.0 & 0.23 & 0.07 & 0.26 & 12.5 & 70 & 15 & 6 \\
\hline & Upper & 123 & 332.6 & 0.9 & 2.8 & 0.14 & 0.09 & 0.28 & 13.4 & 74 & 10 & 3 \\
\hline \multirow[t]{3}{*}{ Peterson } & Lower & 247 & 1065.4 & 1.2 & 4.7 & 0.23 & 0.26 & 0.44 & 12.3 & 56 & 38 & 5 \\
\hline & Middle & 219 & 1089.8 & 1.0 & 5.1 & 0.25 & 0.24 & 0.33 & 12.7 & 60 & 13 & 6 \\
\hline & Upper & 120 & 263.9 & 0.5 & 2.3 & 0.16 & 0.06 & 0.24 & 14.4 & 5 & 12 & 6 \\
\hline \multirow[t]{2}{*}{ Sand } & Middle & 120 & 228.6 & 0.3 & 1.9 & 0.14 & 0.02 & 0.11 & 15.4 & 2 & 18 & 9 \\
\hline & Upper & 120 & 202.8 & 1.6 & 1.8 & 0.10 & 0.01 & 0.10 & 11.7 & 11 & 7 & 3 \\
\hline \multirow[t]{3}{*}{ Slagle } & Lower & 325 & 2736.2 & 2.2 & 8.5 & 0.29 & 1.09 & 0.61 & 13.5 & 73 & 22 & 6 \\
\hline & Middle & 325 & 2601.7 & 0.7 & 8.0 & 0.33 & 0.94 & 0.49 & 13.3 & 71 & 9 & 7 \\
\hline & Upper & 165 & 830.4 & 1.2 & 4.9 & 0.23 & 0.21 & 0.31 & 10.8 & 41 & 6 & 7 \\
\hline \multirow[t]{3}{*}{ Woodpecker } & Lower & 132 & 645.0 & 0.9 & 4.3 & 0.16 & 0.15 & 0.34 & 12.4 & 64 & 52 & 7 \\
\hline & Middle & 120 & 463.7 & 3.4 & 3.7 & 0.13 & 0.15 & 0.37 & 13.1 & 71 & 35 & 4 \\
\hline & Upper & 120 & 351.3 & 0.5 & 2.9 & 0.16 & 0.08 & 0.18 & 13.9 & 33 & 4 & 6 \\
\hline
\end{tabular}


Chapter 3. Bioenergetic assessment of potential Arctic Grayling restoration sites in Big Manistee River, MI tributaries.

Cameron W. Goble", and Nancy A. Auer

Department of Biological Sciences, Michigan Technological University, 1400 Townsend Drive, Houghton, Michigan 49931, USA 


\begin{abstract}
Historically, the Big Manistee River in Michigan supported an abundant population of Arctic Grayling Thymallus arcticus, a species which has been extinct in the State since 1936. Research conducted by the Little River Band of Ottawa Indians and Michigan Technological University in Big Manistee River tributaries has renewed interest in re-establishing this once abundant native fish. Rivers that formerly held Arctic Grayling are now occupied by non-native salmonids which have similar habitat requirements and feeding strategies and are likely competitors. This study presents a bioenergetic assessment of eight Big Manistee River tributaries to determine their potential as Arctic Grayling re-introduction sites. Invertebrate drift densities and salmonid abundance were measured in June 2012 using drift-nets and multi-pass electrofishing surveys. Drift densities were combined with water depth/velocity profiles into a mechanistic feeding model to calculate reach-scale values of Net Energy Intake (NEI) which was modeled with salmonid abundance to assess relationships. No statistically significant relationships were found between salmonid densities, drift densities, or NEI suggesting that food may not the primary limiting factor in this system. The largest NEI values were seen in the upper-most tributary reaches and overall, $59 \%$ of the reaches were energetically profitable indicating they can provide suitable resources for supporting Arctic Grayling. Coupled with findings of previously published work on abiotically suitable habitat and population viability assessments results from this work support the re-establishment of Arctic Grayling in the Big Manistee River.
\end{abstract}

\title{
Introduction
}


As with many stream-resident members of the Salmonidae family (hereafter salmonids) Arctic Grayling Thymallus arcticus are known to feed primarily on drifting aquatic and terrestrial invertebrates throughout their life-cycle (Armstrong 1986; O'Brien et al. 2001; Jones et al. 2003). Like Arctic Grayling, fluvial Brook Trout Salvelinus fontinalis, and Brown Trout Salmo trutta are known to feed upon drifting aquatic invertebrates, deriving much of their energetic intake from suspended aquatic and terrestrial invertebrates, while opportunistically feeding upon benthic or "other" prey items (Allan 1980; Armstrong 1986; Klemetsen et al. 2003). For fluvial species such as Arctic Grayling, Brook Trout, or Brown Trout, there is a trade-off between the amount of energy expended holding a feeding position and capturing prey with the amount of energy assimilated by consuming prey (Fausch 1984). Mechanistic drift-feeding models such as the Net Energy Intake (NEI) model developed by Fausch (1984) and further refined by Hughes and Dill (1990) have shown that these energetic trade-offs are a function of channel morphology, water depth and velocity, prey densities and size, and a fish's body size (Fausch 1984; Hughes and Dill 1990; Jenkins and Keeley 2010). Such models have proven useful in: predicting micro-habitat use and dominance hierarchies within individual channel units (e.g. Fausch 1984; Hughes and Dill 1990; Hill and Grossman 1993) predicting reach-scale habitat selection and movement patterns (Gowan and Fausch 2002), and assessing habitat suitability for fluvial salmonids (Baker and Coon 1997; Jenkins and Keeley 2010; Urabe et al. 2010).

The feeding habits of Arctic Grayling have been variously described as "not very selective" (Brown 1938), "opportunistic" (deBruyen and McCart 1974), or size and/or 
taxa selective (Jones et al. 2003). In lentic systems, Arctic Grayling feed on zooplankton throughout much of their life-cycle while also broadening their diet to include benthic macro-invertebrates, and small fishes (Miller 1946; Schmidt and O'Brien 1982; Northcote 1995). Fluvial Arctic Grayling also feed on zooplankton and other microcrustaceans at early life-stages (Brown 1938) however they tend to shift their diet towards larger prey items at earlier ages than those living in lakes (Stewart et al. 2007). While some of the Arctic Grayling dietary shift may be due to generally lower zooplankton abundances in lotic vs. lentic systems, Jones et al. (2003) found that even when zooplankton are abundant, young-of-year adfluvial Arctic Grayling will select larger macro-invertebrate prey suggesting that they are preferentially selecting prey items that are more energetically profitable than zooplankton. The diets of adult fluvial Arctic Grayling are comprised primarily of aquatic and terrestrial invertebrates generally reflecting the availability of various taxa (deBruyen and McCart 1974). Stewart et al. (2007) summarized Arctic Grayling diets for populations across northern Canada and Alaska and found that chironomids (Diptera), mayflies (Ephemeroptera), and caddisflies (Trichoptera) were generally the most consumed prey by juvenile and adult Arctic Grayling. Brook Trout and Brown Trout are also considered to be opportunistic feeders (Cada et al. 1987; Tiberti et al. 2016) that feed primarily on invertebrates (Allan 1980; Bachman 1984) and are known to exhibit piscivory at large sizes (East and Magnon 1991; L'Abee-Lund et al. 1992). Interestingly, in North America Brown Trout negatively impact native Brook Trout (Grant et al., 2002; Carlson et al., 2007) whereas in Europe, Brook Trout negatively impact native Brown Trout (Blanchet et al., 2007; Korsu et al., 
2009) and both species are presumed to negatively impact Arctic Grayling (Vincent 1962; Kaya 1992).

The potential for dietary overlap leading to direct feeding competition should be greatest between species that haven't co-evolved to occupy unique habitat and feeding niches (Olson et al. 2016). Conversely, for species that co-evolved, resource partitioning and/or niche shifts (Fausch et al. 1997) should lead to comparatively low levels of direct competition (Connell 1980). Despite having evolved in different geographic regions the life history characteristics of Brook Trout and Brown Trout are strikingly similar to each other (Dewald and Wilzbach 1992). In a study of diet and habitat Haugen and Rygg (1996) found segregation between native Brown Trout and European Grayling Thymallus thymallus (that co-evolved with Brown Trout) because the species typically occupied different habitats and fed on different prey items in a Norwegian reservoir. Similarly, Olson et al. (2016) studied the feeding habits of an Asian subspecies of Arctic Grayling (T. a. baicalensis) and a co-evolved drift-feeding salmonid species, the Lenok Brachymystax lenok, in their native rivers in Mongolia and found high levels of dietary overlap between the species when drift densities were high but at low drift densities Lenok shifted their strategy to benthic feeding resulting in low dietary overlap. In one of the few studies of dietary overlap for Arctic Grayling in North America, Cutting et al. (2016) studied an adfluvial population in Montana and found higher levels of dietary overlap between Arctic Grayling and non-native salmonids (i.e. Brook Trout and Cutthroat*Rainbow Trout hybrids Oncorhynchus clarkia*Oncorhynchus mykiss) than 
between Arctic Grayling and native species such as Burbot Lota lota, and suckers Catostomus species.

Research conducted by the Little River Band of Ottawa Indians (LRBOI) and Michigan Technological University (MTU) has spurred renewed interest in reestablishing this once abundant native fish species in Michigan's waters. Danhoff et al. (2017) assessed abiotic habitat in eight tributaries of the Big Manistee River and found that seven-of-eight met $>80 \%$ of the literature derived criteria for suitable Arctic Grayling habitat at the tributary-scale. Further analyses at the reach-scale (i.e. $120-$ $325 \mathrm{~m}$ ) identified 13 specific reaches within the tributaries which met $>80 \%$ of the abiotic criteria suggesting that abiotically suitable habitat for Arctic Grayling can be found in the Big Manistee River watershed (Danhoff et al. 2017). Goble et al. (In Review) described the distributions and habitat associations of two salmonids currently occupying the same eight tributaries and found evidence that Brown Trout densities were influencing the habitat associations of both Brook Trout and Slimy Sculpin. From this work, it was proposed that an additional assessment criterion be added to the Arctic Grayling habitat suitability criteria of Danhoff et al (2017) where Brown Trout densities should be $<0.10$ fish $/ \mathrm{m}^{2}$ which is a threshold suggested by Quist and Hubert (2005) above which biotic constraints (i.e. predation/competition) may become more limiting than abiotic habitat. Four-of-eight tributaries and 12-of-22 reaches met the proposed Brown Trout density threshold of which four reaches (but no tributaries) overlapped with those identified by Danhoff et al (2017) as the "most" abiotically suitable for Arctic Grayling reintroduction. 
In addition to assessing abiotic habitat and fish community characteristics, work is needed to quantify other biotic components of the watershed that may determine the success of potential Arctic Grayling re-introductions. This work seeks to expand upon the findings of Danhoff et al (2017) and Goble et al. (In Review) to model the energetic capacity of potential Arctic Grayling restoration sites as an additional assessment criterion. If the current salmonid population densities show a strong positive link with invertebrate drift abundance or bioenergetic measures it can be assumed that the potential for dietary competition with an additional drift-feeding salmonid (i.e. Arctic Grayling) would be greater than if that link is negative or non-existent (Olson et al. 2016). The hypothesis tested for this work was that there would be no significant difference in reachscale net energy intake, measured as drifting invertebrate abundance, in eight tributaries to the Big Manistee River during May to August.

\section{Methods}

This study was conducted in a portion of the Big Manistee River watershed (Figure 3.1) located between two mainstem hydroelectric dams, Tippy Dam and Hodenpyl Dam (which is located $21 \mathrm{rkm}$ upriver of Tippy Dam) which prevent upstream fish movement. These movement barriers effectively divide the watershed into three distinct segments hereafter referred to as Lower, Middle, and Upper Manistee (Goble and Auer In Review). Eight $1^{\text {st }}$ to $3^{\text {rd }}$ order tributary streams in the Middle Manistee watershed were selected by MTU and LRBOI for Arctic Grayling habitat suitability assessments conducted between 2011 and 2013 (Table 3.1) based on evidence of their ability to support self-sustaining salmonid populations (LRBOI unpublished data) and proximity to 
the present-day LRBOI Tribal Reservation. Within each tributary three sampling reaches were established to represent a range of abiotic and biotic conditions found throughout the Middle Manistee watershed (Auer et al. 2013). Reaches were classified as Lower (closest to mainstem), Middle, and Upper (most upstream) based on their distance from the tributary confluence relative to the overall length of the stream and were set at 40x mean wetted stream width or a minimum length of $120 \mathrm{~m}$ for reaches averaging $<3 \mathrm{~m}$ wide (Lazorchak et al. 2000). Surveys of instream habitat (see Danhoff et al. 2017 for habitat assessment methods) and fish populations were conducted monthly June through August 2012 in 22 of the 24 sampling reaches (two reaches were not fully sampled due to access constraints). The abundance of drifting invertebrates, and the bioenergetic potential (NEI) of each of the 22 reaches was quantified during June 2012 sampling and compared to fish population densities during that sampling period.

\section{Depth and Water Velocity Profiles}

Transects across the wetted channel (between 56 and 146 depending on reach length) were spaced approximately two meters apart from the downstream reach boundary to the upstream reach boundary. At each transect, wetted stream width was measured to the nearest $0.5 \mathrm{~m}$ and the transect was divided into six evenly spaced points (hereafter focal-points) across the width of the stream (i.e. $0,20,40,60,80$, and $100 \%$ ). At each focal-point water depth was measured to the nearest $0.01 \mathrm{~m}$, and bottom and $60 \%$ column velocities were measured to the nearest $0.01 \mathrm{~m} / \mathrm{sec}$. The depth and velocity measurements from each focal-point were used to calculate the mean $( \pm \mathrm{SD})$ and 
maximum depth and velocity for each reach and were used in the development of the reach-scale NEI models described below.

\section{Fish population surveys}

To calculate fish densities, one multi-pass depletion electrofishing survey was conducted in June 2012 in each of the 22 reaches using a Smith-Root LR-14 backpack electrofishing unit set to output pulsed DC current at $30 \mathrm{~Hz}, 12 \%$ duty cycle, and peak voltage of $275 \mathrm{~V}$. During the surveys, $6 \mathrm{~mm}$ mesh block nets were placed at both the downstream and upstream reach boundaries to prevent fish from escaping or entering the reach in order to meet the closed population assumption required for estimating abundance (Hayes et al. 2007). Three passes were conducted back to back in all but two reaches, Eddington Middle, and Peterson Upper, where two passes yielded depletions > $80 \%$ and a third pass was deemed unnecessary. All fish were identified to species, counted, measured to the nearest $1.0 \mathrm{~mm}$ total length (TL), weighed to the nearest $0.1 \mathrm{~g}$, and placed into an instream holding tank until all electrofishing passes were complete to prevent recaptures for the duration of the survey.

Salmonids smaller than $100 \mathrm{~mm}$ TL were classified as young-of-year (YOY) or juveniles, and those $100 \mathrm{~mm}$ TL or larger were classified as sub-adults or adults based on previously collected age and growth data from the Middle Manistee watershed (LRBOI unpublished data). Population estimates were calculated for each salmonid species for specific age groups (i.e. YOY Brook Trout, adult Brook Trout, YOY Brown Trout, and adult Brown Trout) and all salmonid species and age groups combined (i.e. all salmonids) using the Carle Strub k-pass maximum likelihood estimator (Carle and Strub 1978) under 
the "removal" function in the Fisheries Stock Assessment (FSA) (Ogle 2015) package for program R (R Development Core Team 2015). The selection of this estimator was based upon its flexibility in allowing any number of passes $>2$ to be modeled using the same estimator. Density estimates (fish $/ \mathrm{m}^{2}$ ) were calculated for each salmonid species by agegroup, and all salmonids combined by dividing the numerical population estimates by the total area of each reach. Biomass $\left(\mathrm{g} / \mathrm{m}^{2}\right)$ was calculated by multiplying each numerical population estimate by the mean weight of the species (or both salmonid species combined) in each reach and dividing by the total reach area.

Invertebrate Drift Surveys

Invertebrate drift was sampled once in each of the 22 reaches between 29 May and 26 June 2012. Drifting invertebrates were captured with an array of three drift nets $(250 \mu \mathrm{m}$ mesh, $30 \mathrm{~cm} \times 30 \mathrm{~cm}$ mouth opening; BioQuip Products Inc.) set with the mouth openings perpendicular to flow spaced approximately evenly across the wetted-width of the channel. Nets were placed immediately upstream of each sampling reach in the first riffle when possible or near the downstream end of the first run if no riffles were available within 50-100m upstream of the reach. To capture emerged adult aquatic insects and floating terrestrial insects each net was set with at least $2.5 \mathrm{~cm}$ of the net mouth extending above the water surface. Following the methods of Urabe et al. 2010, net deployments began approximately 1-hour before sunrise (0450-0537 EST) and continued until approximately 3-hours after sunrise (0800-0827 EST). Nets were left in place for approximately 1 -hour (mean $=57.8$ minutes, $\mathrm{SD}=4.7$ minutes) at which time each net was pulled and the contents were rinsed into individually labeled sample jars 
prior to being re-set in the same location until four 1-hour sets had been conducted. The volume of water filtered by each net $\left(\mathrm{m}^{3}\right)$ was determined by measuring the water depth and velocity (60\% column depth) at three points (left net-edge, center net, and right netedge) across the net opening to calculate discharge $\left(\mathrm{m}^{3} / \mathrm{sec}\right.$; Gallagher and Stephenson 1999) which was then scaled by the set duration. The contents of each net were fixed in $10 \%$ neutral buffered formalin for preservation until laboratory processing.

One drift net sample from each of the four sampling periods (e.g. 1-hour presunrise, sunrise to 1-hour post, etc.) was randomly selected for identification, enumeration, and measurement. Samples were rinsed in a $250 \mu \mathrm{m}$ sieve, drained, and weighed to the nearest $0.1 \mathrm{~g}$. One quarter of the total mass of each sample (unsorted detritus and invertebrates) was removed as a sub-sample based on procedures described by Sebastien et al. (1988) which was sorted under a low magnification stereo microscope (Motic SMZ-140, Omano OM9959). Insects were counted and identified to order and noted as aquatic or terrestrial in origin while other invertebrate taxa (e.g. gastropods, annelids, amphipods, etc.) were counted and identified to phylum, class, or order. All invertebrates were photographed under low magnification (OptixCam OCS-10.0X) and measured to the nearest $0.01 \mathrm{~mm}$ using a microscope imaging and measurement software (OCView 7) in order to calculate the mean $( \pm \mathrm{SD})$ length of prey items available in each sampling reach. Subsample taxa counts were extrapolated to expected counts for the total mass of each sample prior to calculating invertebrate density and biomass estimates. Numerical densities of each invertebrate taxon were determined by dividing the extrapolated subsample counts by the volume of water filtered by each net which was 
used to calculate a mean $( \pm \mathrm{SD})$ drift density estimate for each reach. Biomass densities for each reach were calculated for the total invertebrate biomass (not taxa specific) collected by each net. All invertebrates in each $25 \%$ sub-sample were combined, rinsed in $70 \% \mathrm{ETOH}$, dried at room temperature for $\sim 5$ minutes and the total sample was weighed to the nearest $0.1 \mathrm{mg}$ (Mettler Toledo AB204). As with numerical densities each subsample biomass was extrapolated to the total sample mass and divided by the volume of water filtered by each net to calculate mean $( \pm \mathrm{SD})$ biomass density estimates $\left(\mathrm{mg} / \mathrm{m}^{3}\right)$ for each sample reach.

Net Energy Intake (NEI) Modeling

The NEI modeling followed the structure described by Hughes and Dill (1990) and Urabe et al. (2010) where NEI (J/h) at each focal-point (Equation 1) is calculated as the difference between potential energy gained from prey (Gross Energy Intake, GEI) and the energy expended holding a feeding position and capturing prey (SC).

$$
\mathrm{NEI}_{i}=\mathrm{GEI}_{i}-\mathrm{SC}_{i}
$$

The GEI $(\mathrm{J} / \mathrm{h})$ at each focal-point can be decomposed into the following equation (Equation 2).

$$
\mathrm{GEI}_{i}=\mathrm{CA}_{i} * \mathrm{~V}_{f g, i} * \mathrm{D} * \mathrm{PE} * 3,600 / 10^{9}
$$

CA is the area where prey can be captured $\left(\mathrm{cm}^{2}\right), \mathrm{V}$ is the water velocity at the focalpoint $(\mathrm{cm} / \mathrm{sec}), \mathrm{D}$ is the prey density $\left(\mathrm{mg} / \mathrm{m}^{3}\right)$, and PE is the average energy content $(\mathrm{J} / \mathrm{g})$ 
of the prey items which was set to Cummins and Wuycheck's (1971) 20,189 J/g standard for Insecta following the methods of Urabe et al. 2010.

Based on the measured water depths and velocities in the study reaches and visual observations of fish positions CA was calculated using the following equation from Urabe et al. (2010) for describing focal points approximately $3 \mathrm{~cm}$ above the substrate (Equation 3).

$$
\begin{gathered}
\mathrm{CA}_{i}=\pi \mathrm{MCD}_{i}^{2} / 2-\left[\pi \mathrm{MCD}_{i i}^{2} * \sin ^{-1}\left(\sqrt{\mathrm{MCD}_{i}^{2}-9} / \mathrm{MCD}\right) / 180-9 \sqrt{\mathrm{MCD}_{i}^{2}-9}\right] \\
+6 * \mathrm{MCD}
\end{gathered}
$$

In this equation MCD is defined as the maximum distance $(\mathrm{cm})$ from a fish's focal point at which prey can be captured (Hughes and Dill 1990). The MCD at a given focal point is determined by a fish's reaction distance $(\mathrm{RD} ; \mathrm{cm})$, the water velocity at the focal point $\left(\mathrm{V}_{f g, i}\right)$ and the fish's maximum sustainable swimming speed (VMAX; cm/sec) which is approximately $10 *$ a fish's fork length (FL; Winstone et al. 1985) and was calculated using the following equation (Equation 4) from Hughes and Dill (1990).

$$
\mathrm{MCD}_{i}=\sqrt{\mathrm{RD}_{i}^{2}-\left(\mathrm{V}_{f g, i} * \mathrm{RD}_{i} / \mathrm{VMAX}\right)^{2}}
$$

A fish's RD is a function of both prey size and fish body size (Hughes and Dill 1990) and is calculated using the following equation (Equation 5) from Hughes and Dill (1990) where prey length (PL) is set at the mean length ( $\mathrm{mm}$ ) of prey items captured in 
each reach during drift surveys, and FL is the mean fork length $(\mathrm{mm})$ of all salmonid species captured in all reaches which was calculated as $11.63 \mathrm{~cm}$.

$$
\mathrm{RD}_{i}=12 * \mathrm{PL} *\left(1-e^{(-0.2 * \mathrm{FL})}\right)
$$

A fish's swimming cost (SC, J/h) which is a measure of the amount of energy required to maintain position in the current and energy expended capturing prey, is determined by its body weight (BW) and water velocity and was calculated using the following equation (Equation 6) from Fausch (1984).

$$
\left.\mathrm{SC}_{i}=4.18605 * 0.9906 * \mathrm{BW}^{0.784} * e^{\left(0.0186 * \mathrm{~V}_{f g, i}\right)}\right)
$$

The preceding equations were applied to all transect points to calculate an NEI value for each focal-point. All negative focal-point NEI scores were adjusted to zero prior to calculating the overall reach-level NEI value (Urabe et al. 2010) by calculating the mean $( \pm \mathrm{SD})$ of all the focal-point NEI values.

\section{Data Analyses}

Analysis of variance (ANOVA) was performed using SAS version 9.2 (Proc Glm; SAS Institute, Cary, North Carolina) to test for differences in invertebrate drift densities, biomass, and taxa composition between sampling reaches. When significant reach effects were observed, post-hoc least squares analysis was conducted using a Tukey-Kramer adjustment to determine which reaches statistically differed in drifting invertebrate abundances. Mean NEI scores were compared between tributaries using ANOVA and least squares analyses (Proc Glm; SAS Institute). Regression analyses were performed 
(Proc Reg) to test for relationships between salmonid abundance and measures of: drifting invertebrate density, biomass, and reach-scale NEI. These relationships were examined for each age-group of Brook and Brown Trout, combined age-groups (i.e. all individuals) of Brook and Brown Trout, and all age-groups of both species combined. To examine if invertebrate drift abundance and NEI may interact with abiotic habitat in determining fish densities principal components analysis (PCA) was performed (Proc Princomp; SAS Institute) to explore whether a combination of abiotic habitat and drift abundance would be useful for explaining the variance in salmonid densities between reaches. Each potential explanatory variable was $\log (X+0.0001)$ transformed prior to ordination and standardized by using the correlation matrix rather than the covariance matrix due to different measurement scales (Kwak and Peterson 2007). Following the ordination procedures, stepwise linear regression analyses (Proc Reg; SAS Institute) were performed using the top 5 PCA axes which together explained $>85 \%$ of the variance (excluding fish abundance) between reaches as potential explanatory variables for each of the aforementioned salmonid abundance metrics. Since PCA ordination requires Logtransformation of each potential explanatory variable, all salmonid abundance metrics were $\log (\mathrm{X}+0.0001)$ transformed and alpha levels for determining each variable's significance were set at 0.05 .

\section{Results}

All eight tributaries and 13 of the 22 reaches showed positive values of net energy intake (NEI) potential (Table 3.2). The highest tributary-level NEI scores were observed in Woodpecker, Slagle, and Eddington Creeks while the lowest NEI scores occurred in 
Hinton, Arquilla, and Cedar Creeks (Table 3.2) but none of the differences were statistically significant. Similarly, no significant differences in NEI were observed between reach locations (i.e. Upper, Middle, and Lower) although NEI values in 6-of-7 lower reaches were $<1$, and all values $>100$ occurred in Upper reaches (Table 3.3). Invertebrate biomass and numerical densities did not significantly differ between tributaries (Table 3.2). However, biomass densities were greater in the Upper reaches than in the Lower reaches across all tributaries $(P=0.001)$ and marginally greater $(P=$ 0.05) than in the Middle reaches (Table 3.3). Biomass density in Middle reaches did not significantly differ from Lower reaches. Numerical drift densities were greater overall in Upper reaches than either Middle $(P=0.023)$ or Lower $(P=0.019)$ reaches (Table 3.2). Biomass densities were significantly different $(P=0.003)$ between the 22 sampling reaches with the greatest biomass seen in the Upper reach of Woodpecker Creek, and the lowest biomass in the Upper reach of Hinton Creek (Table 3.2). However, numerical densities did not differ significantly between specific reaches $(P=0.32)$.

Variation in NEI between reaches was best explained by differences in invertebrate biomass densities (partial $r^{2}=0.44$ ) and mean prey length (partial $r^{2}=0.24$ ) which accounted for $68 \%$ of the observed variation (Equation 7; Figure 3.2).

$$
\begin{gathered}
\operatorname{Ln}(\mathrm{NEI})=-10.22025+3.25572(\text { LnPrey-biomass })+10.45285(\text { LnPrey-length }) \\
\left(r^{2}=0.68, P<0.0001\right)
\end{gathered}
$$

Brook Trout and/or Brown Trout were captured in all of the 22 sampling reaches and comprised 58\% of the 10,090 fish captured during 2012 (Rainbow Trout were caught 
in nine reaches but only accounted for $0.6 \%$ of the overall catch) indicating the presence of suitable salmonid habitat and prey resources in the eight tributaries. Brook Trout were found in 21 reaches, and at densities ranging from $<0.01$ to $1.31 \mathrm{fish} / \mathrm{m}^{2}$ (Table 3.4), and biomass ranging from 0.05 to $20.83 \mathrm{~g} / \mathrm{m}^{2}$ (Table 3.4). Brown Trout were captured in 19 reaches, and at densities ranging from $<0.01$ to $0.39 \mathrm{fish} / \mathrm{m}^{2}$ (Table 3.4), and biomass ranging from $<0.01$ to $12.48 \mathrm{~g} / \mathrm{m}^{2}$ (Table 3.4). No significant correlations were seen between fish densities or biomass and NEI, invertebrate drift density, or invertebrate drift biomass for any of the age-groups or species (including all salmonids combined).

Principal component analysis revealed that approximately $87 \%$ of the observed variance between reaches could be explained by five PCA-axes. The four main factors contributing to the first axis (which accounted for $47 \%$ of the total variance) were: discharge $($ eigenvector $=0.325)$, mean column velocity $($ eigenvector $=0.315)$, large woody debris $(L W D)$ area (eigenvector $=0.309)$, and the proportion of riffle habitat in a reach $($ eigenvector $=0.307)$ indicating that PCA-1 was a measure of physical habitat. Principal component axis-2 (which accounted for $17 \%$ of the total variance) was mainly associated with: water temperature (eigenvector $=0.389)$, invertebrate biomass $($ eigenvector $=0.357)$, and NEI (eigenvector $=0.342)$ indicating that PCA-2 was a measure of energetic capacity. Each of the remaining PCA axes accounted for $<10 \%$ of the total variance and were associated with combinations of habitat and invertebrate drift metrics (Appendix 3.1). Stepwise regressions of fish biomass with the first five PCA axes revealed a significant relationship between total Brook Trout biomass and PCA axes one $\left(P=0.0007\right.$; partial $\left.r^{2}=0.47\right)$, and two $\left(P=.0048\right.$; partial $\left.r^{2}=0.16\right)$ which accounted for 
$63 \%$ of the observed variation in Brook Trout biomass between reaches (Equation 8;

Figure 3.3).

$$
\begin{aligned}
\operatorname{Ln}(\text { BKT-biomass })= & -0.44484-0.60897(\mathrm{PCA}-1)-0.60159(\mathrm{PCA}-2) \\
& \left(r^{2}=0.63, P<0.0001\right)
\end{aligned}
$$

Drift composition also differed between tributaries $(P<0.001)$, reach locations $(P$ $=0.024)$, and individual reaches $(P<0.001)$. Overall, 26 invertebrate taxa were collected during drift sampling with Dipterans (primarily Chironomidae, Simuliidae, and Ceratopogonidae families) and ostracods (class Ostracoda) making up 52\% (28 and 24\% respectively) of all drifting invertebrates captured (Figure 3.4). The greatest proportion of invertebrates $($ mean $=43 \%$; range $=22-91 \%)$ in each reach was represented by one of five taxa (Figure 3.4). Diptera were the most abundant taxa in 10 reaches, Ostracoda in 9 reaches, Ephemeroptera, Cladocera, and Collembola were each the most abundant taxa in single reaches (Figure 3.4). Slagle Creek and Peterson Creek had the greatest number of taxa (median $=13.5$ and 12.5 taxa respectively) while Hinton Creek had the fewest taxa $($ median $=8)$. The greatest number of invertebrate taxa were found in the Middle reaches, and significantly fewer taxa $(P=0.019)$ were found in the Upper reaches. No significant differences were seen in mean prey lengths across tributaries, reach locations, or individual reaches and the overall mean length of invertebrates was $1.64 \mathrm{~mm}(\mathrm{SD}=$ $0.55 \mathrm{~mm})$. 


\section{Discussion}

In the portion of the Big Manistee River watershed examined in this study Brook Trout and Brown Trout are widely distributed and occupy all of the surveyed tributary reaches indicating their potential as Arctic Grayling competitors in this system. A significant positive relationship between the densities of these potential competitors and measures of invertebrate densities and biomass would suggest that food resources are potentially a limiting factor for salmonids in these tributaries. However, no significant relationships between fish abundance and any measure of invertebrate density or net energy intake (NEI) potential was observed during this study suggesting that food resources may not be strongly limiting for salmonids in Big Manistee River tributaries during certain times of year (i.e. early summer) and at current population densities. Additionally, at the tributary and reach scales all eight of the tributaries and $59 \%$ of the reaches surveyed showed positive values of NEI suggesting that they may provide (or are near reaches with) adequate food resources to support potential Arctic Grayling reintroduction.

Optimal foraging theory suggests that organisms have evolved to select for feeding strategies and food items that are the most energetically profitable to maximize their fitness (Emlen 1966; MacArthur and Pianka 1966; Werner and Hall 1974). In Michigan, Arctic Grayling are thought to be the only fluvial salmonid species native to the State's Lower Peninsula. However, the species was driven to extinction in the early $20^{\text {th }}$ century by a combination of overharvest, habitat destruction, and competition with introduced salmonids. Through introductions of Brown Trout, and Rainbow Trout and 
the presumed range expansion of Brook Trout from the Upper Peninsula (Hubbard 1887; Smedley 1938) new and potentially physiologically and/or behaviorally dominant driftfeeding species were added to what had historically been Arctic Grayling habitats increasing the potential for interspecific competition. The use of NEI models to assess reach or stream-level habitat quality and predict fish abundance is relatively new compared to traditional habitat suitability and predictive models (Fausch 2014; Rosenfeld et al. 2014). This type of model was originally developed as a means of predicting optimal foraging positions and assessing competition between native and introduced salmonid species in Michigan streams (Fausch 1984; Fausch and White 1986). In unaltered systems where species introductions have not occurred it is thought that coevolution among native species can lead to resource partitioning and niche shifts that minimize competition (Connell 1980). Examples of this resource partitioning and niche shifting strategy can be seen in the closely related salmonid species native to Japan (Nakano and Furukawa-Tanaka 1994; Fausch et al. 1997) and North America (Van Leeuwen et al. 2011; Dennert et al. 2016) as well as more evolutionary divergent salmonid species in Asia (Olson et al. 2016) and Europe (Haugen and Rygg 1996). However, for species with similar habitat requirements and life-history characteristics that have not co-evolved (as is the case for Arctic Grayling, Brook Trout, and Brown Trout) it could be expected that they have each evolved similar feeding strategies to optimize their fitness which would lead to greater competitive interactions in sympatric populations (Connell 1980). 
The apparent lack of a direct relationship between salmonid abundance and measures of drift densities and NEI in this study is contrary to the findings of Jenkins and Keeley (2010), Urabe et al. (2010), and Wall et al. (2015). However, in the Big Manistee River tributaries assessed in this study food abundance and energetic potential may be high enough to not be limiting to salmonid populations, or the populations are primarily regulated by other abiotic and/or biotic factors. Goble et al. (In Review) described the relationships of Brook and Brown Trout in each of the 22 study reaches and found evidence that Brown Trout densities may be influencing the distribution and abundances of Brook Trout. The stream assessed by Jenkins and Keeley (2010) was a high elevation $(1650 \mathrm{~m})$ western trout stream containing native Cutthroat Trout Oncorhynchus clarkii. Urabe et al. (2010) studied seven mountain streams (elevations not reported) in Japan containing native Masu Salmon Oncorhynchus masou, and Whitespotted Char Salvelinus leucomaenis. Wall et al. (2015) studied 15 streams in the Columbia River basin containing native migratory Rainbow Trout. In all cases the species studied were native to the system and either represented an allopatric population (Jenkins and Keeley 2010) or co-evolved sympatric populations (Urabe et al. 2010) which would likely exhibit lower levels of competition than the co-occurring populations of two non-native species found in the Big Manistee River tributaries of this study. Another possible explanation for the lack of a direct correlation between salmonid densities and invertebrate drift is that the tributaries in this study were relatively small (mean discharge $=0.18 \mathrm{~m}^{3} / \mathrm{sec}$ ) allowing for fish movements between reaches (and elsewhere) to easily occur, masking potential reach-level relationships. 
Although no statistically significant relationship was seen between fish abundance and drifting invertebrate densities, invertebrate biomass, or NEI, if Arctic Grayling are re-introduced into the Big Manistee River (or other river systems in the State of Michigan) they potentially would have to compete for food and space with non-native salmonids currently found in those habitats. Previous research on the feeding habits of Arctic Grayling and other salmonids indicates that this competition is expected to occur during all post-hatch life-stages. In an early comparison of feeding habits of Arctic Grayling and "Trout" (species unknown) fry, Brown (1938) found that unlike the Trout which could feed on all sizes of zooplankton at their first feeding attempt, gape limitation of Arctic Grayling fry prevented them from successfully consuming adult zooplankters until much later in their development than the Trout species. Fluvial (and adfluvial) Arctic Grayling are believed to feed on zooplankton and other microcrustaceans for only a short period before transitioning to feeding almost exclusively on larger macroinvertebrates, fish eggs, and small fishes (Armstrong 1986; Northcote 1995; Jones et al. 2003) which mirrors the reported diets of Brook and Brown Trout (Allan 1980; East and Magnon 1991; L'Abee-Lund et al. 1992). However, there is evidence of resource partitioning occurring between native Arctic Grayling and introduced Brook Trout in fluvial Montana populations (Byorth and Magee 1998) suggesting that the two species are capable of co-existing. The likelihood of resource partitioning and co-existence of Arctic Grayling and Brown Trout is less clear. Studies of the closely related European Grayling and Brown Trout in their native Europe indicate that Brown Trout are more aggressive and caused a habitat-use and dietary shift in Grayling during periods of low 
food availability (Haugen and Rygg 1996). Whether the same habitat and dietary shifts would occur with Arctic Grayling remains unknown.

It should be noted that the data collected for this study represent the conditions found at a specific time of year (early summer) in 22 reaches of eight Big Manistee River tributaries in Michigan. Thus, they may not fully capture the spatial temporal variability that might occur in fish densities or invertebrate abundances at different scales or timeframes (Lanthier et al. 2013; Naman et al. 2016). Further study of these relationship(s) should be conducted over a variety of spatial and temporal scales to determine if the patterns observed in this study hold true in other systems in Michigan and beyond. Nevertheless, the modeling of the characteristics and relationships of the current fish and invertebrate communities in these tributaries provides insight into potential competitive mechanisms if Arctic Grayling re-introductions occur in Michigan. The results of this study suggest that food resources may not be a strongly limiting factor in the success of potential re-introduction efforts in the Middle portion of the Big Manistee River watershed due to an apparent lack of a significant relationship between Brook and Brown Trout abundance with invertebrate drift or net energy intake. Additionally, this work identified a wide range of NEI values across the study reaches ranging from zero (i.e. not energetically profitable) to $>1,000 \mathrm{~J} / \mathrm{hr}$. The most energetically profitable reaches should be prioritized (if otherwise suitable) for Arctic Grayling re-introductions since they would provide better opportunities for growth and fitness than low NEI reaches. When compared with other reach-scale NEI values reported in other studies $(\sim 700 \mathrm{~J} / \mathrm{hr}$ maximum in Wall et al. $2015 ; \sim 400 \mathrm{~J} / \mathrm{hr}$ maximum in Jenkins 
and Keeley 2010; 300 J/hr maximum in Urabe et al. 2010) the Manistee River tributaries showed somewhat higher maximum values suggesting either comparatively high productivity or low energetic costs (i.e. lower swimming cost) in the Manistee River tributaries.

Based on these findings and those of Danhoff et al. (2017) and Goble et al. (In Review) the most suitable reaches for Arctic Grayling re-introductions in the Middle Manistee River tributaries are: Eddington Middle, and Lower; and Peterson Lower (Figure 3.5). At the tributary-scale Slagle and Woodpecker Creeks both rank highly in abiotic habitat suitability (Danhoff et al. 2017) and NEI but Brown Trout densities exceed the $0.1 \mathrm{fish} / \mathrm{m}^{2}$ threshold proposed by Goble et al. (In Review). However, due to the extremely high NEI value for the Upper reaches $(567.36 \& 1,169 \mathrm{~J} / \mathrm{hr}$ respectively) and relatively high value $(134 \mathrm{~J} / \mathrm{hr})$ in the Middle reach of Woodpecker Creek some of the potential negative effects of Brown Trout competition may be mitigated by abundant food and energetic potential indicating that these tributaries may be the most suitable for Arctic Grayling re-introduction overall. Incorporating reach-scale measures of NEI has also been proposed for use in the Michigan Department of Natural Resources (MIDNR) Arctic Grayling restoration initiative as a criterion for assessing potential Arctic Grayling re-introduction sites throughout the State of Michigan. Coupling NEI modeling with detailed abiotic habitat and fish community assessments will provide resource managers a more complete set of criteria for determining the best possible locations to attempt Arctic Grayling re-introductions. 


\section{Acknowledgements}

The authors would like to thank all the full-time and seasonal staff at the Little River Band of Ottawa Indians Natural Resources Department who provided funding and assistance conducting field surveys and lab work, the Department of Biological Sciences at Michigan Technological University provided support for this research with additional funding received through Graduate Teaching Assistantships and a National Science Foundation GK-12 fellowship awarded to Cameron Goble. Most of the funding was provided by the Little River Band of Ottawa Indians through a U.S. Fish and Wildlife Service Tribal Wildlife Grant (U-17-NA-1) awarded to Nancy Auer, Casey Huckins, J. Marty Holtgren, and Stephanie Ogren. This work was submitted by Cameron Goble in partial fulfillment of a Doctor of Philosophy degree at Michigan Technological University and special thanks go to the members of the graduate committee: Nancy Auer, Casey Huckins, James Magee, John Vucetich, as well as J. Marty Holtgren and Stephanie Ogren for their insightful comments and reviews of this manuscript. This is contribution \# xxx of the Great Lakes Research Center, MTU. 


\section{References}

Allan, J. D. 1980. Determinants of diety of Brook Trout (Savelinus fontinalis) in a mountain stream. Canadian Journal of Fisheries and Aquatic Sciences 38:184192.

Armstrong, R. H. 1986. A review of Arctic Grayling studies in Alaska, 1952-1982. University of Alaska Institute of Arctic Biology. Biological Papers of the University of Alaska No. 23, Fairbanks, Alaska.

Auer, N. A., C. J. Huckins, B. M. Danhoff, and C. W. Goble. 2013. Development of a Native Species Restoration Plan for the 1836 Treaty Area: Suitability of the Big Big Manistee River for Arctic Grayling Re-establishment. Michigan Technological University Project Completion Report U-17-NA-1, Houghton, Michigan.

Bachman, R. A.. 1984. Foraging behavior of free-ranging wild and hatchery Brown Trout in a stream. Transactions of the American Fisheries Society 113:1-32.

Baker, E. A., and T. G. Coon. 1997. Development and evaluation of alternative habitat suitability criteria for Brook Trout. Transactions of the American Fisheries Society 126:65-76.

Bebe, J. 1887. Trout vs. Grayling. The American Angler 5:72-73.

Bissell, J. H. 1890. Grayling in Michigan. Transactions of the American Fisheries Society 19:27-29.

Blanchet, S., G. Loot, G. Grenouillet, and S. Brosse. 2007. Competitive interactions between native and exotic salmonids: A combined field and laboratory demonstration. Ecology of Freshwater Fish 16:133-143.

Brown, C. J. D. 1938. The feeding habits of the Montana Grayling (Thymallus montanus). The Journal of Wildlife Management 2:135-145. 
Byorth, P. A., and J. P. Magee. 1998. Competitive interactions between arctic grayling and brook trout in the Big Hole River Drainage, Montana. Transactions of the American Fisheries Society 127:921-931.

Cada, G. F., J. M. Loar, and D. K. Cox. 1987. Food and feeding preferences of Rainbow and Brown Trout in southern appalachian streams. The American Midland Naturalist 117:374-385.

Carlson, S. M., A. P. Hendry, and B. H. Letcher. 2007. Growth rate differences between resident native brook trout and non-native brown trout. Journal of Fish Biology $71: 1430-1447$.

Carle, F. L., and M. R. Strub. 1978. A new method for estimating population size from removal data. Biometrics 34:621-630.

Connell, J. H. 1980. Diversity and the coevolution of competitors, or the ghost of competition past. Oikos 35:131-138.

Cummins, K. W., and J. C. Wuycheck. 1971. Caloric equivalents for investigations in ecological energetics. Internationale Vereinigung für Theoretische und Angewandte Limnologie Verhandlungen 18:1-158.

Cutting, K. A., W. F. Cross, M. L. Anderson, and E. G. Reese. 2016. Seasonal change in trophic niche of adfluvial Arctic Grayling (Thymallus arcticus) and coexisting fishes in a high-elevation lake system. PLOS ONE 11:e015687

Danhoff, B. M., C. J. Huckins, N. A. Auer, C. W. Goble, S. A. Ogren, and J. M. Holtgren. 2017. Abiotic Habitat Assessment for Arctic Grayling in a Portion of the Big Manistee River, MI. Transactions of the American Fisheries Society XX:ppp-ppp. 
deBruyn, M. and P. McCart. 1974. Life History of the Grayling (Thymallus arcticus) in Beaufort Sea drainages in the Yukon Territory. Pages 1-39 in P. J. McCart editor. Fisheries Research Associated with Proposed Gas Pipeline Routes in Alaska, Yukon, and Northwest Territories. Arctic Gas Biological Report Series Volume 15.

Dennert, A. M., S. L. May-McNally, M. H. Bond, T. P. Quinn, and E. B. Taylor. 2016. Trophic biology and migratory patterns of sympatric Dolly Varden (Salvelinus malma) and Arctic Char (Salvelinus alpinus). Canadian Journal of Zoology 94:529-539.

Dewald, L., and M. A. Wilzbach. 1992. Interactions between native Brook Trout and hatchery Brown Trout: effects on habitat use, feeding, and growth. Transactions of the American Fisheries Society 121:287-296.

East, P., and P. Magnon. 1991. Some factors regulating piscivory of Brook Trout, Salvelinus fontinalis, in lakes of the Laurentian Shield. Canadian Journal of Fisheries and Aquatic Sciences 48:1735-1743.

Emlen, J. M. 1966. The role of time and energy in food preference. The American Naturalist 100:611-617.

Fausch, K. D. 1984. Profitable stream positions for salmonids: relating specific growth rate to net energy gain. Canadian Journal of Zoology 62:441-451.

Fausch, K. D. 2014. A historical perspective on drift foraging models for stream salmonids. Environmental Biology of Fishes 97:453-464.

Fausch, K. D., S. Nakano, and S. Kitano. 1997. Experimentally induced foraging mode shift by sympatric charrs in a Japanese mountain stream. Behavioral Ecology 8:414-420. 
Fausch, K. D., and R. J. White. 1986. Competition among juveniles of Coho Salmon, Brook Trout, and Brown Trout in a laboratory stream, and implications for Great Lakes tributaries. Transactions of the American Fisheries Society 115:363-381.

Gallagher, A. S., and N. J. Stevenson. 1999. Streamflow. Pages 149-157 in M. B. Bain, and N. J. Stevenson, editors. Aquatic Habitat Assessment: Common Methods. American Fisheries Society, Bethesda, Maryland.

Goble, C. W., N. A. Auer, C. J. Huckins, B. M. Danhoff, J. M. Holtgren, and S. A. Ogren. In Review. Fish distributions and habitat associations in Big Manistee River, MI tributaries: implications for Arctic Grayling restoration.

Goble, C. W., and N. A. Auer. In Prep. Simulated population viability for re-introduced Arctic Grayling in the Big Manistee River, MI.

Gowan, C., and K. D. Fausch. 2002. Why do foraging stream salmonids move during summer? Environmental Biology of Fishes 64:139-153.

Grant, G. C., B. Vondracek, and P. W. Sorensen. 2002. Spawning interactions between sympatric Brown and Brook Trout may contribute to species replacement. Transactions of the American Fisheries Society 131:569-576.

Haugen, T. O., and T. A. Rygg. 1996. Food- and habitat-segregation in sympatric grayling and Brown Trout. Journal of Fish Biology 49:301-318.

Hayes, D. B., J. R. Bence, T. J. Kwak, and B. E. Thompson. 2007. Abundance, Biomass, and Production. Pages 327 - 374 in C. S. Guy, and M. L. Brown, editors. Analysis and interpretation of freshwater fisheries data. American Fisheries Society, Bethesda, Maryland.

Hill, J., and G. D. Grossman. 1993. An energetic model of microhabitat use for Rainbow Trout and Rosyside Dace. Ecology 74:685-698. 
Hubbard, B. 1887. Memorials of a half-Century. Page 581. G. P. Putnam's Sons, New York.

Hughes, N. F., and L. M. Dill. 1990. Position choice by drift-feeding salmonids: model and test for Arctic Grayling (Thymallus arcticus) in subarctic mountain streams, interior Alaska. Canadian Journal of Fisheries and Aquatic Sciences 47:20392048.

Jenkins, A. R., and E. R. Keeley. 2010 Bioenergetic assessment of habitat quality for stream-dwelling Cutthroat Trout (Oncorhynchus clarkii bouvieri) with implications for climate change and nutrient supplementation. Canadian Journal of Fisheries and Aquatic Sciences 67:371-385.

Jones, N. E., W. M. Tonn, and G. J. Scrimgeour. 2003. Selective feeding of age-0 Arctic Grayling in lake-outlet streams of the Northwest Territories, Canada. Environmental Biology of Fishes 67:169-178.

Kaya, C. M. 1992. Restoration of fluvial Arctic Grayling to Montana streams: Assessment of reintroduction potential of streams in the native range, the upper Missouri River drainage above Great Falls. Montana State University. Bozeman, MT.

Klemetsen, A., P. A. Amundsen, J. B. Dempson, B. Jonsson, N. Jonsson, M. F. O’Connell, and E. Mortensen. 2003. Atlantic Salmon Salmo salar L., Brown Trout Salmo trutta L. and Arctic Charr Salvelinus alpinus (L.): a review of aspects of their life histories. Ecology of Freshwater Fish 12:1-59.

Korsu, K., A. Huusko, and T. Muotka. 2009. Does the introduced brook trout (Salvelinus fontinalis) affect growth of the native brown trout (Salmo trutta)? Naturwissenschaften 96:347-353. 
Kwak, T. J., and J. T. Peterson. 2007. Community Indices, Parameters, and Comparisons. Pages 677 - 763374 in C. S. Guy, and M. L. Brown, editors. Analysis and interpretation of freshwater fisheries data. American Fisheries Society, Bethesda, Maryland.

L'Abee-Lund, J. H., A. Langeland, and H. Saegrov. 1992. Piscivory by Brown Trout Salmo trutta L. and Arctic Char Salvelinus alpinus (L.) in Norwegian lakes. Journal of Fish Biology 41:91-101.

Lanthier, G., D. Boisclair, G. Bourque, P. Legendre, M. Lapointe, and B. Angers. 2013. Optimization of temporal versus spatial replication in the development of habitat use models to explain among-reach variations in fish density estimates in rivers. Canadian Journal of Fisheries and Aquatic Sciences 70:600-609.

Lazorchak, J. M., B.H Hill., D. K. Averill, D.V. Peck, and D.J. Klemm (editors). 2000. U.S. Environmental Protection Agency. Environmental Monitoring and Assessment Program Surface Waters: Field Operations and Methods for Measuring the Ecological Condition of Non-Wadeable Rivers and Streams

Leonard, J. W. 1949. The Michigan Grayling. Michigan Conservation, Lansing, Michigan.

MacArthur, R. H., and E. R. Pianka. 1966. On optimal use of a patchy environment. The American Naturalist 100:603-609.

Metcalf, M. 1880. The Michigan Grayling: 1880 Essay and Letters by Martin Metcalf. Pages 135-163 in R. A. Drews editor 1961. Michigan History Volume 45. Michigan Historical Commission, Lansing, Michigan.

Miller, R. B. 1946. Notes on the Arctic Grayling, Thymallus signifer Richardson, from Great Bear Lake. Copeia 4:227-236. 
Nakano, S., and T. Furukawa-Tanaka. 1994. Intra- and interspecific dominance heirarchies and variation in foraging tactics of two species of stream-dwelling chars. Ecological Research 9:9-20.

Naman, S. M., J. S. Rosenfeld, and J. S. Richardson. Causes and consequences of invertebrate drift in running waters: from individuals to populations and trophic fluxes. Canadian Journal of Fisheries and Aquatic Sciences 73:1292-1305.

Northcote, T. G. 1995. Comparative biology and management of Arctic and European Grayling (Salmonidae, Thymallus). Reviews in Fish Biology and Fisheries 5:141194.

O’Brien, J. O., M. Barfield, and K. Sigler. 2001. The functional response of drift-feeding Arctic Grayling: the effects of prey density, water velocity, and location efficiency. Canadian Journal of Fisheries and Aquatic Sciences 58:1957-1963.

Ogle, D.H. 2015. FSA: Fisheries Stock Analysis. R package version 0.8.4.

Olson, K. W., O. P. Jensen, and T. R. Hrabik. 2016. Feeding ecology and prey resource partitioning of Lenok (Brachymystax lenok) and Baikal Grayling (Thymallus arcticus baicalensis) in the Eg and Uur rivers, Mongolia. Ecology of Freshwater Fish 25:565-576.

R Development Core Team. 2015. R: a language and environment for statistical computing. R Foundation for Statistical Computing, Vienna. Available: www.Rproject.org. (December 2015)

Rosenfeld, J. S., N. Bouwes, C. E. Wall, and S. M. Naman. 2014. Successes, failures, and opportunities in the practical application of drift-foraging models. Environmental Biology of Fishes 97:551-574.

SAS Institute Inc. 2008. SAS/STAT ${ }^{\circledR} 9.2$ user's guide. SAS Institute Inc., Cary, North Carolina. 
Schmidt, D., and W. J. O'Brien. 1982. Planktivorous feeding ecology of Arctic Grayling (Thymallus arcticus). Canadian Journal of Fisheries and Aquatic Sciences 39:475482.

Sebastien, R. J., D. M. Rosenberg, and A. P. Wiens. 1988. A method for subsampling unsorted benthic macroinvertebrates by weight. Hydrobiologia 157:69-75.

Smedley, H. H. 1938. Trout of Michigan. Muskegon, Michigan. Privately published. 49 pp.

Stewart, D. B., N. J. Mochnacz, J. D. Reist, T. J. Carmichael, and C. D. Sawatzky. 2007. Fish diets and food webs in the Northwest Territories: Arctic Grayling (Thymallus arcticus). Canadian Manuscript Report of Fisheries and Aquatic Sciences 2796. Fisheries and Oceans Canada. Winnipeg, Manitoba.

Taylor, W. R. 1954. Records of Fishes in the John N. Lowe Collection from the Upper Peninsula of Michigan. Museum of Zoology, University of Michigan, Ann Arbor, MI.

Tiberti, R., S. Brighenti, C. Canedoli, R. Iacobuzio, G. Pasquini, and M. Rolla. 2016. The diet of introduced Brook Trout (Salvelinus fontinalis; Mitchill, 1814) in an alpine area and a literature review on its feeding ecology. Journal of Limnology 75:488507.

Urabe, H., M. Nakajima, M. Torao, and T. Aoyama. 2010. Evaluation of habitat quality for stream salmonids based on a bioenergetics model. Transactions of the American Fisheries Society 139:1665-1676.

Van Leeuwen, T. E., J. S. Rosenfeld, and J. G. Richards. 2011. Adaptive trade-offs in juvenile salmonid metabolism associated with habitat partitioning between Coho Salmon and Steelhead Trout in coastal streams. Journal of Animal Ecology 80:1012-1023. 
Vincent, R. E. 1962. Biogeographical and Ecological Factors Contributing to the Decline of Grayling, Thymallus arcticus Pallas, in Michigan and Montana. Doctoral Dissertation, The University of Michigan, Ann Arbor, Michigan.

Wall, C. E., N. Bouwes, J. M. Wheaton, W. C. Saunders, and S. N. Bennett. 2015. Net rate of energy intake predicts reach-level steelhead (Oncorhynchus mykiss) densities in diverse basins from a large monitoring program. Canadian Journal of Fisheries and Aquatic Sciences 73:1081-1091.

Werner, E. E., and D. J. Hall. 1974. Optimal foraging and the size selection of prey by the Bluegill Sunfish (Lepomis macrochirus). Ecology 55:1042-1052.

Winestone, A. J., A. S. Gee, and P. V. Varallo. 1985. The assessment of flow characteristics at certain weirs in relation to the upstream movement of migratory salmonids. Journal of Fish Biology 27:75-83. 
Table 3.1. Physical habitat characteristics of the 22 Big Manistee River, MI tributary sampling reaches sampled between June 2011 and August 2013.

\begin{tabular}{|c|c|c|c|c|c|c|c|c|}
\hline Tributary & Reach & Reach length (m) & Reach area & $\begin{array}{l}\text { Gradient } \\
(\%)\end{array}$ & $\begin{array}{l}\text { Mean width } \\
\text { (m) }\end{array}$ & Mean depth & Mean discharge $\left(\mathrm{m}^{3} / \mathrm{sec}\right)$ & Mean column velocity $(\mathrm{m} / \mathrm{s})$ \\
\hline \multirow{2}{*}{ Arquilla } & Lower & 160 & 809.6 & 2.4 & $4.7( \pm 1.86)$ & $0.17( \pm 0.13)$ & $0.14( \pm 0.05)$ & $0.27( \pm 0.22)$ \\
\hline & Upper & 198 & 838.9 & 1.6 & $4.0( \pm 1.19)$ & $0.15( \pm 0.10)$ & $0.09( \pm 0.01)$ & $0.22( \pm 0.20)$ \\
\hline \multirow[t]{3}{*}{ Cedar } & Lower & 133 & 276.4 & 8.6 & $2.1( \pm 0.74)$ & $0.12( \pm 0.07)$ & $0.09( \pm 0.02)$ & $0.51( \pm 0.30)$ \\
\hline & Middle & 120 & 213.3 & 0.3 & $1.7( \pm 0.60)$ & $0.18( \pm 0.09)$ & $0.04( \pm 0.02)$ & $0.23( \pm 0.17)$ \\
\hline & Upper & 120 & 343.3 & 0.5 & $2.6( \pm 0.86)$ & $0.09( \pm 0.05)$ & $0.03( \pm 0.01)$ & $0.16( \pm 0.13)$ \\
\hline \multirow[t]{3}{*}{ Eddington } & Lower & 120 & 299.9 & 0.8 & $2.4( \pm 0.69)$ & $0.10( \pm 0.07)$ & $0.05( \pm 0.01)$ & $0.30( \pm 0.19)$ \\
\hline & Middle & 120 & 271.5 & 1.8 & $2.3( \pm 0.59)$ & $0.11( \pm 0.06)$ & $0.06( \pm 0.01)$ & $0.32( \pm 0.19)$ \\
\hline & Upper & 120 & 217.8 & 2.7 & $1.9( \pm 0.45)$ & $0.10( \pm 0.06)$ & $0.05( \pm 0.01)$ & $0.28( \pm 0.18)$ \\
\hline \multirow[t]{3}{*}{ Hinton } & Lower & 199 & 944.9 & 2.6 & $4.5( \pm 1.24)$ & $0.20( \pm 0.10)$ & $0.20( \pm 0.07)$ & $0.37( \pm 0.21)$ \\
\hline & Middle & 120 & 359.4 & 1.4 & $3.0( \pm 0.88)$ & $0.23( \pm 0.13)$ & $0.07( \pm 0.03)$ & $0.26( \pm 0.22)$ \\
\hline & Upper & 123 & 332.6 & 0.9 & $2.8( \pm 0.59)$ & $0.14( \pm 0.07)$ & $0.09( \pm 0.01)$ & $0.28( \pm 0.19)$ \\
\hline \multirow[t]{3}{*}{ Peterson } & Lower & 247 & 1065.4 & 1.2 & $4.7( \pm 0.94)$ & $0.23( \pm 0.14)$ & $0.26( \pm 0.12)$ & $0.44( \pm 0.29)$ \\
\hline & Middle & 219 & 1089.8 & 1.0 & $5.1( \pm 1.09)$ & $0.25( \pm 0.16)$ & $0.24( \pm 0.07)$ & $0.33( \pm 0.23)$ \\
\hline & Upper & 120 & 263.9 & 0.5 & $2.3( \pm 0.53)$ & $0.16( \pm 0.07)$ & $0.06( \pm 0.02)$ & $0.24( \pm 0.09)$ \\
\hline \multirow[t]{2}{*}{ Sand } & Middle & 120 & 228.6 & 0.3 & $1.9( \pm 0.57)$ & $0.14( \pm 0.08)$ & $0.02( \pm 0.01)$ & $0.11( \pm 0.09)$ \\
\hline & Upper & 120 & 202.8 & 1.6 & $1.8( \pm 0.66)$ & $0.10( \pm 0.07)$ & $0.01( \pm 0.01)$ & $0.10( \pm 0.08)$ \\
\hline \multirow[t]{3}{*}{ Slagle } & Lower & 325 & 2736.2 & 2.2 & $8.5( \pm 1.86)$ & $0.29( \pm 0.12)$ & $1.09( \pm 0.08)$ & $0.61( \pm 0.29)$ \\
\hline & Middle & 325 & 2601.7 & 0.7 & $8.0( \pm 1.88)$ & $0.33( \pm 0.18)$ & $0.94( \pm 0.03)$ & $0.49( \pm 0.27)$ \\
\hline & Upper & 165 & 830.4 & 1.2 & $4.9( \pm 1.66)$ & $0.23( \pm 0.13)$ & $0.21( \pm 0.01)$ & $0.31( \pm 0.26)$ \\
\hline \multirow[t]{3}{*}{ Woodpecker } & Lower & 132 & 645.0 & 0.9 & $4.3( \pm 1.45)$ & $0.16( \pm 0.10)$ & $0.15( \pm 0.05)$ & $0.34( \pm 0.23)$ \\
\hline & Middle & 120 & 463.7 & 3.4 & $3.7( \pm 1.16)$ & $0.13( \pm 0.08)$ & $0.15( \pm 0.02)$ & $0.37( \pm 0.29)$ \\
\hline & Upper & 120 & 351.3 & 0.5 & $2.9( \pm 0.71)$ & $0.16( \pm 0.05)$ & $0.08( \pm 0.01)$ & $0.18( \pm 0.16)$ \\
\hline
\end{tabular}


Table 3.2. Net energy intake (NEI) potential (Joules/hr), invertebrate drift density $\left(\# / \mathrm{m}^{3}\right)$, and invertebrate drift biomass $\left(\mathrm{g} / \mathrm{m}^{3}\right)$ estimates for 22 Big Manistee River, MI tributary sampling reaches for samples collected May and June 2012. NEI, drift density, and drift biomass values in bold indicate tributary-level mean and SD. * indicates the four tributaries identified as most abiotically suitable by Danhoff et al. (2017). Sample reaches underlined in bold indicate reaches identified by Goble et al. (In Review) as most biotically suitable based on a proposed Brown Trout density threshold of $0.10 \mathrm{fish} / \mathrm{m}^{2} . \S$ indicates highly abiotically suitable reaches with Brown Trout densities $>0.10 \mathrm{fish} / \mathrm{m}^{2}$.

\begin{tabular}{|c|c|c|c|c|}
\hline Tributary & $\begin{array}{l}\text { Sample } \\
\text { reach }\end{array}$ & NEI (J/hr) & $\begin{array}{l}\text { Drift density } \\
\qquad\left(\# / \mathrm{m}^{3}\right)\end{array}$ & $\begin{array}{l}\text { Drift biomass } \\
\qquad\left(\mathrm{g} / \mathrm{m}^{3}\right)\end{array}$ \\
\hline *Arquilla & Lower & 0.53 & 6.36 & 2.39 \\
\hline \multirow[t]{2}{*}{ *Arquilla } & Upper & 1.96 & 8.00 & 6.52 \\
\hline & & $1.24( \pm 1.01)$ & $7.18( \pm 1.16)$ & $4.46( \pm 2.92)$ \\
\hline Cedar & Lower & 0.00 & 1.22 & 0.22 \\
\hline Cedar & $\underline{\text { Middle }}$ & 0.00 & 9.32 & 2.07 \\
\hline \multirow[t]{2}{*}{ Cedar } & $\underline{\text { Upper }}$ & 3.07 & 38.83 & 5.42 \\
\hline & & $1.02( \pm 1.77)$ & $16.45( \pm 19.79)$ & $2.57( \pm 2.63)$ \\
\hline Eddington & Lower & 88.10 & 6.84 & 4.27 \\
\hline Eddington & Middle & 0.00 & 4.74 & 1.90 \\
\hline \multirow[t]{2}{*}{ Eddington } & Upper & 335.83 & 8.27 & 13.56 \\
\hline & & $141.31( \pm 174.12)$ & $6.62( \pm 1.77)$ & $6.58( \pm 6.16)$ \\
\hline *Hinton & $\underline{\text { Lower }}$ & 0.00 & 0.91 & 0.62 \\
\hline *Hinton & Middle & 1.26 & 4.42 & 2.39 \\
\hline \multirow{2}{*}{ *Hinton } & Upper & 0.00 & 1.34 & 0.94 \\
\hline & & $0.42( \pm 0.73)$ & $2.22( \pm 1.92)$ & $1.32( \pm 0.94)$ \\
\hline Peterson & Lower & 0.36 & 1.95 & 1.43 \\
\hline Peterson & Middle & 8.69 & 3.00 & 1.39 \\
\hline \multirow[t]{2}{*}{ Peterson } & Upper & 0.00 & 5.93 & 3.20 \\
\hline & & $3.01( \pm 4.92)$ & $3.62( \pm 2.07)$ & $2.01( \pm 1.03)$ \\
\hline Sand & Middle & 49.73 & 10.27 & 13.08 \\
\hline \multirow[t]{2}{*}{ Sand } & Upper & 0.00 & 133.14 & 9.27 \\
\hline & & $24.87( \pm 35.17)$ & $71.71( \pm 86.88)$ & $11.18( \pm 2.69)$ \\
\hline *Slagle & §Lower & 0.00 & 3.27 & 0.94 \\
\hline *Slagle & §Middle & 11.49 & 8.97 & 2.19 \\
\hline \multirow[t]{2}{*}{ *Slagle } & $\underline{\text { Upper }}$ & 567.36 & 11.47 & 6.40 \\
\hline & & $192.95( \pm 324.29)$ & $7.90( \pm 4.21)$ & $3.18( \pm 2.86)$ \\
\hline *Woodpecker & §Lower & 0.00 & 6.02 & 1.49 \\
\hline *Woodpecker & §Middle & 133.86 & 11.59 & 6.60 \\
\hline \multirow[t]{2}{*}{ *Woodpecker } & §Upper & 1169.98 & 57.91 & 25.38 \\
\hline & & $434.61( \pm 640.36)$ & $25.17( \pm 28.48)$ & $11.15( \pm 12.58)$ \\
\hline
\end{tabular}


Table 3.3. Net energy intake (NEI) potential (Joules/hr), invertebrate drift density $\left(\# / \mathrm{m}^{3}\right)$, and invertebrate drift biomass $\left(\mathrm{g} / \mathrm{m}^{3}\right)$ estimates for 22 Big Manistee River, MI tributary sampling reaches for samples collected May and June 2012. Values in bold indicate tributary region (i.e. Lower, Middle, Upper) mean and SD. * indicates reaches identified as most abiotically suitable with Brown Trout densities $<0.10 \mathrm{fish} / \mathrm{m}^{2}$. ${ }^{\S}$ indicates highly abiotically suitable reaches where Brown Trout densities $>0.10 \mathrm{fish} / \mathrm{m}^{2}$.

\begin{tabular}{|c|c|c|c|c|}
\hline Tributary & $\begin{array}{l}\text { Sample } \\
\text { reach }\end{array}$ & NEI (J/hr) & $\begin{array}{l}\text { Drift density } \\
\qquad\left(\# / \mathrm{m}^{3}\right)\end{array}$ & $\begin{array}{l}\text { Drift biomass } \\
\qquad\left(\mathrm{g} / \mathrm{m}^{3}\right)\end{array}$ \\
\hline Arquilla & Lower & 0.53 & 6.36 & 2.39 \\
\hline Cedar & Lower & 0 & 1.22 & 0.22 \\
\hline *Eddington & Lower & 88.1 & 6.84 & 4.27 \\
\hline *Hinton & Lower & 0 & 0.91 & 0.62 \\
\hline *Peterson & Lower & 0.36 & 1.95 & 1.43 \\
\hline Slagle & Lower & 0 & 3.27 & 0.94 \\
\hline \multirow[t]{2}{*}{${ }^{\S}$ Woodpecker } & Lower & 0 & 6.02 & 1.49 \\
\hline & & $12.71( \pm 33.24)$ & $3.8( \pm 2.56)$ & $1.62( \pm 1.36)$ \\
\hline Cedar & Middle & 0 & 9.32 & 2.07 \\
\hline *Eddington & Middle & 0 & 4.74 & 1.9 \\
\hline Hinton & Middle & 1.26 & 4.42 & 2.39 \\
\hline §Peterson & Middle & 8.69 & 3 & 1.39 \\
\hline Sand & Middle & 49.73 & 10.27 & 13.08 \\
\hline Slagle & Middle & 11.49 & 8.97 & 2.19 \\
\hline \multirow[t]{2}{*}{${ }^{\S}$ Woodpecker } & Middle & 133.86 & 11.59 & 6.6 \\
\hline & & $29.29( \pm 49.32)$ & $7.47( \pm 3.35)$ & $4.23( \pm 4.27)$ \\
\hline Arquilla & Upper & 1.96 & 8 & 6.52 \\
\hline Cedar & Upper & 3.07 & 38.83 & 5.42 \\
\hline Eddington & Upper & 335.83 & 8.27 & 13.56 \\
\hline Hinton & Upper & 0 & 1.34 & 0.94 \\
\hline Peterson & Upper & 0 & 5.93 & 3.2 \\
\hline Sand & Upper & 0 & 133.14 & 9.27 \\
\hline Slagle & Upper & 567.36 & 11.47 & 6.4 \\
\hline \multirow[t]{2}{*}{ Woodpecker } & Upper & 1169.98 & 57.91 & 25.38 \\
\hline & & $259.78( \pm 424.88)$ & $33.11( \pm 44.91)$ & $8.84( \pm 7.68)$ \\
\hline
\end{tabular}


Table 3.4. Density $\left(\mathrm{fish} / \mathrm{m}^{2}\right)$ and biomass $\left(\mathrm{g} / \mathrm{m}^{2}\right)$ estimates of all sizes of Brook Trout, Brown Trout, and both species combined in 22 Big Manistee River, MI tributary sampling reaches in May and June 2012. Values in bold indicate tributary region (i.e. Lower, Middle, Upper) mean and SD. * indicates reaches identified as most abiotically suitable with Brown Trout densities $<0.10$ fish $/ \mathrm{m}^{2} .{ }^{\S}$ indicates highly abiotically suitable reaches where Brown Trout densities $>0.10 \mathrm{fish} / \mathrm{m}^{2}$.

\begin{tabular}{|c|c|c|c|c|c|c|c|}
\hline Tributary & $\begin{array}{l}\text { Sample } \\
\text { reach }\end{array}$ & $\begin{array}{c}\text { Brook Trout } \\
\text { density }\left(\text { fish } / \mathrm{m}^{2} \text { ) }\right.\end{array}$ & $\begin{array}{c}\text { Brown Trout } \\
\text { density (fish } / \mathrm{m}^{2} \text { ) }\end{array}$ & $\begin{array}{l}\text { Salmonid density } \\
\left(\text { fish } / \mathrm{m}^{2}\right)\end{array}$ & $\begin{array}{c}\text { Brook Trout } \\
\text { biomass }\left(\mathrm{g} / \mathrm{m}^{2}\right)\end{array}$ & $\begin{array}{c}\text { Brown Trout } \\
\text { biomass }\left(\mathrm{g} / \mathrm{m}^{2}\right)\end{array}$ & $\begin{array}{l}\text { Salmonid biomass } \\
\left(\mathrm{g} / \mathrm{m}^{2}\right)\end{array}$ \\
\hline Arquilla & Lower & 0.01 & 0.11 & 0.12 & 0.11 & 4.94 & 4.97 \\
\hline Cedar & Lower & 0.27 & 0.06 & 0.3 & 4.17 & 2.22 & 5.55 \\
\hline *Eddington & Lower & 0.15 & 0.06 & 0.2 & 1.97 & 1.06 & 2.6 \\
\hline *Hinton & Lower & 0.03 & 0.08 & 0.11 & 0.27 & 2.74 & 2.79 \\
\hline *Peterson & Lower & $<0.01$ & 0.04 & 0.04 & 0.15 & 2.25 & 2.52 \\
\hline Slagle & Lower & $<0.01$ & 0.11 & 0.11 & 0.05 & 6.94 & 7.54 \\
\hline \multirow[t]{2}{*}{${ }^{\S}$ Woodpecker } & Lower & 0.01 & 0.16 & 0.2 & 0.08 & 6.05 & 7.88 \\
\hline & & $0.07( \pm 0.10)$ & $0.09( \pm 0.04)$ & $0.15( \pm 0.09)$ & $\boldsymbol{0 . 9 7}( \pm 1.57)$ & $3.74( \pm 2.23)$ & $4.83( \pm 2.30)$ \\
\hline Cedar & Middle & 1.31 & 0 & 1.31 & 20.83 & 0 & 21.39 \\
\hline *Eddington & Middle & 0.11 & 0 & 0.17 & 2.63 & 0 & 3.79 \\
\hline Hinton & Middle & 0.09 & 0.28 & 0.36 & 2.67 & 10.72 & 12.68 \\
\hline$\S$ Peterson & Middle & $<0.01$ & 0.13 & 0.13 & 0.12 & 6.61 & 6.14 \\
\hline Sand & Middle & 0.2 & 0.01 & 0.21 & 3.42 & 0.18 & 3.66 \\
\hline Slagle & Middle & 0 & 0.21 & 0.22 & 0 & 12.48 & 12.57 \\
\hline \multirow[t]{2}{*}{${ }^{\S}$ Woodpecker } & Middle & 0.01 & 0.34 & 0.35 & 0.37 & 10.75 & 10.99 \\
\hline & & $0.25( \pm 0.47)$ & $0.14( \pm 0.14)$ & $0.39( \pm 0.41)$ & $4.29( \pm 7.43)$ & $5.82( \pm 5.67)$ & $10.17( \pm 6.30)$ \\
\hline Arquilla & Upper & 0.21 & 0.16 & 0.36 & 2.59 & 4.82 & 7.63 \\
\hline Cedar & Upper & 0.43 & 0 & 0.43 & 5.41 & 0 & 5.42 \\
\hline Eddington & Upper & 0.26 & 0 & 0.26 & 3.51 & 0 & 3.92 \\
\hline Hinton & Upper & 0.07 & 0.39 & 0.46 & 1.49 & 9.26 & 9.86 \\
\hline Peterson & Upper & 0.07 & 0 & 0.07 & 2.64 & 0 & 2.58 \\
\hline Sand & Upper & 0.14 & $<0.01$ & 0.14 & 2.25 & 0.15 & 2.42 \\
\hline Slagle & Upper & 0.01 & 0.06 & 0.07 & 0.52 & 7.11 & 7.97 \\
\hline \multirow[t]{2}{*}{ Woodpecker } & Upper & 0.02 & 0.12 & 0.14 & 0.78 & 1.81 & 1.97 \\
\hline & & $0.15( \pm 0.14)$ & $0.10( \pm 0.13)$ & $0.24( \pm 0.16)$ & $2.39( \pm 1.58)$ & $2.89( \pm 3.70)$ & $5.22( \pm 2.98)$ \\
\hline
\end{tabular}




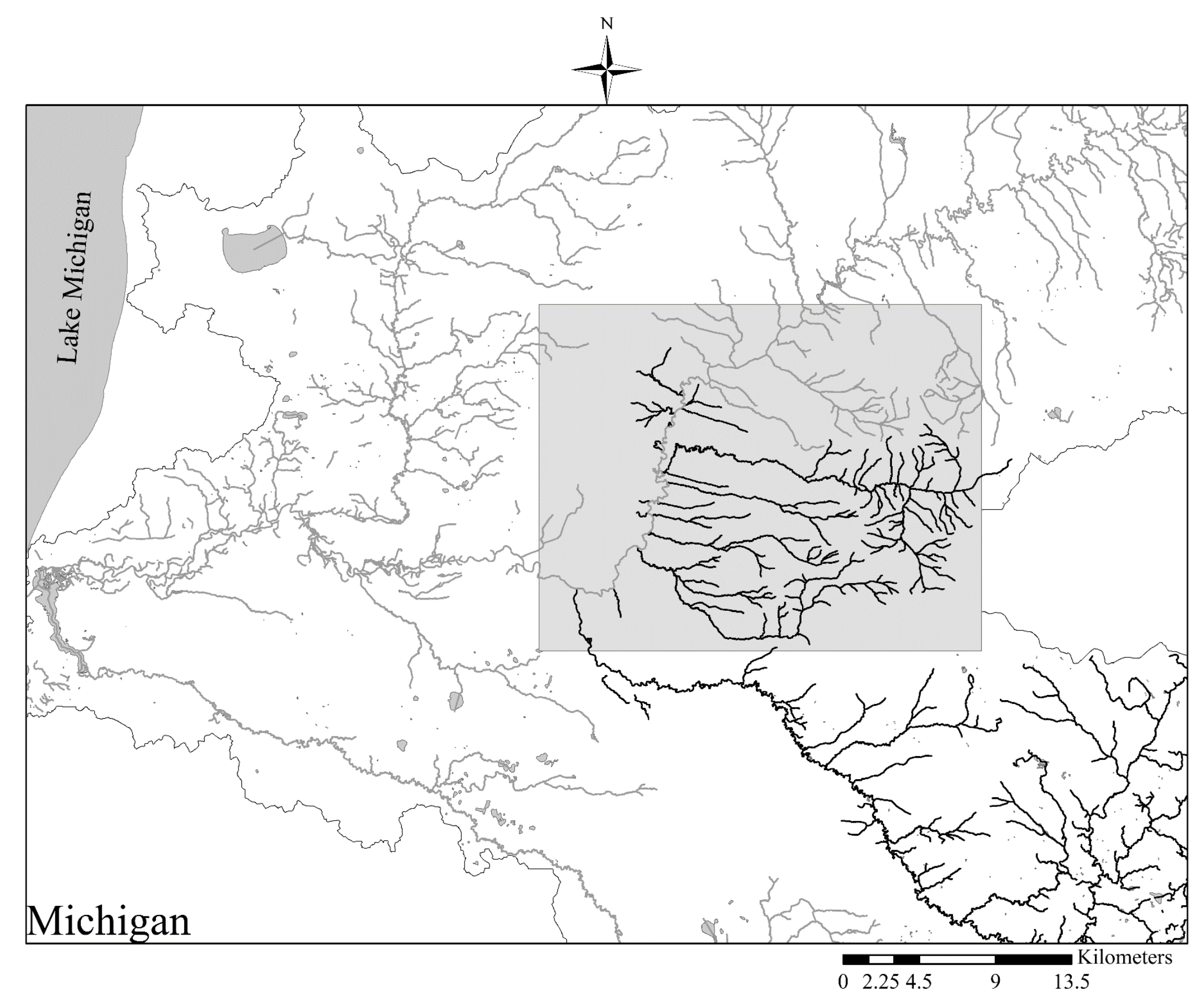

Figure 3.1. Location of the Big Manistee watershed in the State of Michigan. Highlighted box indicates the $2011-2013$ study area. 


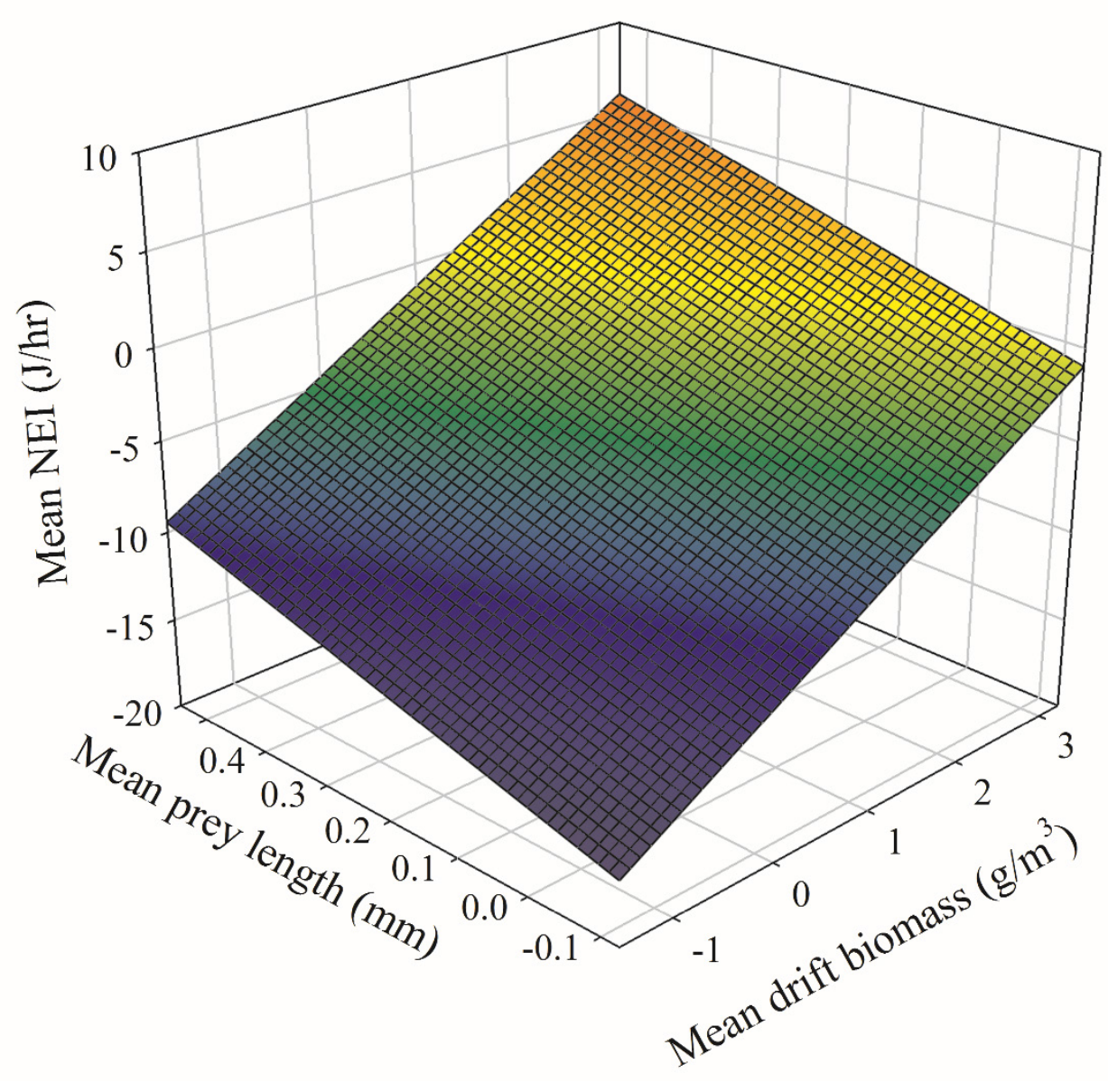

Figure 3.2. Relationship of mean prey length $(\mathrm{mm})$ and mean drift biomass $\left(\mathrm{g} / \mathrm{m}^{3}\right)$ to reach level NEI values. The mesh grid represents the values predicted by the regression equation: $\operatorname{Ln}(\mathrm{NEI})=-10.22025+3.25572($ LnPrey-biomass $)+10.45285($ LnPrey-length $)$ * Note all values have been $\log (\mathrm{X}+0.0001)$ transformed. 


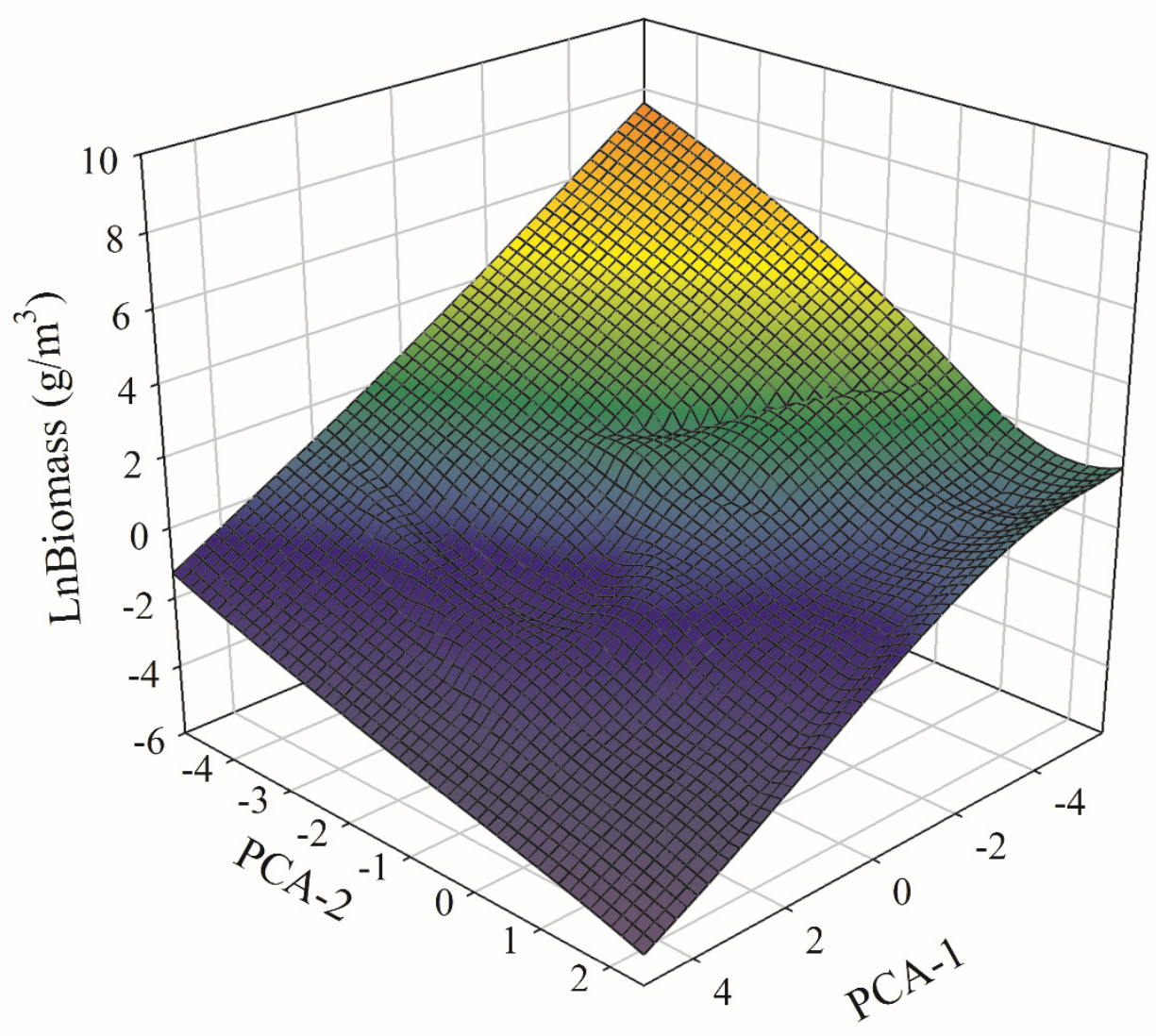

Figure 3.3. Relationship PCA axis-1 and PCA axis-2 to $\log (X+0.0001)$ transformed Brook Trout biomass $\left(\mathrm{g} / \mathrm{m}^{3}\right)$. The mesh grid represents the values predicted by the regression equation: $\mathrm{Ln}(\mathrm{BKT}-\mathrm{biomass})=-0.44484-0.60897(\mathrm{PCA}-1)-0.60159(\mathrm{PCA}-2)$. 


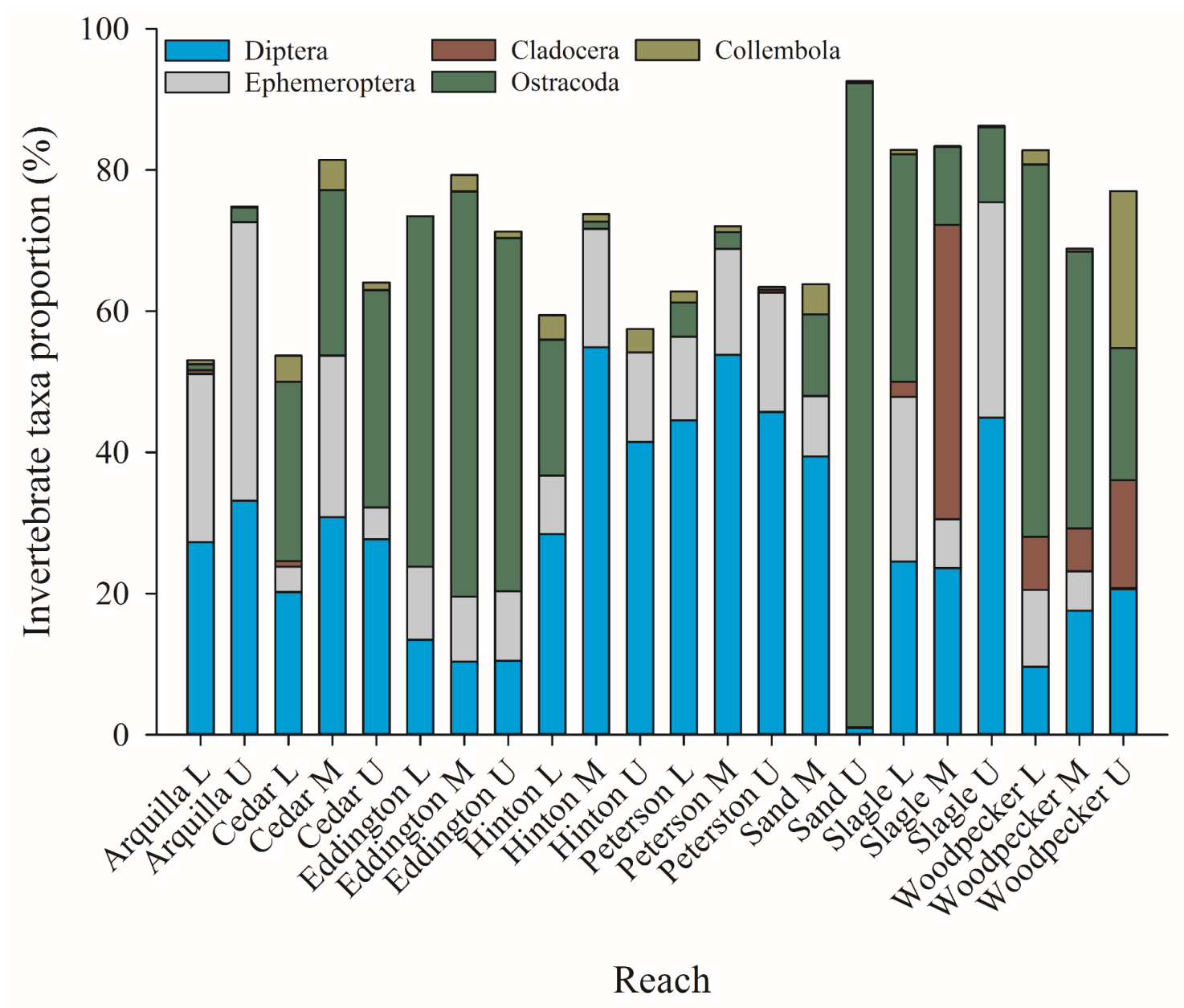

Figure 3.4. Proportions of each of the five dominant invertebrate taxa in 22 Big Manistee River tributary sampling reaches during 2012 sampling. 


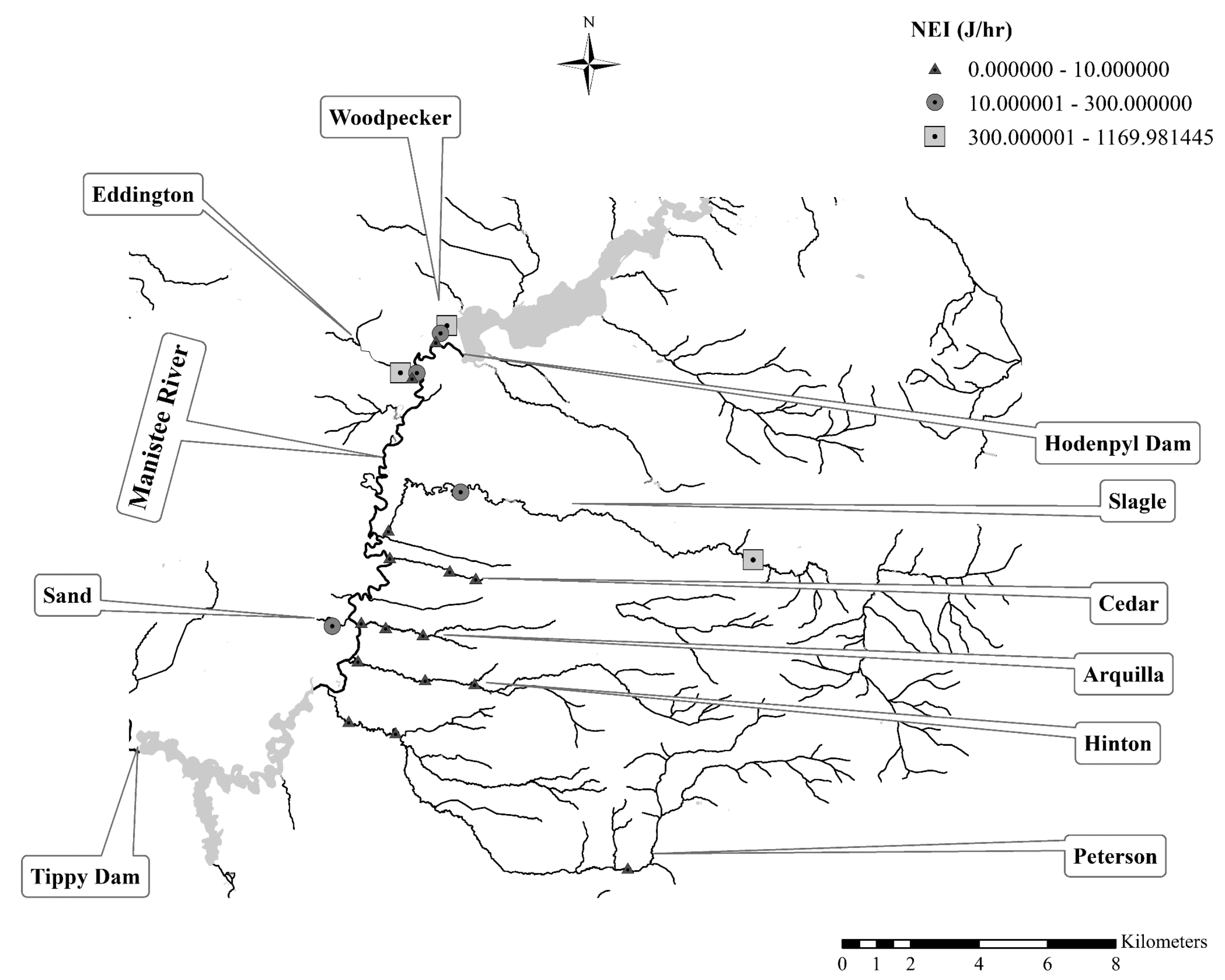

Figure 3.5. Inset map showing the NEI values of each of the 22 Big Manistee River tributary sampling reaches. Reach symbols are scaled to represent the relative NEI scores with larger symbols indicating greater NEI values. 
Appendix 3.1. Eigenvectors from PCA analysis of abiotic habitat variables, invertebrate drift density and biomass, NEI, and mean prey length. * Note all variables were $\log (\mathrm{X}+0.0001)$ transformed prior to PCA.

\begin{tabular}{|c|c|c|c|c|c|c|c|c|}
\hline \multicolumn{9}{|c|}{ Eigenvectors } \\
\hline & Prin 1 & Prin2 & Prin3 & Prin4 & Prin5 & Prin6 & Prin7 & Prin8 \\
\hline $\begin{array}{l}\text { Reach area } \\
\qquad\left(\mathrm{m}^{2}\right)\end{array}$ & 0.2993 & 0.2380 & -0.0369 & 0.1849 & 0.1194 & 0.1834 & 0.0548 & -0.0351 \\
\hline $\begin{array}{c}\text { Discharge } \\
\left(\mathrm{m}^{3}\right)\end{array}$ & 0.3249 & 0.1157 & 0.0328 & 0.2494 & -0.0415 & 0.0208 & 0.1637 & 0.2150 \\
\hline $\begin{array}{c}\text { Water } \\
\text { temperature } \\
\text { (C) }\end{array}$ & 0.0157 & 0.3897 & -0.2962 & 0.1500 & -0.4194 & -0.3579 & 0.3522 & -0.3321 \\
\hline $\begin{array}{c}\text { LWD area } \\
\left(\mathrm{m}^{2}\right)\end{array}$ & 0.3092 & 0.0567 & -0.0506 & -0.1369 & 0.1951 & -0.0027 & 0.3690 & -0.0404 \\
\hline $\begin{array}{l}\text { Mean depth } \\
\text { (m) }\end{array}$ & 0.2493 & 0.2604 & -0.1820 & 0.2371 & -0.1398 & -0.0311 & -0.4403 & 0.2754 \\
\hline Max depth (m) & 0.2673 & 0.2340 & -0.1599 & -0.2152 & -0.0199 & 0.2558 & -0.4389 & 0.0200 \\
\hline $\begin{array}{c}\text { Mean bottom } \\
\text { velocity } \\
(\mathrm{m} / \mathrm{sec})\end{array}$ & 0.2867 & -0.2733 & 0.1329 & -0.0180 & -0.0073 & -0.0206 & 0.2788 & 0.2829 \\
\hline $\begin{array}{l}\text { Mean column } \\
\text { velocity } \\
(\mathrm{m} / \mathrm{sec})\end{array}$ & 0.3151 & -0.1722 & 0.0954 & 0.0935 & -0.0704 & -0.0449 & 0.2043 & 0.3418 \\
\hline Pool (\%) & 0.1096 & 0.2175 & -0.2787 & -0.6236 & 0.4594 & -0.0891 & 0.1373 & 0.0694 \\
\hline Riffle (\%) & 0.3079 & -0.0583 & 0.1249 & -0.1483 & -0.0525 & 0.0097 & -0.2110 & -0.5053 \\
\hline Run (\%) & -0.1684 & 0.2227 & 0.0739 & 0.4039 & 0.6138 & -0.3626 & -0.1600 & 0.1038 \\
\hline $\begin{array}{l}\text { Wetted width } \\
\text { (m) }\end{array}$ & 0.2972 & 0.2573 & 0.0063 & 0.1866 & 0.1040 & 0.1207 & 0.1107 & -0.1467 \\
\hline $\begin{array}{c}\text { Course } \\
\text { substrate }(\%)\end{array}$ & 0.2193 & -0.1850 & 0.3888 & 0.1573 & 0.2423 & 0.1454 & -0.0570 & -0.3428 \\
\hline NEI (J/hr) & -0.0300 & 0.3419 & 0.4812 & -0.2516 & -0.2716 & 0.1235 & -0.0639 & 0.2701 \\
\hline $\begin{array}{l}\text { Drift density } \\
\qquad\left(\# / \mathrm{m}^{3}\right)\end{array}$ & -0.2368 & 0.2568 & 0.1132 & 0.1435 & 0.0888 & 0.5452 & 0.2452 & -0.1856 \\
\hline $\begin{array}{l}\text { Drift Biomass } \\
\qquad\left(\mathrm{g} / \mathrm{m}^{3}\right)\end{array}$ & -0.2297 & 0.3574 & 0.2538 & -0.0666 & 0.0364 & 0.1172 & 0.1779 & 0.1769 \\
\hline $\begin{array}{c}\text { Mean prey } \\
\text { length (mm) }\end{array}$ & 0.1123 & 0.1916 & 0.5129 & -0.1703 & -0.0462 & -0.5172 & -0.0613 & -0.1373 \\
\hline
\end{tabular}




\begin{tabular}{|c|c|c|c|c|c|c|c|c|c|}
\hline \multicolumn{10}{|c|}{$\underline{\text { Eigenvectors }}$} \\
\hline & Prin9 & Prin10 & Prin11 & Prin 12 & Prin13 & Prin14 & Prin 15 & Prin16 & Prin 17 \\
\hline $\begin{array}{l}\text { Reach area } \\
\qquad\left(\mathrm{m}^{2}\right)\end{array}$ & -0.1898 & -0.2376 & 0.0353 & -0.3673 & -0.1329 & -0.2634 & 0.6368 & 0.2022 & 0.0648 \\
\hline $\begin{array}{c}\text { Discharge } \\
\left(\mathrm{m}^{3}\right)\end{array}$ & 0.1259 & -0.0496 & 0.1571 & -0.1046 & -0.0989 & 0.0237 & -0.1109 & -0.7699 & 0.2706 \\
\hline $\begin{array}{c}\text { Water } \\
\text { temperature } \\
\text { (C) }\end{array}$ & 0.2874 & -0.0378 & -0.1986 & 0.2027 & 0.1327 & -0.0613 & 0.1048 & 0.0477 & 0.0115 \\
\hline $\begin{array}{l}\text { LWD area } \\
\qquad\left(\mathrm{m}^{2}\right)\end{array}$ & -0.5782 & 0.1563 & -0.4441 & 0.2228 & -0.1502 & 0.2624 & -0.0750 & -0.0319 & 0.0181 \\
\hline $\begin{array}{l}\text { Mean depth } \\
\text { (m) }\end{array}$ & 0.1012 & 0.5004 & -0.0239 & -0.0200 & -0.1755 & 0.3276 & 0.0009 & 0.2670 & 0.1394 \\
\hline Max depth (m) & -0.0827 & -0.0465 & -0.1562 & 0.3808 & 0.2693 & -0.5026 & -0.0989 & -0.1605 & -0.0633 \\
\hline $\begin{array}{l}\text { Mean bottom } \\
\text { velocity } \\
(\mathrm{m} / \mathrm{sec})\end{array}$ & 0.1246 & -0.0355 & 0.1334 & 0.2617 & 0.2674 & -0.1564 & -0.0443 & 0.3951 & 0.5566 \\
\hline $\begin{array}{l}\text { Mean column } \\
\text { velocity } \\
(\mathrm{m} / \mathrm{sec})\end{array}$ & 0.1318 & 0.1037 & 0.1562 & 0.2225 & 0.0814 & 0.0134 & 0.2158 & 0.0018 & -0.7296 \\
\hline Pool (\%) & 0.3980 & 0.1046 & 0.1100 & -0.1712 & 0.0432 & 0.1105 & 0.0784 & -0.0229 & -0.0001 \\
\hline Riffle (\%) & 0.0088 & -0.2051 & 0.4416 & 0.3684 & -0.1920 & 0.3564 & 0.1446 & -0.0139 & 0.0600 \\
\hline Run (\%) & -0.0173 & -0.2266 & -0.0075 & 0.3107 & 0.2051 & 0.1129 & 0.0750 & -0.0144 & 0.0080 \\
\hline $\begin{array}{l}\text { Wetted width } \\
\qquad(\mathrm{m})\end{array}$ & -0.0044 & -0.2323 & 0.1823 & -0.2734 & 0.0843 & 0.0180 & -0.6641 & 0.2992 & -0.2270 \\
\hline $\begin{array}{c}\text { Course } \\
\text { substrate }(\%)\end{array}$ & 0.4960 & 0.1723 & -0.4991 & -0.0422 & -0.0893 & -0.0797 & 0.0094 & -0.0080 & -0.0139 \\
\hline NEI (J/hr) & 0.0710 & -0.3593 & -0.2678 & -0.0672 & 0.2268 & 0.3892 & 0.0876 & 0.0193 & 0.0067 \\
\hline $\begin{array}{l}\text { Drift density } \\
\qquad\left(\# / \mathrm{m}^{3}\right)\end{array}$ & -0.0385 & 0.4331 & 0.2517 & 0.1147 & 0.3844 & 0.1178 & 0.1188 & -0.0493 & 0.0334 \\
\hline $\begin{array}{l}\text { Drift Biomass } \\
\qquad\left(\mathrm{g} / \mathrm{m}^{3}\right)\end{array}$ & 0.1193 & 0.0074 & 0.1055 & 0.3264 & -0.6619 & -0.2759 & -0.1077 & 0.1218 & -0.0026 \\
\hline $\begin{array}{l}\text { Mean prey } \\
\text { length }(\mathrm{mm})\end{array}$ & -0.2360 & 0.3821 & 0.1860 & -0.1943 & 0.1331 & -0.2697 & -0.0107 & -0.0420 & 0.0022 \\
\hline
\end{tabular}


Appendix 3.2. Density estimates (fish $/ \mathrm{m}^{2}$ ) of all sizes of Brook Trout, Brown Trout, and both species combined in 22 Big Manistee River, MI tributary sampling reaches in May and June 2012. Values in bold indicate tributary-level mean and SD.

\begin{tabular}{|c|c|c|c|c|}
\hline Tributary & $\begin{array}{l}\text { Sample } \\
\text { reach }\end{array}$ & $\begin{array}{c}\text { Brook Trout } \\
\text { density }\left(\text { fish } / \mathrm{m}^{2}\right)\end{array}$ & $\begin{array}{c}\text { Brown Trout } \\
\text { density }\left(\text { fish } / \mathrm{m}^{2}\right)\end{array}$ & $\begin{array}{l}\text { Salmonid density } \\
\left(\text { fish } / \mathrm{m}^{2}\right)\end{array}$ \\
\hline Arquilla & Lower & 0.01 & 0.11 & 0.12 \\
\hline \multirow[t]{2}{*}{ Arquilla } & Upper & 0.21 & 0.16 & 0.36 \\
\hline & & $0.11( \pm 0.14)$ & $0.13( \pm 0.04)$ & $0.24( \pm 0.17)$ \\
\hline Cedar & Lower & 0.27 & 0.06 & 0.30 \\
\hline Cedar & Middle & 1.31 & 0.00 & 1.31 \\
\hline \multirow[t]{2}{*}{ Cedar } & Upper & 0.43 & 0.00 & 0.43 \\
\hline & & $0.67( \pm 0.56)$ & $0.02( \pm 0.04)$ & $0.68( \pm 0.55)$ \\
\hline Eddington & Lower & 0.15 & 0.06 & 0.20 \\
\hline Eddington & Middle & 0.11 & 0.00 & 0.17 \\
\hline \multirow[t]{2}{*}{ Eddington } & Upper & 0.26 & 0.00 & 0.26 \\
\hline & & $0.17( \pm 0.08)$ & $0.02( \pm 0.03)$ & $0.21( \pm 0.04)$ \\
\hline Hinton & Lower & 0.03 & 0.08 & 0.11 \\
\hline Hinton & Middle & 0.09 & 0.28 & 0.36 \\
\hline \multirow[t]{2}{*}{ Hinton } & Upper & 0.07 & 0.39 & 0.46 \\
\hline & & $0.07( \pm \mathbf{0 . 0 3})$ & $0.25( \pm 0.16)$ & $0.31( \pm 0.18)$ \\
\hline Peterson & Lower & $<0.01$ & 0.04 & 0.04 \\
\hline Peterson & Middle & $<0.01$ & 0.13 & 0.13 \\
\hline \multirow[t]{2}{*}{ Peterson } & Upper & 0.07 & 0.00 & 0.07 \\
\hline & & $0.02( \pm 0.04)$ & $0.06( \pm 0.06)$ & $0.08( \pm 0.05)$ \\
\hline Sand & Middle & 0.20 & 0.01 & 0.21 \\
\hline \multirow[t]{2}{*}{ Sand } & Upper & 0.14 & $<0.01$ & 0.14 \\
\hline & & $0.17( \pm 0.04)$ & $0.01( \pm 0.01)$ & $0.17( \pm 0.04)$ \\
\hline Slagle & Lower & $<0.01$ & 0.11 & 0.11 \\
\hline Slagle & Middle & 0.00 & 0.21 & 0.22 \\
\hline \multirow[t]{2}{*}{ Slagle } & Upper & 0.01 & 0.06 & 0.07 \\
\hline & & $0.01( \pm 0.01)$ & $0.13( \pm 0.08)$ & $0.13( \pm 0.07)$ \\
\hline Woodpecker & Lower & 0.01 & 0.16 & 0.20 \\
\hline Woodpecker & Middle & 0.01 & 0.34 & 0.35 \\
\hline \multirow[t]{2}{*}{ Woodpecker } & Upper & 0.02 & 0.12 & 0.14 \\
\hline & & $0.01(0.01)$ & $0.20( \pm 0.12)$ & $0.23( \pm 0.11)$ \\
\hline
\end{tabular}


Appendix 3.3. Biomass estimates (grams of fish $/ \mathrm{m}^{2}$ ) of all sizes of Brook Trout, Brown Trout, and both species combined in 22 Big Manistee River, MI tributary sampling reaches in May and June 2012. Values in bold indicate tributary-level mean and SD.

\begin{tabular}{|c|c|c|c|c|}
\hline Tributary & $\begin{array}{c}\text { Sample } \\
\text { reach }\end{array}$ & $\begin{array}{c}\text { Brook Trout } \\
\text { biomass }\left(\mathrm{g} / \mathrm{m}^{2}\right)\end{array}$ & $\begin{array}{l}\text { Brown Trout } \\
\text { biomass }\left(\mathrm{g} / \mathrm{m}^{2}\right)\end{array}$ & $\begin{array}{c}\text { Salmonid } \\
\text { biomass }\left(\mathrm{g} / \mathrm{m}^{2}\right)\end{array}$ \\
\hline Arquilla & Lower & 0.11 & 4.94 & 4.97 \\
\hline \multirow[t]{2}{*}{ Arquilla } & Upper & 2.59 & 4.82 & 7.63 \\
\hline & & $1.35( \pm 1.75)$ & $4.88( \pm 0.08)$ & $6.29( \pm 1.88)$ \\
\hline Cedar & Lower & 4.17 & 2.22 & 5.55 \\
\hline Cedar & Middle & 20.83 & 0.00 & 21.39 \\
\hline \multirow[t]{2}{*}{ Cedar } & Upper & 5.41 & 0.00 & 5.42 \\
\hline & & $10.14( \pm 9.28)$ & $0.74( \pm 1.28)$ & $10.79( \pm 9.18)$ \\
\hline Eddington & Lower & 1.97 & 1.06 & 2.60 \\
\hline Eddington & Middle & 2.63 & 0.00 & 3.79 \\
\hline \multirow[t]{2}{*}{ Eddington } & Upper & 3.51 & 0.00 & 3.92 \\
\hline & & $2.70( \pm 0.77)$ & $0.35( \pm 0.61)$ & $3.44( \pm 0.73)$ \\
\hline Hinton & Lower & 0.27 & 2.74 & 2.79 \\
\hline Hinton & Middle & 2.67 & 10.72 & 12.68 \\
\hline \multirow[t]{2}{*}{ Hinton } & Upper & 1.49 & 9.26 & 9.86 \\
\hline & & $1.47( \pm 1.20)$ & $7.58( \pm 4.25)$ & $8.44( \pm 5.09)$ \\
\hline Peterson & Lower & 0.15 & 2.25 & 2.52 \\
\hline Peterson & Middle & 0.12 & 6.61 & 6.14 \\
\hline \multirow[t]{2}{*}{ Peterson } & Upper & 2.64 & 0.00 & 2.58 \\
\hline & & $0.97( \pm 1.45)$ & $2.95( \pm 3.36)$ & $3.75( \pm 2.07)$ \\
\hline Sand & Middle & 3.42 & 0.18 & 3.66 \\
\hline \multirow[t]{2}{*}{ Sand } & Upper & 2.25 & 0.15 & 2.42 \\
\hline & & $2.83( \pm 0.83)$ & $0.16( \pm 0.02)$ & $3.04( \pm 0.87)$ \\
\hline Slagle & Lower & 0.05 & 6.94 & 7.54 \\
\hline Slagle & Middle & 0.00 & 12.48 & 12.57 \\
\hline \multirow[t]{2}{*}{ Slagle } & Upper & 0.52 & 7.11 & 7.97 \\
\hline & & $0.19( \pm 0.29)$ & $8.84( \pm 3.15)$ & $9.36( \pm 2.78)$ \\
\hline Woodpecker & Lower & 0.08 & 6.05 & 7.88 \\
\hline Woodpecker & Middle & 0.37 & 10.75 & 10.99 \\
\hline \multirow[t]{2}{*}{ Woodpecker } & Upper & 0.78 & 1.81 & 1.97 \\
\hline & & $0.41( \pm 0.35)$ & $6.20( \pm 4.47)$ & $6.95( \pm 4.58)$ \\
\hline
\end{tabular}


Chapter 4. Simulated population viability for re-introduced Arctic Grayling populations in the Big Manistee River, MI.

Cameron W. Goble*, and Nancy A. Auer

Department of Biological Sciences, Michigan Technological University, 1400 Townsend Drive, Houghton, Michigan 49931, USA 


\begin{abstract}
There is renewed interest in trying to re-introduce extirpated Arctic Grayling Thymallus arcticus into Michigan waters. This was sparked by work conducted in 20112013 by the Little River Band of Ottawa Indians and Michigan Technological University in a collaborative effort to begin determining abiotic and biotic conditions which impact survival of all Arctic Grayling life history stages and in 2016 the Michigan Department of Natural Resources established a statewide Arctic Grayling Restoration Initiative. Population viability assessment (PVA) allows for the modeling of a species extinction risk and sensitivity to environmental and/or anthropogenic factors at various life-stages. Here we present a PVA based on literature-derived life history data for potential Arctic Grayling reintroduction in the Big Manistee River, Michigan. Overall, 76\% of 54 scenarios predicted positive population growth and low probabilities of extinction. Overharvest of adult fish was thought to be the primary driver behind the loss of the species from the state. However, the results of PVA simulations indicate that Arctic Grayling populations at southern latitudes (i.e. Michigan and Montana) can be most sensitive to factors affecting fecundity and early life-history survival. Past research indicates that at higher latitudes Arctic Grayling exhibit slower growth rates and later maturation than southern populations and this shifted the sensitivity analyses to where adult survival became the most influential factor. The observed differences in sensitivities at different latitudes highlights the importance of performing PVA prior to and following the implementation of Arctic Grayling re-introduction management strategies.
\end{abstract}




\section{Introduction}

A species' risk of extinction can be driven by several factors including such occurrences as habitat loss or destruction, overharvest, predation, non-native species introductions, and inbreeding depression (Mills 2007). While the mechanisms behind extinctions are varied and often intertwined, the fundamental issue is that when a population's overall mortality rates (juvenile + adult) exceed replacement-level birth rates (i.e. negative population growth) for an extended period of time the population will be on a trajectory towards potential extinction. A species' life history characteristics often determine which vital rates (e.g. births vs. mortalities) are most sensitive to the aforementioned factors and ultimately drive the population to extinction. It has been proposed (Crone 2001) that while both survival and fecundity are important in determining a species risk of extinction, in general slow-growing, long-lived, and less fecund species tend to be most sensitive to changes in adult survival. Conversely, fastgrowing, short-lived, and highly fecund species tend to be more sensitive to changes in reproductive rates and early life history survival (Crone 2001). This hypothesis has been tested for a variety of taxa including cetaceans (Manlik et al. 2016), terrestrial and marine mammals (Heppell et al. 2000), turtles (Heppell 1998), birds (Saether and Bakke 2000), and fish (Wiedmann et al. 2014) and appears to hold true in most cases. While this hypothesis has been indirectly tested for Arctic Grayling Thymallus arcticus based on analyses undertaken to determine the impact of error in age-determination between scale and otolith-aging (DeCicco and Brown 2006), here we conduct population viability and sensitivity analyses for Arctic Grayling in North America. 
Population viability analysis (PVA) is commonly used to model demographic and environmental stochasticity in order to make predictions about the risk of extinction for threatened and endangered animal populations (Lacy 1993). These analyses require information on birth rates, mortality rates, lifespan, reproductive age, as well as the potential effects of environmental factors on these rates. In PVA's conducted on extant populations, scientists and managers are able to gather the necessary demographic and environmental information specifically for the population(s) in question. However, PVA's are increasingly being used (e.g. Bustamante 1998; Wood et al. 2007; Worthington et al. 2011) to make minimum viable population (MVP) and extinction probability (PE) predictions for species reintroductions and Seddon et al. (2007) suggest that PVA's should be included as part of all reintroduction efforts. For extirpated populations, life history information can be compiled from a thorough literature review if local population-specific demographic data are nonexistent but historical and/or regional data from other populations can be acquired. In such cases, it is possible to calculate mean demographic parameter values and their associated variance to model demographic and environmental variability within the species range (Wood et al. 2007; Worthington et al. 2011). In the case of Arctic Grayling, the species has been extirpated from its historical range in the State of Michigan since the mid-1930's (Leonard 1949) necessitating the collection of range-wide demographic data to perform the recommended PVA and sensitivity analyses prior to any attempt to restore the species.

Prior to 1900 the Arctic Grayling was the most abundant member of the Salmonidae family in rivers and streams throughout the northern half of Michigan's 
Lower Peninsula (Mather 1874; Mather 1880 In Mershon 1923) however by 1906 all Arctic Grayling had been extirpated from the Lower Peninsula (Mershon 1916). Attempts to supplement Arctic Grayling stocks in Michigan began as early as the as the 1870's (Metcalf 1880) through egg and brood stock collections from Lower Peninsula rivers such as the Big Manistee and Au Sable (Jerome 1879; Norris 1878 and Mather 1880 In Mershon 1923). As Arctic Grayling stocks in the Lower Peninsula became depleted to the point where in-state collection of gametes was no longer a viable option, eggs and fry were transported from Montana in an attempt to re-establish the species (Creaser and Creaser 1935). The early efforts to stock Arctic Grayling from Montana occurred in 1900 and attempts continued regularly until 1936 (Leonard 1949) after which most Arctic Grayling restoration activities ceased in the Lower Peninsula for the next 50 years (Nuhfer 1992). The last attempt to re-establish Arctic Grayling in the State of Michigan occurred between 1987 and 1991, when the Michigan Department of Natural Resources (MI-DNR) stocked approximately 250,000 Arctic Grayling fry, fingerlings, or yearlings in rivers and lakes throughout the state (Nuhfer 1992). These efforts were unsuccessful and no further restoration investigations were undertaken until 2011 when the Little River Band of Ottawa Indians (LRBOI) and Michigan Technological University (MTU) partnered on research to explore the feasibility of re-establishing Arctic Grayling in the Big Manistee River watershed.

With assessment data collected between 2011 and 2013, and literature-derived Arctic Grayling life history information, a PVA has been developed for a proposed reintroduction in the Big Manistee River, MI watershed located in the northern Lower 
Peninsula of Michigan (Figure 4.1). No population specific demographic or environmental data are known to exist for this system, necessitating the use of literature derived parameter values for simulation. The objective of this study is to model the effects of varying demographic factors in order to estimate the long-term survival probability for a re-introduced Arctic Grayling population in a portion of the Big Manistee River watershed. Based on what was known (or presumed) about the extirpation of Arctic Grayling from the State of Michigan (Vincent 1962; Nuhfer 1992) and reviews of PVA's conducted for other fish species (e.g. Rieman and Allendorf 2001; Worthington et al. 2011; Wiedmann et al. 2014) it was hypothesized that no life-history trait, or human factor, would have a greater impact than any other trait or factor on the predicted long-term persistence of a re-introduced Arctic Grayling population in the Big Manistee River. Based on evidence of geographic variation in life-history traits gathered during the course of literature review it was further hypothesized that PVA would reveal no differences in population sensitivities across a proposed latitudinal gradient of Arctic Grayling life characteristics (i.e. age at maturity and maximum age).

\section{Study area}

The Big Manistee River and surrounding watershed supported one of the last known populations of Arctic Grayling in the Lower Peninsula (Vincent 1962). The river flows through the historical 1836 treaty lands and a portion of the present-day reservation of the Little River Band of Ottawa Indians (LRBOI). With a mainstem river length of 373 $\mathrm{km}$ the Manistee River watershed encompasses $4,610 \mathrm{~km}^{2}$ (Chiotti et al. 2008). Two hydroelectric dams, Tippy Dam, which is 47 river kilometers (rkm) upriver of Lake 
Michigan, and Hodenpyl Dam, which is located at rkm 68, span the mainstem, forming barriers preventing all upstream fish movement. These barriers effectively divide the watershed into three distinct segments, hereafter referred to as either the Lower, Middle, or Upper Manistee watershed. In addition to the mainstem habitat, multiple tributaries discharge into the Middle Manistee providing a total of approximately $300 \mathrm{~km}$ of interconnected stream habitat (Figure 4.1).

The LRBOI have shown great interest in protecting and restoring native and culturally significant species within the 1836 treaty area (Auer et al. 2013). As part of these goals LRBOI and MTU developed habitat assessment criteria in order to determine whether current conditions in the Big Manistee River, Michigan and its tributaries would be suitable for potential Arctic Grayling re-introductions (Auer et al. 2013). Between 2011 and 2013 LRBOI and MTU performed > 100 surveys of the abiotic and biotic characteristics of 23 tributary reaches in the Middle Manistee watershed. Danhoff et al. (2017) assessed abiotic conditions and found suitable habitat for all life-stages of Arctic Grayling in all but one of the tributaries studied. Additionally, Goble et al. (In Review) described fish-habitat relationships and documented successful natural recruitment of Brook Salvelinus fontinalis and Brown Salmo trutta Trout in each tributary indicating that each is able to support naturally reproducing populations of salmonids with similar habitat requirements as Arctic Grayling. Together these findings indicate that there is potential for successfully re-establishing Arctic Grayling in the Big Manistee River watershed and provide necessary assessment criteria, background information, and the impetus for this study as a next step towards future re-introduction efforts. 


\section{Methods}

\section{Population viability analysis}

Population viability analysis involves performing matrix-projection simulations of stage-specific demographic rates and life history traits through time in order to model a population's extinction risk (Mills 2007). Based on literature review of Arctic Grayling life history characteristics throughout the species' North American range a proposed life cycle diagram (Figure 4.2) and associated Lefkovitch matrix (Table 4.1) were developed for PVA model parameterization. The software VORTEX (Lacy and Pollak 2015) was used to perform PVA simulations for a hypothetical reintroduced population of Arctic Grayling in the Middle Manistee watershed and additional simulations along a hypothesized north-south latitudinal gradient of Arctic Grayling life history traits. VORTEX performs Monte Carlo simulations incorporating demographic, environmental, and genetic stochasticity to model the effects of deterministic factors on populations (Lacy 1993; Lacy et al. 2015). User specified mean and standard deviation (SD) values of demographic parameters are selected to model annual variation related to random environmental fluctuations while VORTEX generates individual-based random probabilities to model demographic stochasticity (Lacy 1993; Worthington et al. 2011). Based on these variations, the program performs multiple iterations (user specified) and generates output information including: mean and SD population size after $\mathrm{N}$ years (default is 100 years), intrinsic population growth rate $(r)$, deterministic growth rate, and the survival probability (SP) for the population.

\section{Demographic data collection}


Due to a lack of demographic information for historic Arctic Grayling populations in Michigan, life history data were collected from published sources for extant Arctic Grayling populations elsewhere in North America. When possible, included studies were restricted to those involving native Arctic Grayling populations in fluvial systems.

However, for some demographic parameters data from introduced (and self-sustaining) or lacustrine populations were used if fluvial data were lacking. The following parameters were included in the population viability analyses: Fecundity, age at sexual maturity, maximum age, $1^{\text {st }}$ year survival, juvenile (age-1 to age-2) survival, adult (ages $2^{+}$) survival, sex ratio (proportion of males in the population), proportion of females successfully producing offspring, and population carrying capacity (Table 4.2). In order to compare variability among demographic traits with different scales the coefficient of variation $(\mathrm{CV})$ was calculated for each parameter.

Fecundity

High, Medium, and Low fecundity values were set by calculating the mean ( \pm SD) number of eggs produced per female reported in four native fluvial Arctic Grayling populations in Montana and Alaska (Table 4.2). Mean fecundity from these four populations was considered Medium fecundity or the baseline value, while mean - $1 \mathrm{SD}$ represented Low fecundity, and mean + 1 SD represented High fecundity for all PVA analyses (Table 4.3). To account for the computational demands of simulating highly fecund species (Lacy et al. 2015), fecundity was adjusted by multiplying each value by the mean egg to fry survival reported for an adfluvial Arctic Grayling population in Grebe Lake, Wyoming (Kruse, 1959; Table 4.2). This approach allows the model to run in VORTEX and this adjustment has been used in similar studies with highly fecund fish 109 
species such as Bull Trout Salvelinus confluentus, and Burbot Lota lota (e.g. Rieman and Allendorf 2001; Worthington et al. 2011).

Age at maturity and maximum age

Age at maturity for the PVA was determined based on values reported from four studies encompassing two Arctic Grayling populations in Montana (Liknes and Gould 1987; Kaya 1990), and two populations from Alaska and British Columbia (Butcher et al. 1981, Northcote 1995; Table 4.2). Since a Big Manistee River population would likely resemble those in Montana due to similarity of latitude, age at maturity for the simulated population was set at 2 years (initial pre-scenarios were tested at two and three years with no substantial differences observed). The maximum age of Arctic Grayling seems to vary by latitude and maximum age was derived from a northern population in Canada's Northwest Territories (deBruyn and McCart 1974) and two southern populations in British Columbia and Montana (Butcher et al. 1981; Kaya 1990). As with age at maturity, the maximum age was set at six years for all Big Manistee River simulations based on similar latitudes with Montana populations (Table 4.3).

First year survival

First year survival was divided into two components; egg to fry, and fry to age-1 and as previously described, egg to fry survival was incorporated into the fecundity parameter. Kruse (1959) estimated both egg to fry and fry to age-1 survival for the Grebe Lake, Wyoming population (Table 4.2) and the mean fry to age-1 survival was calculated to represent a Medium estimate of first year survival. As with fecundity, Low and High first year survival rates were represented as the mean value $\pm 1 \mathrm{SD}$ (Table 4.3). 


\section{Juvenile and adult survival}

Mean survival rates for juveniles $(<2$ years) and adults $(\geq 2$ years $)$ were derived from literature values for Arctic Grayling from unexploited or lightly exploited native populations in Alaska and Alberta (Table 4.2). A lack of published information on juvenile-specific survival rates necessitated the use of adult survival values for both adult and juvenile fish meaning that survival rates were held constant from age- 1 until death in this simulated population. Three survival levels were set based on the mean \pm 1 SD to represent Low, Medium, and High survival rates (Table 4.3). A fourth scenario incorporating fishing mortality was developed from harvest estimates provided in two studies (Clark 1992a; 1995; Table 4.3)

Sex ratio and proportion of females successfully producing offspring

Data on Arctic Grayling sex ratios were gathered from two native and one introduced populations (Table 4.2) providing a mean value of $47 \%(\mathrm{SD}=13 \%)$ males in a population. This value was held constant in all simulations. The proportion of females successfully producing offspring in a given year was simulated at two levels: $100 \%$ indicating successful spawning every year, and 50\% indicating unsuccessful spawning events for certain individuals due to fluctuations in environmental conditions. Carrying capacity

Projected carrying capacity for Arctic Grayling in the Middle Manistee watershed was determined by compiling density information from riverine populations in Montana, Alberta, and British Columbia (Table 4.2). Several historical reports of extremely high densities occurring in northern Alaskan lake-river systems (e.g. 1,480 - 2,845 adults per km; summarized in Northcote 1995) were excluded from analyses to avoid inflating 
predicted carrying capacity. This resulted in a mean population density of 23.7 ( $\mathrm{SD}=$ 21.8) Arctic Grayling per km (Table 4.3). Stream lengths in the Big Manistee River watershed were calculated based on GIS mapping of the stream layer of the National Hydrography Dataset (USDA/NRCS - National Geospatial Management Center) conducted using ArcMap $10.3\left(\mathrm{ESRI}^{\circledR}\right)$. All known barriers to fish passage (e.g. dams and impoundments) were marked and only contiguous habitat was included in stream length calculations. For this simulation, only the streams in the Middle Manistee watershed (see study area description) were considered yielding a total of $300 \mathrm{~km}$ of connected stream habitat (Figure 4.1). Multiplying the mean density of Arctic Grayling derived from literature values by total stream length resulted in a carrying capacity estimate of 7,503 $(\mathrm{SD}=6,926)$ individuals for the Middle Manistee watershed. Models

All model scenarios were based on a single re-introduced Arctic Grayling population with an initial size of 1,000 individuals. One criteria in VORTEX is the assumption that all individuals in the initial population are age-1 or older. However, based on the demonstrated success of using remote site egg incubators (RSIs) for restoration of Arctic Grayling in Montana (Kaeding and Boltz 2004; Cayer and McCullough 2013) this method is proposed for potential re-introductions in Michigan. Based on predicted RSI egg to fry survival (Wilson and Auer unpublished data) and fry to age-1 survival described above, the PVA simulations began one year after a hypothetical RSI effort with 100,000 Arctic Grayling eggs (100,000 eggs * 0.5 egg to fry survival in RSIs * 0.02 fry to age-1 survival). Using a factorial design, 54 unique 
scenarios were created to assess how changes in fecundity (High, Medium, and Low), fry to age-1 mortality (High, Medium, and Low), adult mortality (High, Medium, and Low), and proportion of females producing offspring (100\%, and 50\%) would affect the population. All simulations were compared to a "baseline" scenario in which all parameters were set at mean (i.e. Medium) levels with the associated SD values included as environmental variation (EV). An additional scenario was created in which adult mortality was adjusted to mimic values from a harvested population while all other parameters were held at their mean values. Each scenario was modeled over 100 years, with 500 iterations, and extinction was defined as occurring when the population dropped below 100 individuals. Latitudinal gradient scenarios were developed for 22 latitude bands between $43^{\circ}$ and $70^{\circ} \mathrm{N}$, which encompasses the historical range of Arctic Grayling in North America. Age-at-maturity and maximum age were adjusted for each latitude band based on an exponential curve fit to literature derived age-and-growth data collected from across the species range. Sensitivity analyses were performed for each latitudinal scenario using the same $\pm 1 \mathrm{SD}$ adjustments described above for the Big Manistee River scenarios.

\section{Results}

Under the baseline scenario (to which other scenarios were compared) for a potential Big Manistee River Arctic Grayling re-introduction, the simulation predicted a $100 \%$ Survival Probability (SP) with an $r$ of 0.352 (SD = 0.279; Figure 3.4). Overall, 32 of the $54(59.3 \%)$ tested scenarios predicted $100 \%$ population survival (i.e. probability of extinction $=0.0 \%$ ) of a re-introduced Arctic Grayling population over the modeled 100- 
year timeframe with $>68 \%$ of the scenarios predicting $>50 \%$ SP (Table 4.4 ). Course sensitivity analyses showed that for a simulated population in the Big Manistee River (under the parameter ranges tested) fecundity had the greatest effect on SP and $r$ followed by: adult (ages $2^{+}$) survival, proportion of females producing offspring, and juvenile (fry to age-1) survival respectively (Figure 4.5). Eighty-eight $\%$ of the scenarios predicting < $50 \% \mathrm{SP}$, and $92 \%$ of the scenarios predicting $0 \% \mathrm{SP}$ were at the Low fecundity level of 54 offspring per female (Table 4.4). Under high fecundity scenarios, reductions in fry to age-1, juvenile, and adult survival; and spawning periodicity did not substantially increase extinction probability or lead to large reductions in final population size. Similarly, under mean fecundity scenarios extinction probability did not increase by $>$ $25 \%$ unless at least two of the other three parameters were low, although there was greater variation in final population size across all mean fecundity scenarios.

Fine-scale sensitivity analysis revealed that at fecundity levels $<51$ offspring/female all simulated populations went extinct over a 100-year timeframe with a median time to extinction of 9.5 years (range $6-25$ years). However, a relatively small increase in fecundity to 75 offspring/female produced $100 \%$ SP in all simulated populations over a 100 -year timeframe indicating a relatively narrow range $(51-75$ offspring/female) where SP is highly sensitive to changes in fecundity (Figure 6). As with many fish species, the fecundity of Arctic Grayling increases as a function of body size. Northcote (1995) reported individual fecundities ranging from 6,475 to $16,887 \mathrm{eggs} / \mathrm{kg}$ and Kaya (1990) showed average fecundity of approximately 12,000 eggs/kg for Arctic Grayling in Montana. Coggins (1992) provides insight into length-at-age and length- 
weight relationships for Arctic Grayling through a comprehensive age-and-growth dataset compiled from 26 years of studies of Alaskan populations. Kaya (1990) summarized length-at age data for six populations in Montana and Wyoming providing similar information from Arctic Grayling populations at the southern edge of their range. Applying the mean length-at-age, and length-weight relationships reported in these studies indicates that potential Arctic Grayling egg production increases by an average of approximately 1,100 eggs per female for each year of life beyond age- 2 . With a mean egg to fry survival rate of $3.6 \%$ the predicted difference between the number of live fry produced by 6-year old fish vs. a 2-year old fish would be approximately 150 fry, suggesting that protection of older, larger females can have a significant impact on the overall fecundity of a population and should be considered for any proposed Arctic Grayling re-introductions.

Under the mortality levels tested in these simulations, harvest alone would not be expected to drive a re-introduced Big Manistee River Arctic Grayling population to extinction. When all other life history parameters were held at mean $( \pm 1 \mathrm{SD}$ as environmental variation) values a $45 \%$ increase in adult mortality did not affect the overall probability of the population persisting for at least 100 years. Fry to age-1, juvenile, and adult survival; sex ratios; and spawning periodicity, are predicted to have lesser (although measurable) effects than reproductive output on the long-term $\left(100^{+}\right.$ years) SP of a re-introduced Big Manistee River Arctic Grayling population. While increased adult mortality did not negatively affect population persistence it did lead to a measurable decrease in the population growth rate $(r=0.352$ : baseline, $r=0.1594$ : 
harvested) and predicted final population size $(N=7,172$ : baseline, $N=6,275$ :

harvested).

Some of the variability in Arctic Grayling demographics can be explained by the effects of a latitudinal gradient among populations (Figure 4.3). For example, age at sexual maturity of Arctic Grayling appears to be determined by the geographic location of populations (Figure 4.7) with more northerly populations typically maturing later (e.g. five to eight years in northern Alaska; Craig and Poulin 1975) than southern populations (e.g. two to three years in Michigan and Montana; Creaser and Creaser 1935; Brown 1938). Across the species latitudinal range the mean \pm SD age-at-maturity for Arctic Grayling in North America was approximately 4 years $(4.4 \pm 2.3$ years $)$ with a CV of 52\%. Based on published data for Arctic Grayling in North America approximately 94\% of the observed variation in age-at-maturity can be explained by the latitude at which a population is located (Figure 4.7; Equation 1).

$$
\begin{aligned}
& \text { Age-at-maturity }=0.1489 \mathrm{e}^{\left(0.0558^{*} \text { Latitude }\right)} \\
& \left(r^{2}=0.94, P<0.001\right)
\end{aligned}
$$

Maximum age for Arctic Grayling also appears to follow a similar geographic pattern as age-at-maturity. The mean $\pm \mathrm{SD}$ maximum age for Arctic Grayling in North America was approximately 14 years $(13.8 \pm 9.4$ years $)$ with a CV of $68 \%$. Latitude explained approximately $86 \%$ of the observed variation in Arctic Grayling maximum age (Figure 4.7; Equation 2) with northern populations having longer potential lifespans (e.g. 22 years in the Yukon Territory in Canada, deBruyn and McCart 1974) compared to 
southern populations in Canada and Montana (e.g. five to eight years, Butcher et al. 1981; Kaya 1990). While no definitive information about the maximum age of Arctic Grayling in Michigan was found, Creaser and Creaser (1935) reported examining specimens up to four years of age indicating a minimum potential 4-year lifespan in Michigan rivers, which aligns with the latitudinal trend described in Equation 2.

$$
\begin{gathered}
\text { Maximum age }=0.1093 \mathrm{e}^{\left(0.0807^{*} \text { Latitude }\right)} \\
\left(r^{2}=0.86, P<0.001\right)
\end{gathered}
$$

Sensitivity analyses based upon predicted age-at-maturity and maximum age combinations across the North American latitudinal range (see equations $1 \& 2$ ) revealed a shift in the relative "importance" of fecundity (including egg to fry survival) and adult survival. At low latitudes (i.e. $43^{\circ} \mathrm{N}$ through $55^{\circ} \mathrm{N}$ ) fecundity had the greatest impact on a population's predicted growth rate (Figures $4.3 \& 4.8$ ). At high latitudes (i.e. $60^{\circ} \mathrm{N}$ through $70^{\circ} \mathrm{N}$ ) a population's growth rate appears to be driven by adult survival with fecundity having a much smaller relative impact (Figures $4.3 \& 4.8$ ). A narrow $\left(5^{\circ}\right)$ "midlatitude" band where the relative importance of fecundity and adult survival are roughly equal was seen for populations between $55^{\circ} \mathrm{N}$ and $65^{\circ} \mathrm{N}$ suggesting that populations at these latitudes (e.g. northern Alberta, southwestern Alaska, etc.) are sensitive to both reductions in fecundity and increases in adult mortality (Figures $4.3 \& 4.8$ ). Sensitivity analyses performed using a sub-set of data from Arctic Grayling populations in Montana yielded similar results as the Manistee River simulations, and fecundity was again the factor with the largest impact on population growth rate (Figure 4.8) 


\section{Discussion}

For species with a wide geographical range such as Arctic Grayling a population's risk of extinction can be influenced by many factors, which are likely to have very different impacts depending on location and regional life-history characteristics. In North America, Arctic Grayling are believed to have been driven to extinction in their historical Michigan range by some combination of: A) overharvest, B) habitat destruction, and C) competition with and predation by introduced salmonids (Norris 1879; Taylor 1954; Vincent 1962). Although the specific mechanisms may vary, factors such as habitat destruction and competition/predation from introduced salmonids can directly impact all life-stages from egg to adult, suggesting they may potentially exert greater pressure on a population than overharvest alone. While overharvest has been implicated as one of the primary factors leading to the extirpation of Arctic Grayling from Michigan (Norris 1879; Leonard 1949; Vincent 1962), PVA insight into the sensitivity of southern Arctic Grayling populations to reductions in reproductive output indicates that factors affecting egg or larval survival could have played a significant role in the loss of the species in Michigan. Better understanding of the sensitivities of each life-stage to various environmental factors provides improved confidence in the success of potential reintroduction efforts. Since PVA based on literature derived parameter values indicates that reproductive output is potentially the factor with the greatest impact on population persistence for the simulated Big Manistee River Arctic Grayling re-introduction, restoration and management efforts should focus on ways to increase egg production and egg to fry survival. 
Variation in life history characteristics associated with a latitudinal gradient has been studied extensively for both freshwater and marine fishes and demonstrates a general trend both within (e.g. Blanck et al. 2007) and among species (e.g. Winemiller and Rose 1992) of decreased length-at-age, increased age at maturity, and increased longevity with increasing latitude. In a study of age and growth variation in Lake Sturgeon Acipenser fulvescens (a species with a similar latitudinal range to Arctic Grayling) Sunde (1961) found evidence of decreasing length-at age as latitude increased. Similarly, Power and McKinley (1997) performed a meta-analysis of 15 Lake Sturgeon populations across North America and found clear evidence of a latitudinal gradient in length-at-age. For cold/coolwater species with a wide latitudinal range such as Arctic Grayling (i.e. $\sim 43^{\circ} \mathrm{N}$ to $70^{\circ} \mathrm{N}$ ) differences in life-history traits and seasonal growth patterns have the potential to affect the risk of population extinction and sensitivity at specific life-stages.

Range-wide PVA simulations for Arctic Grayling indicate a shift in the relative importance of reproduction and adult mortality in determining a population's susceptibility to extinction based on the literature derived input parameters. North American Arctic Grayling populations living at southern latitudes (i.e. $<55^{\circ} \mathrm{N}$ ) such as those historically found in Michigan, and those currently living in Montana, appear to be more sensitive to factors affecting fecundity and egg to fry survival (Figures $4.3 \& 4.8$ ) than populations found at northern latitudes (i.e. $>60^{\circ} \mathrm{N}$ ). At latitudes $>55^{\circ} \mathrm{N}$ populations presumably become more sensitive to factors affecting adult mortality (Figures $4.3 \& 4.8$ ) due to slower growth rates, later maturation (Figure 4.7), and greater 
longevity (Figure 4.7) associated with shorter optimal growing seasons (Armstrong 1986; Northcote 1995). These findings are supported in the literature for Arctic Grayling and other fish species with large latitudinal ranges. Studies of Arctic Grayling populations on Alaska's Seward Peninsula ( $64^{\circ} \mathrm{N}$ latitude) indicate that high levels of adult mortality caused by angler overharvest lead to long term declines and limited recovery of slow growing populations (DeCicco and Brown 2006). Similarly, overharvest has been shown to be one of the primary drivers responsible for the collapse of many Walleye Sander vitreus populations in northern Canada due to slower growth rates and later maturation than more southerly populations (Mogensen et al. 2014)These intraspecific variations in extinction sensitivities highlight the challenges of conserving and restoring populations of species with large geographic ranges and life-history plasticity and re-enforce the importance of performing PVA assessments as part of the conservation efforts (Boyce 1992; Seddon et al. 2007). As seen in this Arctic Grayling example, conservation measures that may be effective for populations in one geographic area may not be effective in others where an entirely different set of demographic parameters may be more "important" in determining a population's sensitivity of extinction.

The interplay between adult survival and fecundity provides an avenue for management actions to protect the older, larger, and presumably more fecund individuals in a population while still allowing for some harvest from the population (Berkeley et al. 2004). In unexploited fisheries, it is expected that adult mortality decreases as age (and size) increases due to less susceptibility to predation (Berkeley et al. 2004), however, angler harvest generally targets older and larger individuals which can negate any 
decrease in natural mortality (Birkeland and Dayton 2005). It is important to note that in these simulations the increase in mortality was modeled as a constant rate for all ages of adult fish which may not reflect angler preferences for harvesting large individuals (Norris 1879) and the proportional measure of harvest used (i.e. $45 \%$ of the adult population) may not accurately represent the harvest practices that occurred historically. Early accounts of Arctic Grayling fishing in Michigan often describe large numbers of adult fish being harvested (e.g. 2,000 or more fish by a single party, Hinsdale 1932). If reintroduction of Arctic Grayling in the Big Manistee River proceeds, protection of older, larger, and presumably more fecund individuals should be considered a management priority which would have the dual benefit of reducing adult mortality and increasing potential fecundity.

Admittedly, the utility of PVAs for making predictions about future population trajectories and extinction probabilities has been questioned by some (e.g. Beissinger and Westphal 1998). Brook et al. (2000) tested the predictive accuracy of 21 long-term PVA studies and found that in most cases predictions of PE, $r$, and population size were not significantly different from the later observed values indicating that the initial predictions were valid. However, Coulson et al (2001) suggested that those analyses included a study-bias and that the predictive ability of PVA is entirely reliant on the quality of the data inputs. While both arguments have merit, they are not necessarily mutually exclusive. When high-quality input data is available, population viability assessments can provide critical information when used to inform the decision-making process and provide a framework for adaptive management strategies in species restorations. It is 
thought that the real power of PVA comes from the ability to model and make comparisons between potential outcomes of various management actions (Boyce 1992; Mills 2007; Seddon et al. 2007).Coupled with findings of habitat, fish community, and bio-energetic assessments (see Danhoff et al. 2017, Goble et al. In Prep; Goble and Auer In Prep) which identified suitable Arctic Grayling habitat in the Middle Manistee watershed the results of PVA simulations indicate that an Arctic Grayling population could be successfully re-established in the Big Manistee River, MI. It is important to note that the input data used in these simulations was derived from multiple Arctic Grayling populations across the species range, thus relying on spatial rather than temporal variability in demographic parameters. Since the purpose of PVA (and the model structure of Vortex) is to model the effects of temporal variation on populations to make predictions about the future, it is likely that the spatial variation used in these analyses will not fully represent future conditions in the Big Manistee River watershed. Ideally, following the establishment of a starting population (based on habitat assessments and initial PVAs) all re-introduced Arctic Grayling populations would be monitored and reassessed as new population-specific, and temporally variable, demographic data and management outcomes become available.

\section{Acknowledgements}

The authors would like to thank all of the staff at the Little River Band of Ottawa Indians Natural Resources Department. We would also like to thank the Department of Biological Sciences at Michigan Technological University for providing support for this research. Partial funding was provided by the Little River Band of Ottawa Indians 
through a U.S. Fish and Wildlife Service Tribal Wildlife Grant (U-17-NA-1) awarded to Nancy Auer, Casey Huckins, J. Marty Holtgren, and Stephanie Ogren. Additional funding was provided by the Department of Biological Sciences at Michigan Technological University through Graduate Teaching Assistantships and through a National Science Foundation GK-12 fellowship awarded to Cameron Goble. This work was submitted by Cameron Goble in partial fulfillment of a Doctor of Philosophy degree at Michigan Technological University and special thanks go to the members of the graduate committee: Casey Huckins, James Magee, John Vucetich, as well as J. Marty Holtgren and Stephanie Ogren for their insightful comments and reviews of this manuscript. This is contribution \# xxx of the Great Lakes Research Center, MTU. 


\section{References}

Armstrong, R. H. 1986. A review of Arctic Grayling studies in Alaska, 1952-1982. University of Alaska Institute of Arctic Biology. Biological Papers of the University of Alaska No. 23, Fairbanks, Alaska.

Auer, N. A., C. J. Huckins, B. M. Danhoff, and C. W. Goble. 2013. Development of a Native Species Restoration Plan for the 1836 Treaty Area: Suitability of the Big Big Manistee River for Arctic Grayling Re-establishment. Michigan Technological University Project Completion Report U-17-NA-1, Houghton, Michigan.

Barndt, S. A. 1996. The biology and status of Arctic Grayling in Sunnyslope Canal, Montana. Masters Thesis, Montana State University, Bozeman, Montana.

Beauchamp, D. A. 1990. Movements, habitat use, and spawning strategies of Arctic Grayling in a subalpine lake tributary. Northwest Science 64:195-207.

Beissinger, S. R., and M. I. Westphal. 1998. On the use of demographic models of population viability in endangered species management. Journal of Wildlife Management 62:821-841.

Berkeley, S. A., M. A. Hixon, R. J. Larson, and M. S. Love. 2004. Fisheries sustainability via protection of age structure and spatial distribution of fish populations.

Fisheries 29:23-32.

Birkeland, C., and P. K. Dayton. 2005. The importance in fishery management of leaving the big ones. Trends in Ecology and Evolution 20:356-358.

Bissell, J. H. 1890. Grayling in Michigan. Transactions of the American Fisheries Society 19:27-29.

Blanck, A., and N. Lamouroux. 2007. Large-scale intraspecific variation in life-history traits of European freshwater fish. Journal of Biogeography 34:862-875. 
Boyce, M. S. 1992. Population viability analysis. Annual Review of Ecology and Systematics 23:481-506.

Brook, B. W., J. J. O’Grady, A. P. Chapman, M. A. Burgman, H. R. Akçakaya, and R. Frankham. 2000. Predictive accuracy of population viability analysis in conservation biology. Nature 404:385-387.

Brown, C. J. D. 1938. Observations on the life-history and breeding habits of the Montana Grayling. Copeia 1938:132-136.

Bustamante, J. 1998. Use of simulation models to plan species reintroductions: the case of the bearded vulture in southern Spain. Animal Conservation 1:229-238.

Butcher, G. A., J. R. Ellis, and R. B. Davidson. 1981. Aspects of the life history of Arctic Grayling (Thymallus arcticus) in the Liard River drainage, British Columbia. BC Ministry of Environment, Aquatic Studies Branch, Victoria, Canada.

Buzby, K. M., and L. A. Deegan. 2004. Long-term survival of adult Arctic Grayling (Thymallus arcticus) in the Kuparuk River, Alaska. Canadian Journal of Fisheries and Aquatic Sciences 61:1954-1964.

Cayer, E., and A. McCullough 2013. Arctic Grayling Monitoring Report. Montana Fish, Wildlife \& Parks, Bozeman, Montana.

Chiotti, J. A., J. M. Holtgren, N. A. Auer, and S. A. Ogren. 2008. Lake Sturgeon spawning habitat in the Big Big Big Manistee River, Michigan. North American Journal of Fisheries Management 28:1009-1019.

Clark, R. A. 1992a. Influence of stream flows and stock size on recruitment of Arctic Grayling (Thymallus arcticus) in the Chena River, Alaska. Canadian Journal of Fisheries and Aquatic Sciences 49:1027-1034. 
Clark, R. A. 1992b. Fisheries Manuscript No. 92-5 Age and size at maturity of Arctic Grayling in selected waters of the Tanana drainage. Alaska Department of Fish and Game, Anchorage, Alaska.

Clark, R. A. 1995. Fisheries Manuscript No. 95-8 Stock status and rehabilitation of Chena River Arctic Grayling during 1994. Alaska Department of Fish and Game, Anchorage, Alaska.

Coggins, L. G. 1992. Fisheries Data Series No. $92-52$ Compilation of age, weight, and length statistics for Arctic Grayling samples collected in southwest Alaska, 1964 through 1989. Alaska Department of Fish and Game, Anchorage, Alaska.

Coulson, T., G. M. Mace, E. Hudson, and H. Possingham. 2001. The use and abuse of population viability analysis. Trends in Ecology and Evolution 16:219-221.

Craig, P. C., and V. A. Poulin. 1972. Movements and growth of Arctic Grayling (Thymallus arcticus) and juvenile Arctic Char (Salvelinus alpinus) in a small arctic stream, Alaska. Journal of the Fisheries Research Board of Canada 32:689697.

Creaser, C. W., and E. P. Creaser. 1935. The Grayling In Michigan. Michigan Academy of Science, Arts, and Letters 20:599-608.

Crone, E. E. 2001. Is survivorship a better fitness surrogate than fecundity? Evolution 55:2611-2614.

Danhoff, B. M., C. J. Huckins, N. A. Auer, C. W. Goble, S. A. Ogren, and J. M. Holtgren. 2017. Abiotic Habitat Assessment for Arctic Grayling in a Portion of the Big Manistee River, MI. Transactions of the American Fisheries Society XX:ppp-ppp.

deBruyn, M. and P. McCart. 1974. Life History of the Grayling (Thymallus arcticus) in Beaufort Sea drainages in the Yukon Territory. Pages 1-39 in P. J. McCart editor. 
Fisheries Research Associated with Proposed Gas Pipeline Routes in Alaska, Yukon, and Northwest Territories. Arctic Gas Biological Report Series Volume 15.

DeCicco, A. L., and R. J. Brown. 2006. Direct validation of annual growth increments on sectioned otoliths from adult Arctic Grayling and a comparison of otolith and scale ages. North American Journal of Fisheries Management 26:580-586.

Goble, C. W., N. A. Auer, C. J. Huckins, B. M. Danhoff, J. M. Holtgren, and S. A. Ogren. In Review. Fish distributions and habitat associations in Big Manistee River, MI tributaries: implications for Arctic Grayling restoration.

Heppell, S. S. 1998. An application of life-history theory and population model analysis to turtle conservation. Copeia 1998:367-375.

Heppel, S. S., H. Caswell, and L. B. Crowder. 2000. Life histories and elasticity patterns: perturbation analysis for species with minimal demographic data. Ecology 81:654-665.

Hildebrandt, D., and C. Hunt. 1991. Arctic Grayling hooking and tagging mortality and angler catch rates on the Little Smoky River, July-August 1990. Alberta Department of Forestry, Lands, and Wildlife, Fish and Wildlife Division, Edson, Alberta.

Hinsdale, W. B. 1932. Distribution of the Aboriginal Population of Michigan. University of Michigan Press, Ann Arbor, Michigan.

Hubbard, L. Jr. 1900. The doom of Michigan's Grayling. Outing 37:85-86.

Jerome, G. H. 1879. Third Report of the Superintendent of the Michigan State Fisheries for 1877-8. Michigan State Board of Fish Commissioners, Lansing, Michigan. 
Kaeding, L. R., and G. D. Boltz. 2004. Use of remote-site incubators to produce Arctic grayling fry of wild parentage. North American Journal of Fisheries Management 24: 1031-1037.

Kaya, C. M. 1990. Status report on fluvial Arctic Grayling (Thymallus arcticus) in Montana. Unpublished Report to Montana Department of Fish Wildlife and Parks, Helena, Montana.

Kruse, T. E. 1959. Grayling of Grebe Lake, Yellowstone National Park, Wyoming. Fishery Bulletin of the United States Fish and Wildlife Service, Volume 59. Washington, DC.

Kuhnlein, H. V., and M. M. Humphreys. 2017. Traditional animal foods of indigenous peoples of northern North America: http://traditionalanimalfoods.org/. Centre for Indigenous Peoples' Nutrition and Environment, McGill University, Montreal, Canada.

Lacy, R. C. 1993. VORTEX: A computer simulation model for population viability analysis. Wildlife Research 20:45-65

Lacy, R. C., P. S. Miller, and K. Traylor-Holzer. 2015. Vortex 10 user's manual. 15 April 2015 update. IUCN SSC Conservation Breeding Specialist Group, and Chicago Zoological Society, Apple Valley, Minnesota.

Lacy, R. C., and J. P. Pollak. 2015. Vortex: A stochastic simulation of the extinction process. Version 10.1. Chicago Zoological Society, Brookfield, Illinois.

Leonard, J. W. 1949. The Michigan Grayling. Michigan Conservation, Lansing, Michigan.

Liknes, G. A., and W. R. Gould. 1987. The distribution, habitat and population characteristics of fluvial Arctic Grayling (Thymallus arcticus) in Montana. Northwest Science 61:122-129. 
Lund, J. A. 1974. The reproduction of salmonids in the inlets of Elk Lake, Montana. Master's Thesis, Montana State University, Bozeman, Montana

Magee, J. P., and A. R. McCullough. 2008. Big Hole River Arctic Grayling recovery project: annual monitoring report 2007. Montana Fish Wildlife and Parks, Bozeman Montana.

Manlik, O., J. A. McDonald, J. Mann, H. C. Raudino, L. Bejder, M. Krutzen, R. C. Connor, M. R. Heithaus, R. C. Lacy, and W. B. Sherwin. 2016. The relative importance of reproduction and survival for the conservation of two dolphin populations. Ecology and Evolution 6:3496-3512.

Mather, F. 1874. The Michigan Grayling and its habitat. Forest and Stream 2:164-165.

Mather, F. 1880. A few words on fish propagation and protection. Pages 182-188 in W. B. Mershon. 1923. Recollections of my Fifty Years Hunting and Fishing. Stratford Company, Boston, Massachusetts.

Mershon, W. B. 1916. The Grayling in Michigan, why and how "the flower of fishes" was exterminated - doubtful whether any are left in the state. Forest and Stream $86: 799$.

Mershon, W. B. 1923. Recollections of My Fifty Years Hunting and Fishing. The Stratford Company, Boston, Massachusetts.

Metcalf, M. 1880. The Michigan Grayling: 1880 Essay and Letters by Martin Metcalf. Pages 135-163 in R. A. Drews editor 1961. Michigan History Volume 45. Michigan Historical Commission, Lansing, Michigan.

Mills, L. S. 2007. Conservation of Wildlife Populations Demography, Genetics, and Management. Blackwell Publishing, Malden, Massachusetts.

Mogen, J. T. 1996. Status and biology of the spawning populations of Red Rock Lakes Arctic Grayling. Master's Thesis, Montana State University, Bozeman, Montana. 
Mogensen, S., J. R. Post, and M. G. Sullivan. 2014. Vulnerability to harvest differs across climate, productivity, and diversity clines. Canadian Journal of Fisheries and Aquatic Sciences. 71:416-426.

Myers, R. A., J. A. Hutchings, and N. J. Barrowman. 1997. Why do fish stocks collapse? The example of Cod in Atlantic Canada. Ecological Applications 7:91-106.

Neyme, J. L. 2005. Environmental and evolutionary processes affecting population dynamics and life-history of Arctic Grayling in western and interior Alaska. Master's Thesis, University of Alaska Fairbanks, Fairbanks, Alaska.

Norris, L. D. 1878. The Michigan Grayling. What must be done to prevent the annihilation of this excellent food and game fish. Transactions of the Michigan Sportsman's Association. Pages 173-181 in W. B. Mershon. 1923. Recollections of my Fifty Years Hunting and Fishing. Stratford Company, Boston, Massachusetts.

Norris, T. 1879. The Michigan Grayling. Scribner's Monthly, November 1879:17-23

Northcote, T. G. 1995. Comparative biology and management of Arctic and European Grayling (Salmonidae, Thymallus). Reviews in Fish Biology and Fisheries 5:141194.

Nuhfer, A. J. 1992. Evaluation of the reintroduction of the Arctic Grayling into Michigan lakes and streams. Michigan Department of Natural Resources Fisheries Research Report, Ann Arbor, Michigan.

Power, M., and R. S. McKinley. 1997. Latitudinal variation in Lake Sturgeon size as related to the thermal opportunity for growth. Transactions of the American Fisheries Society 126:549-558. 
Purchase, C. F., and J. A. Brown. 2000. Interpopulation differences in growth rates and food conversion efficiencies of young Grand Banks and Gulf of Maine Atlantic Cod (Gadus morhua). Canadian Journal of Fisheries and Aquatic Sciences 57:2223-2229.

Rieman, B. E., and F. W. Allendorf. 2001. Effective population size and genetic conservation criteria for Bull Trout. North American Journal of Fisheries Management 21:756-764.

Saether, B. E., and O. Bakke. 2000. Avian life-history variation and contribution of demographic traits to the population growth rate. Ecology 81:642-653.

Seddon, P. J., D. P. Armstrong, and R. F. Maloney. 2007. Developing the science of reintroduction biology. Conservation Biology 21:303-312.

Sunde, L. A. 1961. Growth and reproduction of the Lake Sturgeon (Acipenser fulvescens Rafinesque) of the Nelson River in Manitoba. Master's Thesis, University of British Columbia, Vancouver, British Columbia.

Taylor, W. R. 1954. Records of Fishes in the John N. Lowe Collection from the Upper Peninsula of Michigan. Museum of Zoology, University of Michigan, Ann Arbor, MI.

Vincent, R. E. 1962. Biogeographical and Ecological Factors Contributing to the Decline of Grayling, Thymallus arcticus Pallas, in Michigan and Montana. Doctoral Dissertation, The University of Michigan, Ann Arbor, Michigan.

Walker, J. 2005. Alberta wildlife status report No. 57. Status of the Arctic Grayling (Thymallus arcticus) in Alberta. Alberta Sustainable Resource Development, Fish and Wildlife Division, and Alberta Conservation Association, Edmonton, Canada.

Wiedmann, M. A., R. Primicerio, A. Dolgov, C. A. M. Ottesen, and M. Aschan. 2014. Life history variation in Barents Sea fish: implications for sensitivity to fishing in a changing environment. Ecology and Evolution 4:3596-3611. 
Winemiller, K. O., and K. A. Rose. 1992. Patterns of life-history diversification in North American fishes: implications for population regulation. Canadian Journal of Fisheries and Aquatic Sciences 49:2196-2218.

Wood, D. J. A., J. L. Koprowski, and P. W. W. Lurz. 2007. Tree squirrel introduction: a theoretical approach with population viability analysis. Journal of Mammalogy 88:1271-1279.

Worthington, T., P. Kemp, and P. E. Osborne. 2011. Factors affecting the population viability of the Burbot, Lota lota. Fisheries Management and Ecology 18:322332. 
Table 4.1. Lefkovitch matrix for Big Manistee River Arctic Grayling PVA. $S P_{F r y-A g e-1}$ represents survival probability during the fry to age-1 stage, $S P_{A}$ represents survival probability during the adult stage, $P F O_{A}$ represents proportion of adult females successfully producing offspring, $E g g s / Q_{A}$ represents the number of eggs produced per adult female, and $P_{E g g-F r y}$ represents the probability of survival from egg to swim-up fry stage.

\begin{tabular}{ccccccc}
\hline Fry to & Age-1 & Age-2 & Age-3 & Age-4 & Age-5 & Age-6 \\
Age-1 & & & & &
\end{tabular}

\begin{tabular}{|c|c|c|c|c|c|c|c|}
\hline $\begin{array}{l}\text { Fry to } \\
\text { Age-1 }\end{array}$ & 0 & 0 & $\begin{array}{c}P F O_{A} E_{g g S S} /{ }_{A} \\
P_{E g g-F r y}\end{array}$ & $\begin{array}{c}P_{A} O_{A} \text { Eggs } / Q_{A} \\
P_{\text {Egg-Fry }}\end{array}$ & $\begin{array}{c}P F O_{A} \text { Eggs } /{ }_{A} \\
P_{E g g-F r y}\end{array}$ & $\begin{array}{c}P F O_{A} E_{g g g S} / P_{A} \\
P_{E g g-F r y}\end{array}$ & $\begin{array}{c}P F O_{A} \text { EggS } / O_{A} \\
P_{E g g-F r y}\end{array}$ \\
\hline Age-1 & $S P_{\text {Fry-Age-1 }}$ & & & & & & \\
\hline Age-2 & & $S P_{A}$ & & & & & \\
\hline Age-3 & & & $S P_{A}$ & & & & \\
\hline Age-4 & & & & $S P_{A}$ & & & \\
\hline Age-5 & & & & & $P_{A}$ & & \\
\hline Age-6 & & & & & & $S P_{A}$ & \\
\hline
\end{tabular}


Table 4.2. Published demographic and life history parameters for fluvial and adfluvial Arctic Grayling used to calculate population viability analysis (PVA) inputs for a simulated species reintroduction in a portion of the Big Manistee River watershed, Michigan. $\mathrm{F}=$ Fluvial, AF = Adfluvial.

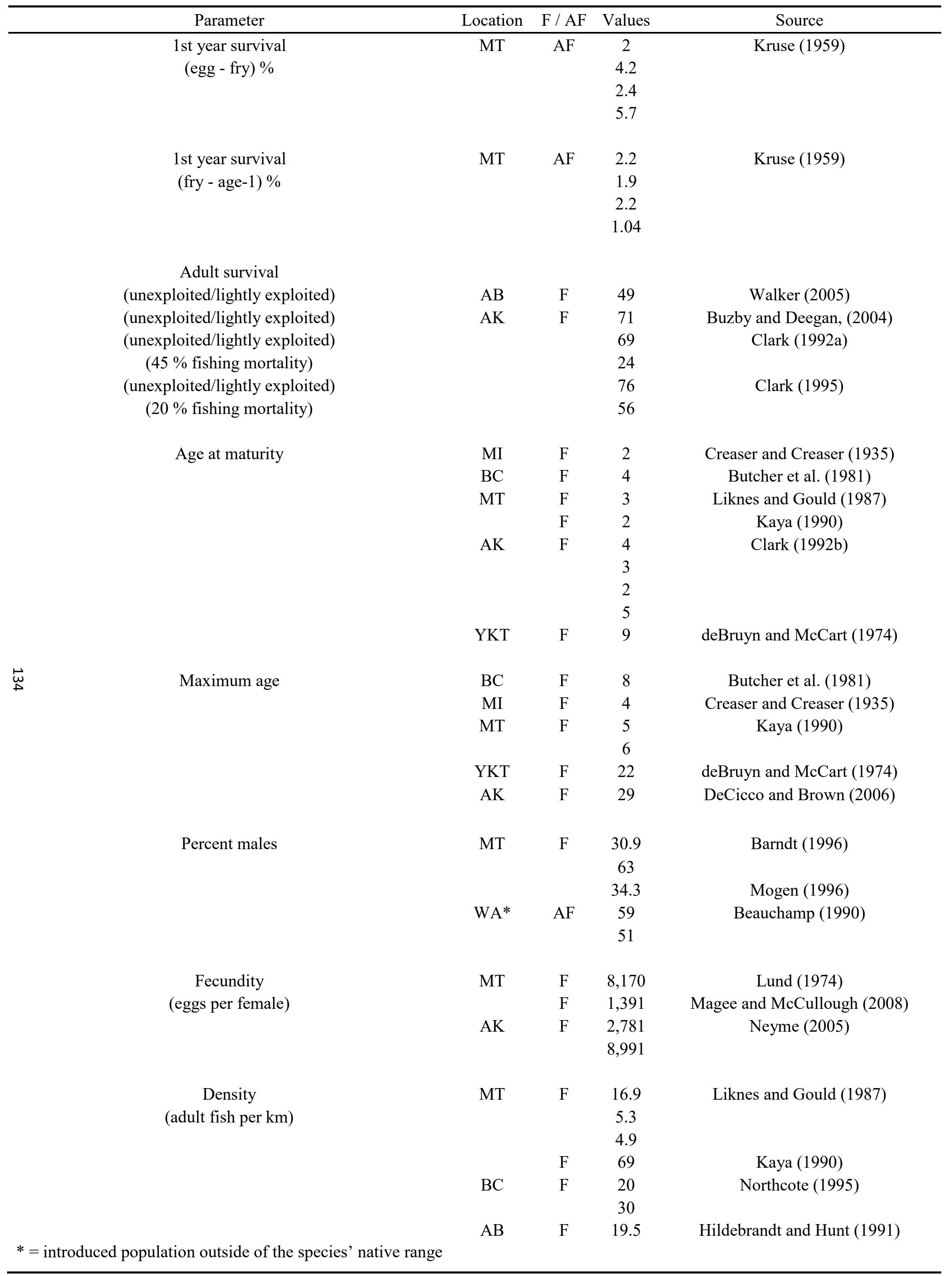


Table 4.3. Literature derived input parameters used to create 54 factorial population viability scenarios (and one additive adult harvest scenario) for a simulated Arctic Grayling reintroduction in a portion of the Big Manistee River watershed, Michigan. Coefficient of variation (CV) is shown for parameters with mean values calculated from the literature.

\begin{tabular}{|c|c|c|}
\hline Parameter & Values & $\mathrm{CV}(\%)$ \\
\hline $\begin{array}{l}\text { Juvenile survival } \\
\text { (fry - age-1) } \%\end{array}$ & $\begin{array}{c}\text { Low - } 1.3 \% \\
\text { Medium - } 1.8 \% \\
\text { High }-2.3 \%\end{array}$ & 29.9 \\
\hline Adult survival & $\begin{array}{c}\text { Low }-54.3 \% \\
\text { Medium }-66.2 \% \\
\text { High }-78.1 \% \\
+45 \% \text { harvest mortality - } 24.0 \%\end{array}$ & 17.9 \\
\hline Age at maturity & 2 years & 52.0 \\
\hline Maximum age & 6 years & 68.0 \\
\hline Percent males & $47 \%$ & 30.3 \\
\hline $\begin{array}{l}\text { Fecundity (offspring per female) } \\
\text { *includes egg survival }\end{array}$ & $\begin{array}{c}\text { Low - } 54 \\
\text { Medium - } 191 \\
\text { High - } 328\end{array}$ & 71.3 \\
\hline $\begin{array}{l}\text { Proportion of females } \\
\text { producing offspring }\end{array}$ & $\begin{array}{l}\text { Low }-50 \% \\
\text { High }-100 \%\end{array}$ & -- \\
\hline $\begin{array}{l}\text { Carrying capacity (ages } 2+\text { ) } \\
*=\mathrm{CV} \text { for population densities } \mathrm{r}\end{array}$ & $\begin{array}{r}7,503 \\
\text { ported in Table 2. }\end{array}$ & $92.3 *$ \\
\hline
\end{tabular}


Table 4.4. Survival probabilities for 54 factorial population viability simulations of a re-introduced Arctic Grayling population in the Big Manistee River, Michigan (refer to Table 3 for parameter descriptions).

\begin{tabular}{|c|c|c|c|c|c|c|}
\hline \multirow{2}{*}{$\begin{array}{l}\text { Juvenile } \\
\text { Survival }\end{array}$} & \multirow{2}{*}{$\begin{array}{l}\text { Adult } \\
\text { Survival }\end{array}$} & \multirow{2}{*}{$\begin{array}{l}\text { Proportion of females } \\
\text { producing offspring }\end{array}$} & & \multicolumn{3}{|c|}{ Fecundity } \\
\hline & & & & Low & Medium & High \\
\hline \multirow{6}{*}{ Low } & Low & Low & & 0 & 0 & 89 \\
\hline & & High & & 0 & 99 & 100 \\
\hline & Medium & Low & Survival Probability & 0 & 75 & 100 \\
\hline & & High & $(\%)$ & 0 & 100 & 100 \\
\hline & High & Low & & 0 & 100 & 100 \\
\hline & & High & & 20 & 100 & 100 \\
\hline \multirow[t]{6}{*}{ Medium } & Low & Low & & 0 & 39 & 100 \\
\hline & & High & & 0 & 100 & 100 \\
\hline & Medium & Low & Survival Probability & 0 & 100 & 100 \\
\hline & & High & (\%) & 2 & 100 & 100 \\
\hline & High & Low & & 0 & 100 & 100 \\
\hline & & High & & 100 & 100 & 100 \\
\hline \multirow[t]{6}{*}{ High } & Low & Low & & 0 & 99 & 100 \\
\hline & & High & & 0 & 100 & 100 \\
\hline & Medium & Low & Survival Probability & 0 & 100 & 100 \\
\hline & & High & $(\%)$ & 94 & 100 & 100 \\
\hline & High & Low & & 2 & 100 & 100 \\
\hline & & High & & 100 & 100 & 100 \\
\hline
\end{tabular}




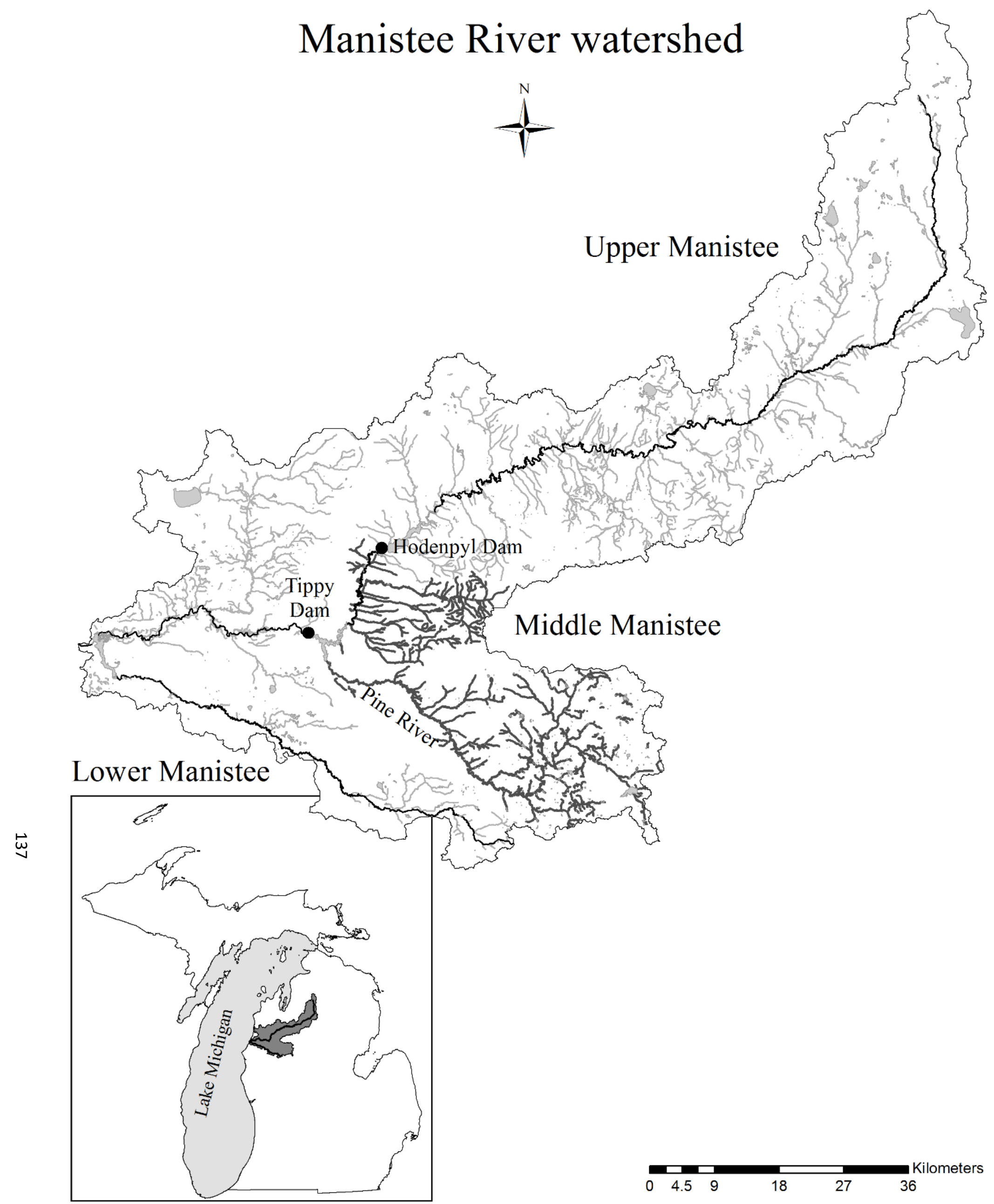

Figure 4.1. Location of Big Manistee River watershed in the State of Michigan (Inset) and connected stream habitat in the 2011-2013 Middle Manistee study area (dark gray stream lines). Streams in the Upper and Lower Manistee segments are shown in light gray. 


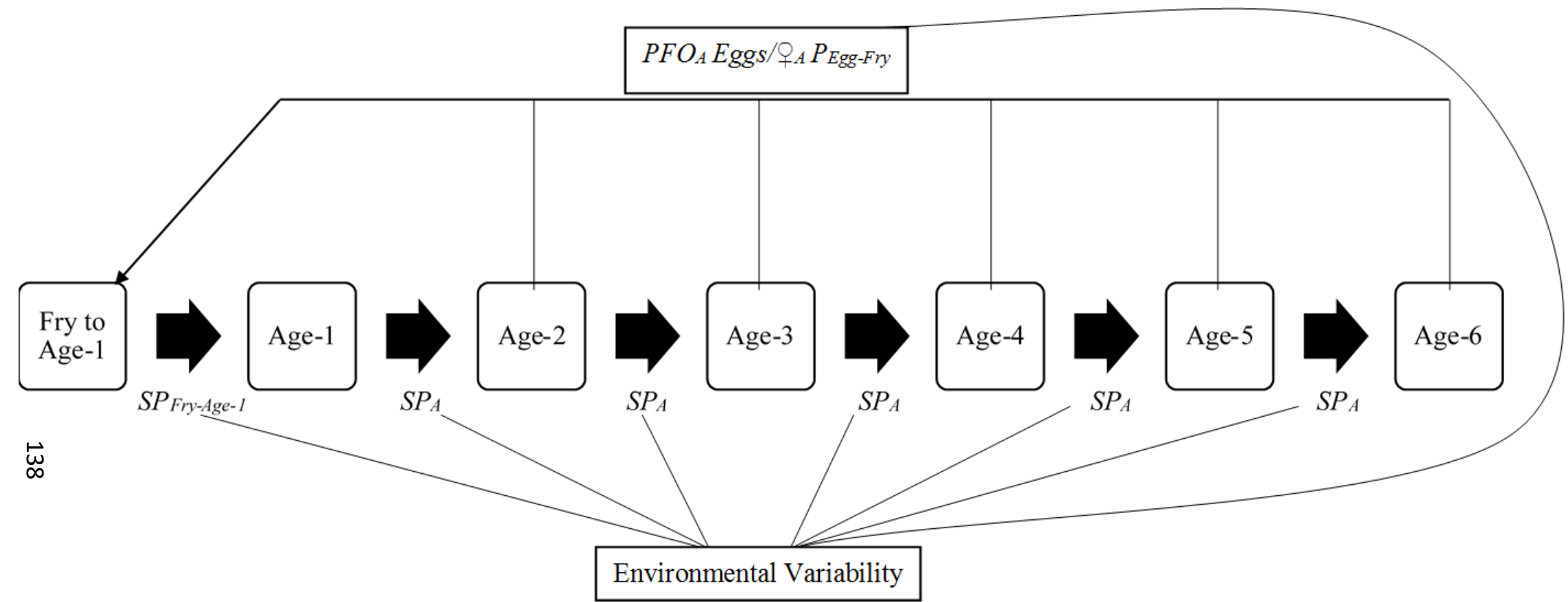

Figure 4.2. Life cycle diagram for Big Manistee River Arctic Grayling PVA. $S P_{F r y-A g e-I}$ represents survival probability during the fry to age-1 stage, $S P_{A}$ represents survival probability during the adult stage, $P F O_{A}$ represents proportion of adult females successfully producing offspring, $E g g S /{ }_{A}$ represents the number of eggs produced per adult female, $P_{\text {Egg-Fry }}$ represents the probability of survival from egg to swim-up fry stage, and EV represents environmental variation. 


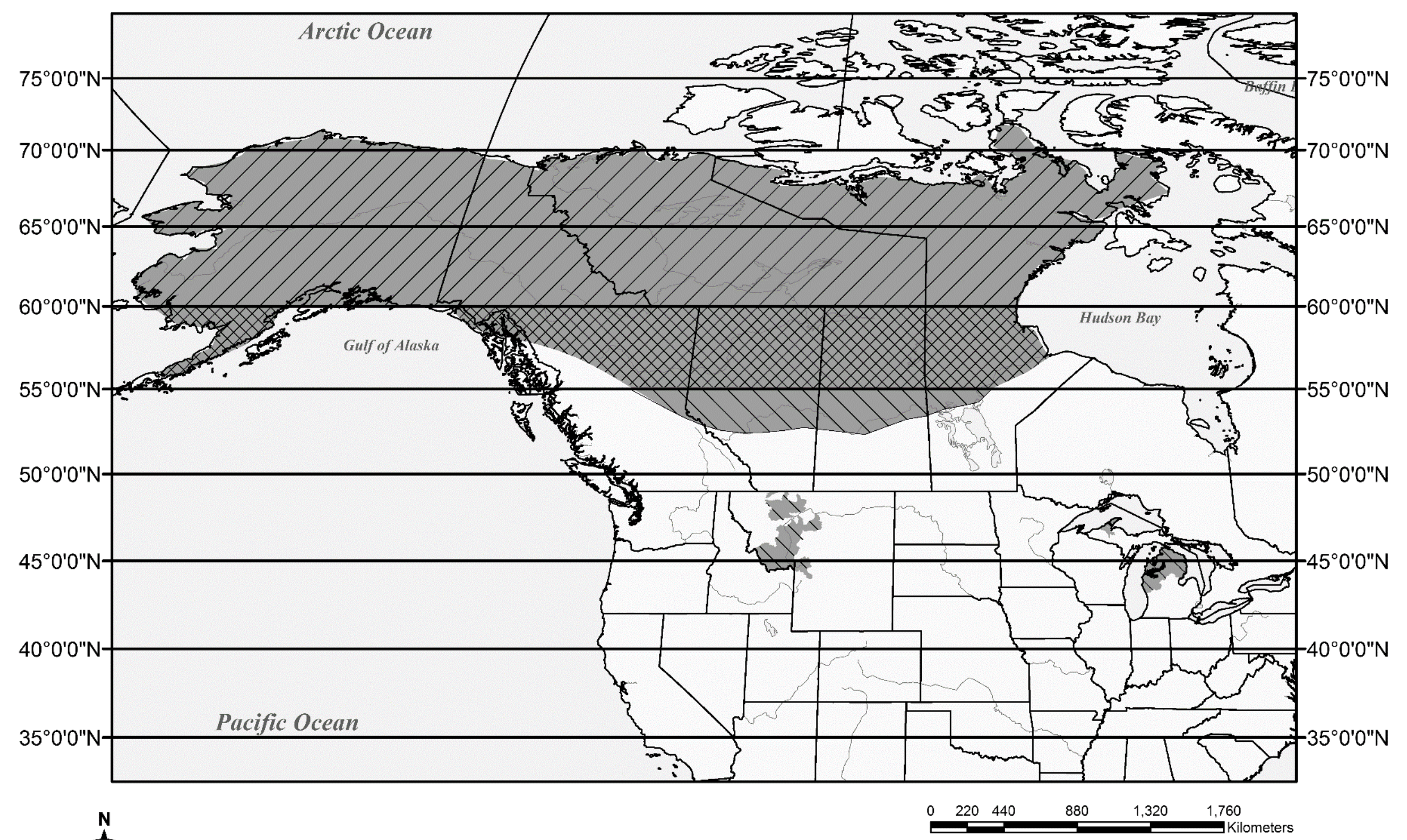

Coordinate System: World Robinson Central Meridian: $100^{\circ} 0^{\prime} 0^{\prime \prime} \mathrm{W}$

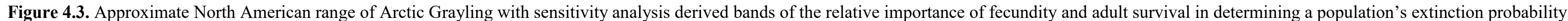
Left diagonal lines indicate greatest sensitivity to changes in fecundity, cross-hatch indicates approximately equal sensitivity to changes in fecundity and adult mortality, and right diagonal lines indicate greatest sensitivity to changes in adult survival. 


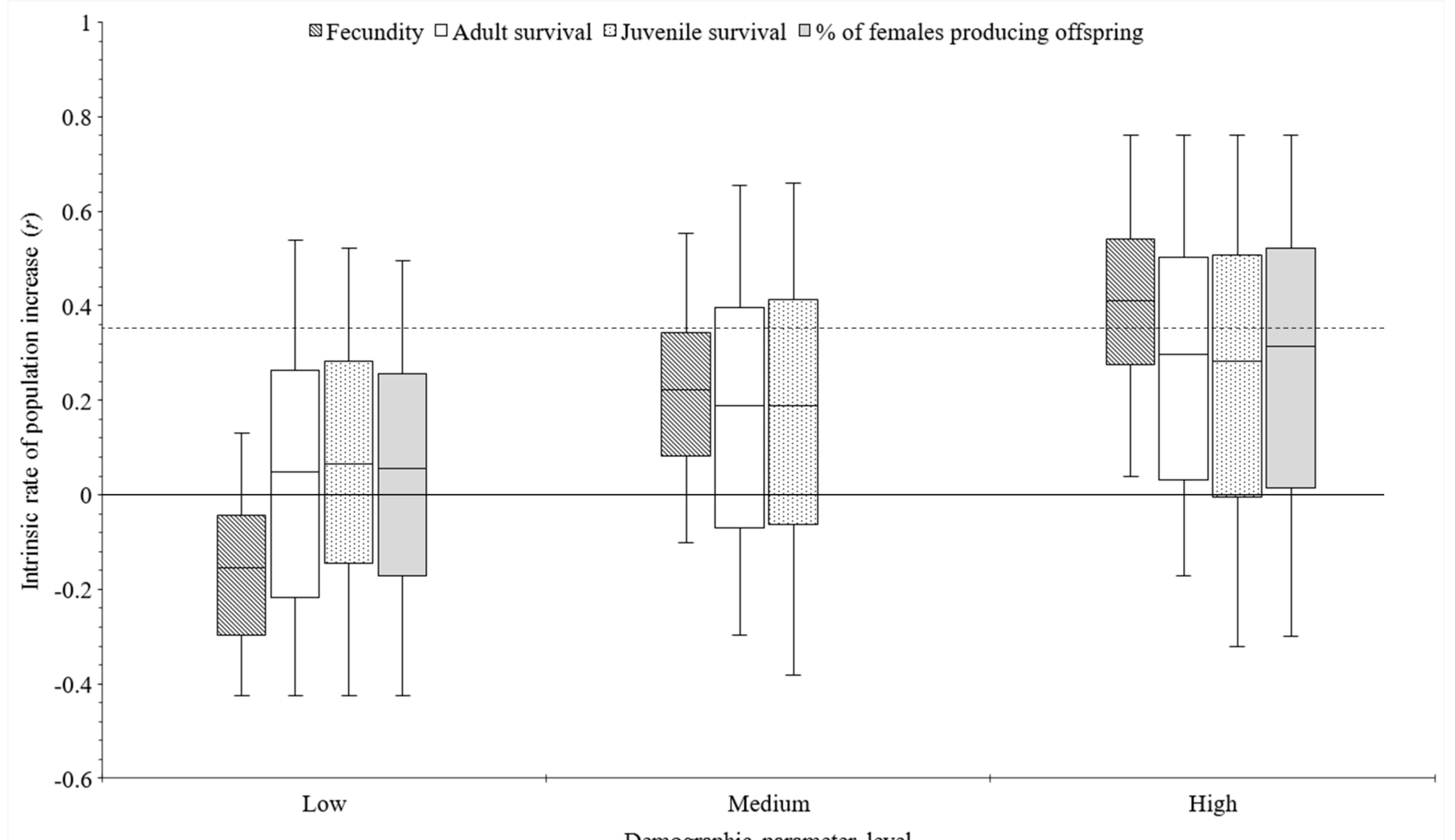

Demographic parameter level

Figure 4.4. Intrinsic rates of population increase $(r)$ for simulated Arctic Grayling populations with varied demographic parameters in a portion of the Big Manistee River watershed, Michigan. The four parameters tested were: fecundity, adult (age $2^{+}$) survival, fry to age-1 survival, and the proportion of females producing offspring each year. See Table 3 for values corresponding with "Low", "Medium", and "High" parameter levels. Dashed horizontal line represents $r=0.352$ in the baseline scenario, solid horizontal line represents $r=0$. 

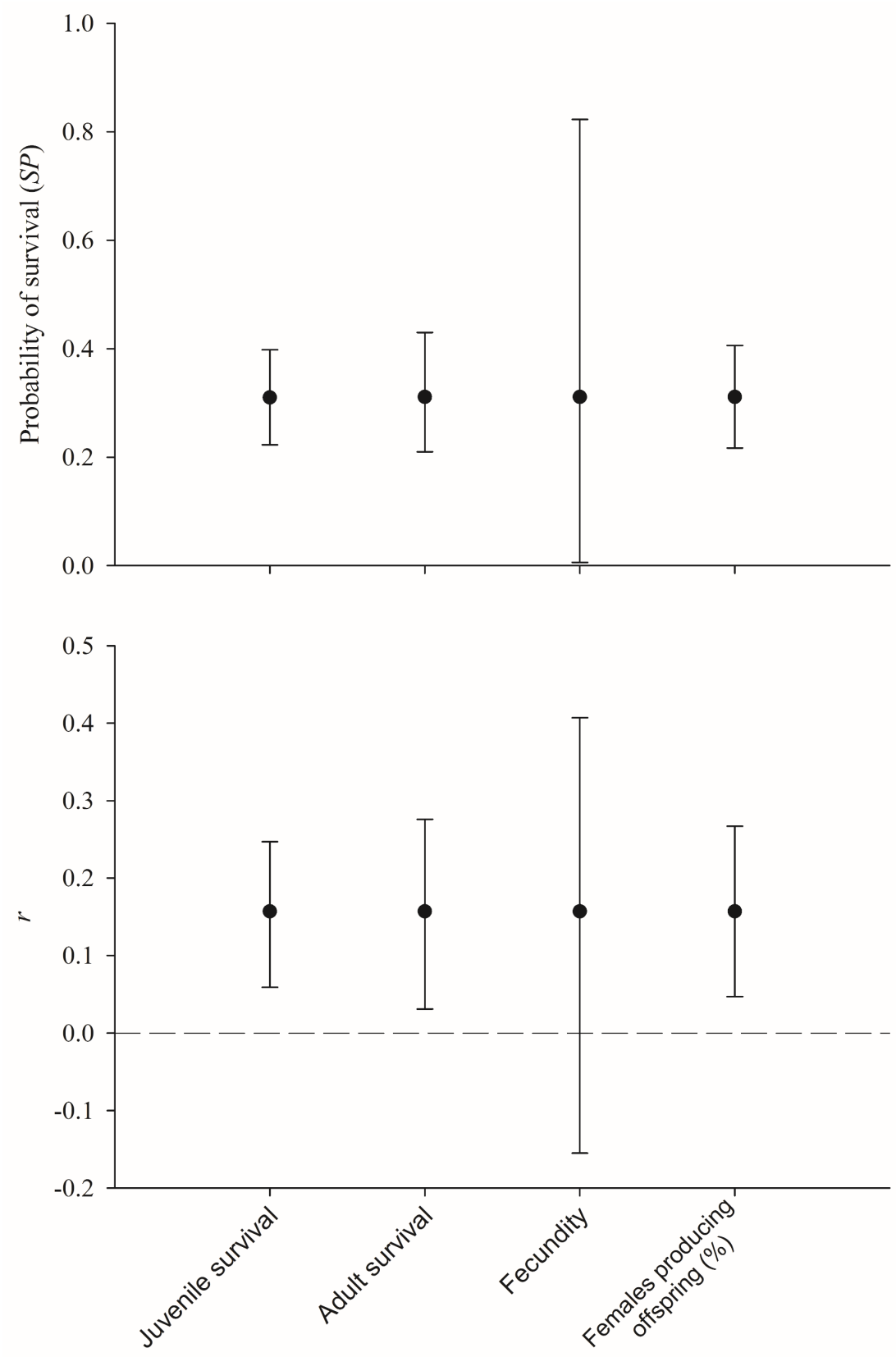

Life history parameter

Figure 4.5. Sensitivity plot of minimum and maximum probability of survival (SP; panel A) and intrinsic population growth rate ( $r$; panel B) for 54 factorial simulation scenarios. Black circles indicate mean SP and $r$ across all scenarios, vertical lines indicate the relative impact of each life history parameter on SP and $r$, and horizontal dashed line indicates zero population growth (above the line $=$ a growing population, below the line $=$ a declining population). 


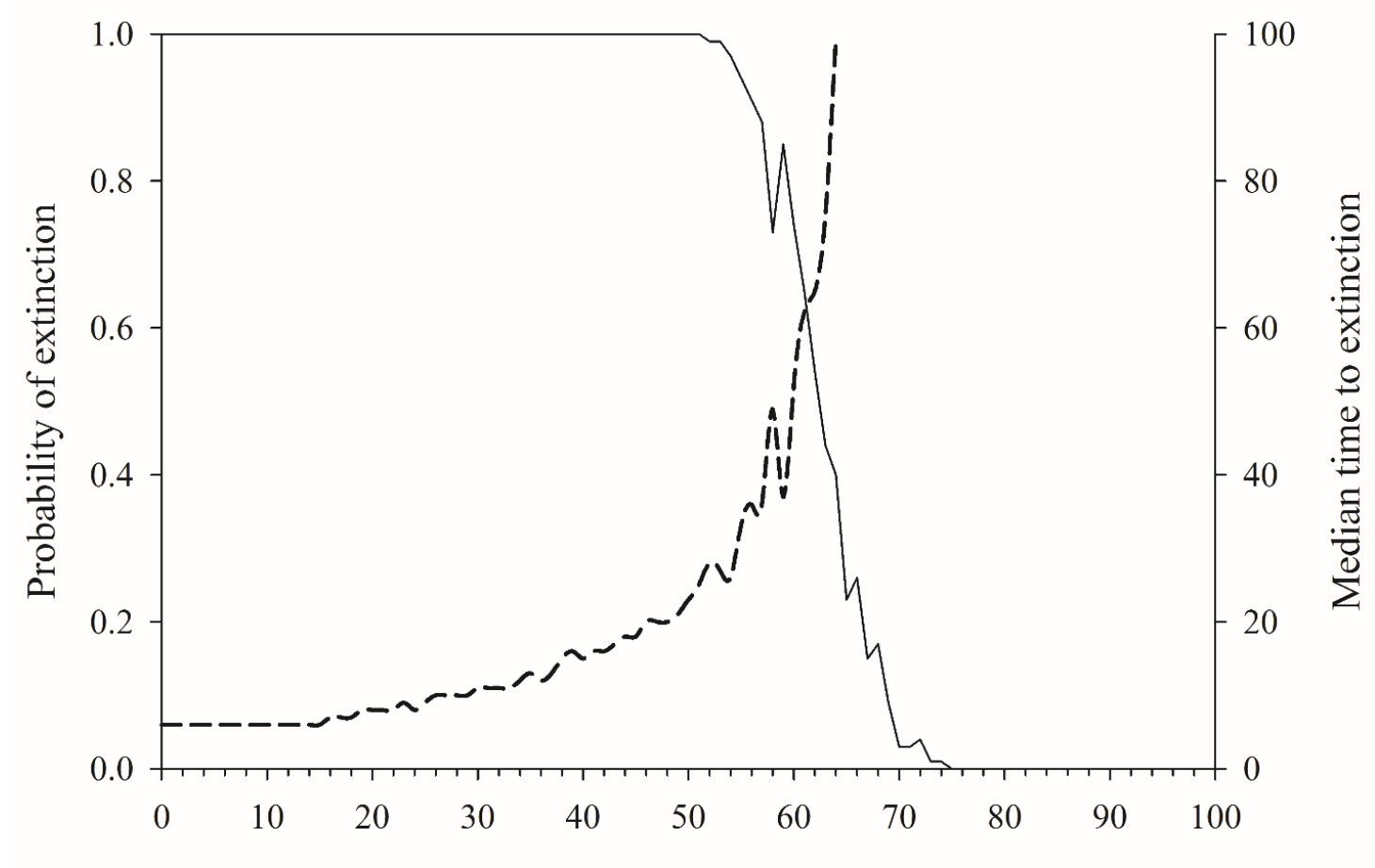

Fecundity (\# offspring / female)

Figure 4.6. Extinction probability (solid line) and median time to extinction (dashed line) over a range of "Low" fecundity values for a simulated reintroduced Arctic Grayling population in a portion of the Big Manistee River watershed, Michigan. Fecundity is measured as the mean number of eggs produced per female * egg to fry survival. 
○ Age at maturity $\bullet$ Maximum age

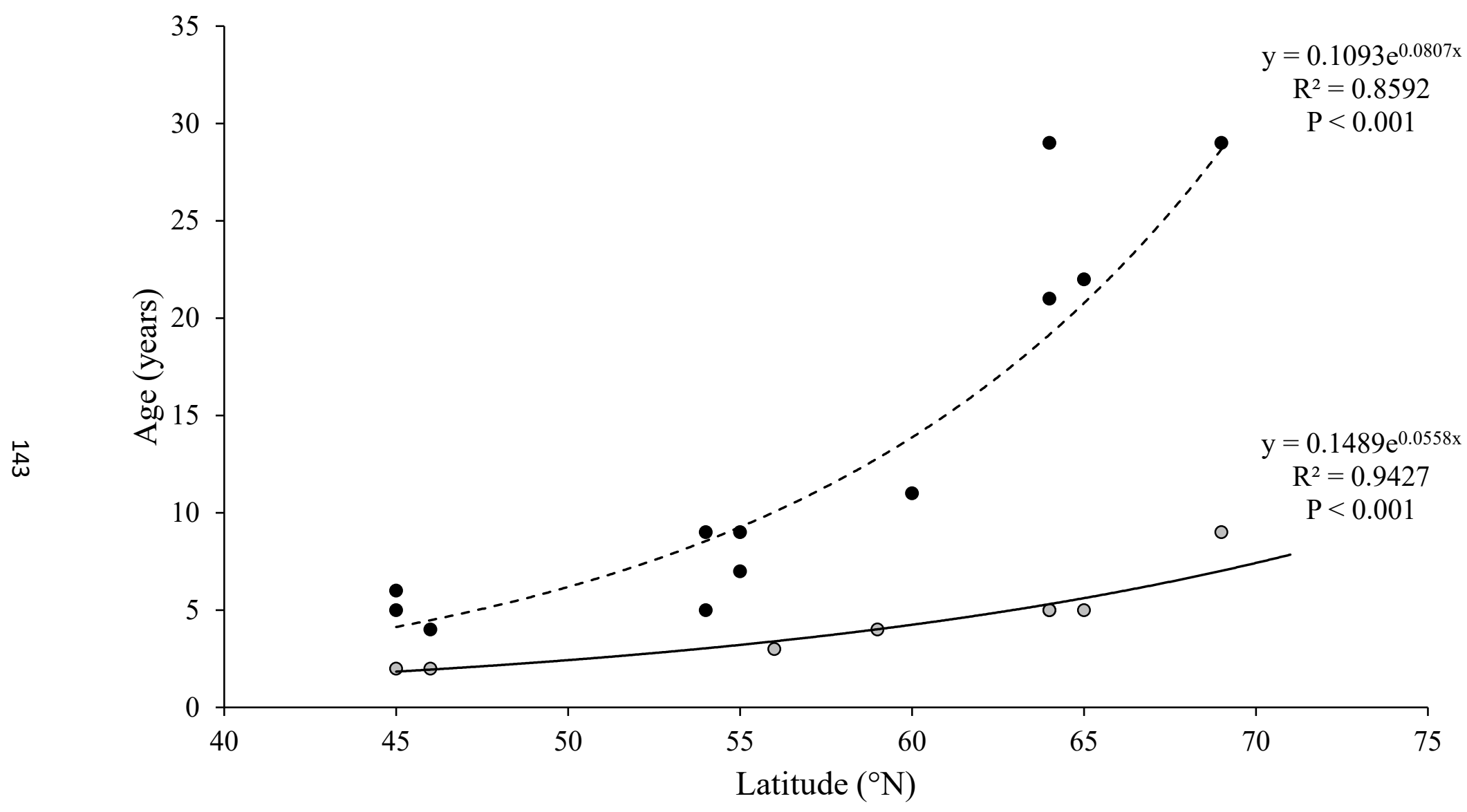

Figure 4.7. Trends in Arctic Grayling age at maturity (gray circles, solid regression line) and maximum age (black circles, dashed regression line) with increasing latitude. Data points represent values reported from across the species' North American range (see Table 2). 

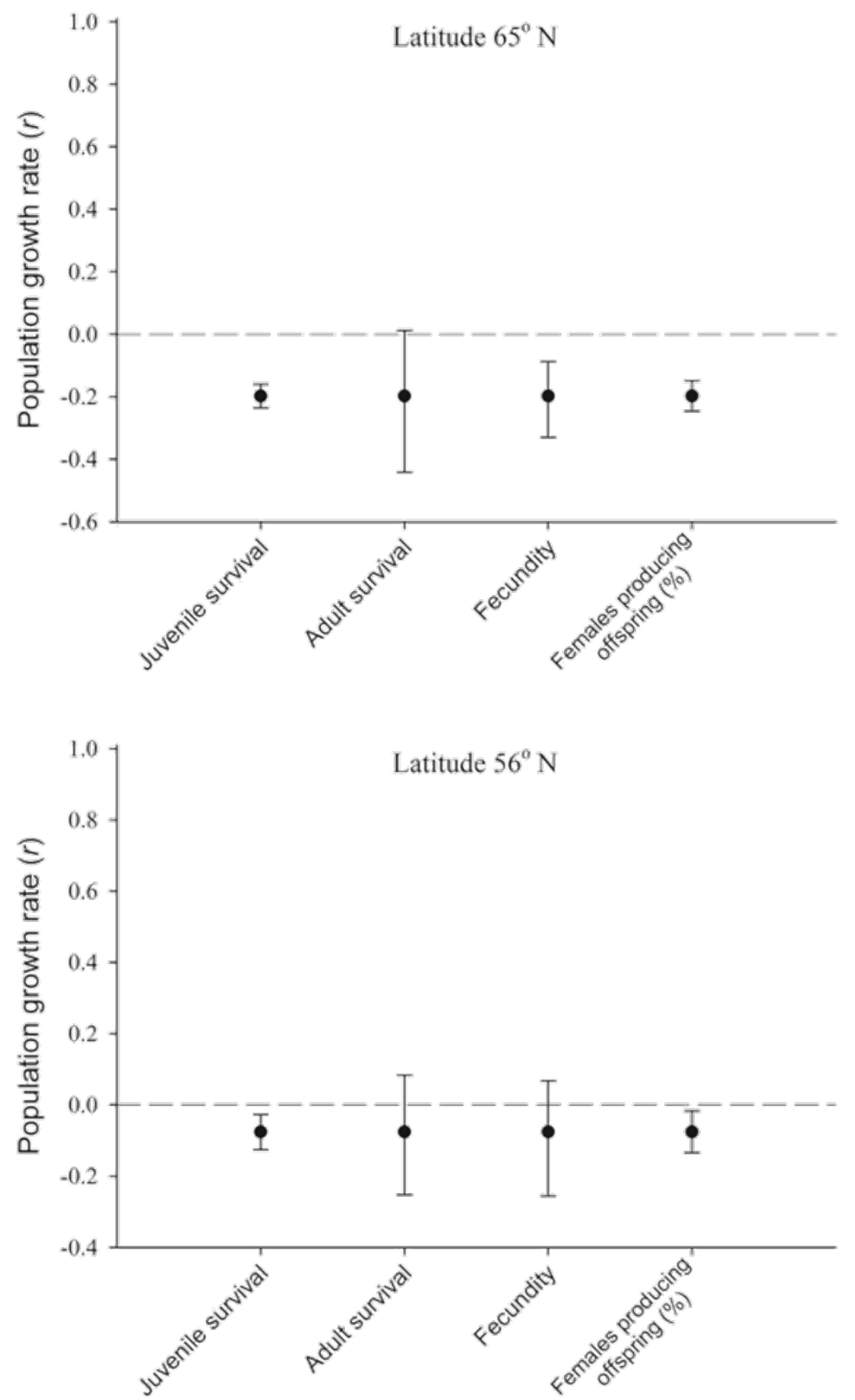

宫

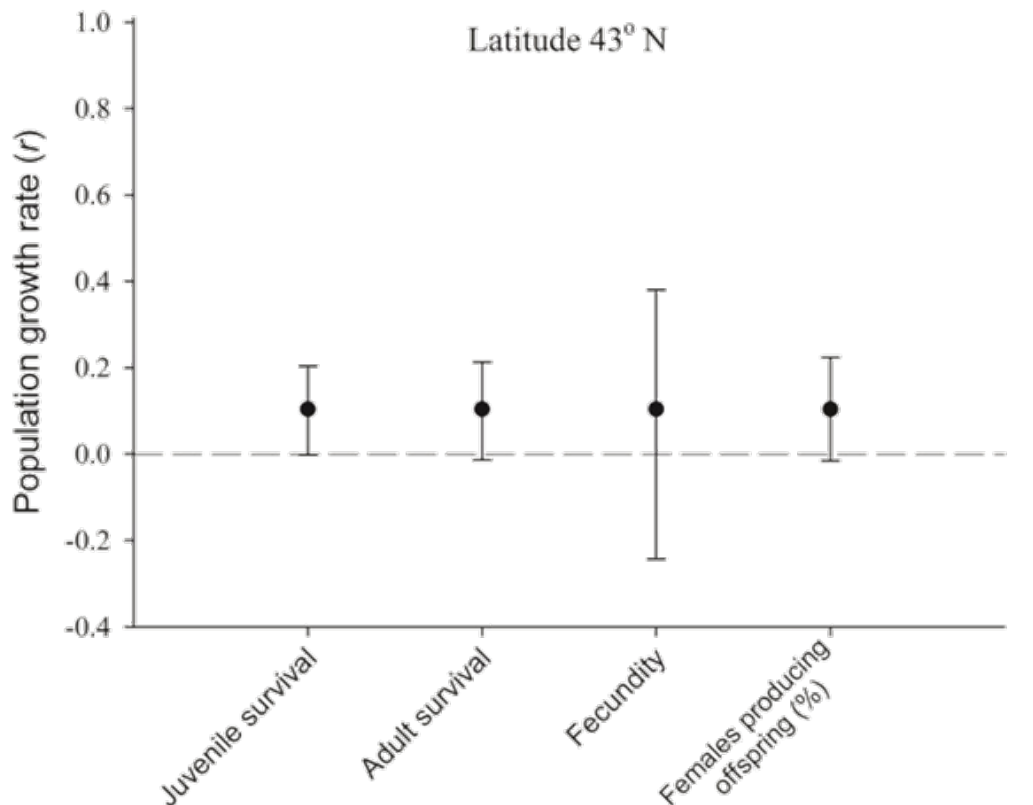

Life history parameter

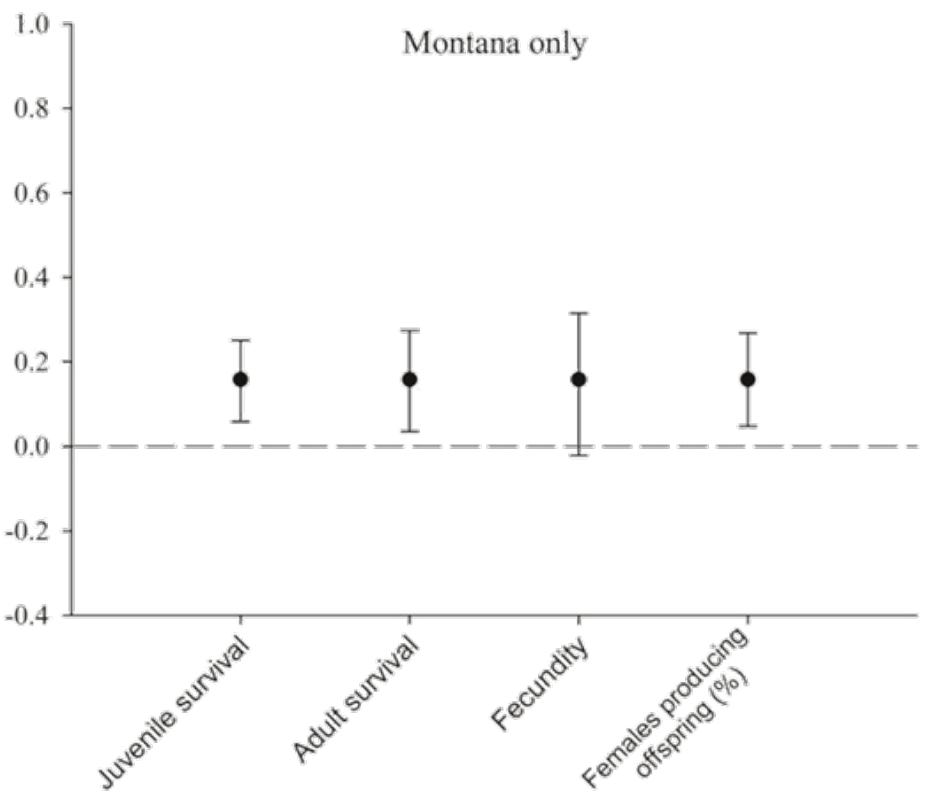

Life history parameter

Figure 4.8. Sensitivity plots of population growth rate $(r)$ across the North American latitudinal range of Arctic Grayling. Black circles indicate mean $r$ and vertical lines indicate the relative impact of each life history parameter on $r$. 
Appendix A. Fish community characteristics based on assessments conducted between June 2011 and August 2013 in 23 Big Manistee River tributary reaches.

A.1. Total numbers of fish captured during fish community assessment surveys from June 2011 - to August 2013. * indicates unidentified lamprey species (ABL, CHL, NBL, or SVL), ** indicates possibly misidentified specimen in 2011.

\begin{tabular}{lcccc}
\hline $\begin{array}{c}\text { Species Common Name } \\
\text { (Species Abbreviation) }\end{array}$ & $\mathbf{2 0 1 1}$ & $\mathbf{2 0 1 2}$ & $\mathbf{2 0 1 3}$ & Total \\
\hline & & & & \\
American Brook Lamprey (ABL) & 4 & 7 & 15 & $\mathbf{2 6}$ \\
Black Bullhead (BBH) & 1 & 14 & - & $\mathbf{1 5}$ \\
Brook Trout (BKT) & 562 & 1982 & 159 & $\mathbf{2 7 0 3}$ \\
Bluegill (BLG) & - & 2 & - & $\mathbf{2}$ \\
Blacknose Dace (BND) & 16 & 95 & - & $\mathbf{1 1 1}$ \\
Brown Trout (BKT) & 985 & 3836 & 1090 & $\mathbf{5 9 1 1}$ \\
Brook Stickleback (BRS) & 3 & 11 & 1 & $\mathbf{1 5}$ \\
Blackside Darter (BSD) & 4 & 31 & 68 & $\mathbf{1 0 3}$ \\
Chestnut Lamprey (CHL) & 8 & 51 & 18 & $\mathbf{7 7}$ \\
Central Mudminnow (CMM) & 4 & - & - & $\mathbf{4}$ \\
Creek Chub (CRC) & 6 & 13 & - & $\mathbf{1 9}$ \\
Fathead Minnow (FHM) & - & 2 & - & $\mathbf{2}$ \\
Johnny Darter (JOD) & 7 & 21 & 2 & $\mathbf{3 0}$ \\
* Lamprey Species (LAY) & - & 21 & 7 & $\mathbf{2 8}$ \\
Longnose Dace (LND) & - & 5 & 1 & $\mathbf{6}$ \\
Northern Brook Lamprey (NBL) & 5 & 3 & - & $\mathbf{8}$ \\
Northern Redbelly Dace (NRD) & 1 & 5 & 1 & $\mathbf{7}$ \\
Pumpkinseed Sunfish (PKS) & - & 1 & - & $\mathbf{1}$ \\
Rainbow Trout (RBT) & 20 & 62 & 301 & $\mathbf{3 8 3}$ \\
** Redear Sunfish (RES) & 1 & - & - & $\mathbf{1}$ \\
Slimy Sculpin (SLS) & 894 & 3915 & 214 & $\mathbf{5 0 2 3}$ \\
Smallmouth Bass (SMB) & - & 1 & - & $\mathbf{1}$ \\
Silver Lamprey (SVL) & 1 & 8 & 2 & $\mathbf{1 1}$ \\
White Sucker (WHS) & 3 & 4 & - & $\mathbf{7}$ \\
& & & & \\
Total & $\mathbf{2 5 2 5}$ & $\mathbf{1 0 0 9 0}$ & $\mathbf{1 8 7 9}$ & $\mathbf{1 4 4 9 4}$ \\
\hline & & & &
\end{tabular}


A.2. Summary fisheries statistics for Arquilla Creek Lower. Four surveys were conducted between July 27, 2011 and August 9, 2012.

\begin{tabular}{lccc}
\hline Species & Count & Mean Length $(\mathrm{mm})$ & Mean Weight $(\mathrm{g})$ \\
\hline Black Bullhead & 5 & $134( \pm 13)$ & $31.2( \pm 3.5)$ \\
Brook Trout & 22 & $95( \pm 39)$ & $13.3( \pm 15.7)$ \\
Brown Trout & 206 & $147( \pm 63)$ & $46.5( \pm 53.3)$ \\
Blackside Darter & 2 & $67( \pm 2)$ & 2.9 \\
Chestnut Lamprey & 9 & $139( \pm 24)$ & $7.5( \pm 1.5)$ \\
Johnny Darter & 12 & $53( \pm 4)$ & $1.5( \pm 0.4)$ \\
Lamprey species & 1 & 102 & 1.7 \\
Northern Brook Lamprey & 1 & 143 & 4.2 \\
Rainbow Trout & 3 & $218( \pm 6)$ & $92.8( \pm 3.7)$ \\
Slimy Sculpin & 99 & $66( \pm 14)$ & $4.7( \pm 2.7)$ \\
Silver Lamprey & 1 & 142 & NA \\
\hline
\end{tabular}

A.3. Summary fisheries statistics for Arquilla Creek Middle. Four surveys were conducted between July 27, 2011 and August 14, 2012.

\begin{tabular}{lccc}
\hline Species & Count & Mean Length $(\mathrm{mm})$ & Mean Weight $(\mathrm{g})$ \\
\hline Brook Trout & 60 & $101( \pm 43)$ & $15.2( \pm 18.8)$ \\
Brown Trout & 366 & $135( \pm 69)$ & $41.9( \pm 50.2)$ \\
Chestnut Lamprey & 3 & $126( \pm 36)$ & $4.8( \pm 5.3)$ \\
Slimy Sculpin & 416 & $60( \pm 14)$ & 9.6 \\
\hline
\end{tabular}

A.4. Summary fisheries statistics for Arquilla Creek Upper. Four surveys were conducted between August 2, 2011 and August 14, 2012.

\begin{tabular}{lccc}
\hline Species & Count & Mean Length $(\mathrm{mm})$ & Mean Weight $(\mathrm{g})$ \\
\hline Brook Trout & 348 & $99( \pm 42)$ & $12.6( \pm 18.4)$ \\
Brown Trout & 274 & $117( \pm 67)$ & $30.9( \pm 46.3)$ \\
Slimy Sculpin & 301 & $60( \pm 19)$ & 6.6 \\
\hline
\end{tabular}


A.5. Summary fisheries statistics for Cedar Creek Lower. Four surveys were conducted between July 25, 2011 and August 15, 2012.

\begin{tabular}{lccc}
\hline Species & Count & Mean Length $(\mathrm{mm})$ & Mean Weight $(\mathrm{g})$ \\
\hline Brook Trout & 105 & $92( \pm 48)$ & $15.4( \pm 27.1)$ \\
Brown Trout & 30 & $142( \pm 56)$ & $36.1( \pm 32.8)$ \\
Chestnut Lamprey & 1 & NA & NA \\
Rainbow Trout & 1 & 36 & 0.4 \\
Slimy Sculpin & 80 & $64( \pm 10)$ & $3.5( \pm 1.9)$ \\
\hline
\end{tabular}

A.6. Summary fisheries statistics for Cedar Creek Middle. Four surveys were conducted between July 25, 2011 and August 15, 2012.

\begin{tabular}{lccc}
\hline Species & Count & Mean Length $(\mathrm{mm})$ & Mean Weight $(\mathrm{g})$ \\
\hline Brook Trout & 651 & $108( \pm 33)$ & $15.9( \pm 14.4)$ \\
Slimy Sculpin & 218 & $55( \pm 14)$ & 3.9 \\
\hline
\end{tabular}

A.7. Summary fisheries statistics for Cedar Creek Upper. Four surveys were conducted between July 25, 2011 and August 15, 2012.

\begin{tabular}{lccc}
\hline Species & Count & Mean Length $(\mathrm{mm})$ & Mean Weight $(\mathrm{g})$ \\
\hline Brook Trout & 345 & $98( \pm 35)$ & $12.5( \pm 11.2)$ \\
Slimy Sculpin & 148 & $60( \pm 14)$ & 3.7 \\
\hline
\end{tabular}


A.8. Summary fisheries statistics for Eddington Creek Lower. Four surveys were conducted between July 6, 2011 and August 6, 2012.

\begin{tabular}{lccc}
\hline Species & Count & Mean Length $(\mathrm{mm})$ & Mean Weight $(\mathrm{g})$ \\
\hline Brook Trout & 137 & $89( \pm 43)$ & $12.9( \pm 17.1)$ \\
Brown Trout & 26 & $113( \pm 38)$ & $18.7( \pm 14.8)$ \\
Central Mudminnow & 4 & $72( \pm 5)$ & $4.1( \pm 0.6)$ \\
Northern Redbelly Dace & 2 & $53( \pm 6)$ & $1.4( \pm 0.4)$ \\
Rainbow Trout & 3 & $173( \pm 28)$ & $62.3( \pm 29.1)$ \\
Slimy Sculpin & 282 & $62( \pm 16)$ & 6.2 \\
\hline
\end{tabular}

A.9. Summary fisheries statistics for Eddington Creek Middle. Four surveys were conducted between July 6, 2011 and August 6, 2012.

\begin{tabular}{lccc}
\hline Species & Count & Mean Length $(\mathrm{mm})$ & Mean Weight $(\mathrm{g})$ \\
\hline Brook Trout & 108 & $117( \pm 47)$ & $23.8( \pm 19.8)$ \\
Brown Trout & 13 & $139( \pm 20)$ & $27.9( \pm 14.8)$ \\
Rainbow Trout & 3 & $167( \pm 15)$ & $48.1( \pm 12.3)$ \\
Slimy Sculpin & 106 & $59( \pm 15)$ & 5.1 \\
\hline
\end{tabular}

A.10. Summary fisheries statistics for Eddington Creek Upper. Four surveys were conducted between July 6, 2011 and August 6, 2012.

\begin{tabular}{lccc}
\hline Species & Count & Mean Length $(\mathrm{mm})$ & Mean Weight $(\mathrm{g})$ \\
\hline Brook Trout & 211 & $99( \pm 37)$ & $13.6( \pm 12.8)$ \\
Brown Trout & 1 & 133 & 23.1 \\
Slimy Sculpin & 63 & $68( \pm 15)$ & 6.2 \\
\hline
\end{tabular}


A.11. Summary fisheries statistics for Hinton Creek Lower. Eight surveys were conducted between July 13, 2011 and August 12, 2013.

\begin{tabular}{lccc}
\hline Species & Count & Mean Length $(\mathrm{mm})$ & Mean Weight $(\mathrm{g})$ \\
\hline American Brook Lamprey & 20 & $138( \pm 10)$ & $4.8( \pm 1.0)$ \\
Black Bullhead & 6 & $100( \pm 24)$ & $16.4( \pm 9.9)$ \\
Brook Trout & 98 & $76( \pm 38)$ & $8.4( \pm 20.9)$ \\
Brown Trout & 396 & $131( \pm 57)$ & $34.9( \pm 43.0)$ \\
Blackside Darter & 101 & $57( \pm 6)$ & $1.6( \pm 0.7)$ \\
Chestnut Lamprey & 35 & $126( \pm 14)$ & $4.0( \pm 1.5)$ \\
Johnny Darter & 3 & $48( \pm 2)$ & $1.5( \pm 0.3)$ \\
Lamprey species & 8 & $141( \pm 14)$ & $4.2( \pm 1.0)$ \\
Longnose Dace & 1 & 45 & 0.4 \\
Northern Brook Lamprey & 1 & 135 & 6.7 \\
Rainbow Trout & 4 & $166( \pm 28)$ & $44.4( \pm 20.9)$ \\
Slimy Sculpin & 262 & $65( \pm 14)$ & 4.6 \\
Silver Lamprey & 4 & $114( \pm 17)$ & $2.9( \pm 1.0)$ \\
\hline
\end{tabular}

A.12. Summary fisheries statistics for Hinton Creek Middle. Eight surveys were conducted between July 13, 2011 and August 16, 2013.

\begin{tabular}{lccc}
\hline Species & Count & Mean Length $(\mathrm{mm})$ & Mean Weight $(\mathrm{g})$ \\
\hline Brook Trout & 104 & $137( \pm 39)$ & $29.9( \pm 23.9)$ \\
Bluegill & 1 & 72 & 6.3 \\
Brown Trout & 441 & $141( \pm 52)$ & $38.2( \pm 41.2)$ \\
Pumpkinseed & 1 & 57 & 2.9 \\
Redear Sunfish* & 1 & 47 & 1.9 \\
Slimy Sculpin & 64 & $80( \pm 16)$ & $7.2( \pm 3.8)$ \\
Smallmouth Bass & 1 & 40 & 1 \\
\hline
\end{tabular}

A.13. Summary fisheries statistics for Hinton Creek Upper. Eight surveys were conducted between July 13, 2011 and August 15, 2013.

\begin{tabular}{lccc}
\hline Species & Count & Mean Length $(\mathrm{mm})$ & Mean Weight $(\mathrm{g})$ \\
\hline Brook Trout & 132 & $117( \pm 46)$ & $22.5( \pm 22.0)$ \\
Brown Trout & 440 & $105( \pm 55)$ & $23.5( \pm 72.5)$ \\
Chestnut Lamprey & 1 & 149 & 6.3 \\
\hline
\end{tabular}


A.14. Summary fisheries statistics for Peterson Creek Lower. Four surveys were conducted between July 26, 2011 and August 14, 2012.

\begin{tabular}{lccc}
\hline Species & Count & Mean Length $(\mathrm{mm})$ & Mean Weight $(\mathrm{g})$ \\
\hline American Brook Lamprey & 1 & 112 & 3.4 \\
Brook Trout & 9 & $168( \pm 50)$ & $52.1( \pm 32.4)$ \\
Brown Trout & 86 & $161( \pm 72)$ & $58.5( \pm 56.0)$ \\
Creek Chub & 1 & 50 & 1.3 \\
Slimy Sculpin & 110 & $65( \pm 16)$ & $4.3( \pm 2.9)$ \\
\hline
\end{tabular}

A.15. Summary fisheries statistics for Peterson Creek Middle. Four surveys were conducted between July 26, 2011 and August 9, 2012.

\begin{tabular}{lccc}
\hline Species & Count & Mean Length $(\mathrm{mm})$ & Mean Weight $(\mathrm{g})$ \\
\hline American Brook Lamprey & 1 & 178 & 6.8 \\
Brook Trout & 17 & $153( \pm 54)$ & $45.3( \pm 38.9)$ \\
Brown Trout & 329 & $151( \pm 67)$ & $51.8( \pm 52.1)$ \\
Chestnut Lamprey & 2 & 50 & 1.3 \\
Lamprey species & 1 & 120 & 2.2 \\
Slimy Sculpin & 285 & $60( \pm 17)$ & 6.1 \\
\hline
\end{tabular}

A.16. Summary fisheries statistics for Peterson Creek Upper. Four surveys were conducted between July 26, 2011 and August 8, 2012.

\begin{tabular}{lccc}
\hline Species & Count & Mean Length $(\mathrm{mm})$ & Mean Weight $(\mathrm{g})$ \\
\hline Brook Trout & 38 & $140( \pm 52)$ & $38.7( \pm 28.6)$ \\
Blacknose Dace & 111 & $68( \pm 21)$ & 5.4 \\
Brown Trout & 2 & $137( \pm 92)$ & $42.1( \pm 55.1)$ \\
Creek Chub & 18 & $72( \pm 21)$ & $5.0( \pm 4.5)$ \\
Lamprey species & 16 & $121( \pm 14)$ & $2.5( \pm 1.0)$ \\
Northern Brook Lamprey & 2 & $138( \pm 1)$ & $3.9( \pm 0)$ \\
Northern Redbelly Dace & 1 & 53 & 1.4 \\
Slimy Sculpin & 235 & $74( \pm 22)$ & 9.4 \\
\hline
\end{tabular}


A.17. Summary fisheries statistics for Sand Creek Middle. Four surveys were conducted between July 13, 2011 and August 6, 2012.

\begin{tabular}{lccc}
\hline Species & Count & Mean Length $(\mathrm{mm})$ & Mean Weight $(\mathrm{g})$ \\
\hline Black Bullhead & 4 & $120( \pm 48)$ & $29.5( \pm 27.8)$ \\
Brook Trout & 108 & $99( \pm 51)$ & $17.4( \pm 21.4)$ \\
Brown Trout & 16 & $88( \pm 47)$ & $13.6( \pm 25.6)$ \\
Brook Stickleback & 5 & $44( \pm 6)$ & $0.7( \pm 0.5)$ \\
Fathead Minnow & 2 & $59( \pm 5)$ & $1.7( \pm 1.1)$ \\
Johnny Darter & 11 & $54( \pm 5)$ & $1.4( \pm 0.5)$ \\
Northern Brook Lamprey & 1 & 172 & 7 \\
Slimy Sculpin & 173 & $57( \pm 16)$ & $3.3( \pm 3.0)$ \\
White Sucker & 3 & $38( \pm 5)$ & $0.4( \pm 0.4)$ \\
\hline
\end{tabular}

A.18. Summary fisheries statistics for Sand Creek Upper. Three surveys were conducted between May 30, 2012 and August 7, 2012.

\begin{tabular}{lccc}
\hline Species & Count & Mean Length $(\mathrm{mm})$ & Mean Weight $(\mathrm{g})$ \\
\hline Brook Trout & 62 & $93( \pm 52)$ & $16.3( \pm 22.6)$ \\
Brown Trout & 3 & $146( \pm 1)$ & $30.1( \pm 1.9)$ \\
Slimy Sculpin & 215 & $54( \pm 15)$ & 3.7 \\
\hline
\end{tabular}


A.19. Summary fisheries statistics for Slagle Creek Lower. Four surveys were conducted between August 1, 2011 and August 13, 2012.

\begin{tabular}{lccc}
\hline Species & Count & Mean Length $(\mathrm{mm})$ & Mean Weight $(\mathrm{g})$ \\
\hline Brook Trout & 2 & $151( \pm 114)$ & $66.9( \pm 89.7)$ \\
Brown Trout & 631 & $157( \pm 75)$ & $64.4( \pm 115.2)$ \\
Chestnut Lamprey & 17 & $149( \pm 23)$ & $7.5( \pm 3.7)$ \\
Johnny Darter & 1 & NA & NA \\
Rainbow Trout & 7 & $210( \pm 12)$ & $76.2( \pm 33.6)$ \\
Slimy Sculpin & 473 & $68( \pm 14)$ & 15.6 \\
Silver Lamprey & 6 & $144( \pm 15)$ & $6.6( \pm 2.3)$ \\
\hline
\end{tabular}

A.20. Summary fisheries statistics for Slagle Creek Middle. Four surveys were conducted between August 1, 2011 and August 13, 2012.

\begin{tabular}{lccc}
\hline Species & Count & Mean Length $(\mathrm{mm})$ & Mean Weight $(\mathrm{g})$ \\
\hline American Brook Lamprey & 2 & $156( \pm 20)$ & $1.5( \pm 1.5)$ \\
Brown Trout & 1395 & $147( \pm 74)$ & $59.1( \pm 104.3)$ \\
Chestnut Lamprey & 4 & $175( \pm 20)$ & $13( \pm 7.6)$ \\
Northern Brook Lamprey & 1 & 171 & 2.4 \\
Rainbow Trout & 16 & $211( \pm 11)$ & $90.0( \pm 23.7)$ \\
Slimy Sculpin & 569 & $60( \pm 19)$ & 10.9 \\
White Sucker & 4 & $220( \pm 34)$ & $124.9( \pm 59.4)$ \\
\hline
\end{tabular}

A.21. Summary fisheries statistics for Slagle Creek Upper. Four surveys were conducted between August 2, 2011 and August 13, 2012.

\begin{tabular}{lccc}
\hline Species & Count & Mean Length $(\mathrm{mm})$ & Mean Weight $(\mathrm{g})$ \\
\hline American Brook Lamprey & 2 & $176( \pm 10)$ & $9.5( \pm 1.4)$ \\
Brook Trout & 18 & $136( \pm 48)$ & $35.9( \pm 31.8)$ \\
Bluegill & 1 & 95 & 16 \\
Brown Trout & 139 & $209( \pm 66)$ & $118.0( \pm 84.8)$ \\
Chestnut Lamprey & 2 & $163( \pm 3)$ & $8.1( \pm 0)$ \\
Lamprey Species & 2 & $101( \pm 84)$ & 7.8 \\
Northern Brook Lamprey & 2 & $175( \pm 12)$ & NA \\
Slimy Sculpin & 576 & $62( \pm 15)$ & 12.5 \\
\hline
\end{tabular}


A.22. Summary fisheries statistics for Woodpecker Creek Lower. Eight surveys were conducted between July 11, 2011 and August 13, 2013.

\begin{tabular}{lccc}
\hline Species & Count & Mean Length $(\mathrm{mm})$ & Mean Weight $(\mathrm{g})$ \\
\hline Brook Trout & 20 & $78( \pm 41)$ & $9.9( \pm 20.8)$ \\
Brown Trout & 416 & $123( \pm 68)$ & $39.0( \pm 73.8)$ \\
Chestnut Lamprey & 3 & $163( \pm 36)$ & $9.4( \pm 5.4)$ \\
Johnny Darter & 3 & $58( \pm 2)$ & $1.8( \pm 0.3)$ \\
Longnose Dace & 5 & $75( \pm 2)$ & $3.7( \pm 0.4)$ \\
Rainbow Trout & 324 & $172( \pm 24)$ & $50.2( \pm 19.9)$ \\
Slimy Sculpin & 240 & $65( \pm 16)$ & 5.1 \\
\hline
\end{tabular}

A.23. Summary fisheries statistics for Woodpecker Creek Middle. Eight surveys were conducted between July 11, 2011 and August 14, 2013.

\begin{tabular}{lccc}
\hline Species & Count & Mean Length $(\mathrm{mm})$ & Mean Weight $(\mathrm{g})$ \\
\hline Brook Trout & 31 & $122( \pm 68)$ & $34.4( \pm 41.7)$ \\
Brown Trout & 510 & $120( \pm 60)$ & $31.9( \pm 45.4)$ \\
Rainbow Trout & 18 & $164( \pm 27)$ & $43.1( \pm 17.8)$ \\
Slimy Sculpin & 106 & $72( \pm 16)$ & 5.8 \\
\hline
\end{tabular}

A.24. Summary fisheries statistics for Woodpecker Creek Upper. Five surveys were conducted between July 11, 2011 and May 8, 2013.

\begin{tabular}{lccc}
\hline Species & Count & Mean Length $(\mathrm{mm})$ & Mean Weight $(\mathrm{g})$ \\
\hline Brook Trout & 16 & $156( \pm 23)$ & $38.9( \pm 20.1)$ \\
Brown Trout & 191 & $100( \pm 38)$ & $14.8( \pm 20.0)$ \\
Brook Stickleback & 10 & $54( \pm 10)$ & $1.6( \pm 0.9)$ \\
Northern Redbelly Dace & 4 & $53( \pm 5)$ & $1.6( \pm 0.5)$ \\
Rainbow Trout & 4 & $147( \pm 30)$ & $32.0( \pm 19.4)$ \\
Slimy Sculpin & 2 & $68( \pm 11)$ & $4.5( \pm 0.2)$ \\
\hline
\end{tabular}


Appendix B. Arctic Grayling North American range map with relative sensitivities by latitude, age-at-maturity and maximum age by latitude, and population growth rate sensitivity plots across a hypothesized latitudinal gradient of life-history characteristics. *Note: in sensitivity plots mean population growth rate is represented by circles and relative sensitivities are represented by lengths of the associated error bars. 


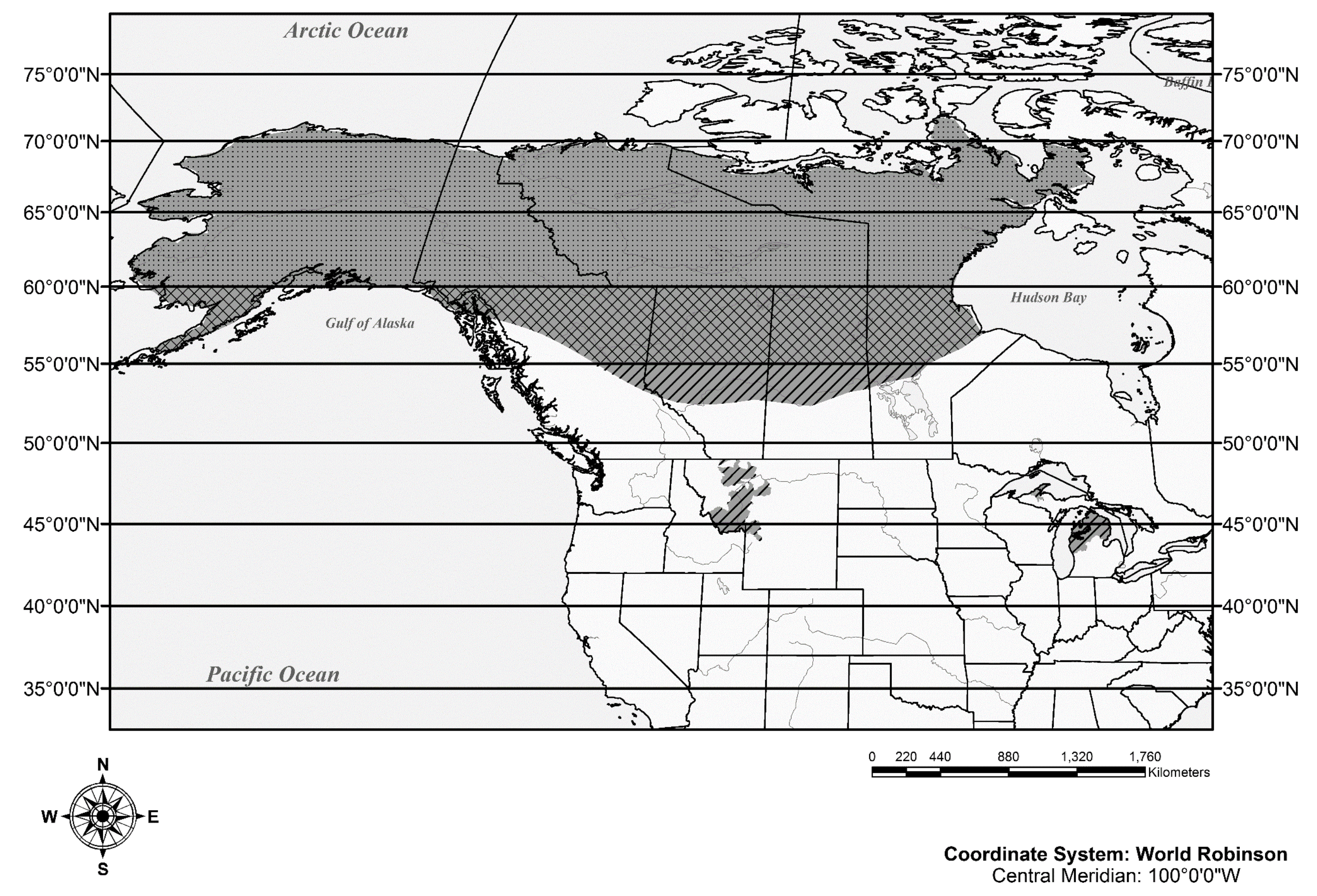

B.1. Arctic Grayling North American range map with proposed latitudinal sensitivity gradient. 
$\circ$ Age at maturity $\bullet$ Maximum age

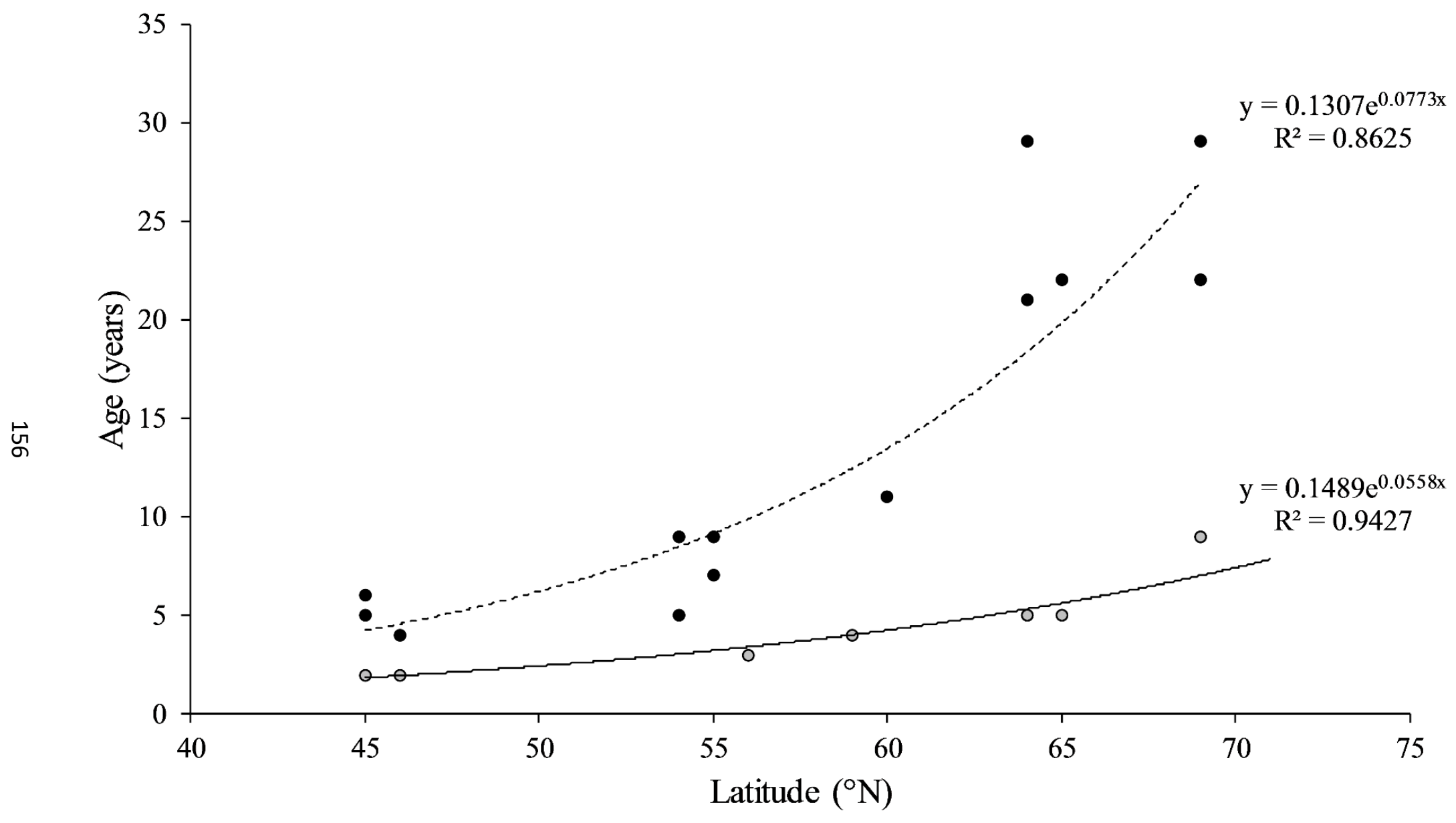

B.2. Latitudinal trends in Arctic Grayling age at maturity and maximum age. 


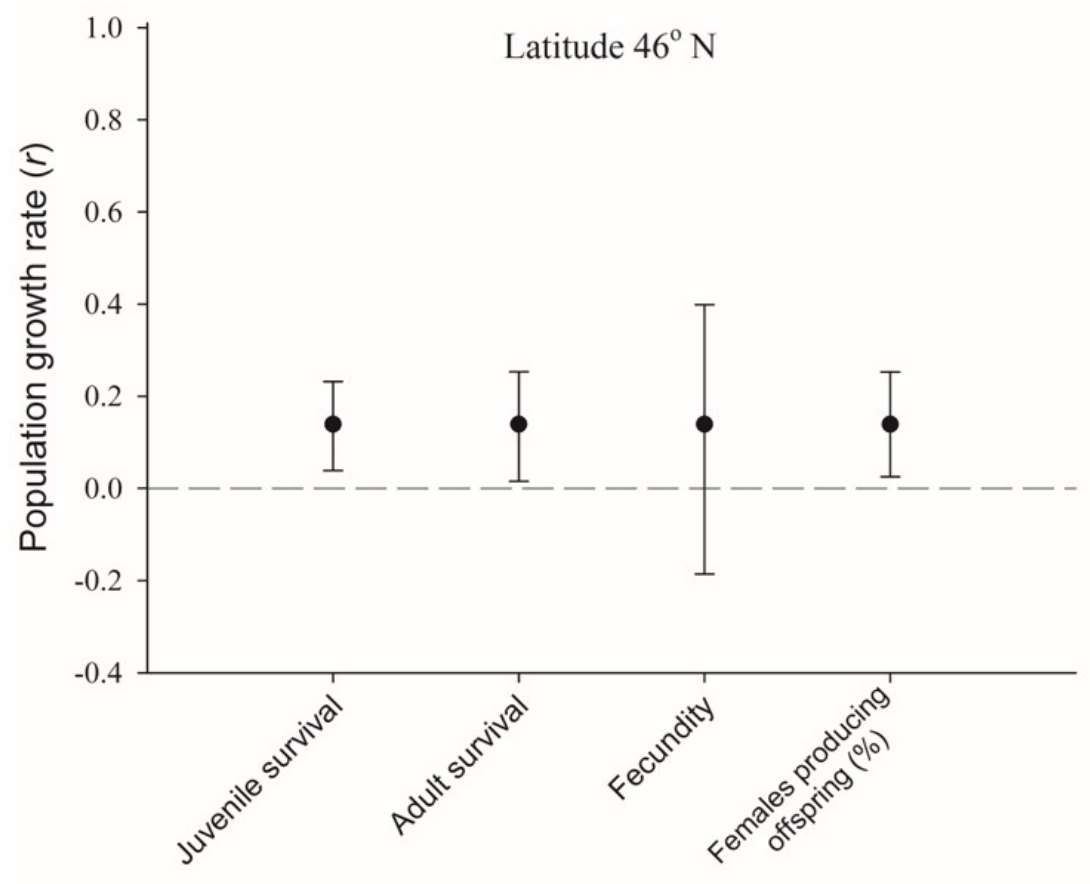

Life history parameter

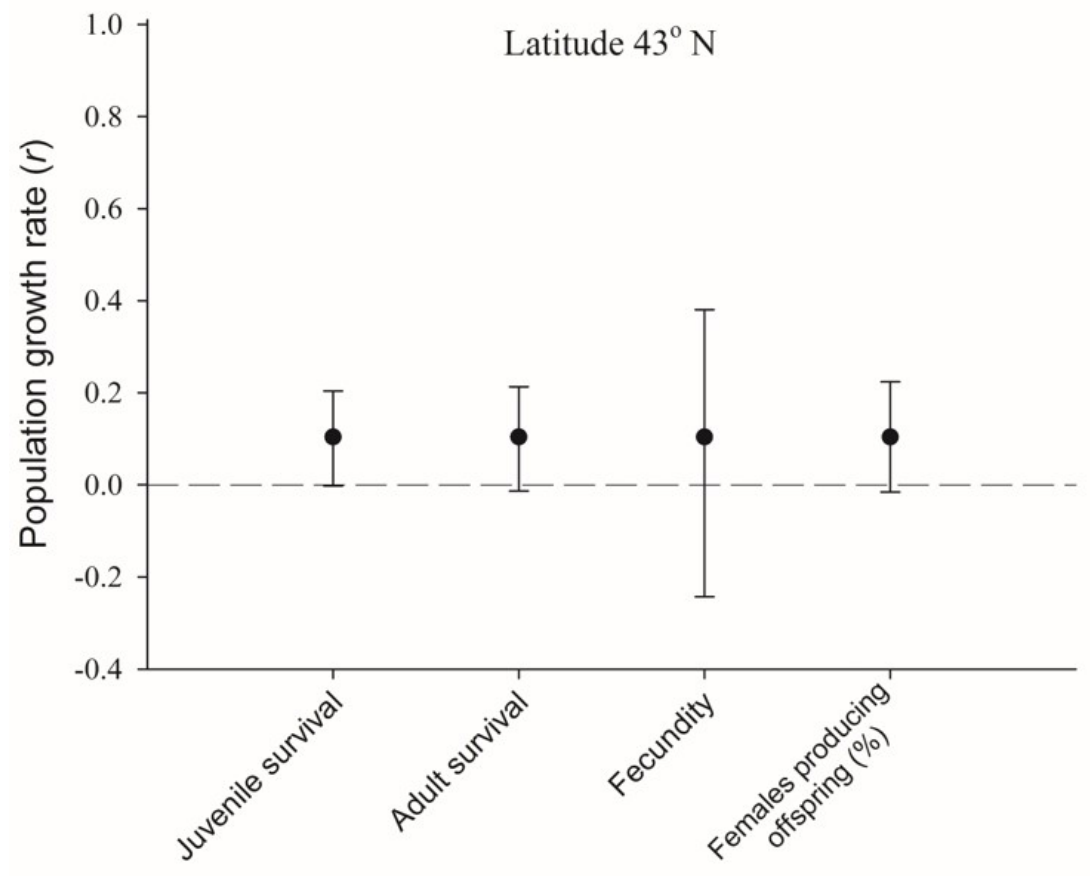

Life history parameter

B.3. Sensitivity plots for Arctic Grayling populations at $43^{\circ} \mathrm{N}$ and $46^{\circ} \mathrm{N}$. 


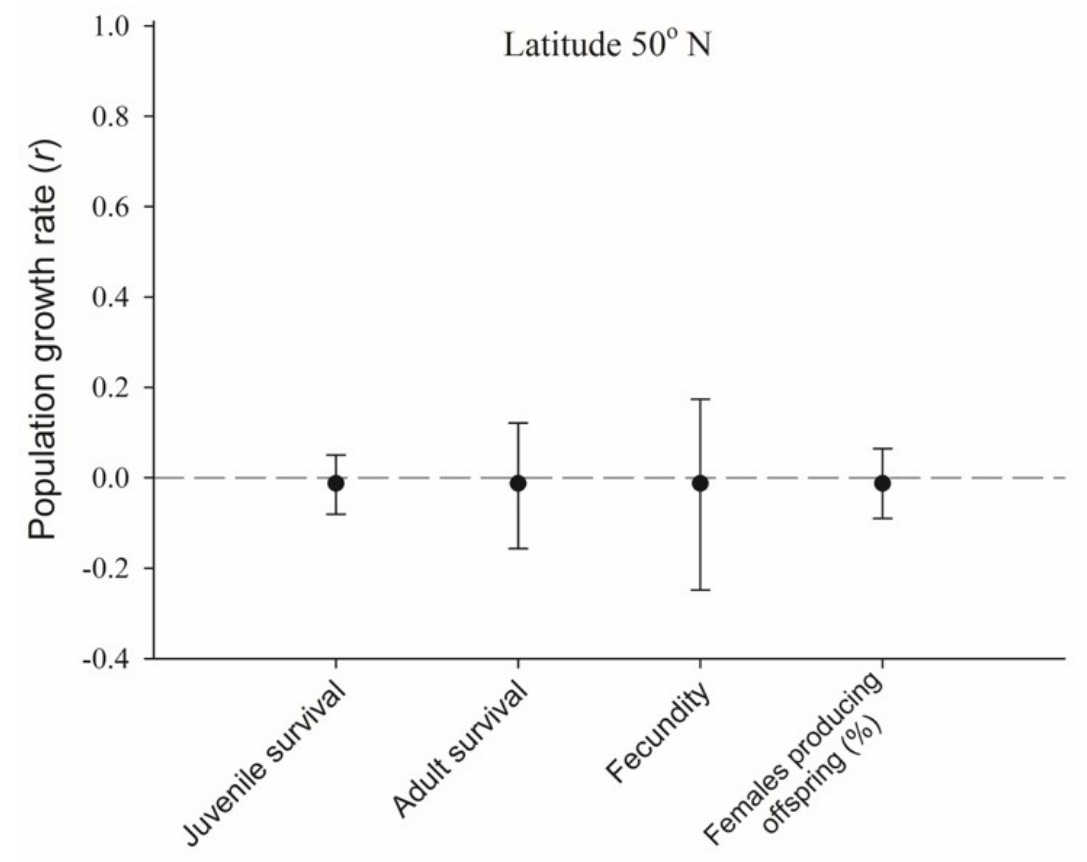

Life history parameter

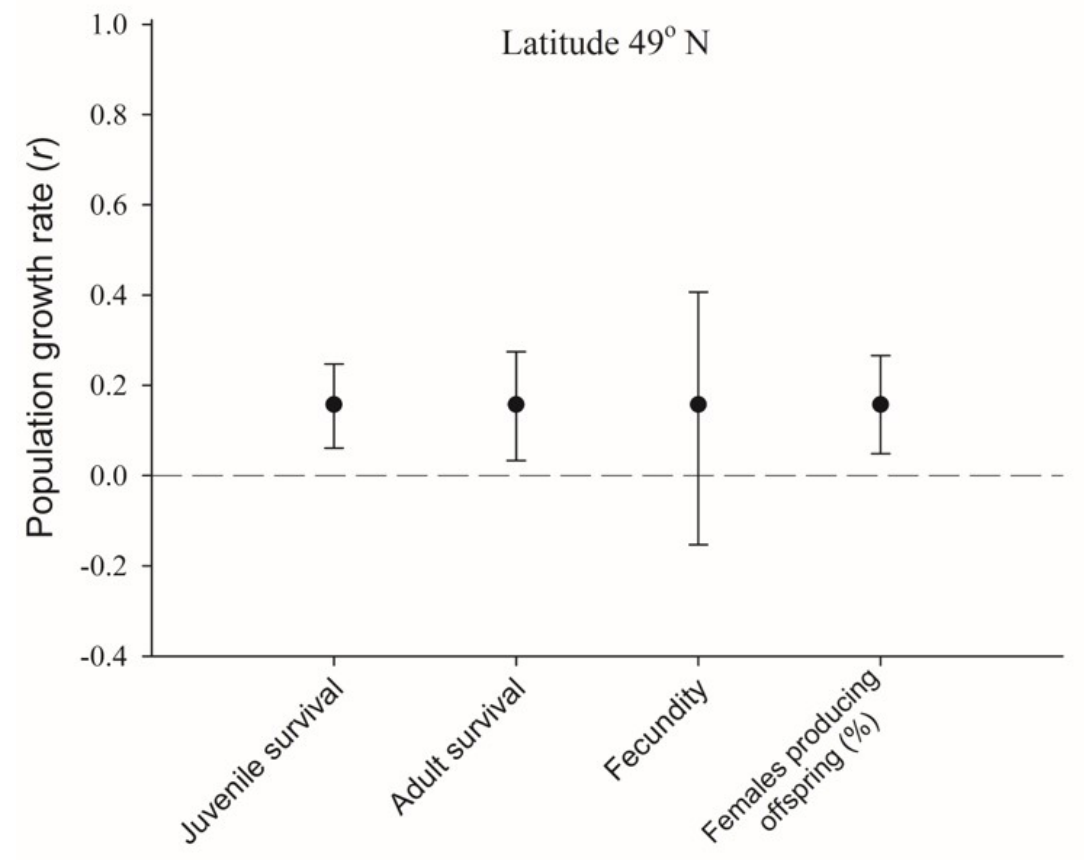

Life history parameter

B.4. Sensitivity plots for Arctic Grayling populations at $49^{\circ} \mathrm{N}$ and $50^{\circ} \mathrm{N}$. 158 


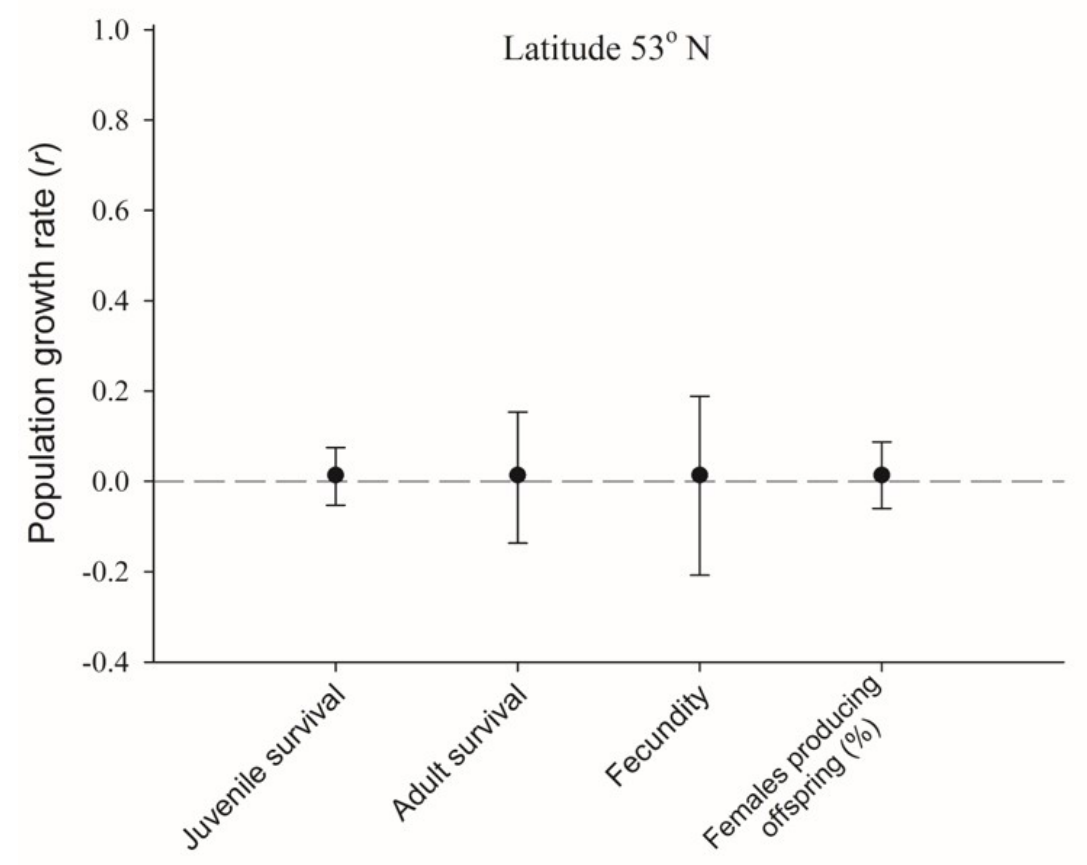

Life history parameter

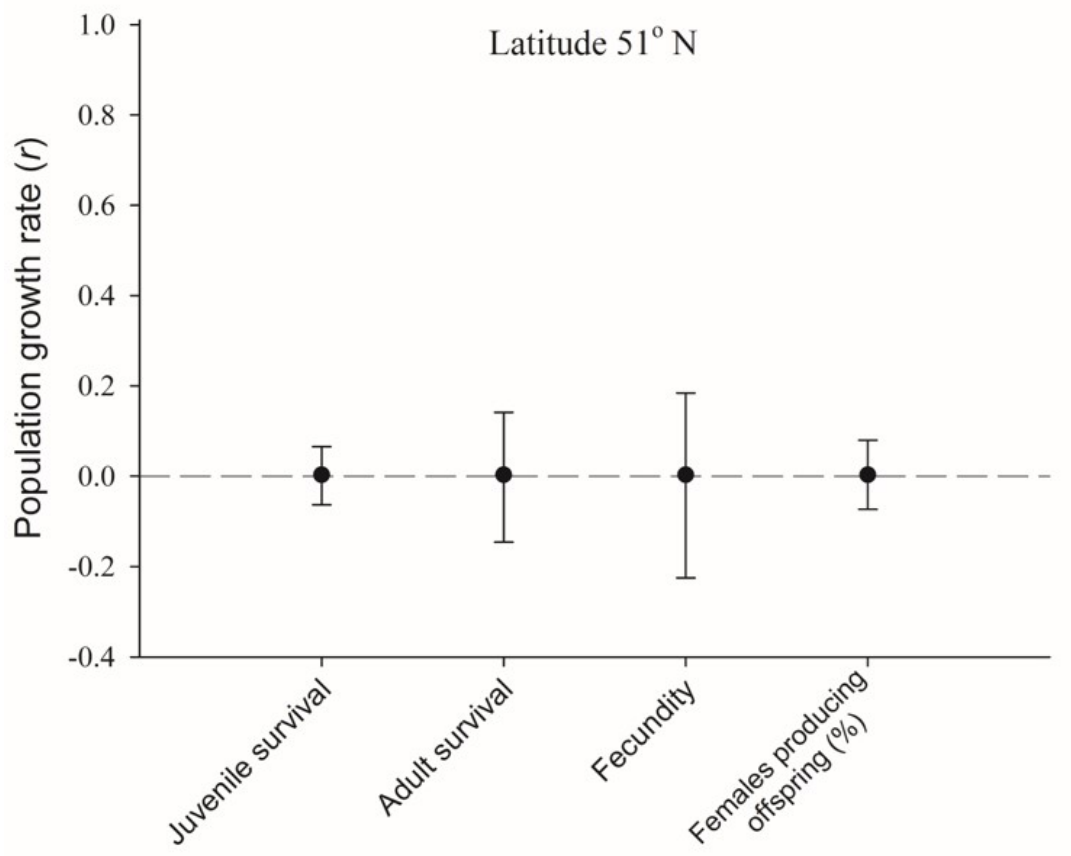

Life history parameter

B.5. Sensitivity plots for Arctic Grayling populations at $51^{\circ} \mathrm{N}$ and $53^{\circ} \mathrm{N}$. 159 


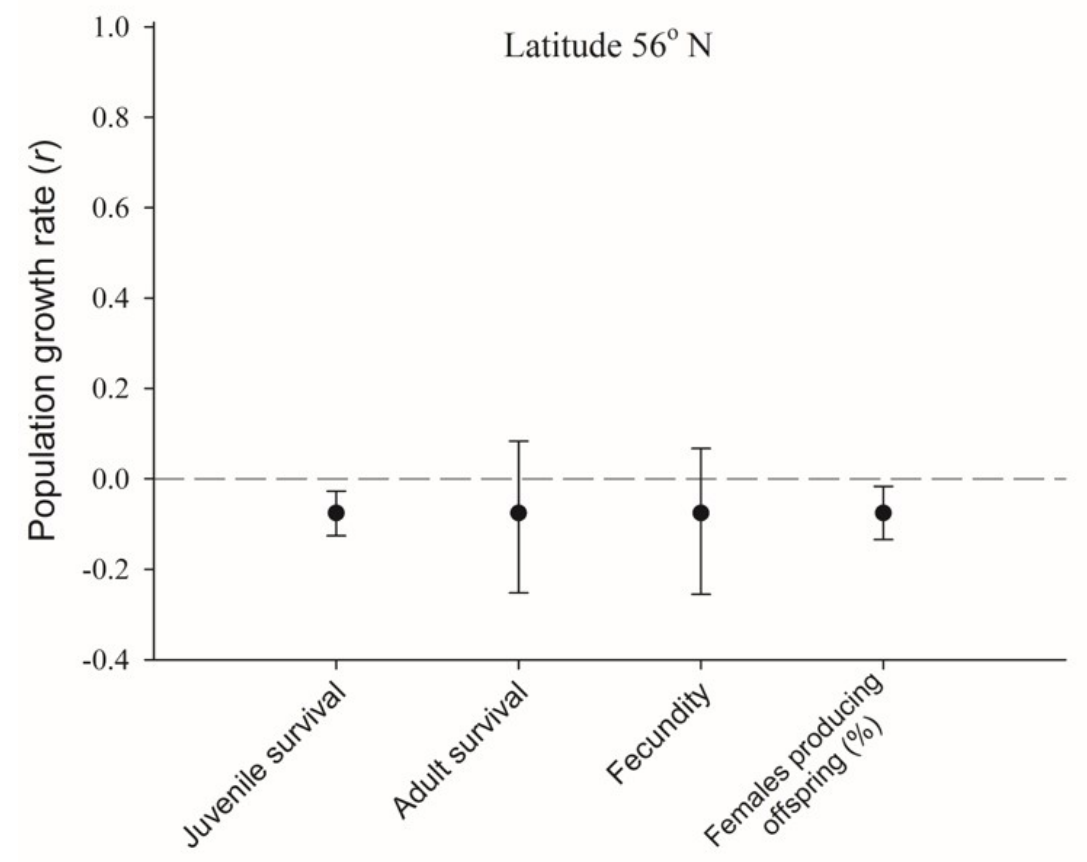

Life history parameter

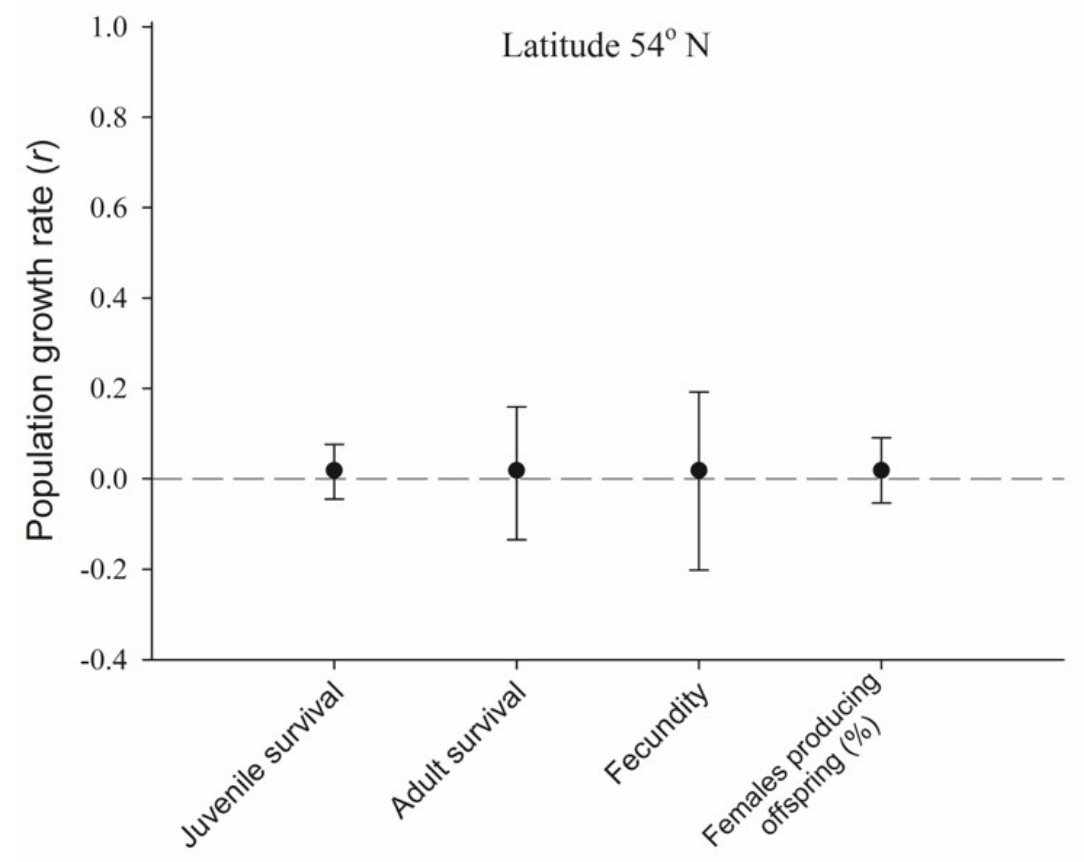

Life history parameter

B.6. Sensitivity plots for Arctic Grayling populations at $54^{\circ} \mathrm{N}$ and $56^{\circ} \mathrm{N}$. 160 


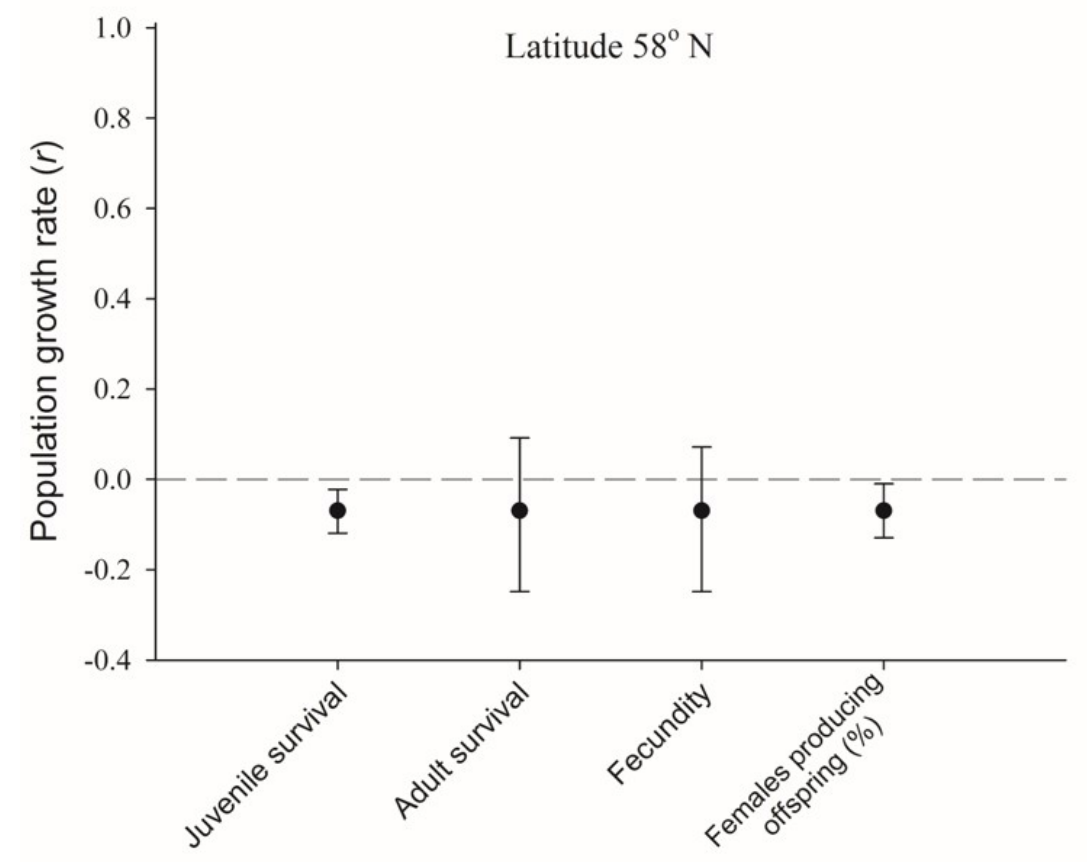

Life history parameter

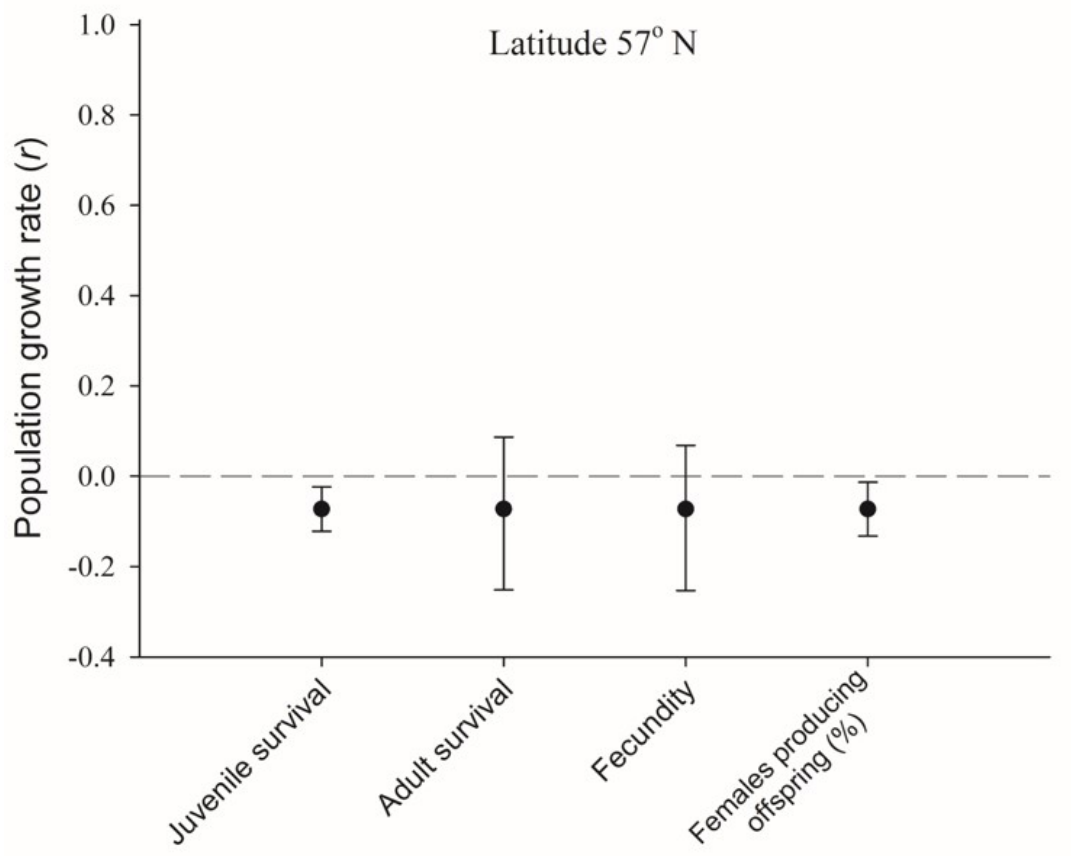

Life history parameter

B.7. Sensitivity plots for Arctic Grayling populations at $57^{\circ} \mathrm{N}$ and $58^{\circ} \mathrm{N}$. 161 


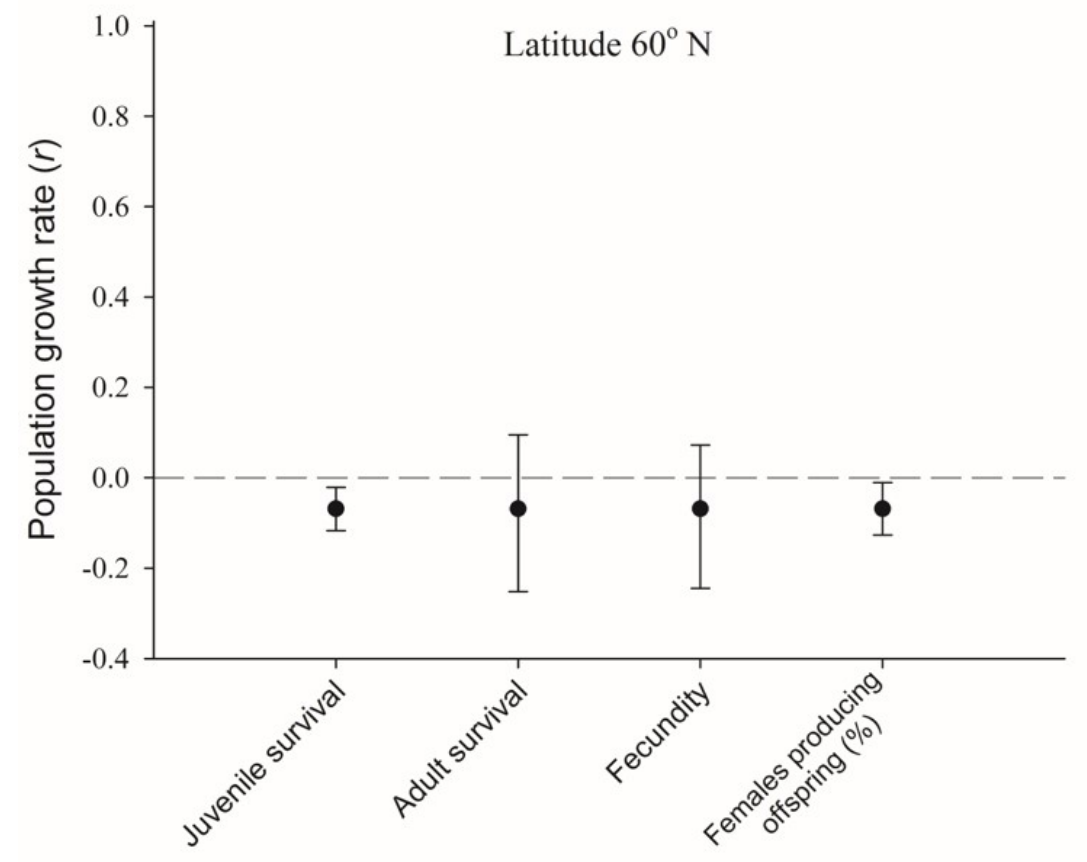

Life history parameter

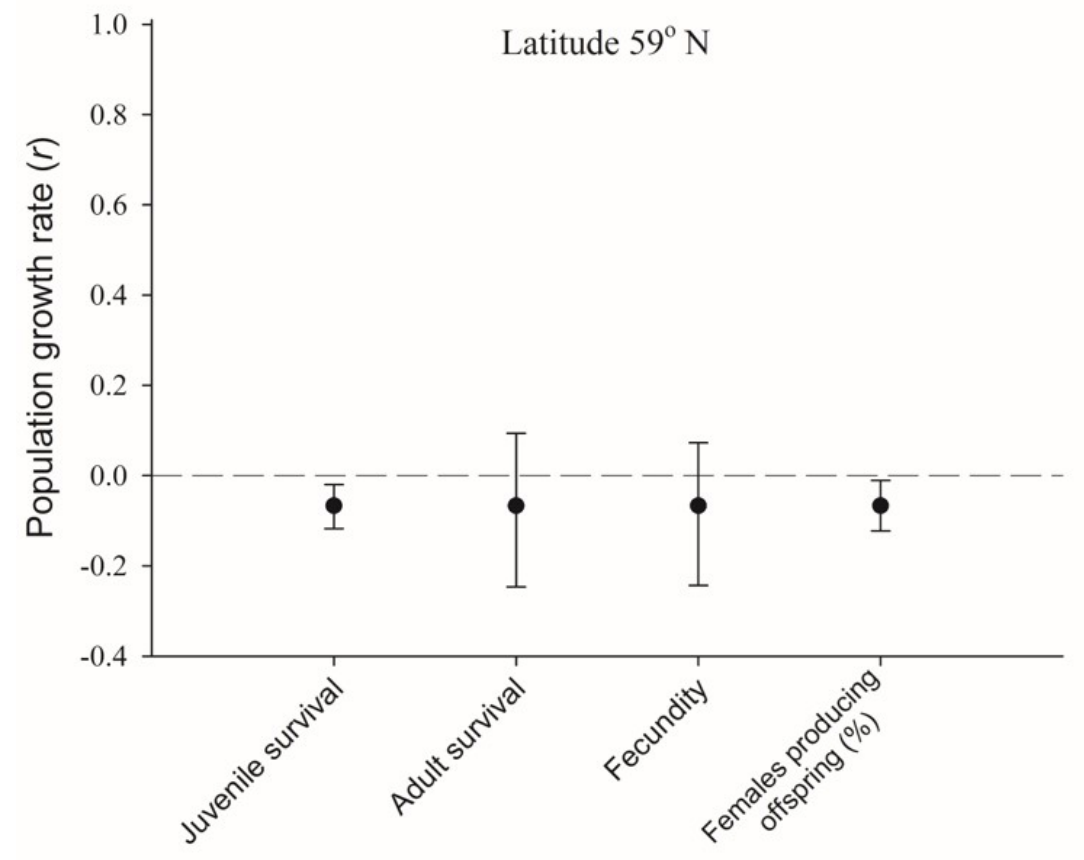

Life history parameter

B.8. Sensitivity plots for Arctic Grayling populations at $59^{\circ} \mathrm{N}$ and $60^{\circ} \mathrm{N}$. 


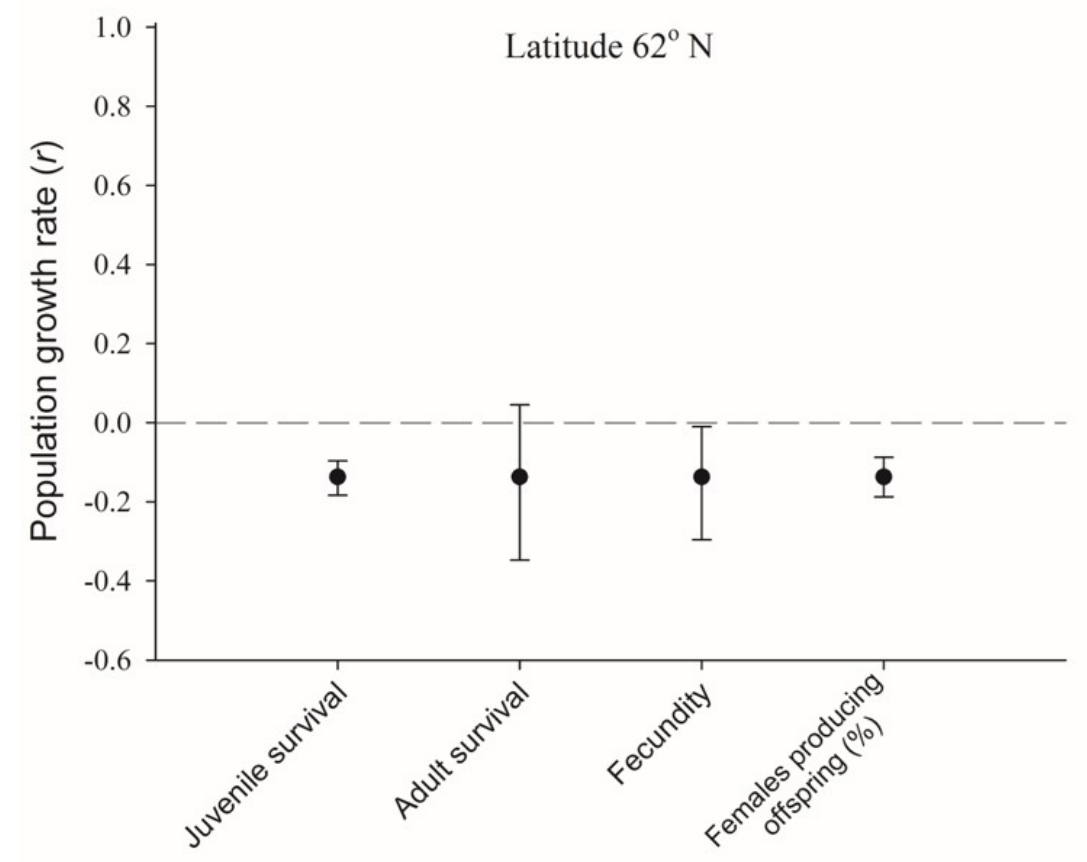

Life history parameter

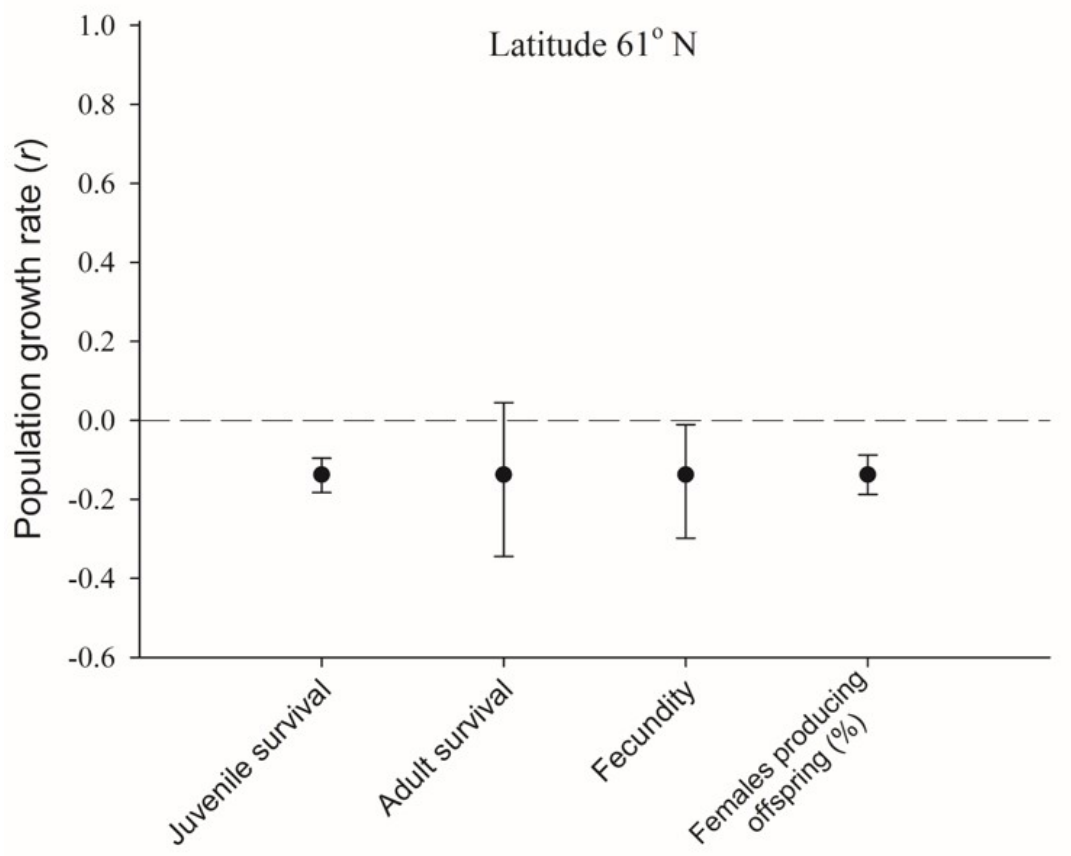

Life history parameter

B.9. Sensitivity plots for Arctic Grayling populations at $61^{\circ} \mathrm{N}$ and $62^{\circ} \mathrm{N}$. 163 


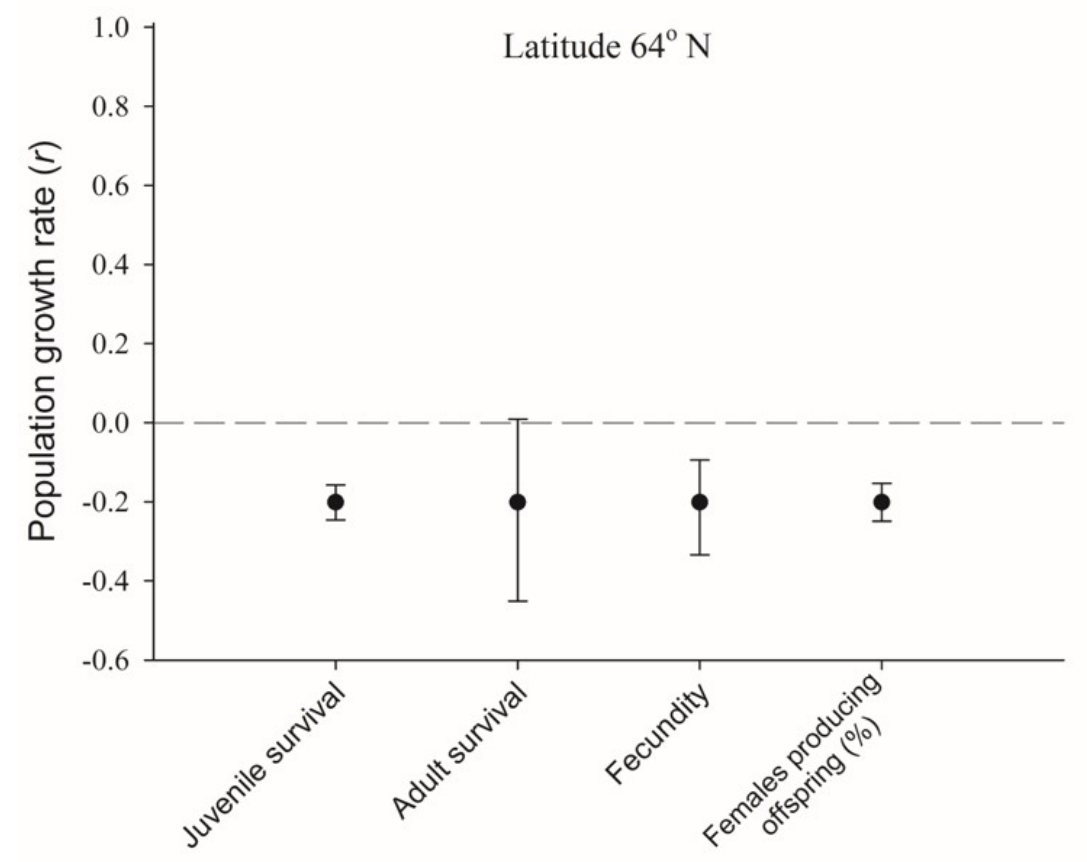

Life history parameter

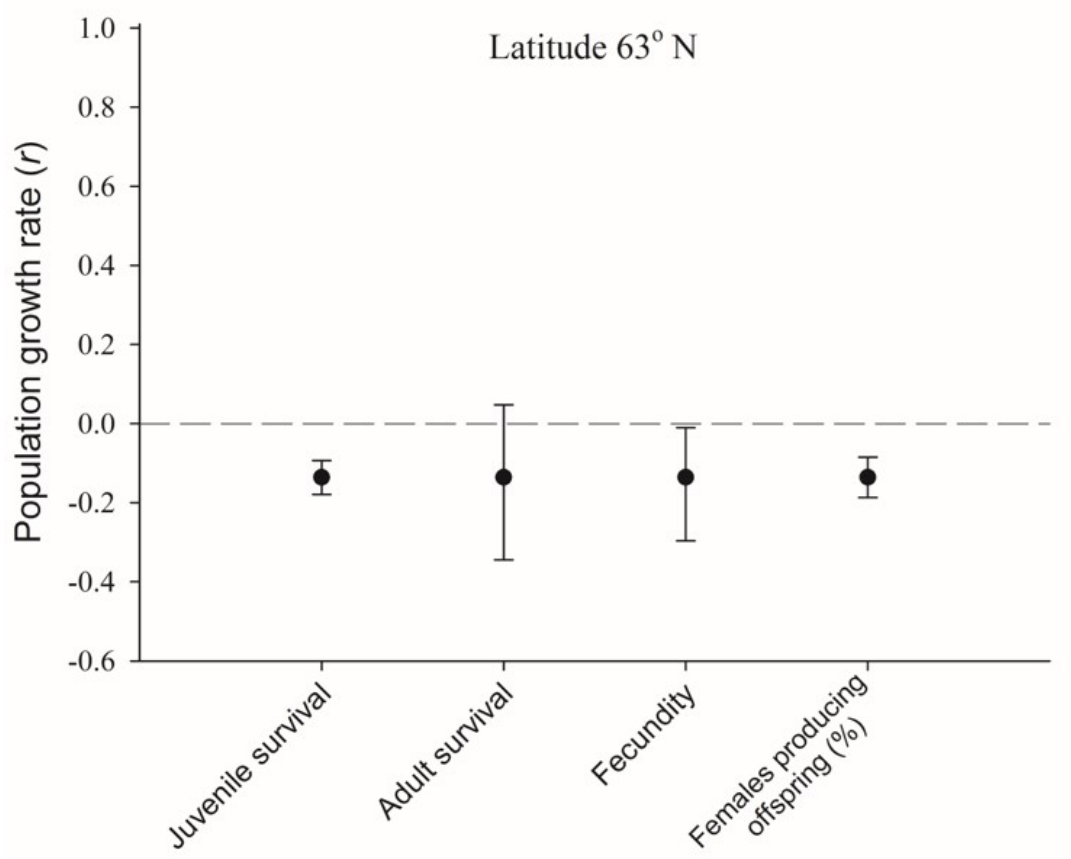

Life history parameter

B.10. Sensitivity plots for Arctic Grayling populations at $63^{\circ} \mathrm{N}$ and $64^{\circ} \mathrm{N}$. 164 


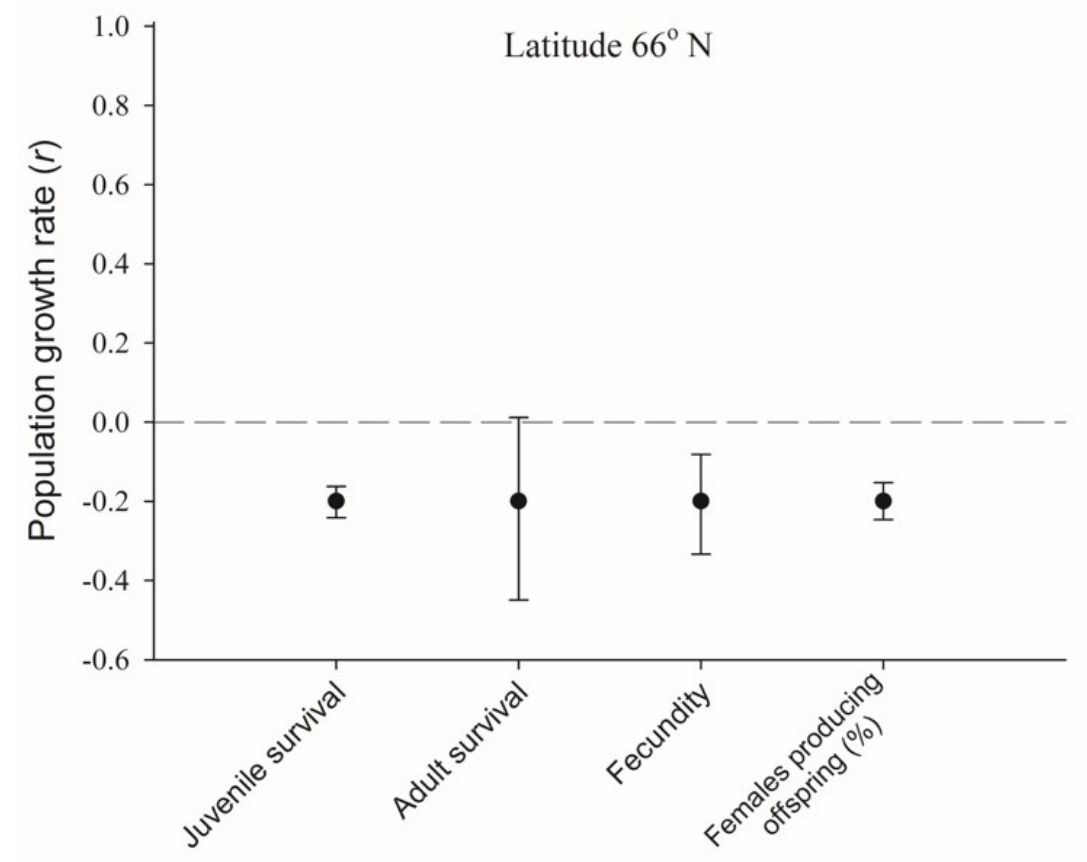

Life history parameter

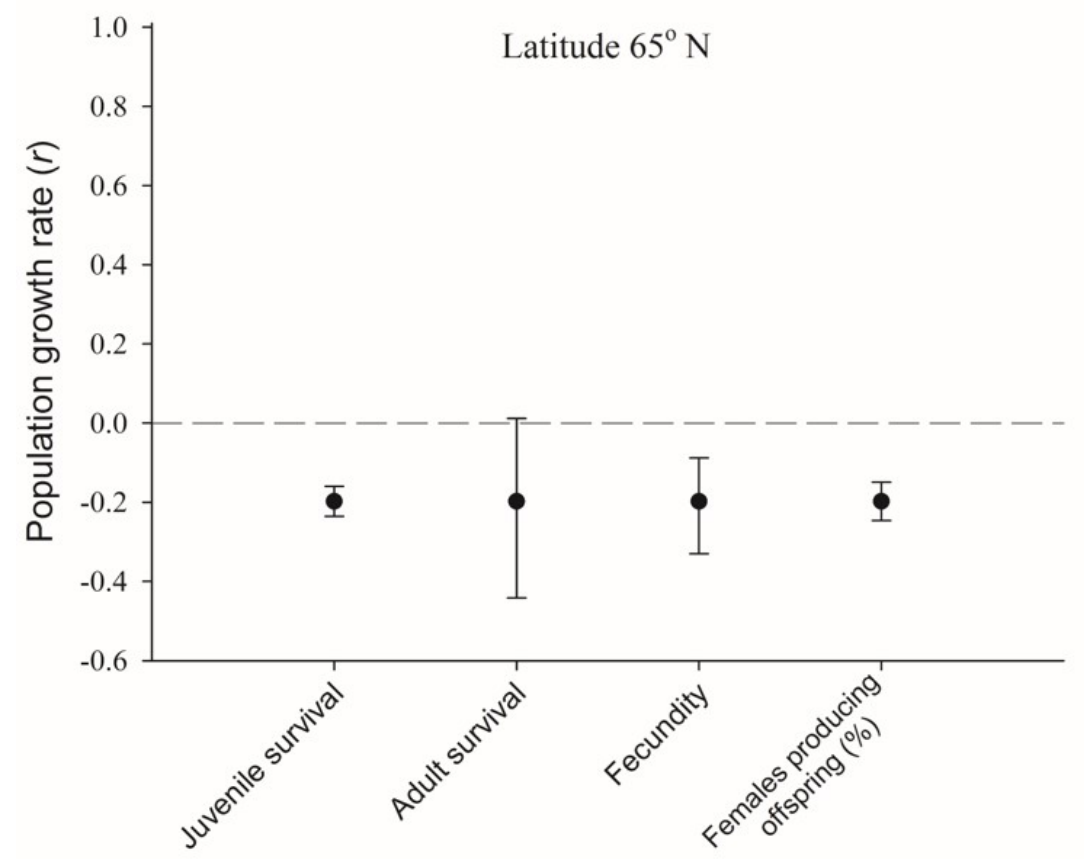

Life history parameter

B.11. Sensitivity plots for Arctic Grayling populations at $65^{\circ} \mathrm{N}$ and $66^{\circ} \mathrm{N}$. 165 


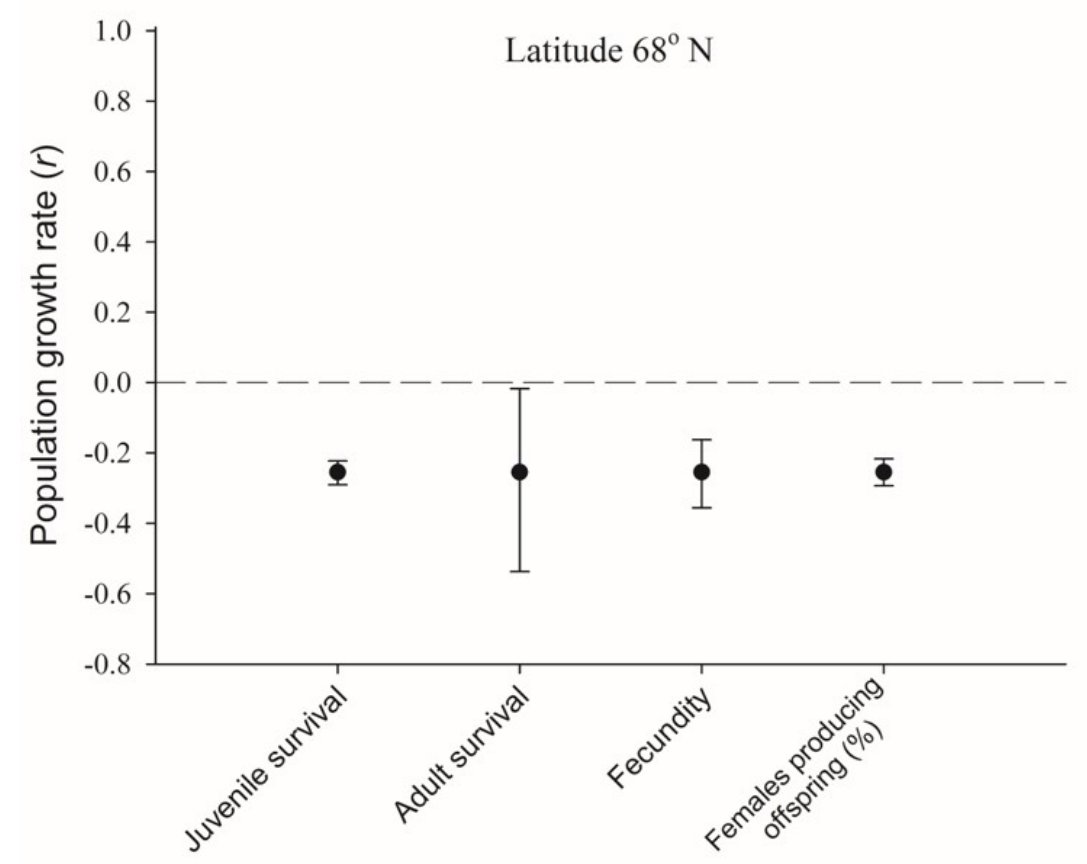

Life history parameter

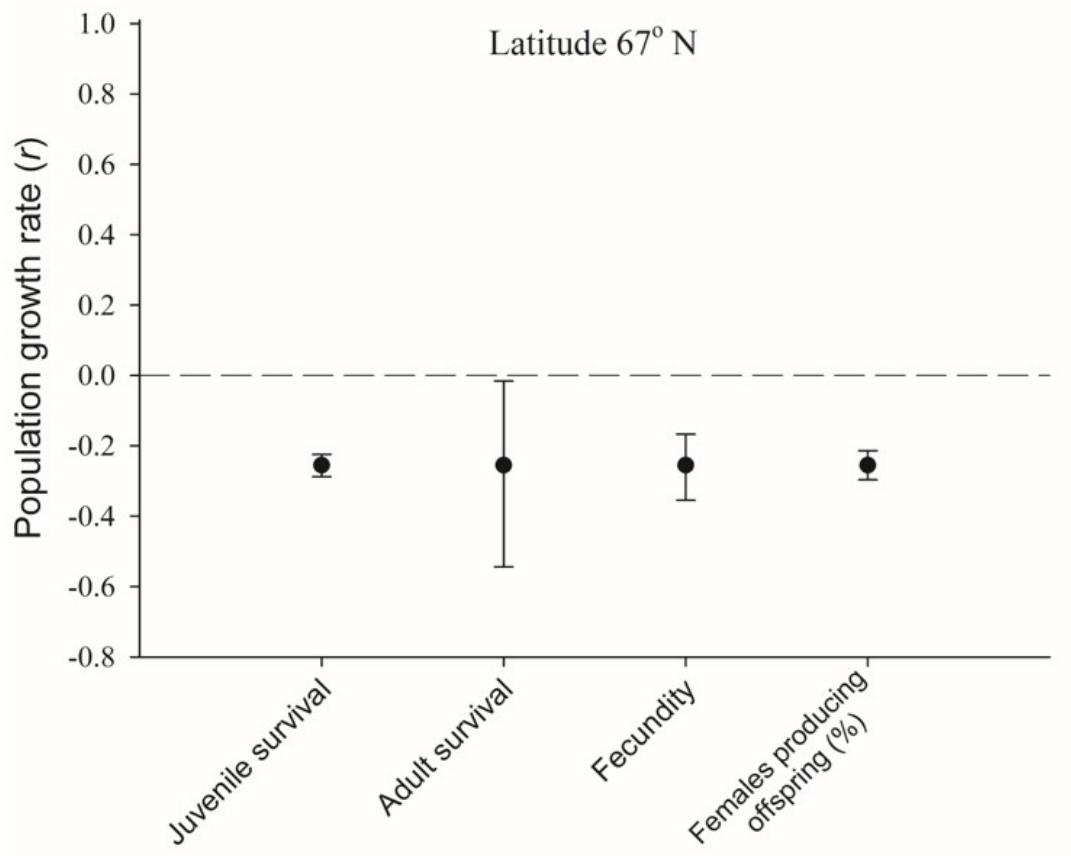

Life history parameter

B.12. Sensitivity plots for Arctic Grayling populations at $67^{\circ} \mathrm{N}$ and $68^{\circ} \mathrm{N}$. 166 


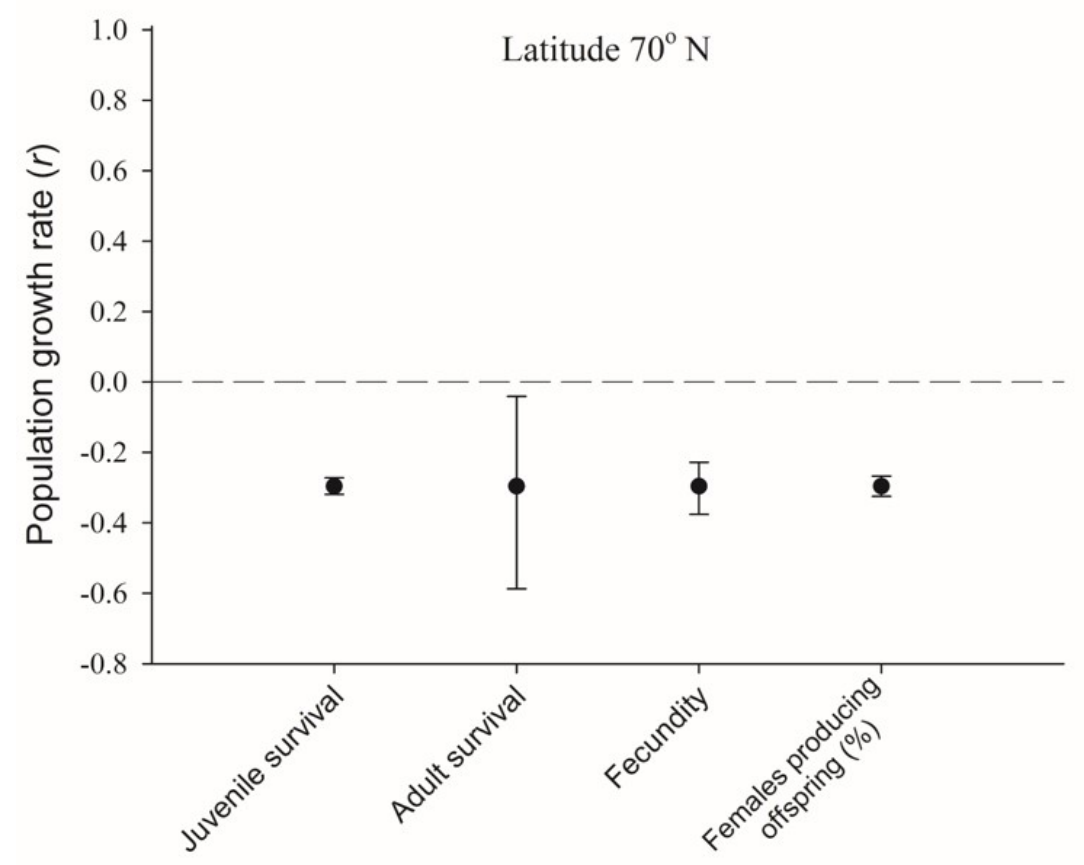

Life history parameter

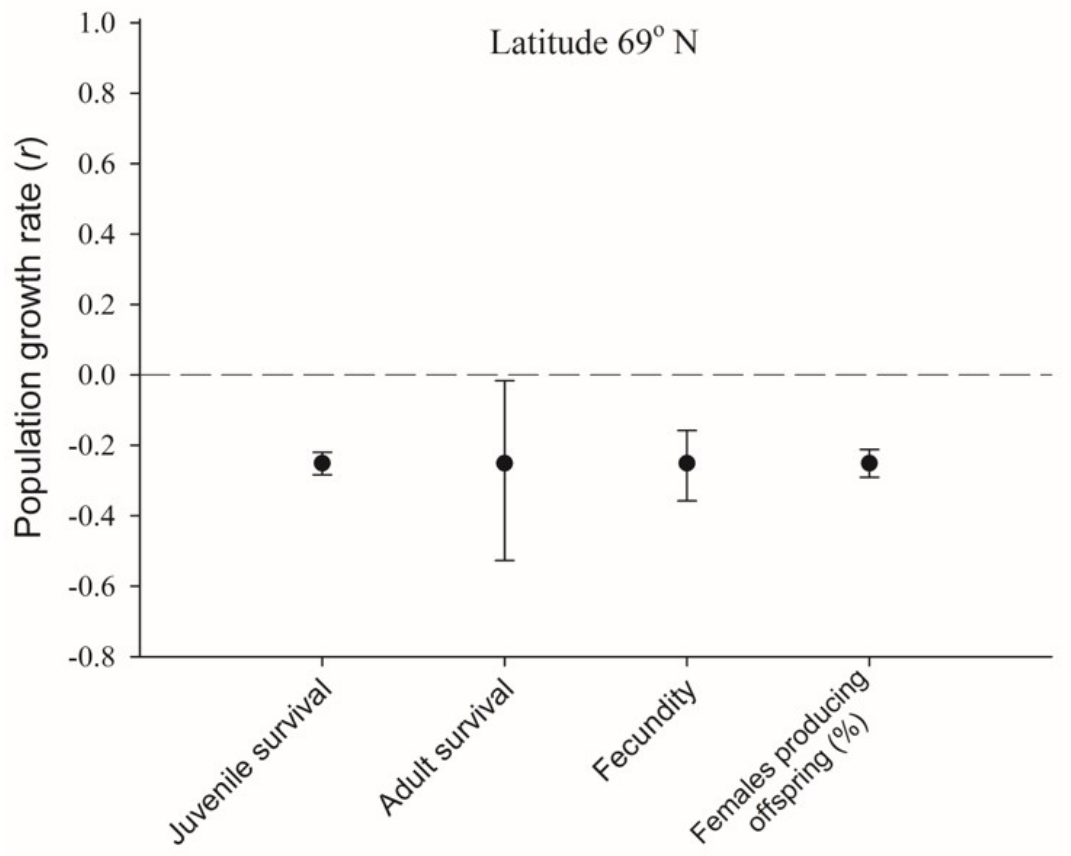

Life history parameter

B.13. Sensitivity plots for Arctic Grayling populations at $69^{\circ} \mathrm{N}$ and $70^{\circ} \mathrm{N}$. 
Appendix C. Invertebrate drift densities from 22 sampling reaches in Big Manistee River, MI tributaries. 


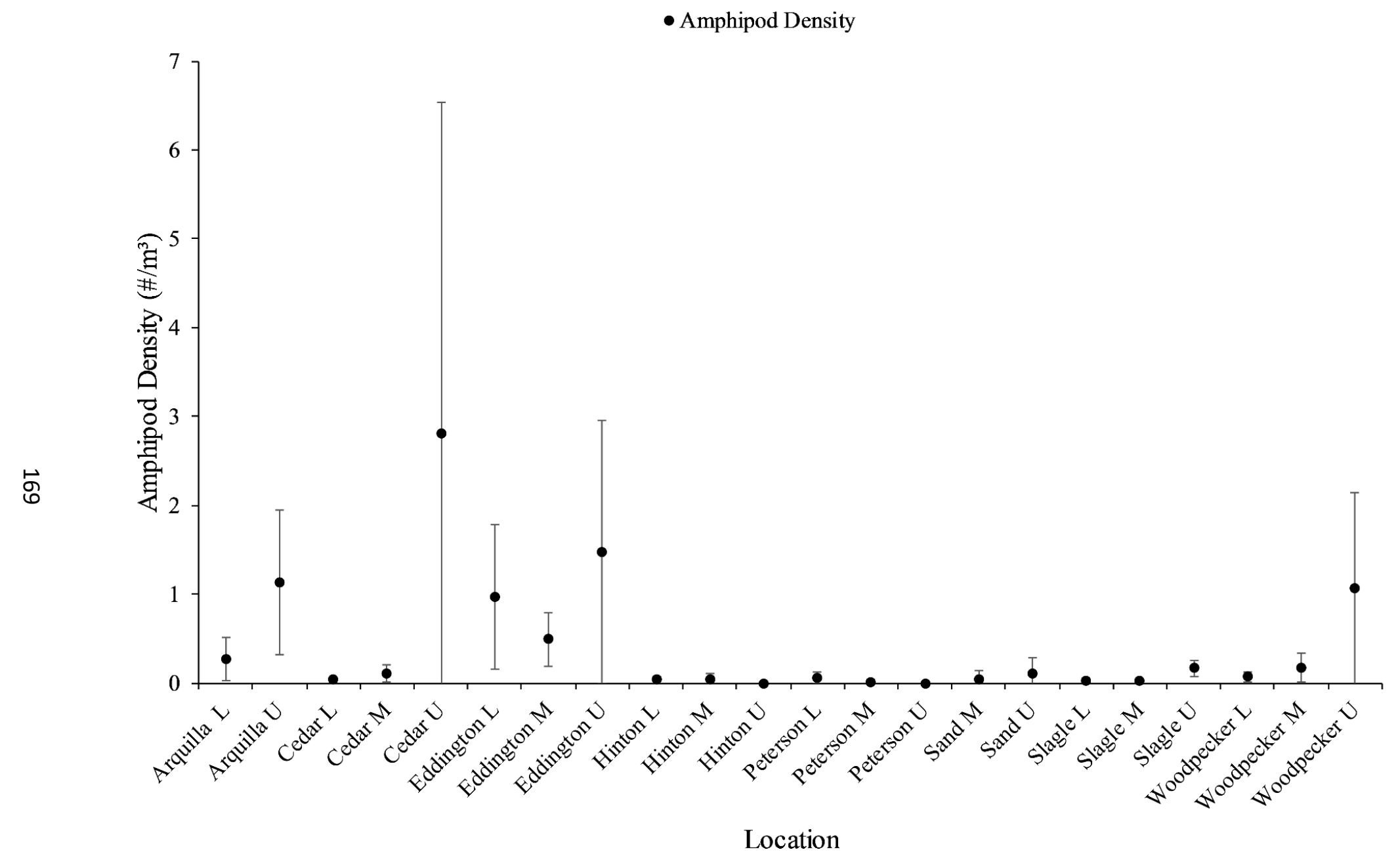

C.1. Density $\left(\# / \mathrm{m}^{3}\right)$ of Amphipods in 22 Big Manistee River tributary reaches during June 2012. 


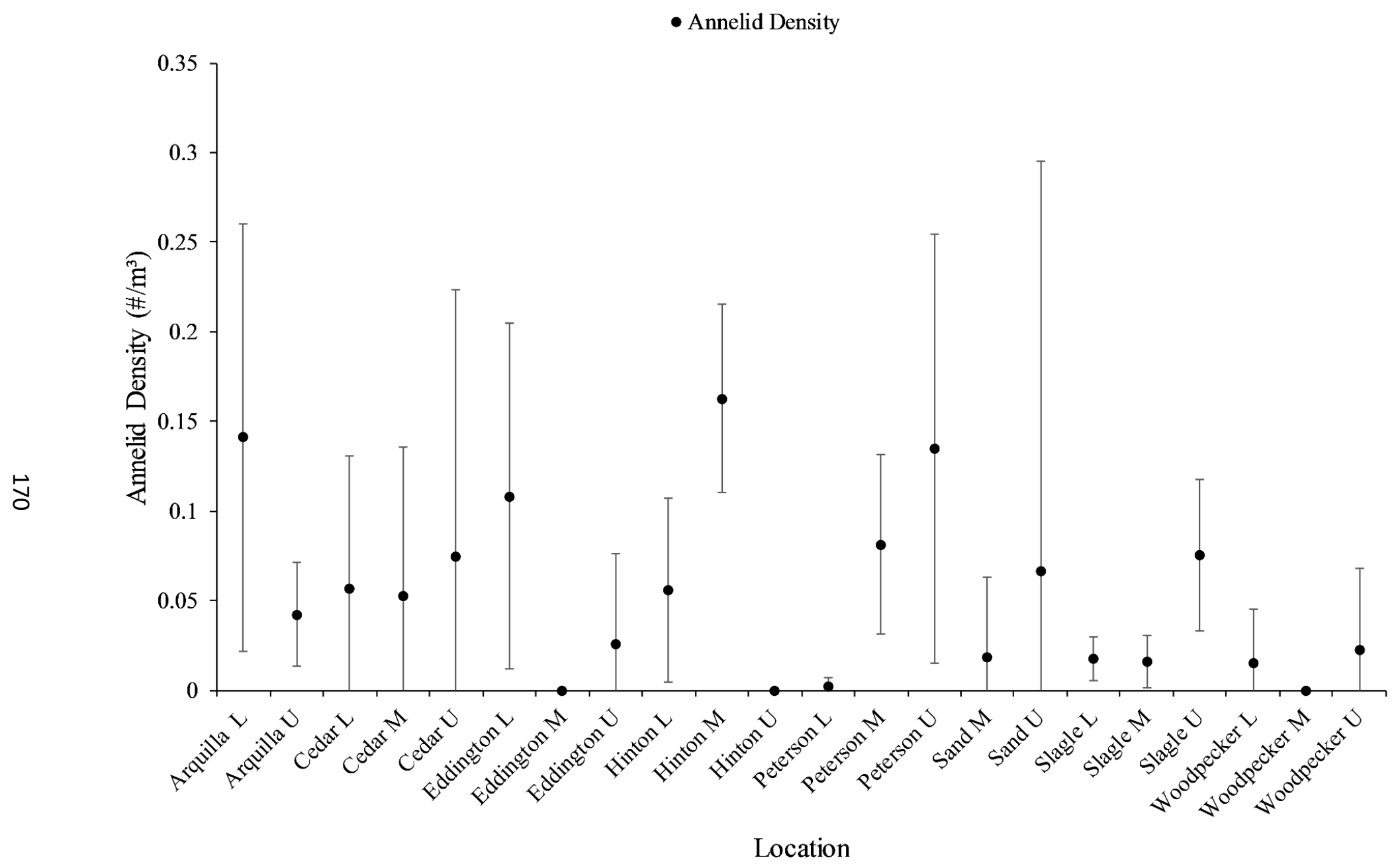

C.2. Density $\left(\# / \mathrm{m}^{3}\right)$ of Annelids in 22 Big Manistee River tributary reaches during June 2012. 


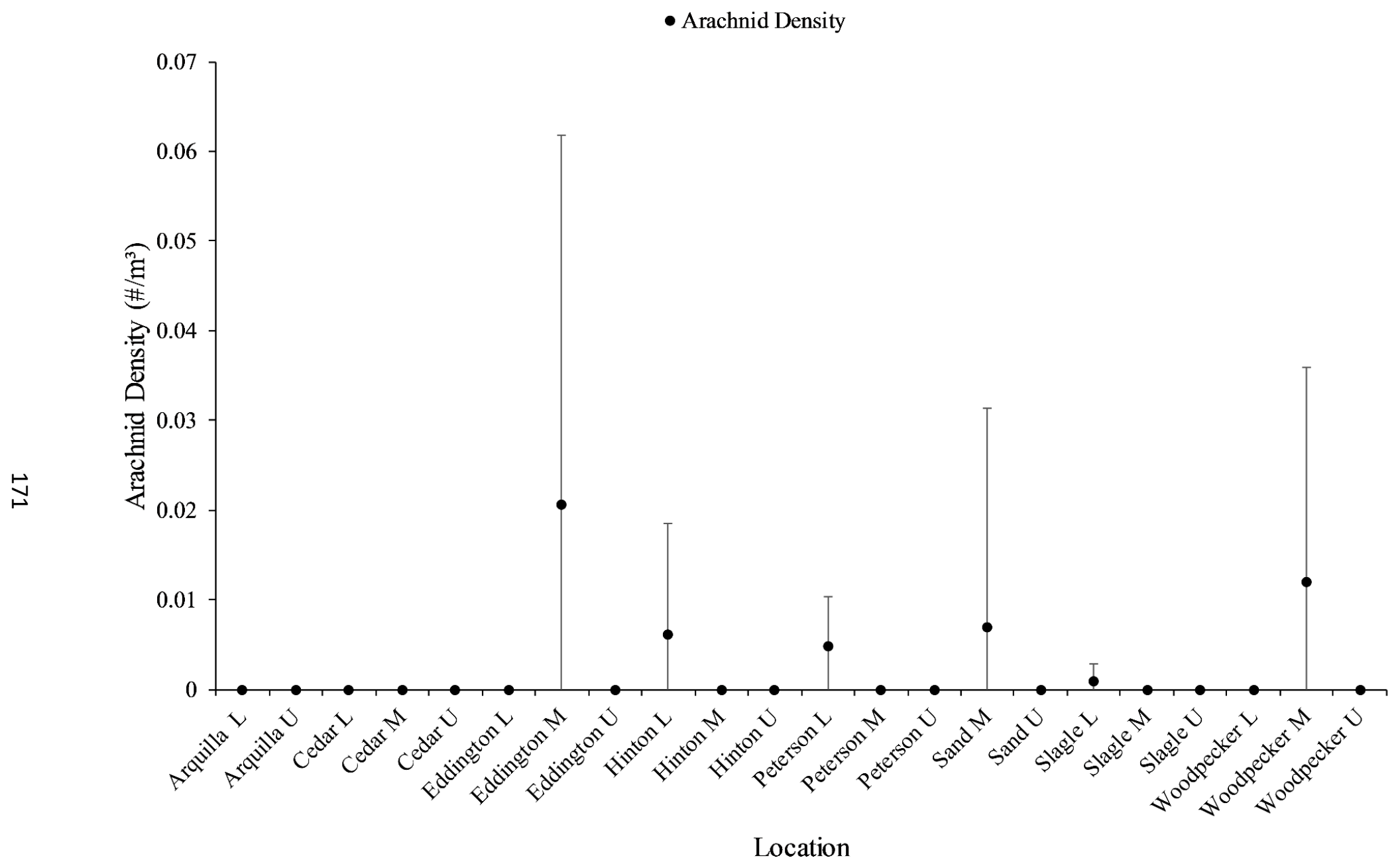

C.3. Density $\left(\# / \mathrm{m}^{3}\right)$ of Arachnids in 22 Big Manistee River tributary reaches during June 2012. 


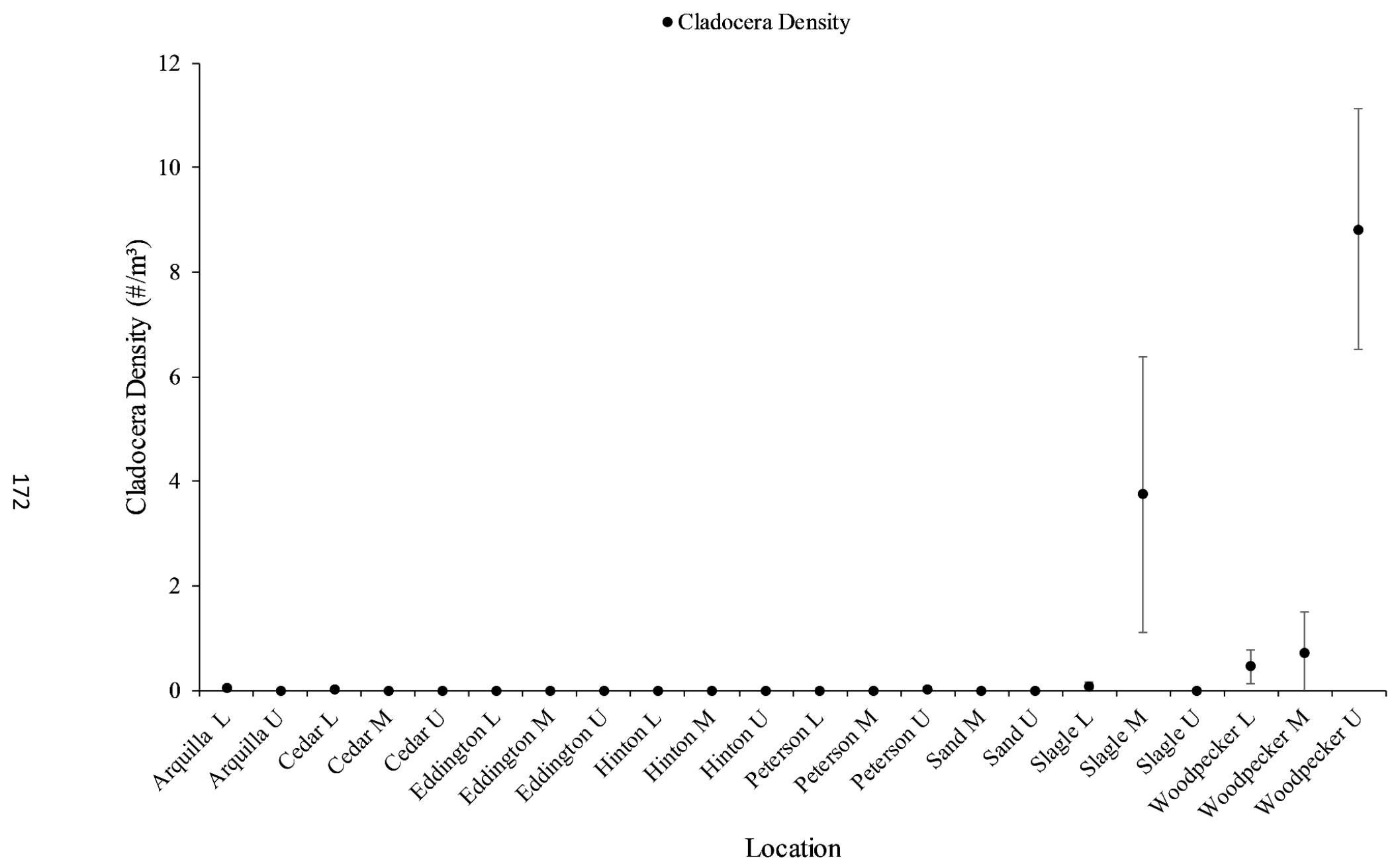

C.4. Density $\left(\# / \mathrm{m}^{3}\right)$ of Cladocera in 22 Big Manistee River tributary reaches during June 2012. 


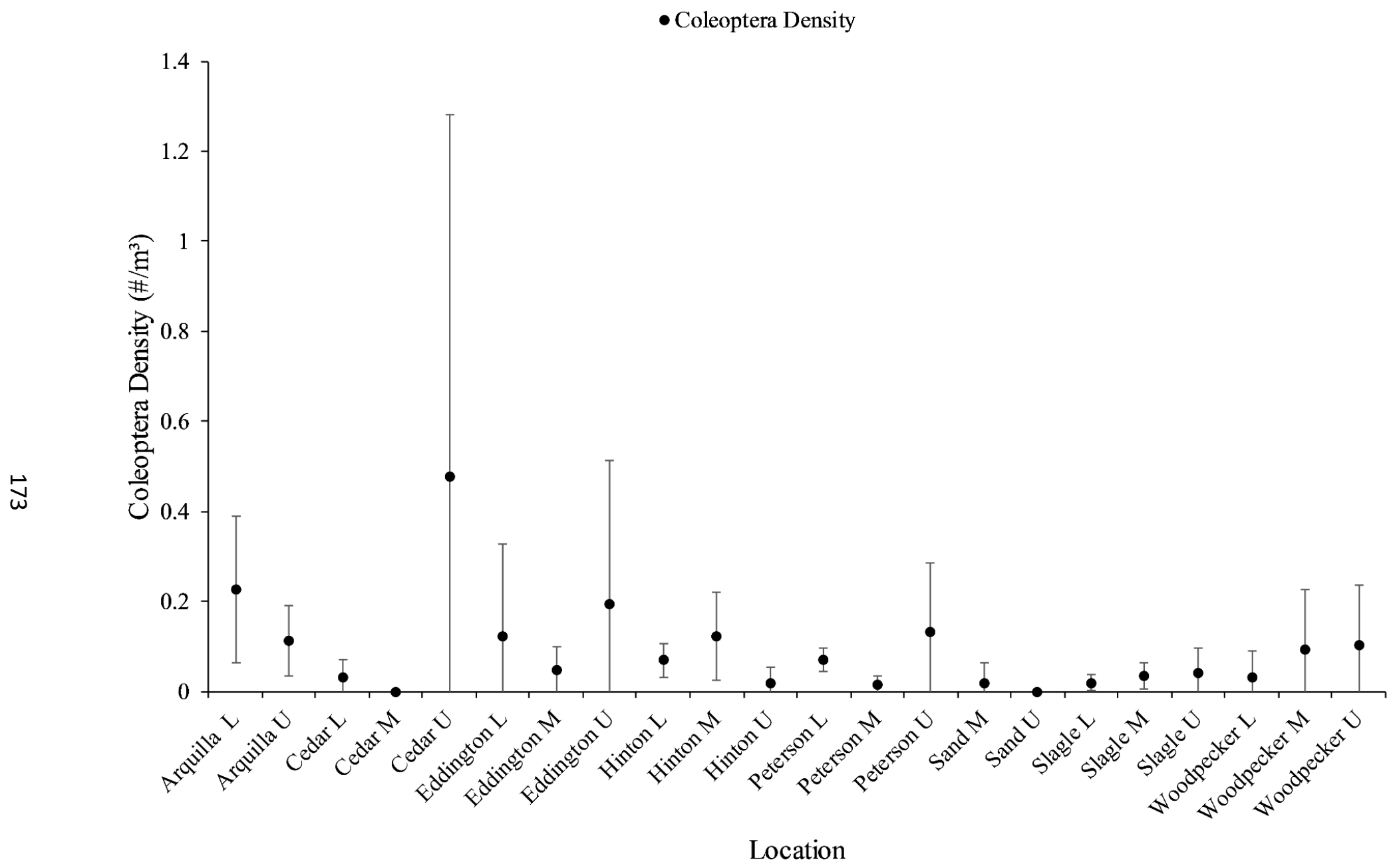

C.5. Density $\left(\# / \mathrm{m}^{3}\right)$ of Coleoptera in 22 Big Manistee River tributary reaches during June 2012. 


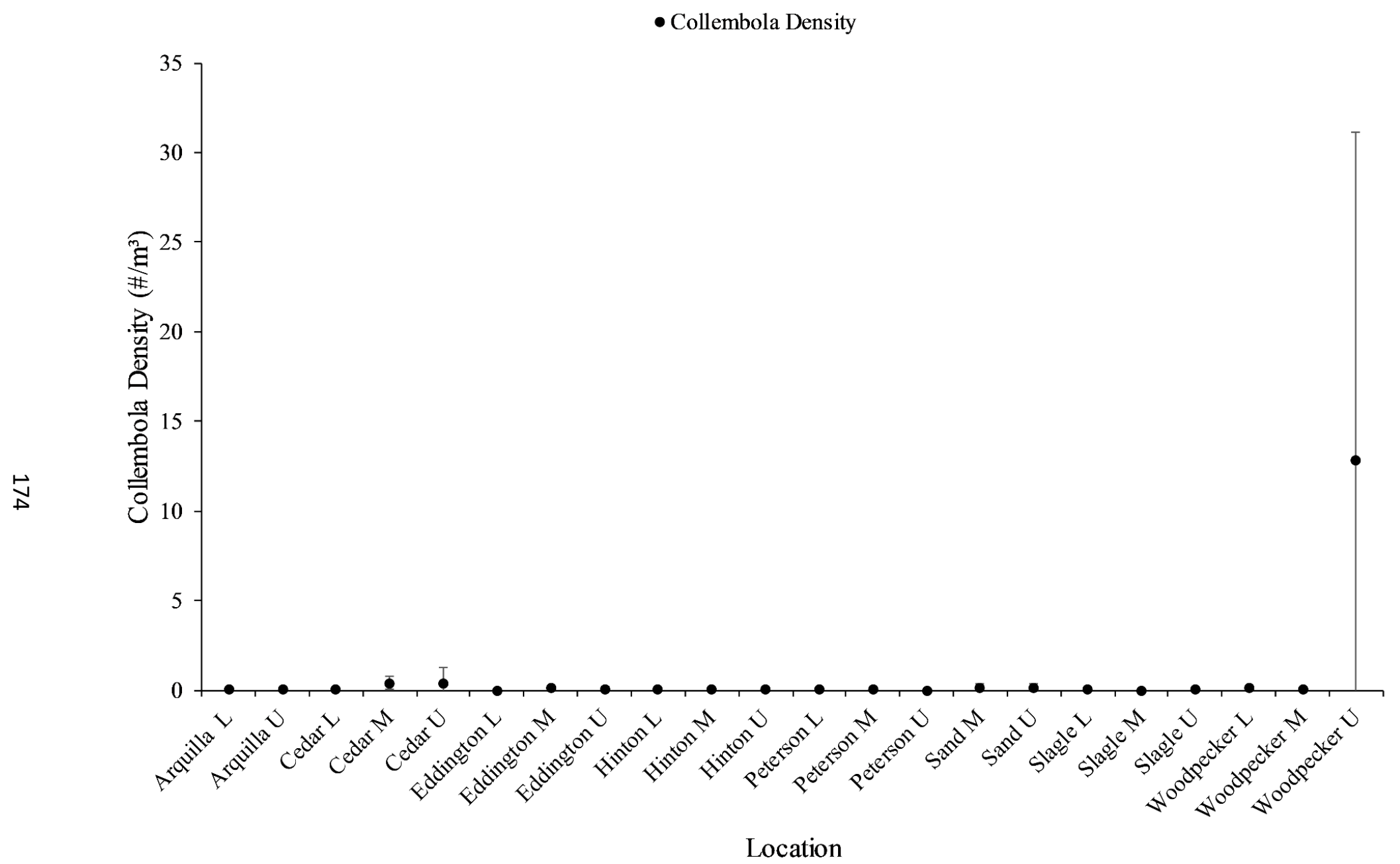

C.6. Density $\left(\# / \mathrm{m}^{3}\right)$ of Collembola in 22 Big Manistee River tributary reaches during June 2012. 


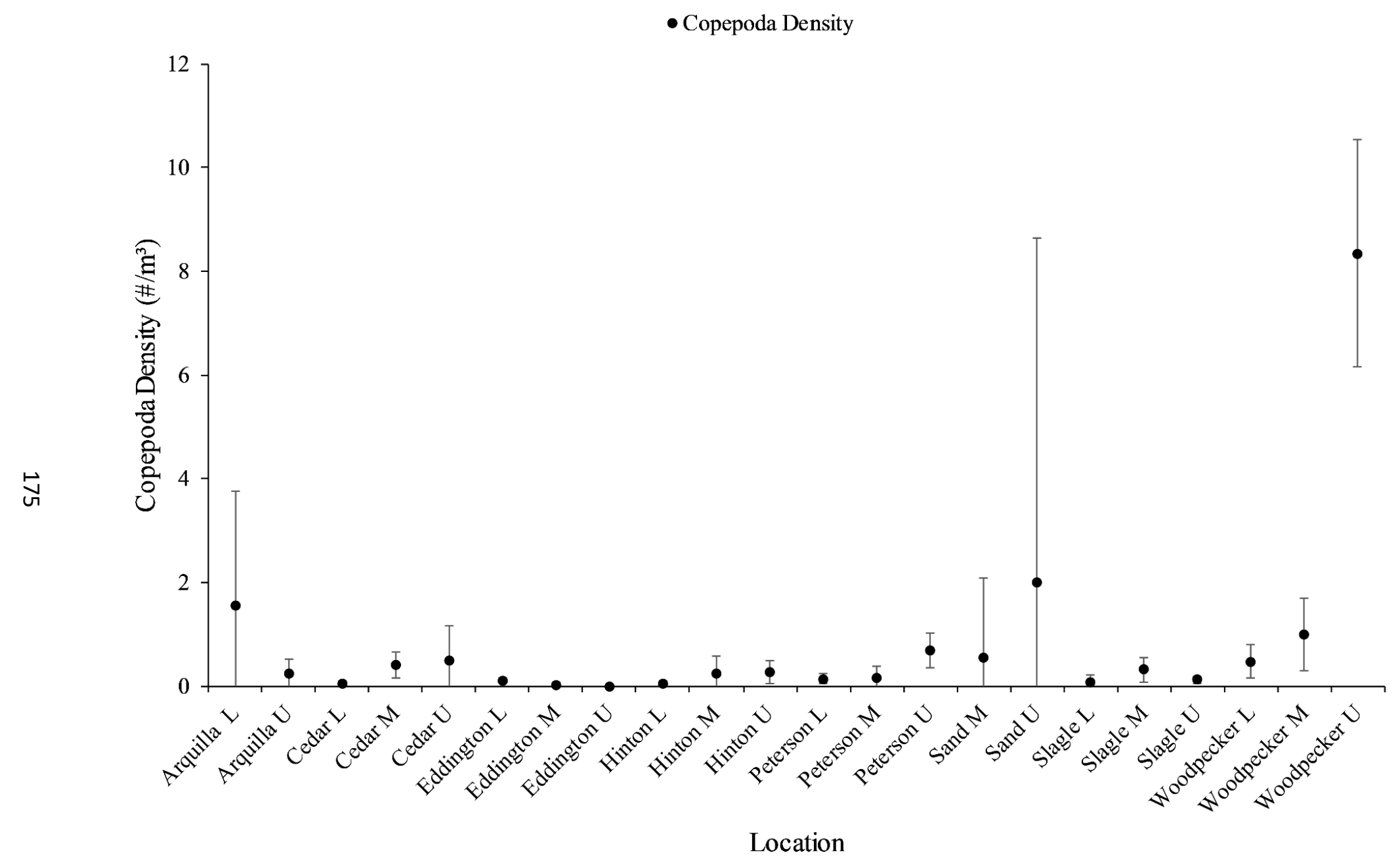

C.7. Density $\left(\# / \mathrm{m}^{3}\right)$ of Copepods in 22 Big Manistee River tributary reaches during June 2012. 


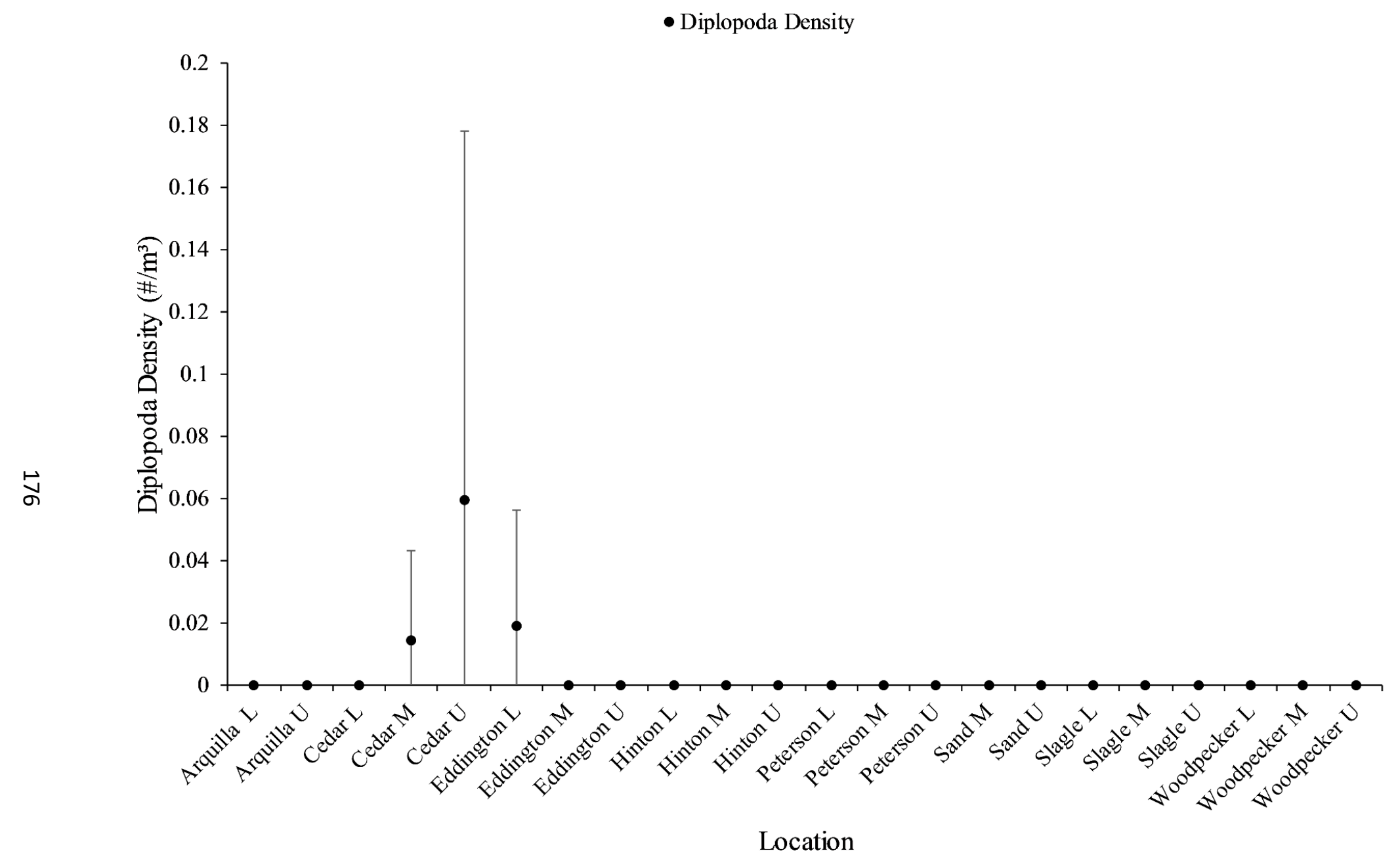

C.8. Density $\left(\# / \mathrm{m}^{3}\right)$ of Diplopoda in 22 Big Manistee River tributary reaches during June 2012. 


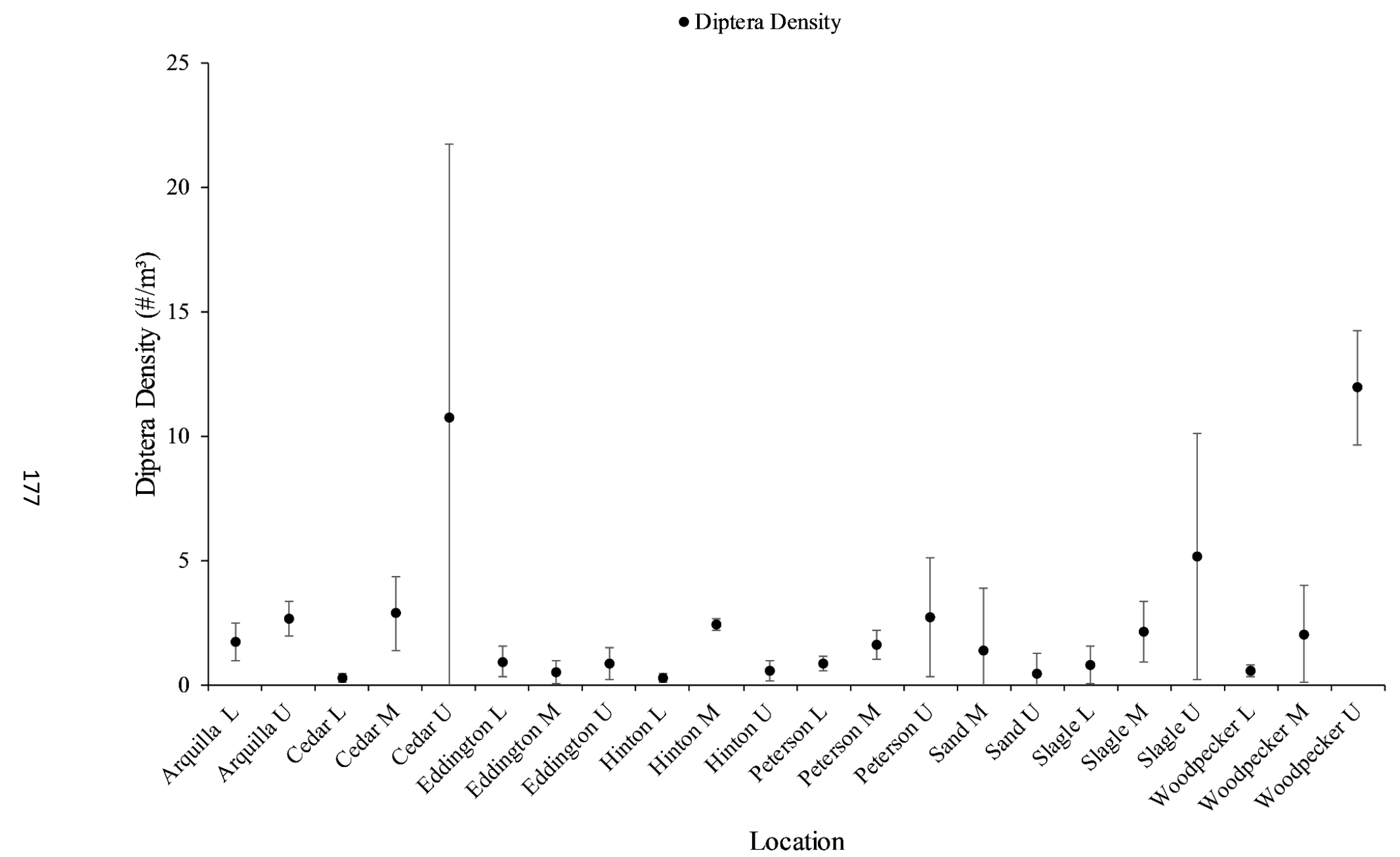

C.9. Density $\left(\# / \mathrm{m}^{3}\right)$ of Diptera in 22 Big Manistee River tributary reaches during June 2012. 


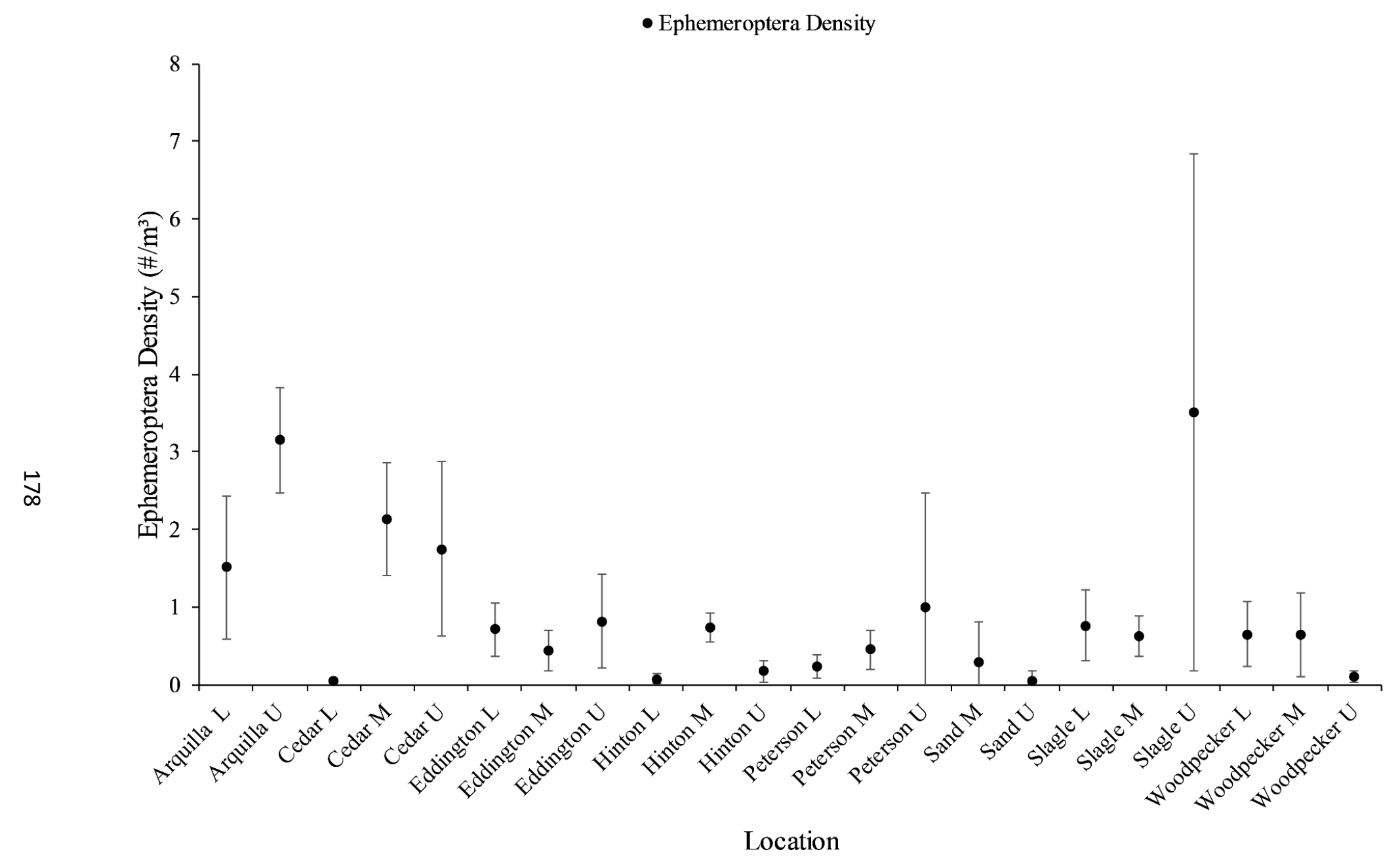

C.10. Density $\left(\# / \mathrm{m}^{3}\right)$ of Ephemeroptera in 22 Big Manistee River tributary reaches during June 2012. 
- Flatworm Density

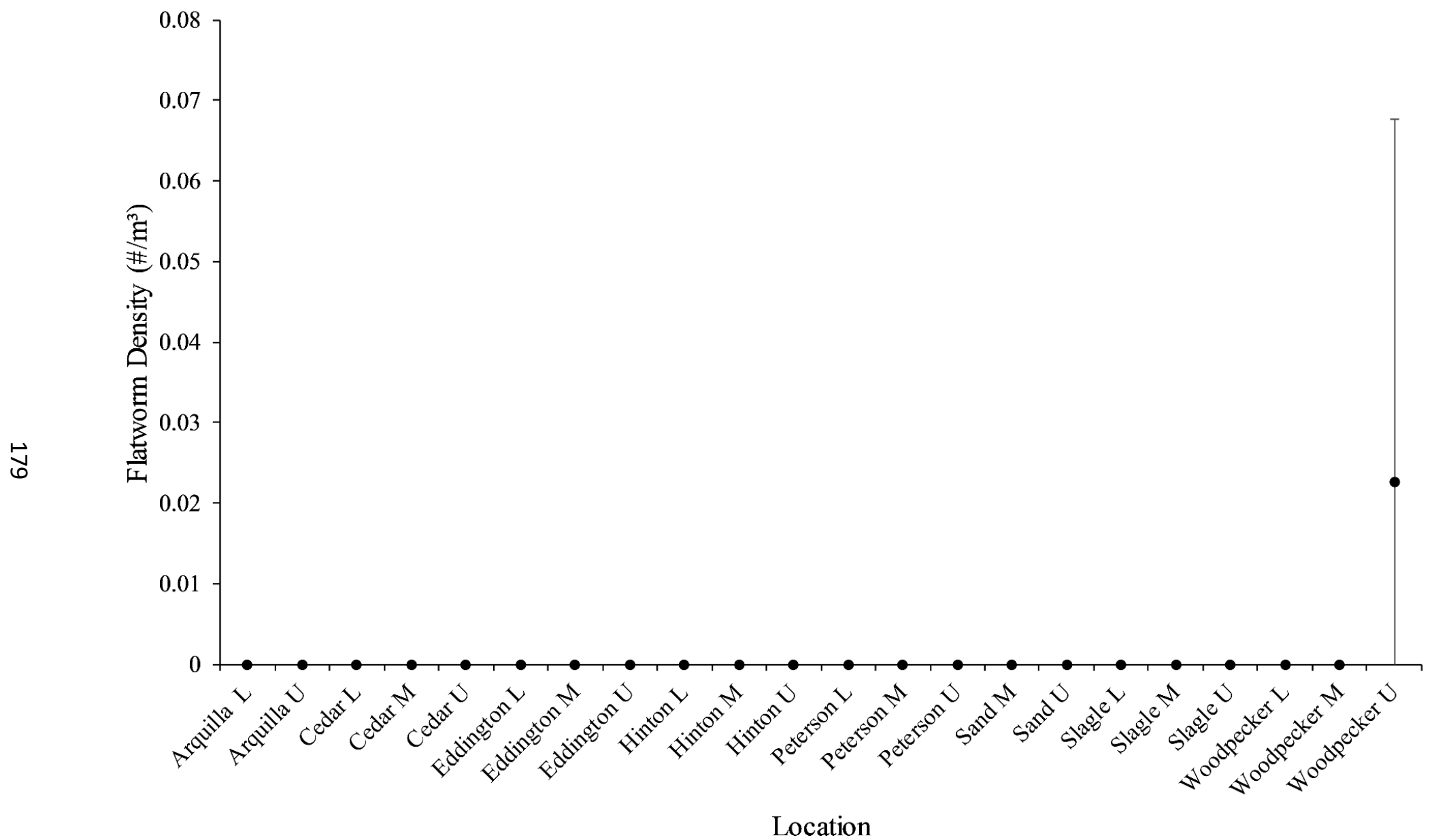

C.11. Density $\left(\# / \mathrm{m}^{3}\right)$ of Flatworms in 22 Big Manistee River tributary reaches during June 2012. 


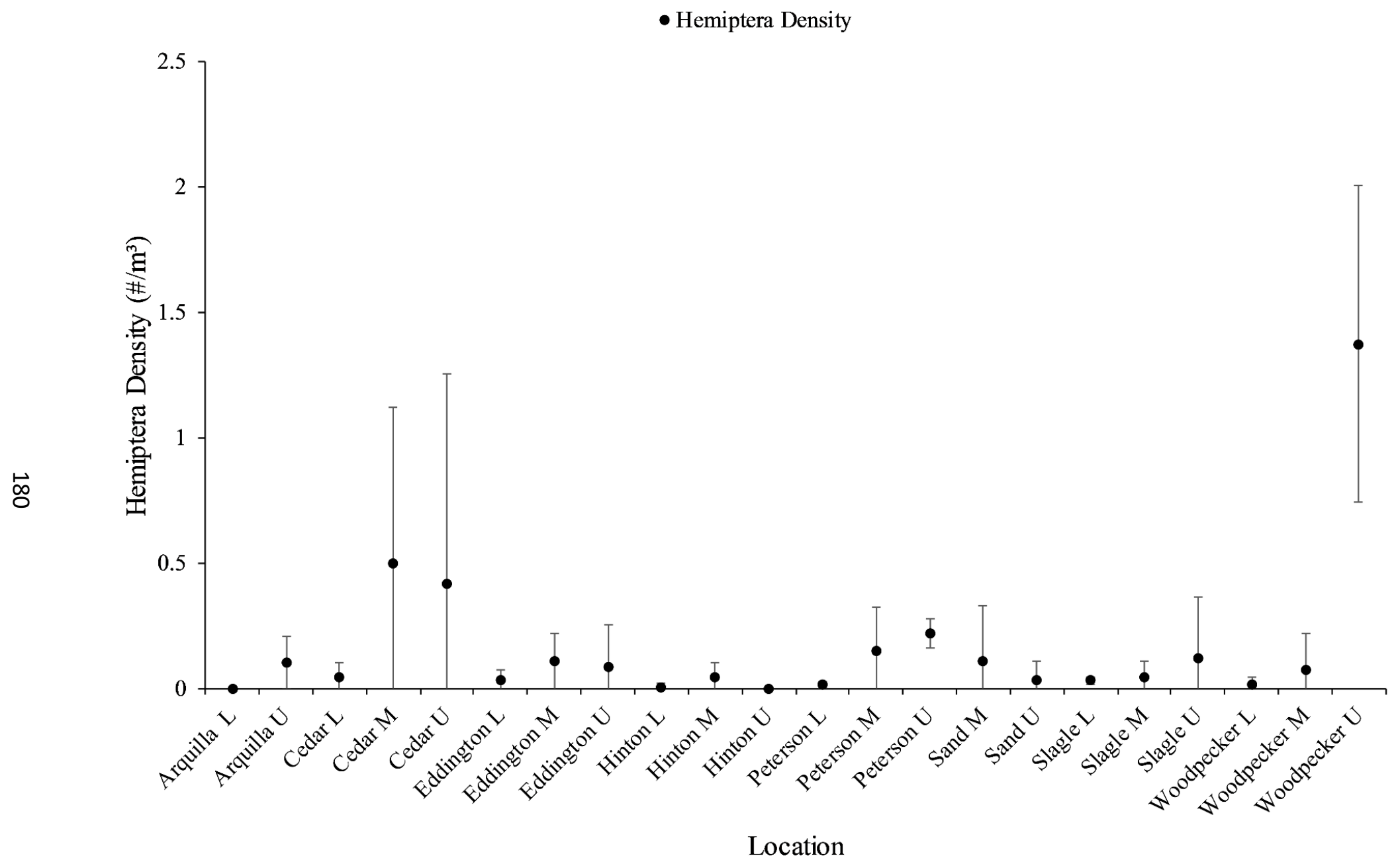

C.12. Density $\left(\# / \mathrm{m}^{3}\right)$ of Hemiptera in 22 Big Manistee River tributary reaches during June 2012. 


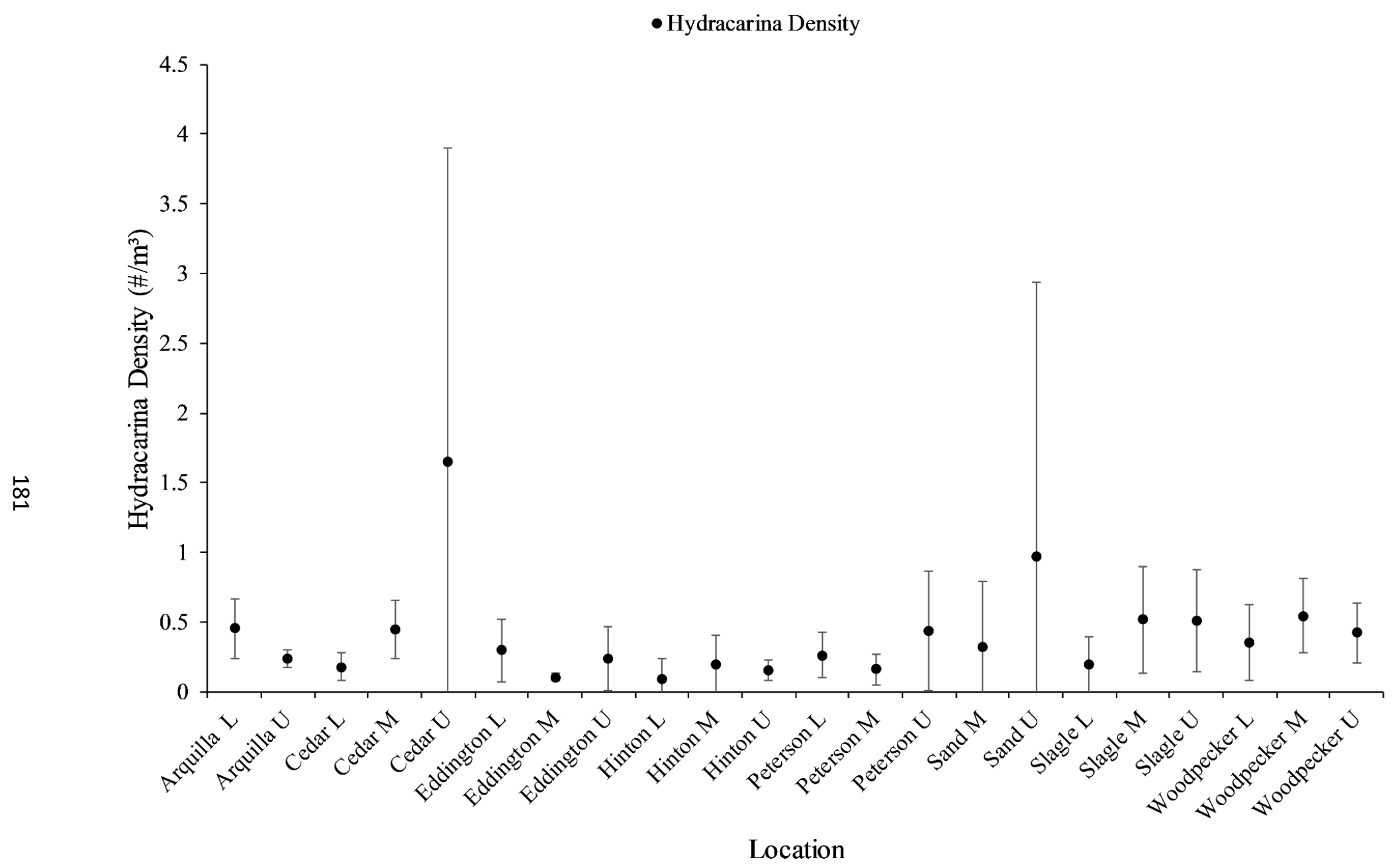

C.13. Density $\left(\# / \mathrm{m}^{3}\right)$ of Hydracarina in 22 Big Manistee River tributary reaches during June 2012. 


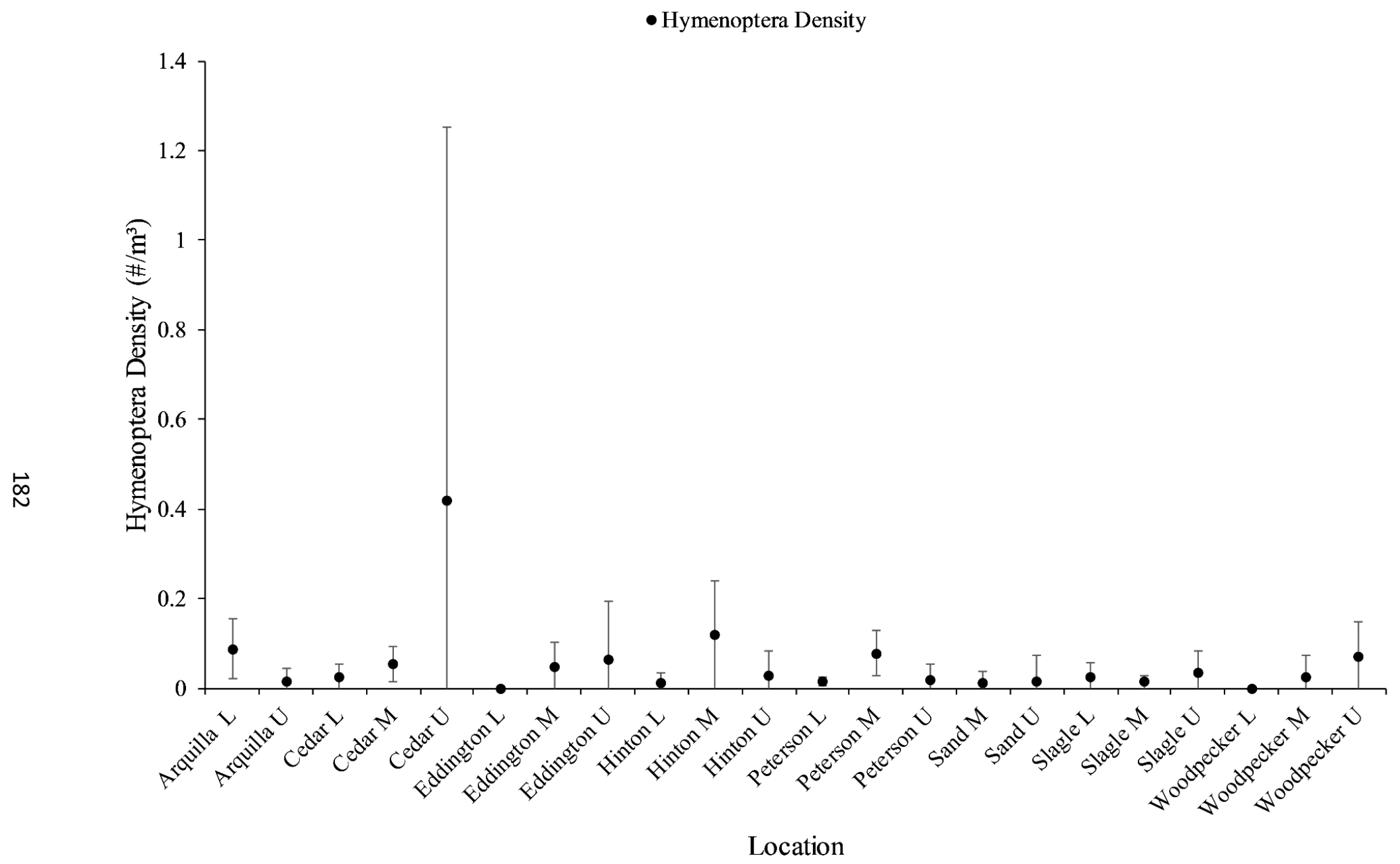

C.14. Density $\left(\# / \mathrm{m}^{3}\right)$ of Hymenoptera in 22 Big Manistee River tributary reaches during June 2012. 


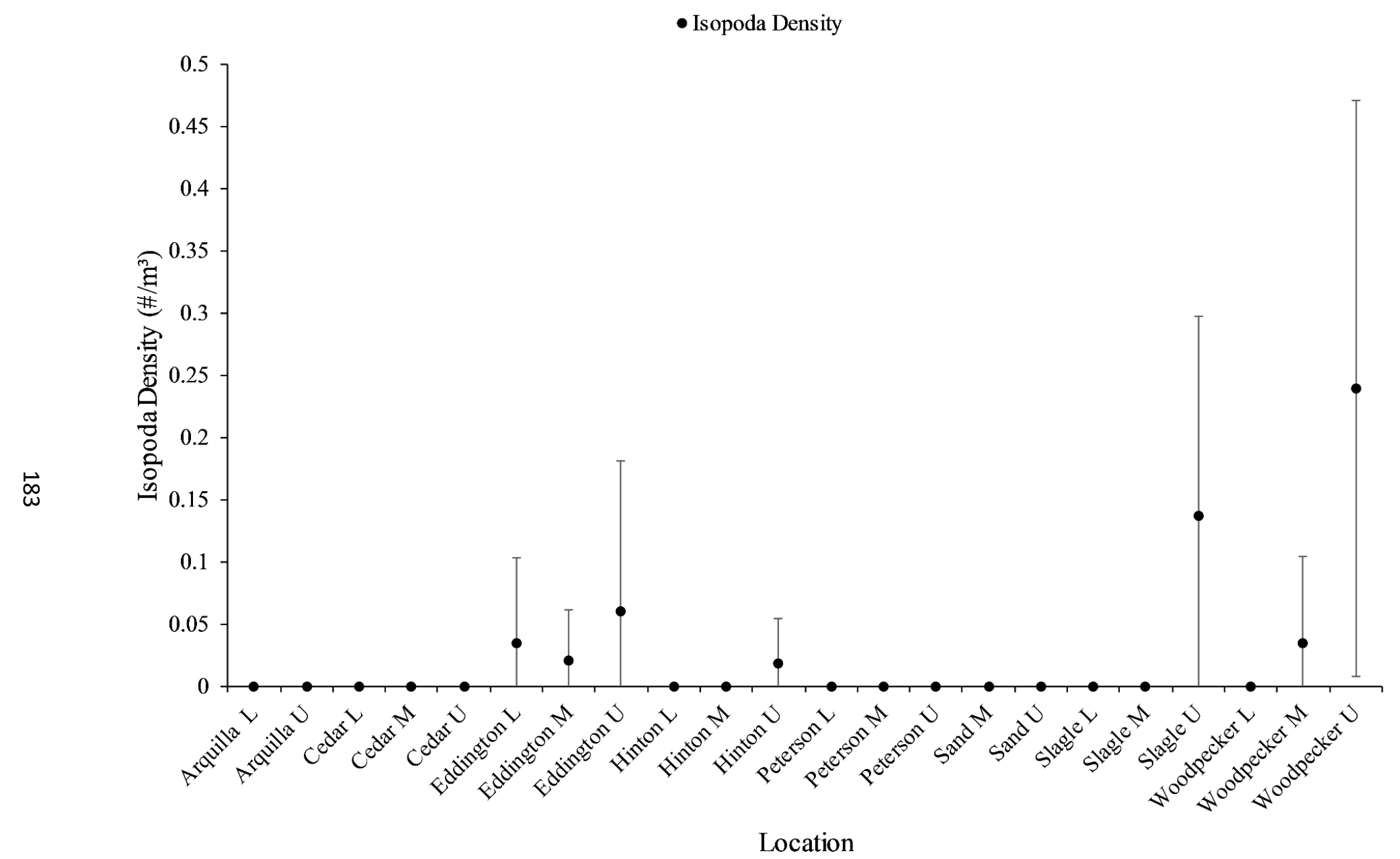

C.15. Density $\left(\# / \mathrm{m}^{3}\right)$ of Isopods in 22 Big Manistee River tributary reaches during June 2012. 


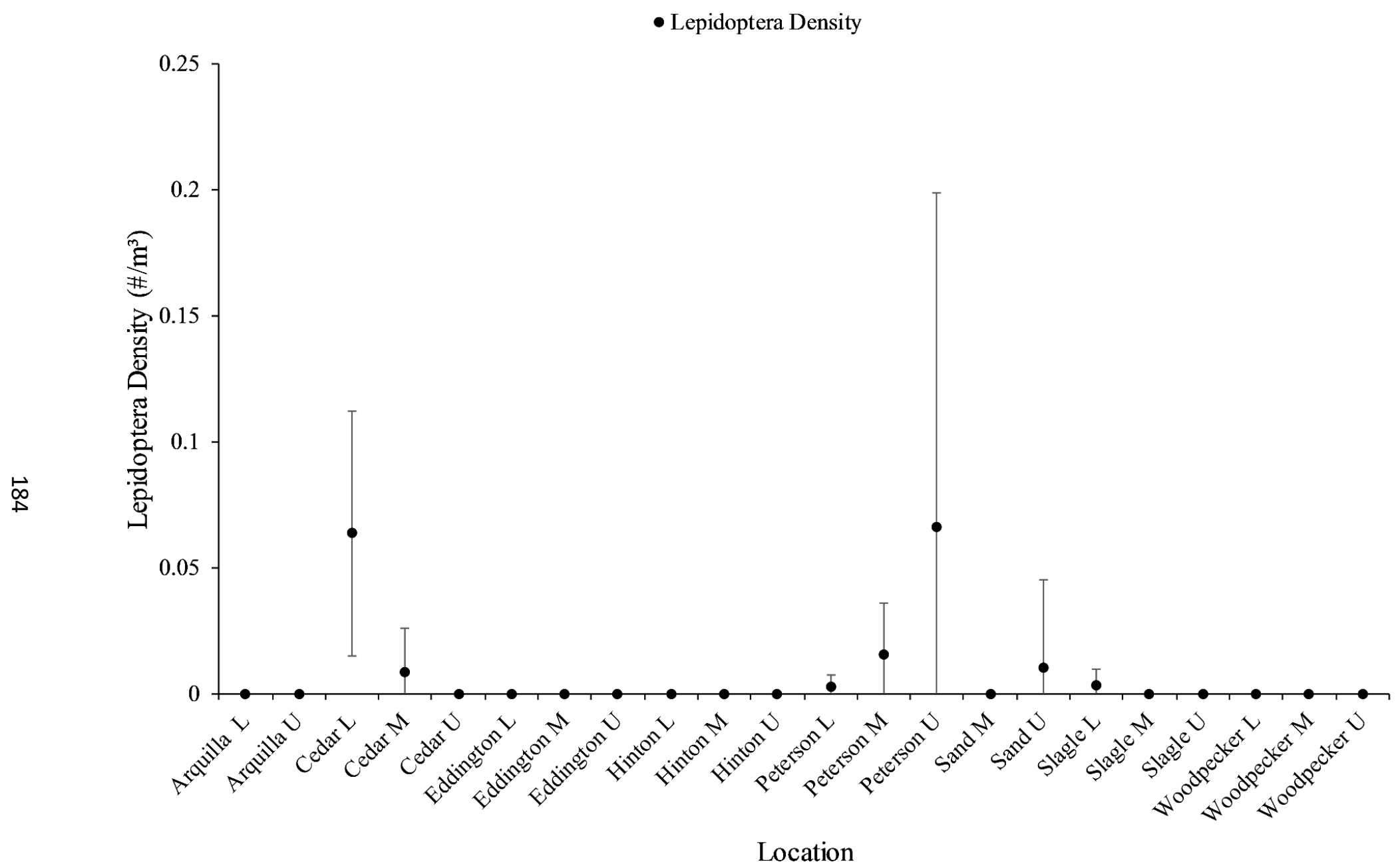

C.16. Density $\left(\# / \mathrm{m}^{3}\right)$ of Lepidoptera in 22 Big Manistee River tributary reaches during June 2012. 
- Megaloptera Density

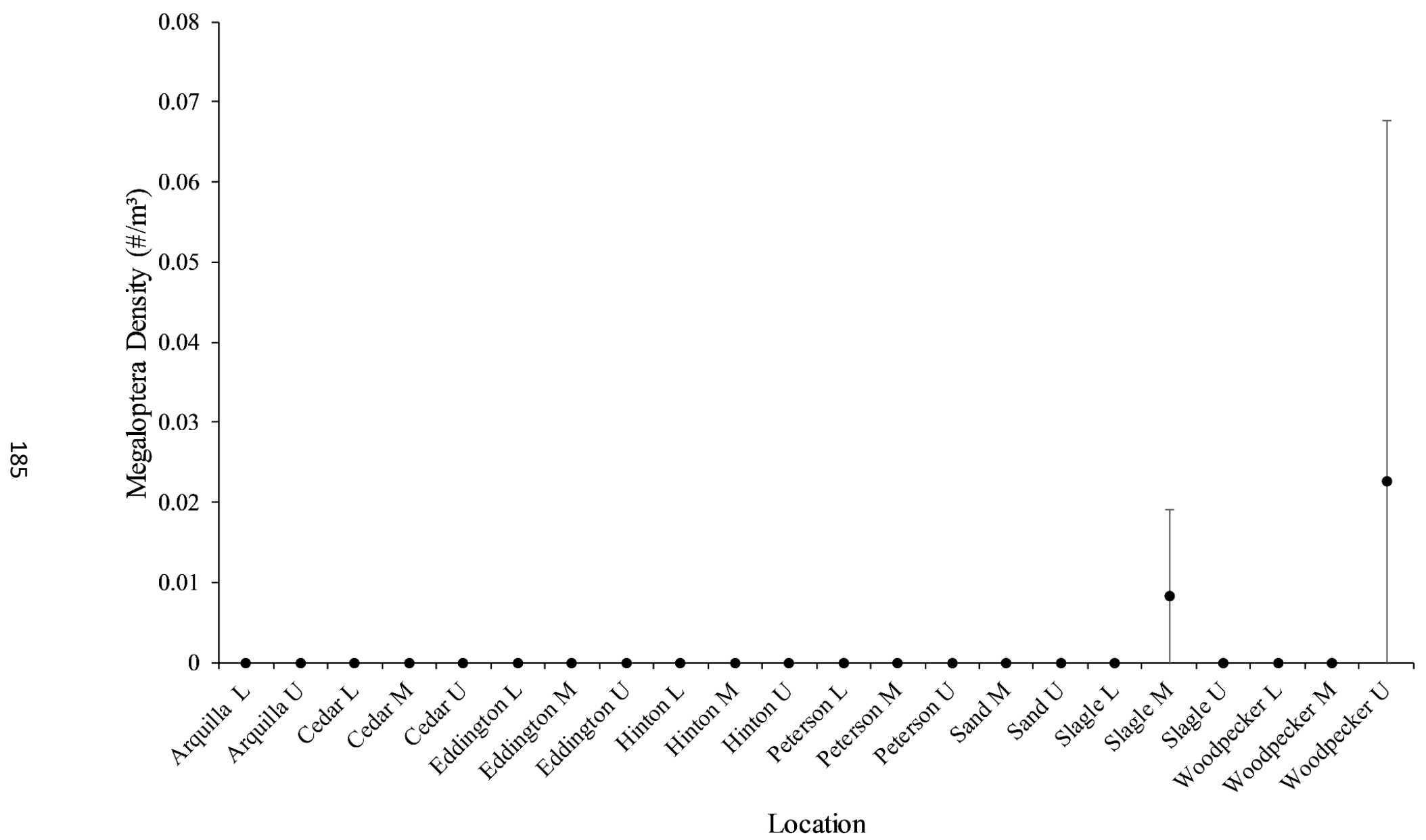

C.17. Density $\left(\# / \mathrm{m}^{3}\right)$ of Megaloptera in 22 Big Manistee River tributary reaches during June 2012. 


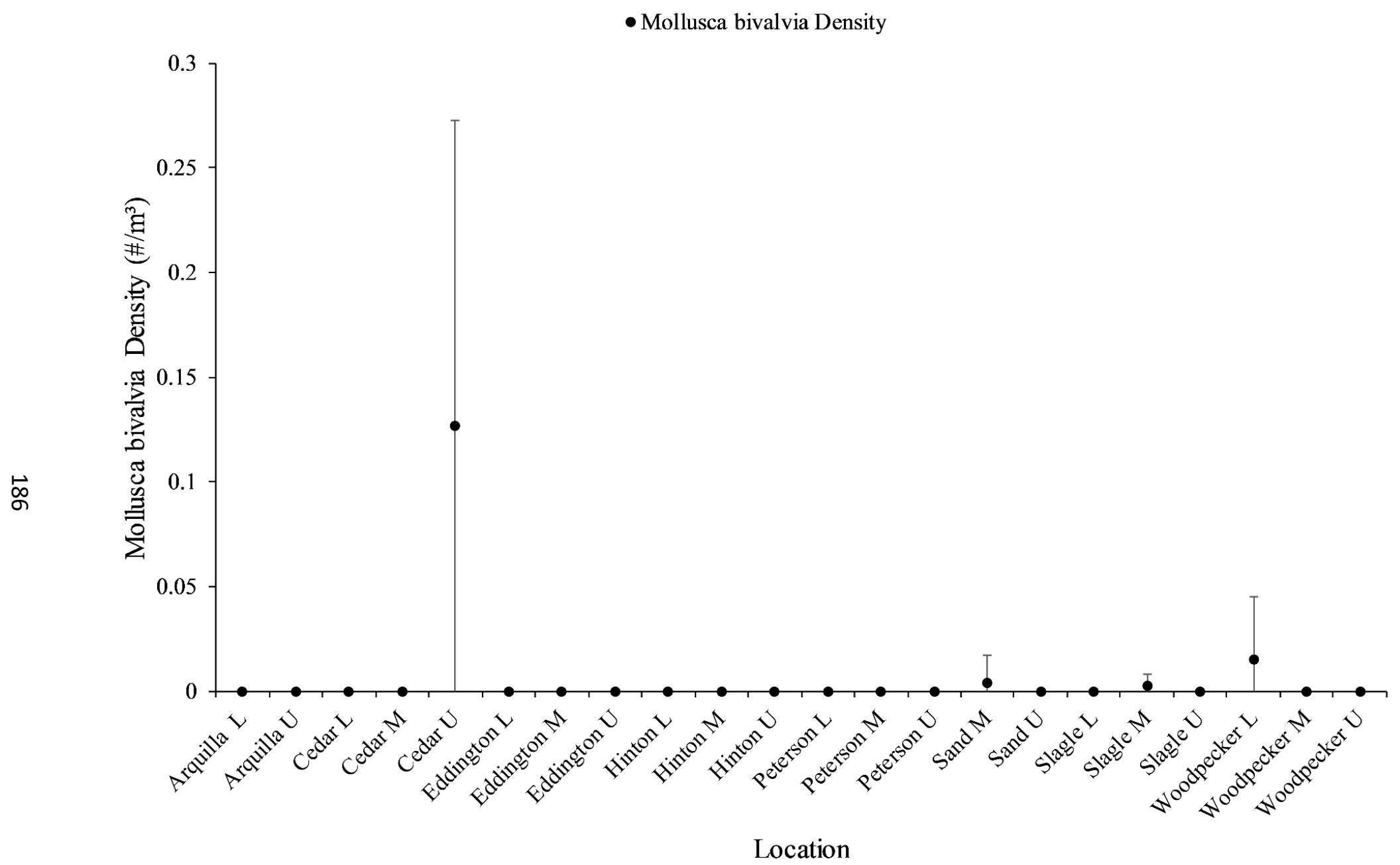

C.18. Density $\left(\# / \mathrm{m}^{3}\right)$ of Bivalves in 22 Big Manistee River tributary reaches during June 2012. 


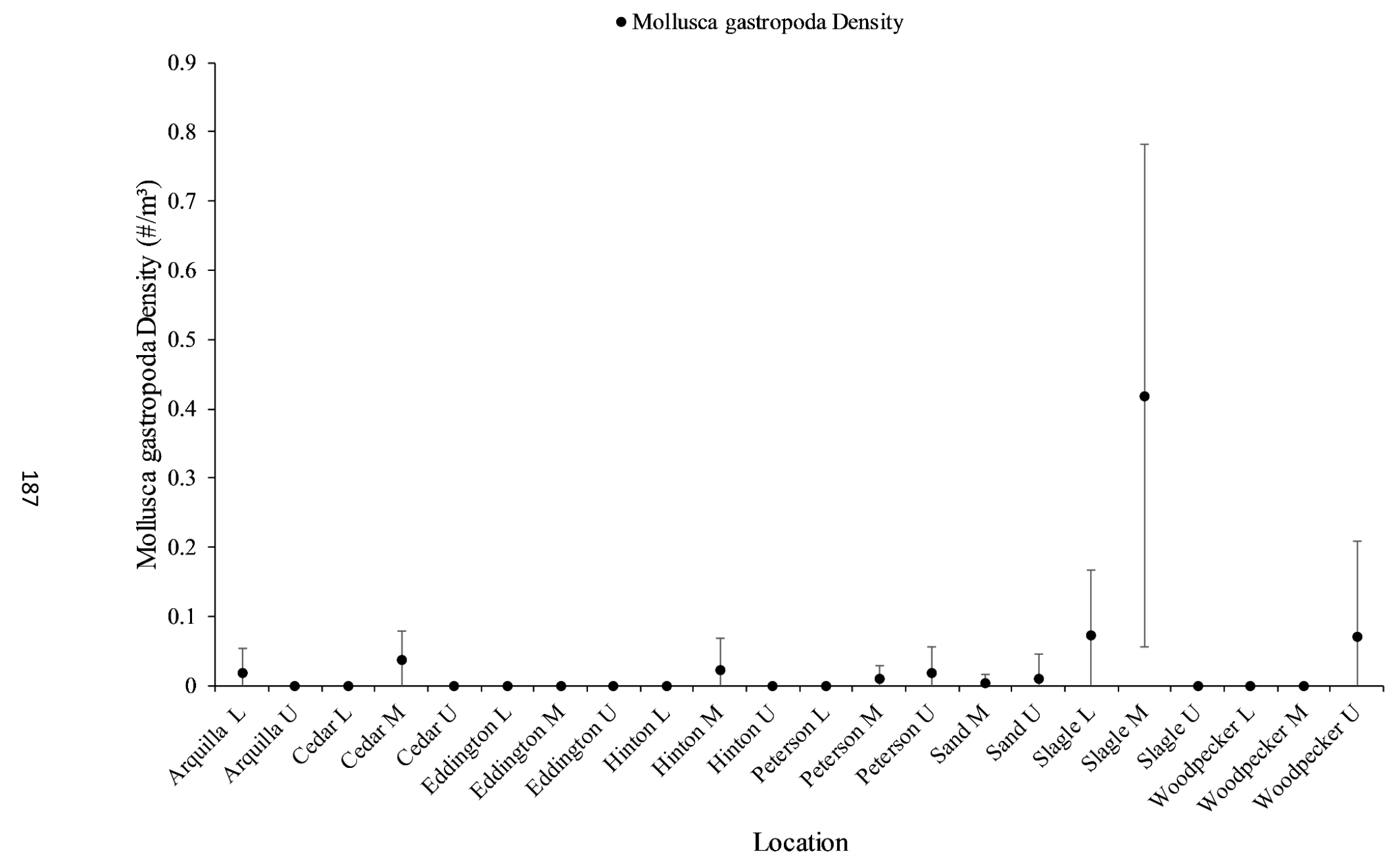

C.19. Density $\left(\# / \mathrm{m}^{3}\right)$ of Gastropods in 22 Big Manistee River tributary reaches during June 2012. 


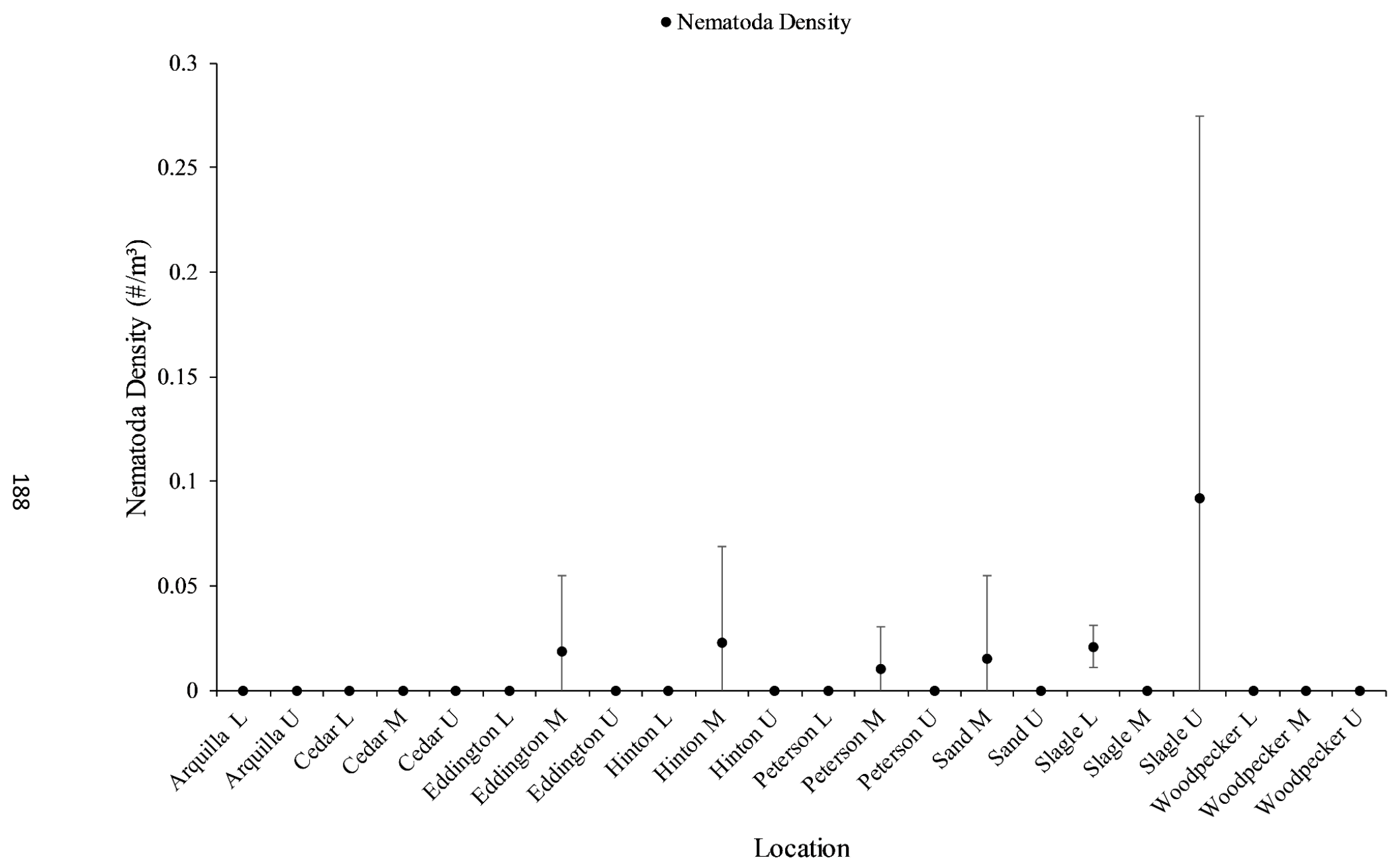

C.20. Density $\left(\# / \mathrm{m}^{3}\right)$ of Nematodes in 22 Big Manistee River tributary reaches during June 2012. 


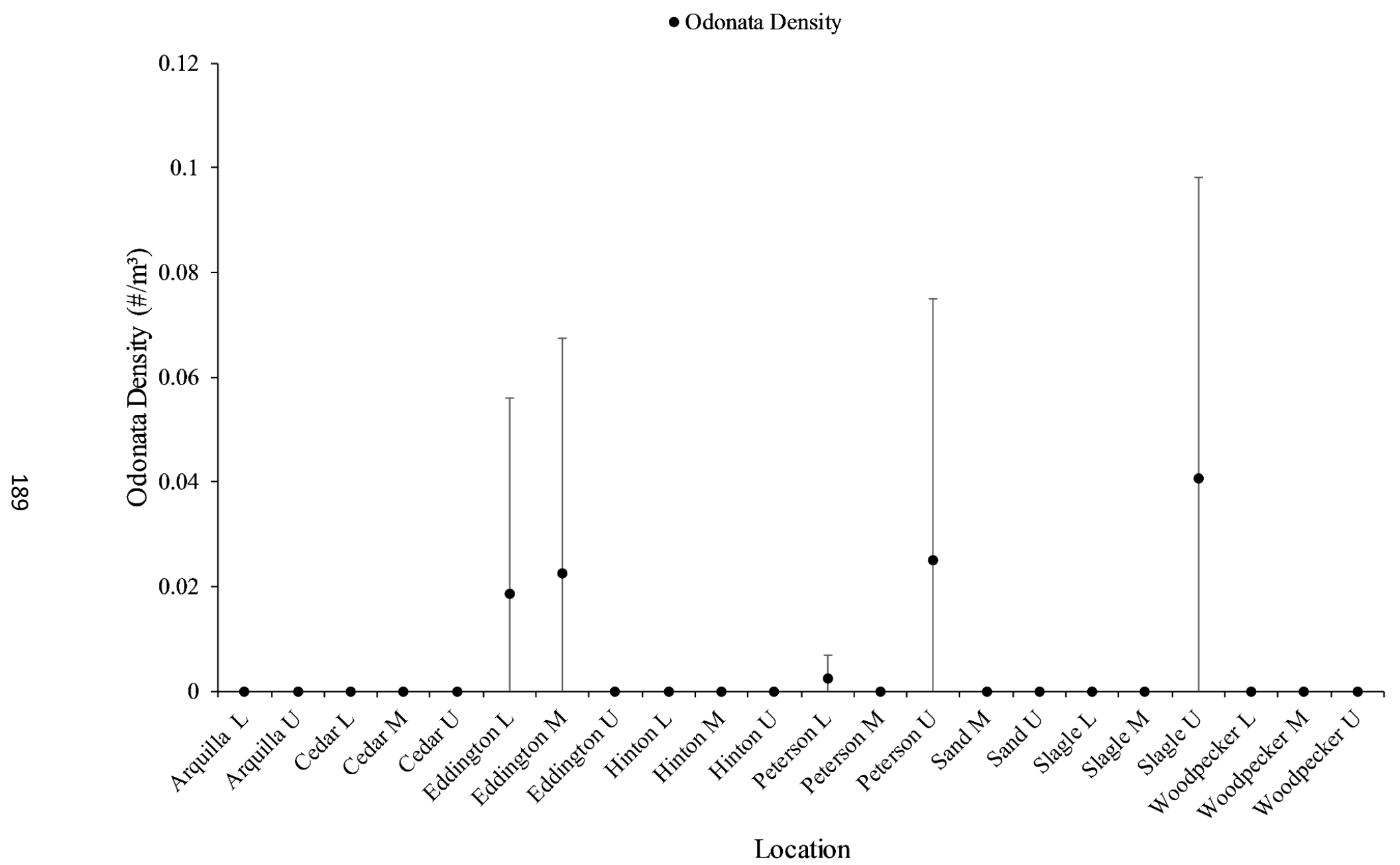

C.21. Density $\left(\# / \mathrm{m}^{3}\right)$ of Odonata in 22 Big Manistee River tributary reaches during June 2012. 


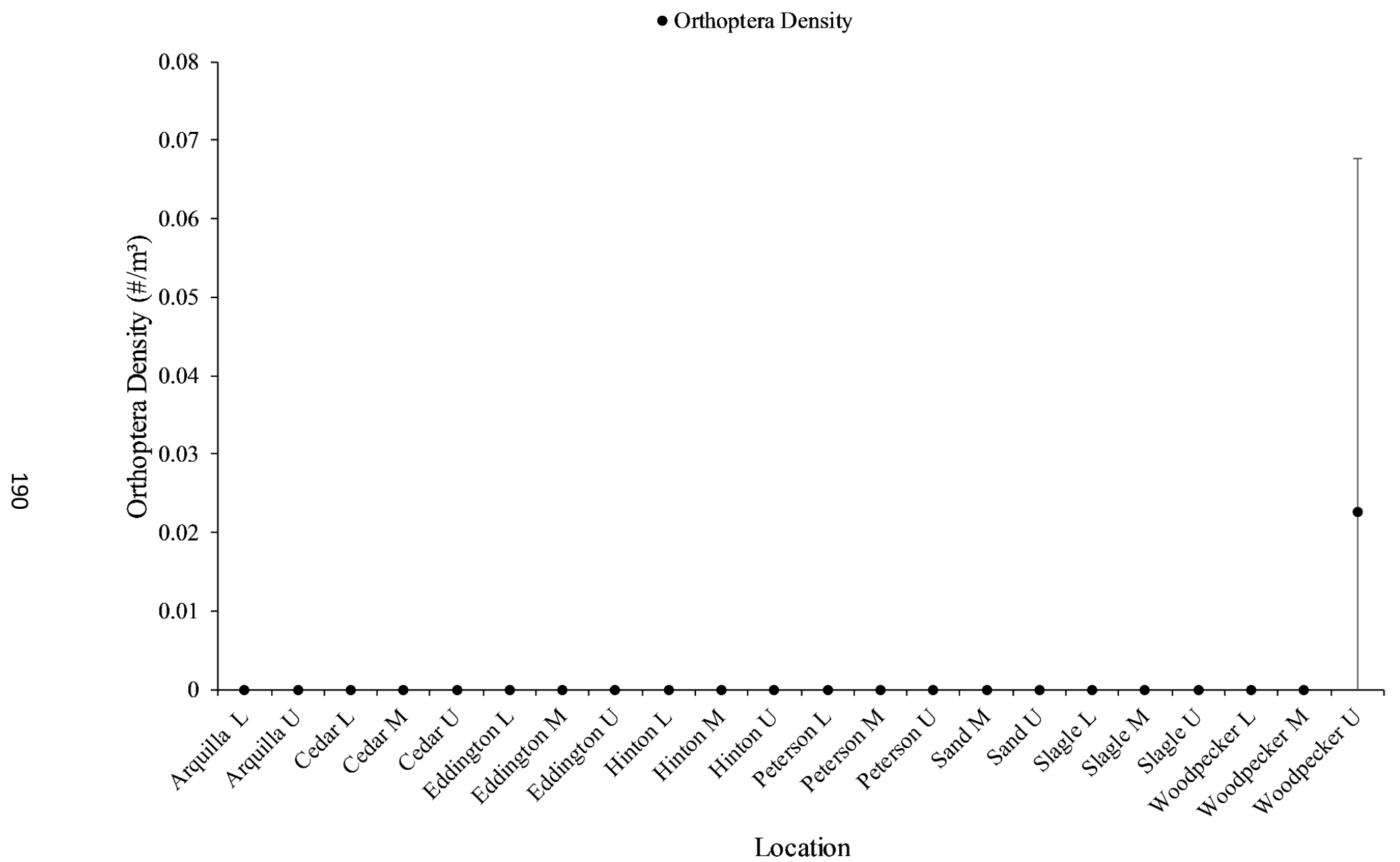

C.22. Density $\left(\# / \mathrm{m}^{3}\right)$ of Orthoptera in 22 Big Manistee River tributary reaches during June 2012. 


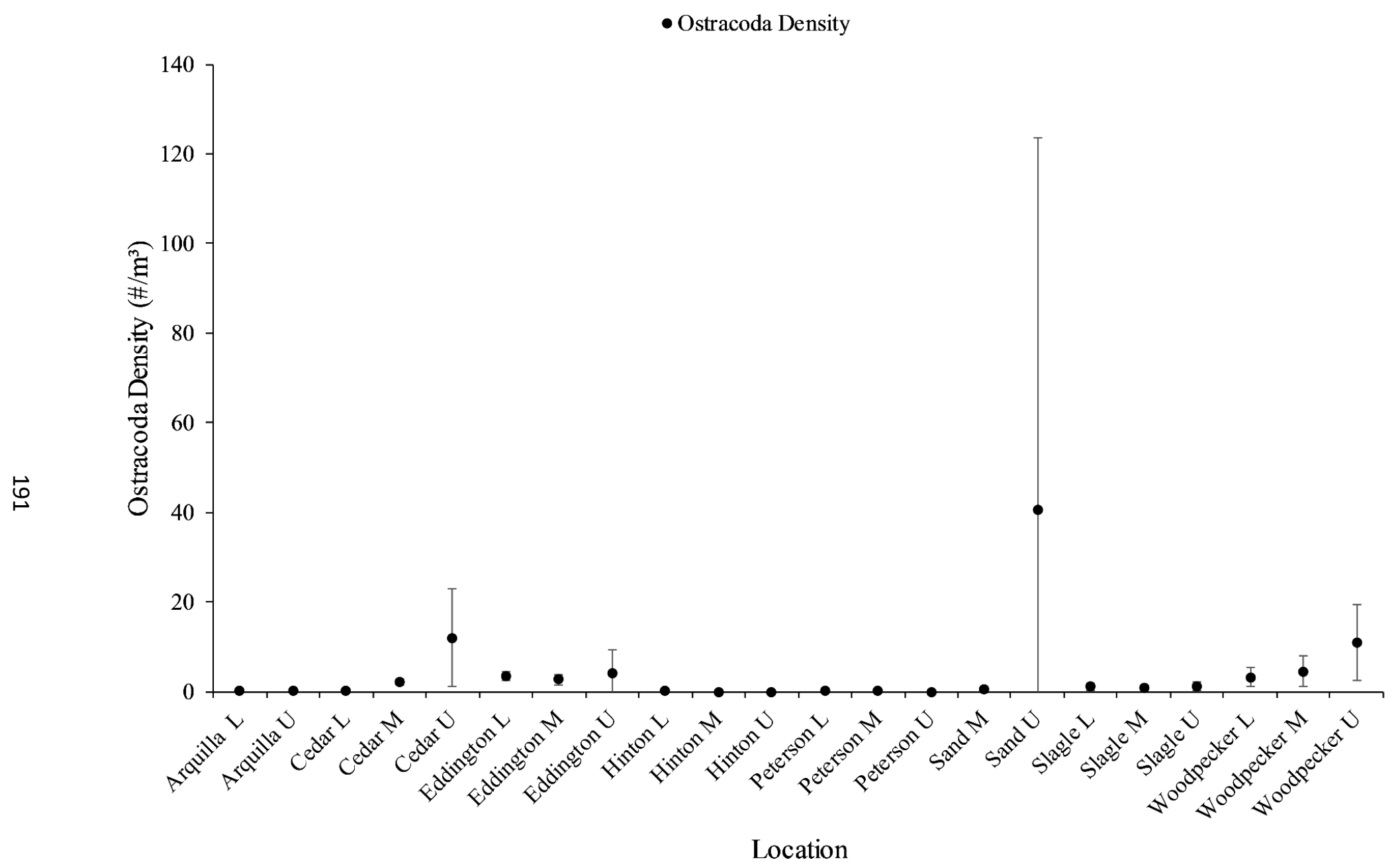

C.23. Density $\left(\# / \mathrm{m}^{3}\right)$ of Ostracods in 22 Big Manistee River tributary reaches during June 2012. 


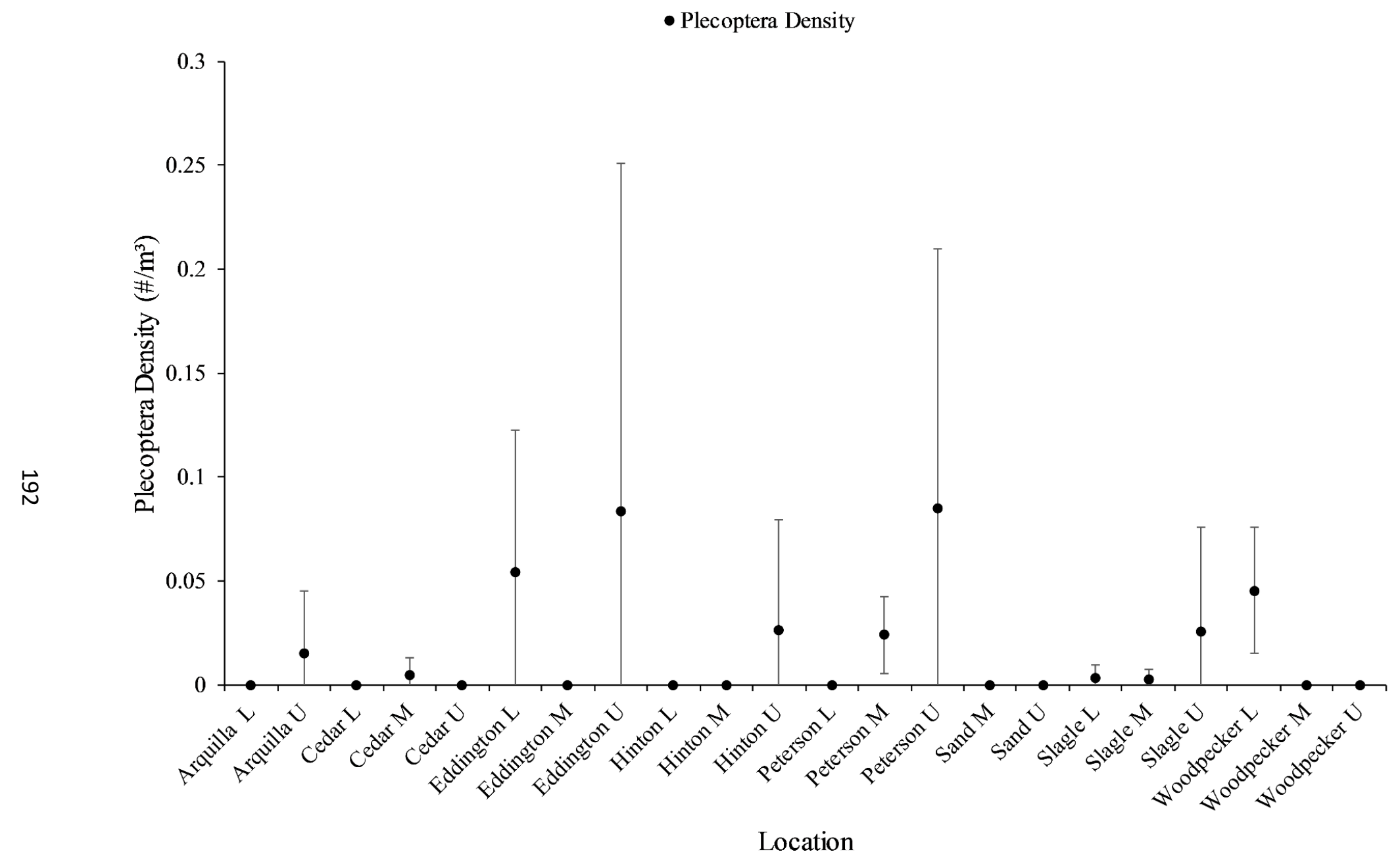

C.24. Density $\left(\# / \mathrm{m}^{3}\right)$ of Plecoptera in 22 Big Manistee River tributary reaches during June 2012. 


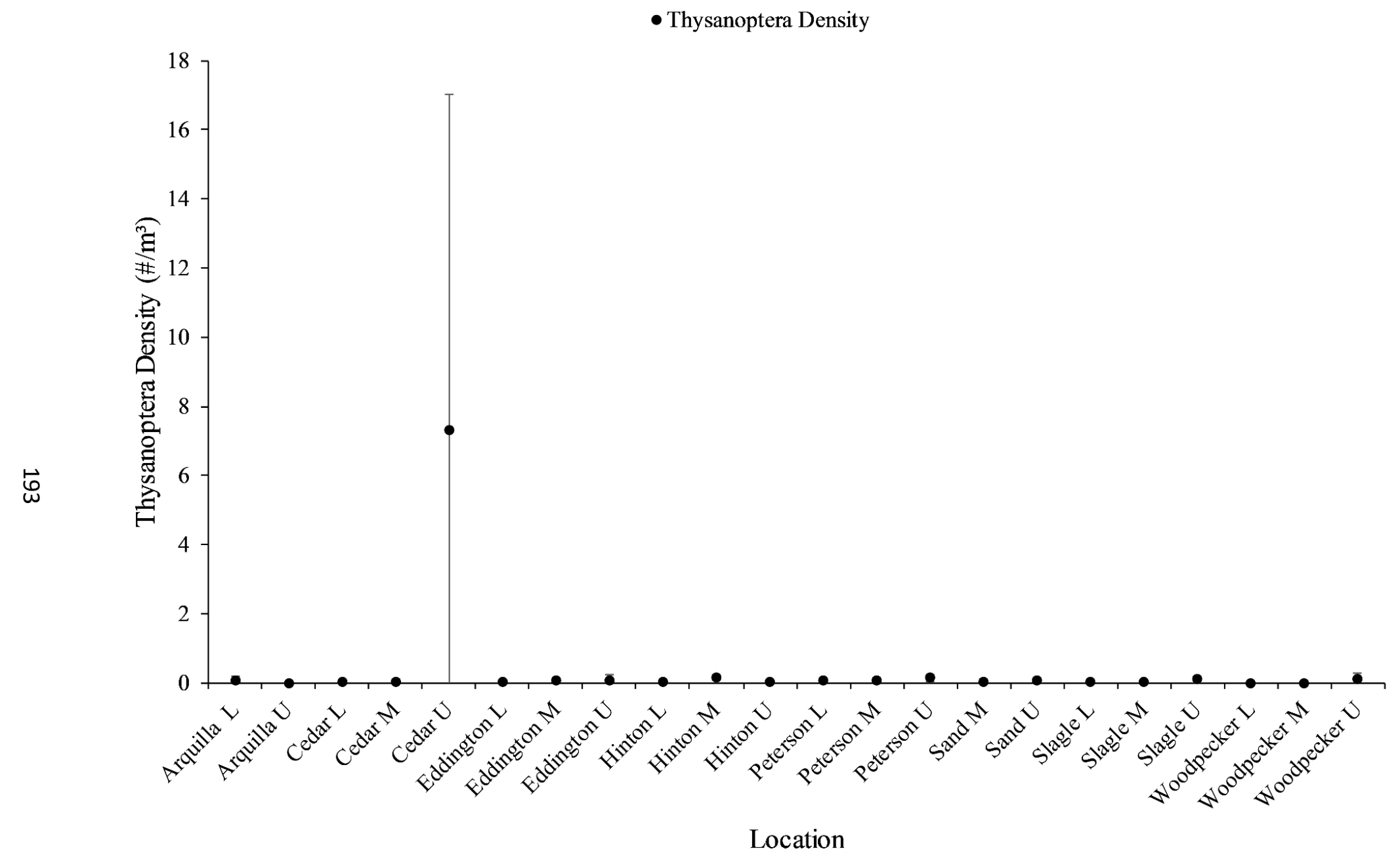

C.25. Density $\left(\# / \mathrm{m}^{3}\right)$ of Thysanoptera in 22 Big Manistee River tributary reaches during June 2012. 


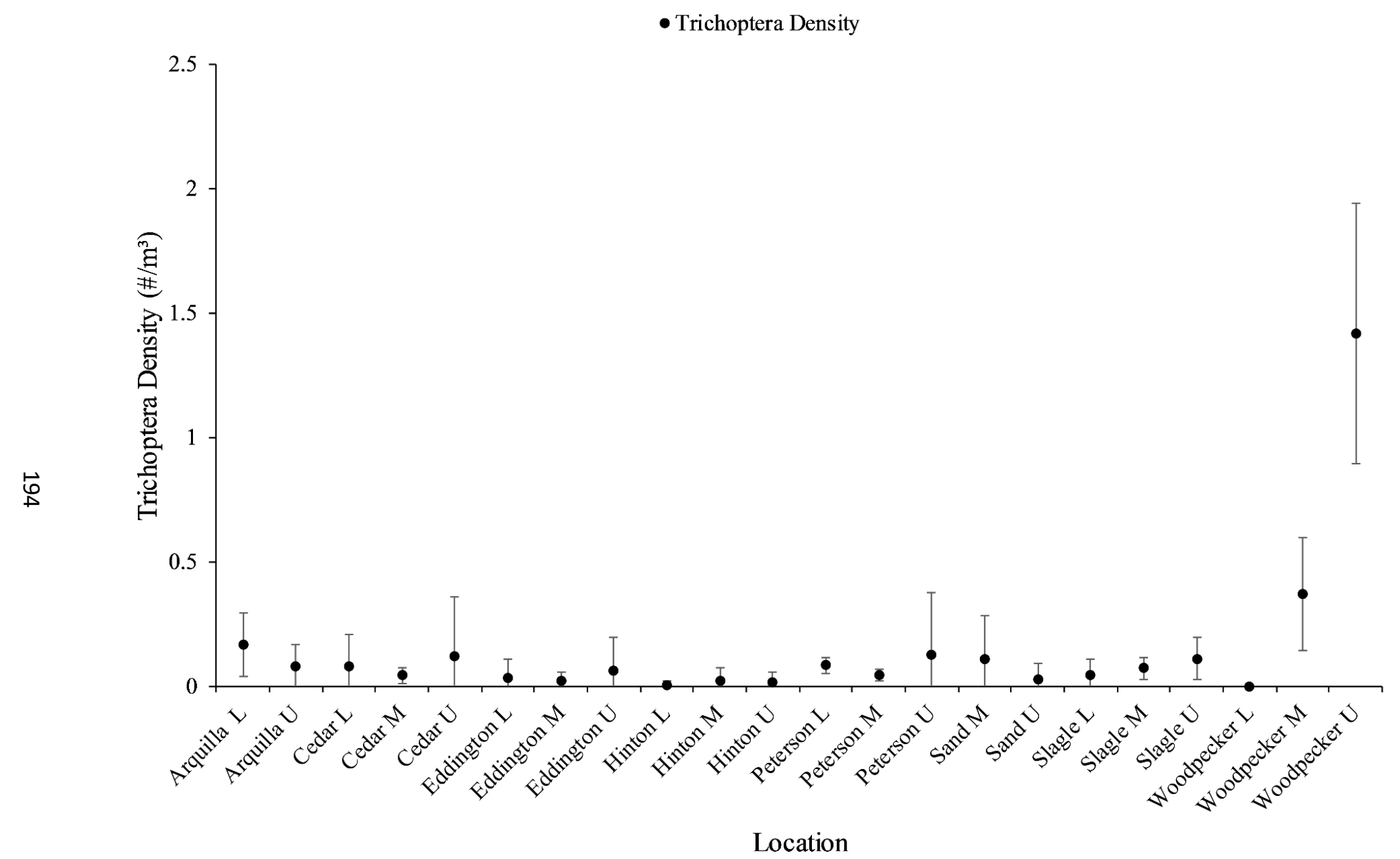

C.26. Density $\left(\# / \mathrm{m}^{3}\right)$ of Trichoptera in 22 Big Manistee River tributary reaches during June 2012. 


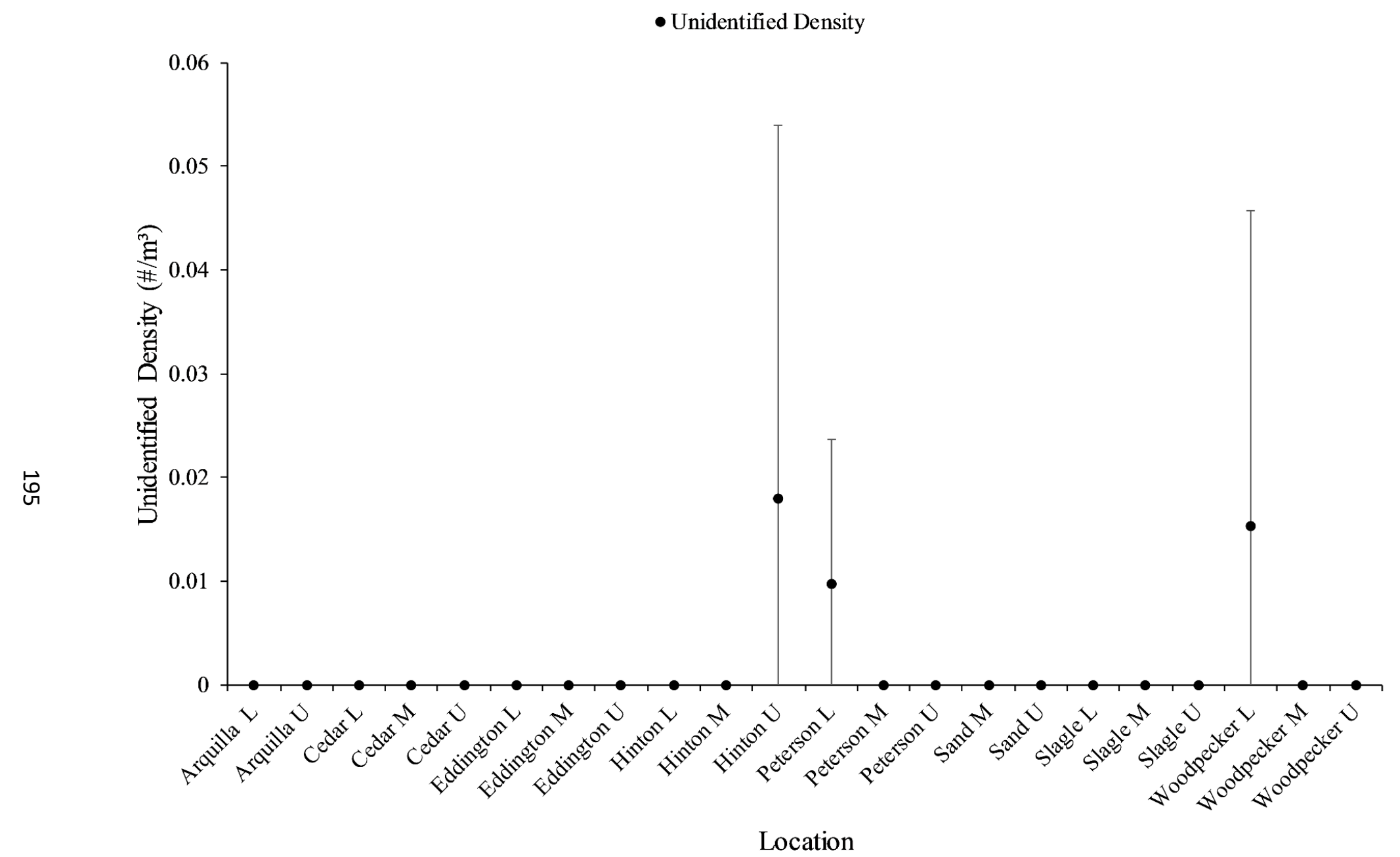

C.27. Density $\left(\# / \mathrm{m}^{3}\right)$ of Unidentified invertebrates in 22 Big Manistee River tributary reaches during June 2012. 
용


Reach

C.28. Proportions of all invertebrate taxa captured in 22 Big Manistee River tributary reaches during June 2012. 